


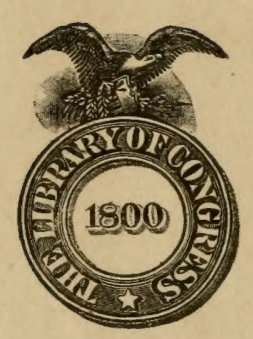




C O T T O N 
<smiles>CCCCCCCCC</smiles> 



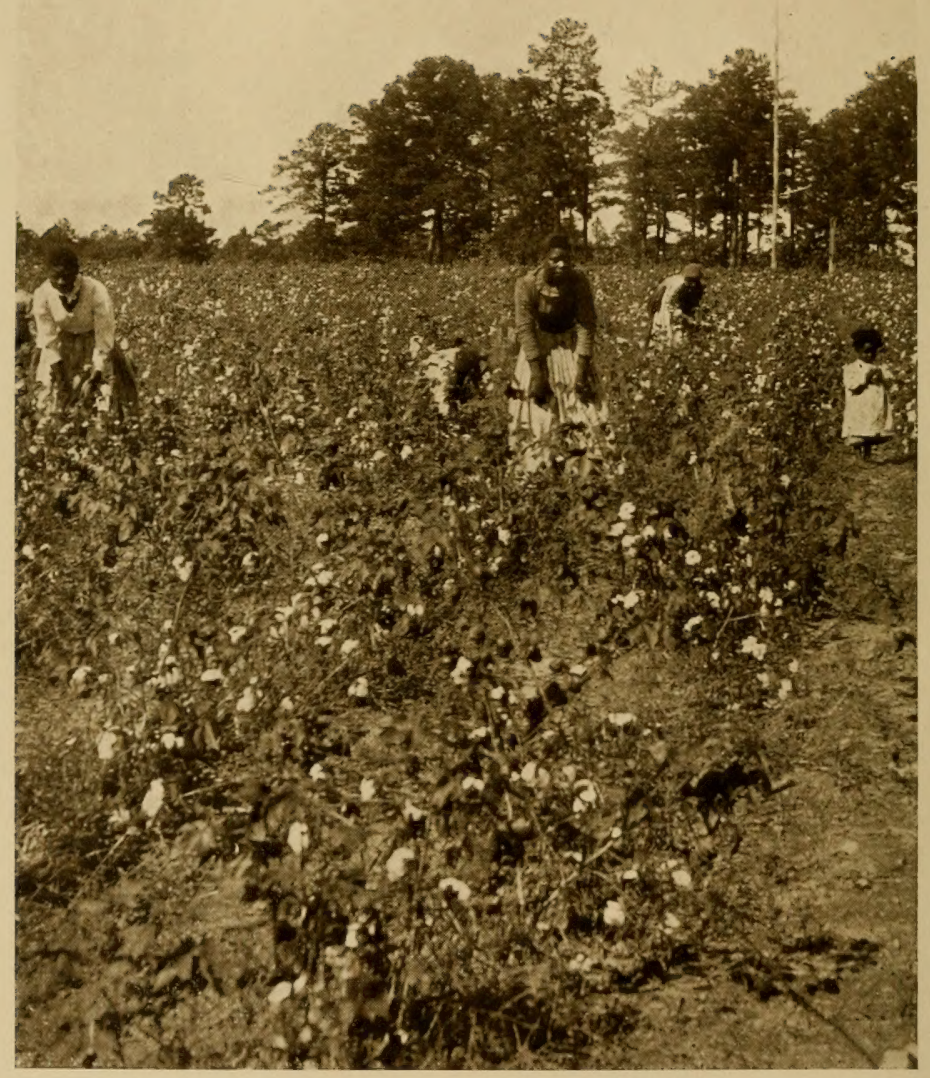

PICKING SCENE.

A great field white with bursting bolls and dotted by a score or more of dusky pickers, and the haunting melody of old-time negro songs-here indeed is a sight and a sound never to be forgotten. 


\section{The ffarm libraty}

C O T T O N

Its Cultivation, Marketing, Manufacture, and the Problems of the Cotton World

BY

CHARLES WILLIAM BURKETT

Professor of Agriculture, North Carolina College of Agriculture and Mechanic Arts,

AND

\section{CLARENCE HAMILTON POE}

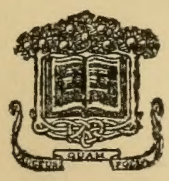

NEW YORK

Doubleday, Page \& Company

I 906 


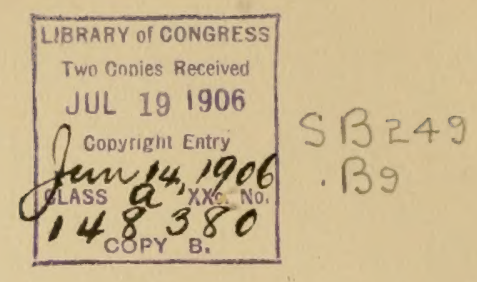

Copyright, 1906, by Doubleday, Page \& Company

Published July, 1906

All rights reserved,

including that of translation into foreign languages

including the Scandinavian

iv 


\section{Yonder bird,}

Which floats, as if at rest,

In those blue tracts above the thunder, where

No vapors cloud the stainless air,

And never sound is heard,

Unless at such rare time

When, from the City of the Blest,

Rings down some golden chime,

Sees not from his high place,

So vast a cirque of summer space

As widens round me in one mighty field,

Which, rimmed by seas and sands,

Doth hail its earliest daylight in the beams

Of gray Atlantic dawns;

And, broad as realms made up of many lands,

Is lost afar

Behind the crimson hills and purple lawns

Of sunset, among plains which roll their streams

Against the Evening Star !

And lo!

To the remotest point of sight,

Although I gaze upon no waste of snow,

The endless field is white;

And the whole landscape glows,

For many a shining league away,

With such accumulated light

As Polar lands would flash beneath a tropic day !

-From "The Cotton Boll," by Eenry Timrod. 



\section{TABLE OF CONTENTS}

INTRO D UCTION: HAIL, THE KING! . 3

\section{SECTION I.-KING COTTON: HIS REALM}

AND HIS SUBJECTS

Chapter I.-History of Cotton: From Ancient India to

Our Own Time

Chapter II.-Acreage and Production: Where the

World's Supply is Grown . . . 20

Chapter III.-Does Foreign Competition Threaten the

South's Supremacy? . . . . 27

Chapter IV.-The Men Who Make Cotton: Whites and

Blacks; Planters and Tenants . . 35

Chapter V.-A 25,000,000 Bale Crop: Will the South

Be Ready When the World Demands It ? . . 42

Chapter VI.-Cotton: What It Means and Will Mean to

the Southern States . . . . 53

Chapter VII.-The Organization of Cotton Growers and

What It May Accomplish . . . 58

Chapter VIII.-Stopping the Leaks in Cotton Profits . 68

SECTION II.-THE COTTON PLANT: HOW IT GROWS AND IS GROWN

Chapter IX.—Structure and Botanical Relations • 77

Chapter X. - Varieties of Cotton and Their Classification 85 
Chaptra XI.-Breeding Up the Cotton Plant . . 93

Chapter XII.-The King's Realm: The Land of Sunshine 104

Chapter XIII.-Soils and How to Handle Them . 109

Chapter XIV.-Bringing Exhausted Soils Back to Life 115

Chapter XV.-Cotton Unique: A Self-Supporting Crop . 120

Chapter XVI.-Buying Fertility for the Soil . . 126

Chapter XVII.-Farm-Made Manures: SavingFertility

for the Soil . . . . . . 134

Сhapter XVIII.-Home-Mixing of Fertilizers: Saving

the Manufacturer's Profit . . . . 139

Chapter XIX. - The Cotton Farmer's Equipment of Tools 147

Chapter XX.-Culture From Seed to Boll . . 153

Chapter XXI.-The Ills That Cotton Is Heir To . 165

Chapter XXII. - Insect Enemies of the Cotton Plant . 175.

Chapter XXIII.-Harvest Time in the Cotton Field . 194

Chapter XXIV.-What Does It Cost to Make Cotton? . 200

\section{SECTION III.-MARKETING AND PRICES}

CHAPter XXV.-Preparing for Marketing: The Work of the Gin . . . . . . 215

Chapter XXVI.-Marketing: The Trip to the Spindle . 224

Chapter XXVII.-The Unceasing Contest Between Bulls and Bears . . . . . . 234

Chapter XXVIII. - Statistics: How the World Watches While the Plant Grows . . . . 249

Chapter XXIX.-Prices: The Puzzling Problem of Cotton Values 
SECTION IV.-MANUFACTURES AND BYPRODUCTS

Chapter XXX.-Cottonseed: Once an Outcast; Now a Prince . . . . . . . . 275

Chapter XXXI.-Cotton Oil: The King Feeds as Well as

Clothes His Subjects . . . 282

Chapter XXXII.-Meal and Hulls: King Cotton Also

Feeds Our Flocks and Herds . . . 290

Chapter XXXIII.-The Rise of Cotton Manufacturing . 301

Chapter XXXIV.-The Cotton Factory in the Southern

States . . . . . 311

Chapter XXXV.-The Making of Cotton Goods . 319

Chapter XXXVI.-Conclusion-The Epic of Cotron

That is Yet to be Written . . . 330 



\section{LIST OF ILLUSTRATIONS}

Picking Scene .

Frontispiece

FACING PAGE

A Monarch that Brooks no Rivals . . . . . 16

Part of Our $\$ 410,000,000$ in Cotton Export Values . . . 17

Production of Cotton 1850 to 1900 . . . . . 22

Cotton Statistics . . . . . . . . . 23

Production of Cotton 1900 (by States) . . . . 34

Breaking Land for Egyptian Cotton . . . . . 35

How The Negro Tenants Live . . . . . 38

Negro Pickers at Work and at Home $\quad$. $\quad$. $\quad$. $\quad$. $\quad 39$

Cotton Picking in the Lowlands . . . . . . 50

"Light-hearted, good-natured and aisily lynched." (Mr. Dooley) 51

Cotton Bolls, Fibres Other than Cotton . . . . 56

The Mechanical Cotton Picker . . . . . . 57

Soft and Compressed Bales: Gathering Samples _ . . 64

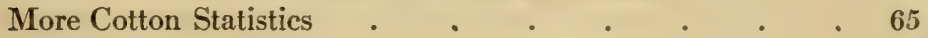

Southern Views . . . . . . . . 72

More Scenes from Dixie . $\quad . \quad$. $\quad$. $\quad . \quad$. $\quad$. 73

The Cotton Association is a Factor to be Reckoned with . . 80

Holding for Better Prices . . . . . . . 81

Varieties of Cotton . . . . . . . . . . $\quad$. 90

Varieties of Cotton . . . . . . . . . 91

Varieties of Cotton . . . . . . 94

Economical and Expensive Cotton-making . . . . . 95

Improvement of Cotton . . . . . . . 100

Where Cotton Grows Best . . . . . . . 101

Getting Fertilizer from the Air . . . . . . 116

Cultivating the Crop . . . . . . . . 117

The Rescue of Old Lands . . . . . . . 122

Old-fashioned Methods Not Yet Forgotten . . . . 123

Diagram Showing Relative Quantities of Nitrogen, Potash and

Phosphoric Acid Required for the Production of an Average

Yield (per Acre) of Corn, Wheat, etc.; Crimson Clover; Cotton-

Cultivation in its Final Stage . . . . . 126 


\section{ILLUSTRATIONS-Continued}

FACING PAGE

Two Ways of Fertilizing . . . . . . . 127

Soils and Their Improvement . . . . . . 134

Comparative Quantities of Plant Food in Different Fertilizing

Ingredients . . . . . . . . . 135

Modern Cotton Making . . . . . . . 146

"How much does it weigh?" . . . . . . 147

Young Plants Just After Germination . . . . . . 164

As Destructive as an Invading Army-The Boll Weevil 165

Starting the Crop . . . . . . . . 180

The Alpha and Omega of Cotton Making . . . . 181

The Boll Weevil's Conquest of Texas . . . . 188

Before the Cotton Factory Came . . . . 189

Transformations of Cotton Bollworm (Heliothis armiger

Hübn) Double page . . . . . . . 188-189

White for the Harvest . . . . . . . . 200

Making Cotton Without Hand Chopping . . . . 201

Ginning and Baling the Cotton . . . . . . 208

Hope and Realization . . . . . . . 209

Waiting 'Turns at the Gin . . . . . . . 228

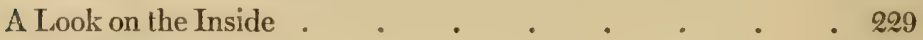

Cotton after Baling . ' . . . . . . . 230

"How Much Do I Git at Fifty Saints a Hund'ed?" . . 231

Stages of Cotton Picking . • • . . . . 242

Nerve Centres of Cotton Finance . ․ . . . . 243

Interior of New York Cotton Exchange. . . . . . 244

Condition of the Cotton Crop . . . . . . 245

The Ebb and Flow of Cotton Prices . . . . . 260

In and About a Cotton Factory . _ . . . . . 261

Cottonseed, the Finest Cattle Food . . . . . 276

Cotton Seed Huller . . . . . . . . 277

Interior View of Cotton Mill . . . . . . . 312

Cotton Manufacturing in the South . . . . , 313

Manufacturing: Fancy Dobby Loom . . . . . 320

Cotton Fabrics. . . . . . . . . 321 


\section{INTRODUCTION :}

\section{HAIL, THE KING!}





\section{INTRODUCTION : HAIL, THE KING!}

"Cotton-what a royal plant it is!" Henry Grady once exclaimed: "The world waits in attendance on its growth; the shower that falls whispering on its leaves is heard around the earth; the sun that shines on it is tempered by the prayers of all the people; the frost that chills it and the dew that descends from the stars are noted, and the trespass of a little worm upon its green leaf is more to England than the advance of the Russian army on her Asian outposts. It is gold from the instant it puts forth its tiny shoot. Its fibre is current in every bank and when, loosing its fleeces to the sun, it floats a sunny banner that glorifies the fields of the humble farmer, that man is marshaled under a flag that will compel the allegiance of the world and wring a subsidy from every nation on earth."

THE ONE CROP FOR WHICH NATURE HAS NO SUBSTITU'TE

And in this flight of eloquence the Georgia orator did not overestimate the importance of the South's great staple crop. We do not exaggerate when we claim that no other plant in all the vegetable kingdom is of so much importance to the human race. Destroy any fruit plant in the world, and men would grow other fruits. Let any lumber 
tree become extinct to-morrow, and other trees will take its place and our building go on as before. Even if corn or wheat or rice should perish from the earth, we could grow enough of the other crop, supplemented by rice, oats, barley, rye, peas, beans, etc., to feed both man and beast with comfort. But there is no substitute for cotton that can be cultivated on a large scale; no substitute, animal or vegetable product, with which civilization's present demand for clothing could be supplied.

Nor is there any plant with a history more marvelous or more romantic-more suggestive of the legend and mythology of its Oriental home where it first began to serve mankind. If Frank Norris had lived in the South instead of California, what an Epic of the Cotton he might have given uswhat a story of Cotton, responding only to the warmth of a Southern sun, and yielding a richer fleece than ever Jason dreamed of ; Cotton, whose influence did most to bring us an alien race from Africa, and then did most to perpetuate in America the institution of human slavery; Cotton, on which a "Dixie Land, the Land of Cotton," once built its hopes while it waged one of the greatest wars of modern times; Cotton, which helped the vanquished people to their feet again, and now bids fair to restore them to a proud position in wealth and industry!

THE BASIS OF THE WORLD'S DOMINANT INDUSTRY

It is probably not too much to say that cotton is now the basis of the domthant industry of the globe. In their primary forms the iron and steel products of the world represent a value of only 
$\$ 1,700,000,000$ yearly, while the estimated value of the world's annual output of cotton goods is $\$ 2,000,000,000$. On cotton most of the human race depends for clothing - three times as much cotton as wool being produced, and the world's wool production having decreased from 2,750,000 bales in 1895 to $1,750,000$ in 1905 , while in the same period the world's cotton supply has grown from 10,304,000 bales to $17,782,000$ bales. And of this enormous cotton supply three-fourths is grown in the Southern section of the United States. Twice the world's total gold output last year would have been required to pay Southern farmers for lint and seed; three-fourths of the capital stock of all the National Banks in the country would have been inadequate.

COTTON EXPORTS EXCEED IN VALUE ALL OTHER AMERICAN AGRICULTURAL EXPORTS

Among our American export crops cotton is a monarch that brooks no rivals. According to a signed statement furnished the writer by Mr. O. P. Austin, Chief of the Bureau of Statistics, Department of Commerce and Labor, January 23, 1906, the total value of our exports of cottonseed and cottonseed products for the year ending June 30,1905 (raw cotton alone $\$ 381,000,000$ ), was $\$ 410,657,752$ as against $\$ 410,205,653$ for "all other agricultural exports." In other words, take all other animal and vegetable products exported any year-wheat, corn, barley, oats, rye, flour, meal, oatmeal, fruits, vegetables, liquors, tobacco, wine, cattle, hogs, horses, sheep, beef, pork, mutton, butter, cheese, canned goods, lard, oils, wool, 
hides, skins, etc., etc., - the entire contribution, except cotton, furnished the outside world by every American farm, ranch, dairy, fruit farm and garden, from Maine to California, from Michigan to Texas, from Alaska to Hawaii, including the South's own not unimportant share-take all this, and with the proceeds of one year's cotton and cottonseed exports, the Southern cotton-grower can buy the whole colossal aggregation, still have a surplus of several hundred thousand left as pin money, and be ready to start business again with the more than $\$ 200,000,000$ he gets annually for supplying the $25,000,000$ spindles of our own country.

"If Europe during the past five years," says Mr. R. H. Edmonds, "had gathered together every dollar's worth of gold produced in all the mines of the earth and shipped it to the South, it would still have fallen $\$ 206,000,000$ short of paying for that part of the cotton crop the South has sent beyond the seas."

\section{COTTON BOTH CLOTHES AND FEEDS MANKIND}

In many ways cotton stands out unique among all the plants that men grow. Not only is it the only crop which has greatly changed the destinies of nations and continents (but for cotton, slavery would not have so flourished in the South as to plunge America into a great civil war), but it is unique in that it contributes to a greater variety of human needs than any other plant that Providence has placed upon the earth. From pole to pole, in every zone and clime; from the cradle to the grave, in every stage of life; from prince to pauper, 
among all sorts and conditions of men, it is of course the chief material used for clothing, but every year more and more of its products are brought to our tables, and it is called upon to feed a steadily increasing number of our flocks and herds.

You get up in the morning from a bed clothed in cotton; you step out on a cotton rug; you let in the light by raising a cotton window-shade; you wash with soap made partly from cottonseed oil products; you dry your face on a cotton towel; you array yourself chiefly in cotton clothing; the "silk" in which your wife dresses is probably mercerized cotton; at the breakfast table you do not get away from King Cotton; cottolene has probably taken the place of lard in the biscuit you eat; the beef and the mutton were probably fattened on cottonseed meal and hulls; your "imported olive oil" is more likely from a Texas cotton farm than from an Italian villa; your "butter" is probably a product of Southern cottonseed; the coal that burns in the fire may have been mined by the light of a cotton-oil lamp; the sheep from which your woolen clothing came were probably fed on cottonseed; the tonic you take may contain an extract of cotton root-bark; the tobacco you smoke not unlikely grew under a cotton cover and is put up in a cotton bag; your morning daily may be printed on cotton waste paper-and even in that Oriental skirmish it tells about the contending forces were clothed in khaki duck, slept under cotton tents, cotton was an essential in the high explosives which were used, and when at last war had done its worst, surgery itself called cotton into requisition to aid the injured and dying. 


\section{THE HANDMAIDEN OF CIVILIZATION}

Cotton, furthermore, is also unique in that more largely than any other plant it contributes to the higher wants of man and more justly than any other plant may be termed the Handmaiden of Civilization. For while the lowest classes of men (and animals) demand food, the demand for clothing and ornament is a mark of civilization. Even as far back as Eden itself, the desire for clothing was the first evidence of knowledge and conscience given by the first man and woman placed on earth. And with all races of mankind since, the progress of enlightenment has been largely registered by the advances in clothing. "Society is founded upon Cloth," was the doctrine of Carlyle's Teufelsdrockh; and he was not far wrong in declaring that "Man's earthly interests are all hooked and buttoned together, and held up, by Clothes. . . . Society sails through the Infinitude on Cloth, as on a Faust's Mantle, or rather like the Sheet of clean and unclean beasts in the Apostle's Dream; and without such Sheet or Mantle, would sink to endless depths or mount to inane limboes, and in either case be no more."

Of so much importance, then, is the crop we are to consider in this volume; the only one of the great staples for which no satisfactory substitute can be found; the only plant in the world that in a large measure both feeds and clothes mankind; the one plant most worthy of being reckoned the aid and ally of Civilization.

Small wonder that more than two generations of men have called it King Cotton, and that its realm is as wide as the earth! Or as certain of our own bards has said: 
COTTON

9

"Where sleeps the poet who shall fitly sing The source wherefrom doth spring That mighty commerce which, confined To the mean channels of no selfish mart, Goes out to every shore

Of this broad earth, and throngs the sea with ships That bear no thunders; hushes hungry lips In alien lands;

Joins with a delicate web remotest strands;

And gladdening rich and poor, Doth gild Parisian domes,

Or feed the cottage smoke of English homes, And only bounds its blessings by mankind !"
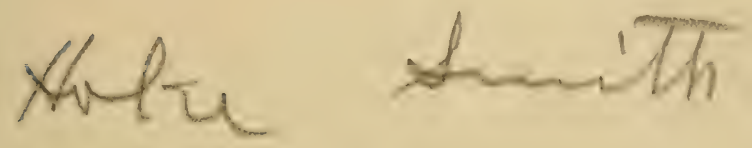



\section{SECTION I.}

\section{KING COTTON: HIS REALM}

AND HIS SUBJECTS 



\section{CHAPTER I.}

THE HISTORY OF COTTON: FROM ANCIENT INDIA TO OUR OWN TIME

We have no desire whatever to inflict upon the long-suffering reader any exhaustive review of the uninteresting remarks on cotton which pedantic scholars have picked up here and there in ancient literature. In fact, the only unpleasant task connected with the writing of this volume has been the enforced reading of several chapters of such matter. Be patient then, gentle reader; we shall not prolong the agony.

To find the first use of cotton by our race, we shall have to take the road to Mandalay and go back to a time five centuries before the birth of Christ-back to the dim past in the land of Buddha and Brahma-and Kim; back to the scene of the great Mahabharata, and the other legendary glories of the dreamy Orient. Before the world had known the sway of a Caesar, long even before the age of Pericles, the old Hindoo law declared that "the sacrificial thread of the Brahman must be made of cotton," and as punishment for theft of cotton thread directed a fine three times the value of the article stolen. 
Herodotus tells us that "the thorax or cuirass sent by Amasis, King of Egypt, to Sparta" in 550 B. C., was "adorned with gold and the fleeces from trees"- and he goes on to explain that in India are trees "the fruit of which is a wool exceeding in beauty and goodness that of a sheep." A crude system of hand-spinning, weaving and dyeing was early worked out by the Hindoos more than two thousand years ago-and singularly enough, in all of the centuries that followed this, intelligent people added practically no improvement to the cotton machinery the elders then planned. What Herodotus reported as to equipment was practically the same as that which Marco Polo found, and there was no change from the time of Marco Polo to that of Arkwright.

Across the Himalayan "Palace of the Snow," from the Hindoos is China; and it was not a great while after India began to use cotton before the Chinese put it into their gardens and sang of it in their poems-evidently treating it, however, as a rare and beautiful, rather than as a useful, plant; so that even in the sixth century after Christ it was a matter of marvel and record with the scribes of that day that the Emperor Outi had a rare robe made of cotton; and it was five hundred years later-in the days of Kubla Khan-before the manufacture of cotton among the Celestials became at all extensive. Since that time, however, cotton has been largely used for clothing the "heathen Chinee," and he has not only used his own product for this purpose, but has imported liberally from India and the Burmese provinces. 
USE IN EGYPT AND INTRODUCTION INTO EUROPE BY THE MOORS

As to the culture and use of cotton by the ancient Egyptians, there are differences of opinion among the doctors; but the weight of evidence indicates its use to a limited extent.

Into Europe the cotton plant was brought a thousand years ago, the Moors having introduced its culture in Spain "when the caliphate of Cordova was at the height of its power and magnificence." But the Spanish Christians looked with such disfavor on everything having to do with the Moors, or gave so little attention to it, that it was long before cotton found favor in the eyes of the Pope's subjects. In the fourteenth century it was at last given a chance to rejoice beneath the sunny Italian skies, and from there its culture spread to France and Greece.

\section{FOUND IN THE NEW WORLD}

In the New World cotton has been grown and used from the dateless past-certainly in clothing Peruvian mummies which had slept the sleep of death for centuries even before Pizarro came to disturb the dreams of the Incas; and among the treasures which Cortez wrested from the Mexican Montezuma and sent to Charles V. were "exquisite cotton fabries dyed in various colors." In the West Indies especially cotton has always flourished.

"In a word," says Mr. R. B. Handy, "everywhere between the parallels of $40^{\circ}$ north latitude and $40^{\circ}$ south latitude, with the exception of our present American 'Cotton Belt,' cotton, either in 
its wild or cultivated state, was known and used at the date of the settlement of America."

\section{EARLY INDIAN WEAVING}

So much for the history of cotton production. As for its manufacture, we have already seen that the crude Indian plan of spinning and weaving was invented before the Christian Era; and this system followed the culture of cotton as it spread through Europe and Asia. So crude is the Indian equipment-a distaff for spinning and a loom composed of "a few sticks or reeds which the Indian carries about with him"- that the total value is only a few shillings. It is thought likely that the Flemings learned the art of using cotton from the Turkish crusaders, and that cotton manufacture was introduced into England in the fifteenth century by artisans who fled from Flanders. And before leaving the subject of Indian weaving, it ought to be said that so wonderful is the skill of the Hindoo that our finest machinery does not make goods equal to that which he produced with his primitive equipment. So fine and gossamer-like were the muslins of Dacca that they were called "webs of woven wind." Tavernier, writing in 1660, says of some Indian fabric, that "when a man puts it on, his skin appears as plainly through it as if he was quite naked; but the merchants are not permitted to transport it, for the Governor is obliged to send it all to the Great Mogul's seraglio, who use it to make the sultanesses' and the noblemen's wives' shifts and garments for the hot weather, and the King and the lords take great pleasure in beholding them in these shifts." 


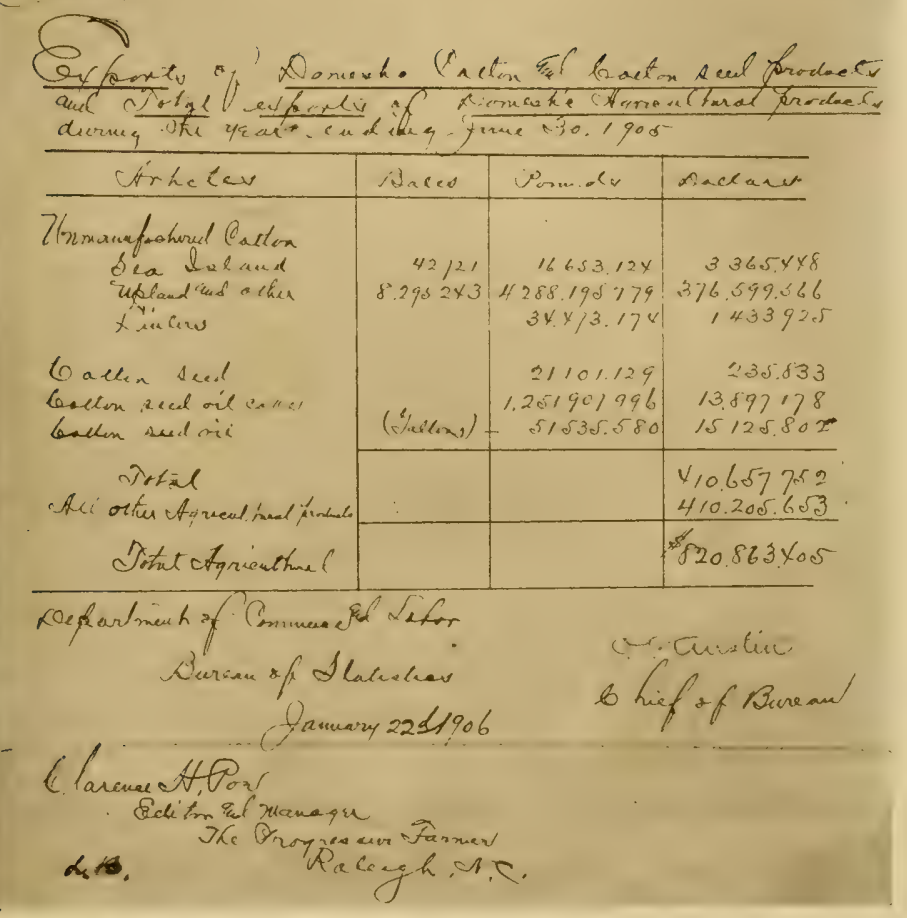

A MONARCH THAT BROOKS NO RIVALS.

Our cotton exports exceed in value all other exports combined -the total value of all other products from every American farm, ranch, dairy, fruit farm, stock farm, and garden, North, South, East and West. 


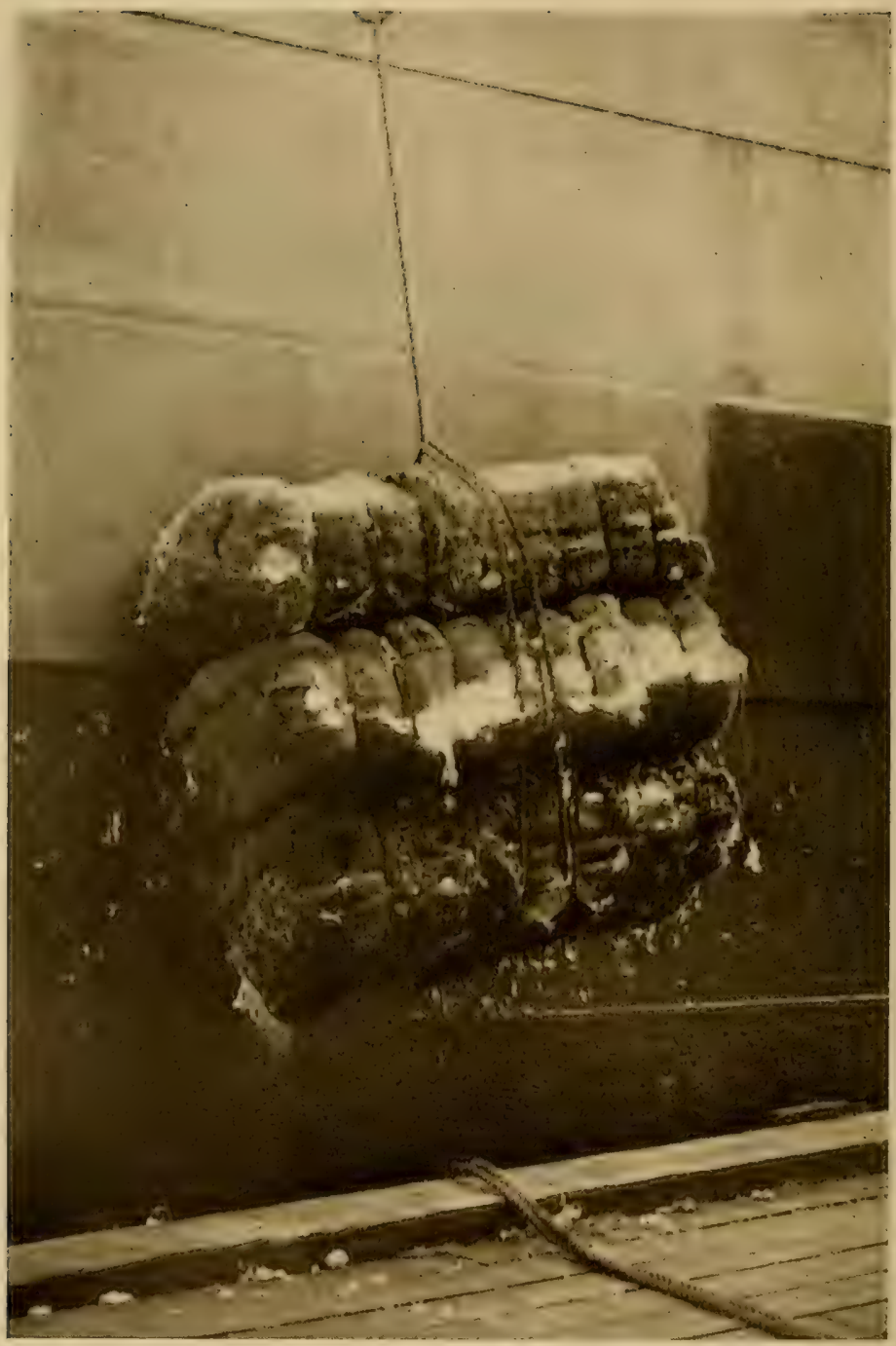

PAR'T OF OUR $\$+10,000,000$ IN CO'T TON EXPORT VALUES

An ocean steamer taking on three bales of compressed cotton for export to English mills. 
THE BEGINNING OF ENGLAND'S GREATEST INDUSTRY

Our English ancestors, late in taking up the manufacture of cotton, even after beginning it allowed the industry to grow slowly. Spinning was done on the distaff, or at best on the one-thread spinningwheel; and for weaving the hand-loom had known but little improvement since the days of the Caesars. Nor was there any kind of co-operation, any division of labor; each individual family attempted to carry on the entire process of spinning and weaving the cloth.

But about 1760 we see the beginnings of a revolution. The Manchester merchants then began to furnish cotton and linen yarn to weavers, paying a fixed price for spinning and weaving the product - and so the industry, hitherto primitive and chaotic, began for the first time to take shape as a definite, well-planned organization.

Very soon after this the export of Fnglish goods began on a small scale, and with surprisingly satisfactory results from the very beginning. Prices were high, and the call for larger supplies insistent. But as the demand grew, the English spinner grew in desperation. Here was a world outside demanding that England clothe it; and yet, for two seemingly inexorable reasons, England could not.

In the first place, while she could get yarn enough for the warp of the goods, she could not get enough cotton for the weft.

And even if she could get cotton enough, she could not find labor enough to spin it. Doing her best with her one-thread wheel, she was spinning only as much as 50,000 of our modern spindles now turn out. 
But these problems hardly began to be urgent before they were solved. Hargreaves, Arkwright, Watt, Cartwright and others with their now famous inventions, showed how to make one man's labor yield more than that of ten men had done before-and succeeded, even if the mad mob did scour the country in search of the new machines they believed would take the bread from the mouths of the laborers.

\section{AMERTCA BEGINS TO SUPPLY ENGLAND'S WANTS}

And just as the English spinners learned how to spin and weave cotton fast enough, just then America answered her question as to where she could get the raw material.

Cotton, on a small scale, was grown in America from the time of the earliest settlements. In 1621 the first planting was made in Virginia. The first permanent settlers in North Carolina in 1664 grew cotton as one of their principal crops, and forty years later cotton furnished one-fifth of the clothing used by the people of the State. South Carolina began cotton culture in 1766, and Georgia early in the eighteenth century.

"Barrels of cotton" and "bags of cotton" soon began to be mentioned as articles of export to England, and in 1751 it appears that one Henry Hansen shipped "in good order and well conditioned, in and upon the good scow called the Mary, whereof is master under God, for this present voyage, Barnaby Badgars, and now riding in the harbour of New York, and by God's grace bound for London-to say, eighteen bales of cotton wool, being marked and numbered," etc. In 1786 Liverpool 
imported 800 pounds of American cotton, in 1787, 16,350 pounds, in $1788,58,500$ pounds, and in $1792,138,328$ pounds.

By this time it was America rather than England which was wrestling with a problem-and our problem was how to separate the seed from the lint in quantities sufficient to supply the British demand. Eli Whitney solved it-just how and when we shall consider at greater length in a subsequent chapter.

It is enough here to say that the year Whitney invented the cotton gin the South grew the equivalent of 10,000 400-pound bales; a hundred years later we grew 10,000,000 4:00-pound bales. 


\section{CHAPTER II.}

ACREAGE AND PRODUCTION: WHERE THE WORLD'S SUPPLY IS GROWN

Of the $17,782,440$ bales making up the 1904-5 cotton crop of the world, it is estimated that the United States grew 13,420,440 bales, the East Indies 2,960,000, Egypt 1,187,000, Brazil, etc., 215,000.

In India, the oldest of cotton-producing countries, the total yield of late years has been decreasing. In 1893-94. India grew 2,993,000 bales (she had grown more than $3,000,000$ three years before) and in 1903-4 she produced only $2,634,400$ bales. The soil of India is well adapted to cotton growing, but the climate is largely unfavorabletoo wet in some places, too dry in others - and the average yield per acre is hardly more than half the average American yield.

\section{EGYPTIAN AND INDIAN PRODUCTION}

The abnormal demand for cotton during the Civil War stimulated Indian production, but "when the final result of the contest between America and India became apparent, America had gained command of the market, and India was considered only as a supplementary source of supply, resorted to mainly in the event of a short crop in the West." 
But if India's interest in cotton growing seems to be waning, Egypt is even more surely awakening to her advantages as a cotton-producing country. In 1894-95 the land of the Pharaohs produced only 650,000 bales; in 1904-5 1,187,000 bales. Much of this increase is undoubtedly due to the great irrigation improvements of which the world has heard so much; but even without these the same steady growth which has marked the course of Egyptian cotton farming since its beginning would doubtless have been maintained. Egypt is the only country whose cotton trade did not decline when the South after Lee's surrender resumed her old place as the home of the fleecy staple. Maho Bey, aided by a Frenchman named Jumel, turned the attention of Egypt to cotton farming in 1820 -whence the name "Maho" and "Jumel" for Egyptian cotton-and she has taken no backward step in the 80 years since she began by sending 5,323 bales to Liverpool.

THREE-FOURTHS OF WORLD'S SUPPLY GROWN IN THE SOUTH

After all, however, the world gives little thought to India or Egypt or Brazil or Russia, when it comes to reckon on the next year's cotton supply. For more than three-fourths of this supply it must look to twelve American States and Territories, in ten of which it is the chief farm product. We have already seen that half our agricultural export values is in cotton. On more than 1,000,000 American farms cotton is the principal source of income. Every foot of the surface of seven of our smaller States-land and water, hill and dale, field and 
forest, marsh and barren-might be planted to cotton without equalling the area which the South annually plants to this favorite farm staple. And all this is in the face of the fact that cotton, more largely than any other American crop, is dependent upon hand labor. The increased cost by reason of this fact, however, naturally leads to correspondingly greater profits, so that in $189924,000,000$ acres planted to cotton (and at prices very much lower than now obtain) produced $\$ 323,000,000$ in values, while the wheat crop from more than twice this area was worth only $\$ 369,000,000$, and the value of the corn crop from about four times the cotton acreage was only $\$ 828,000,000$. 


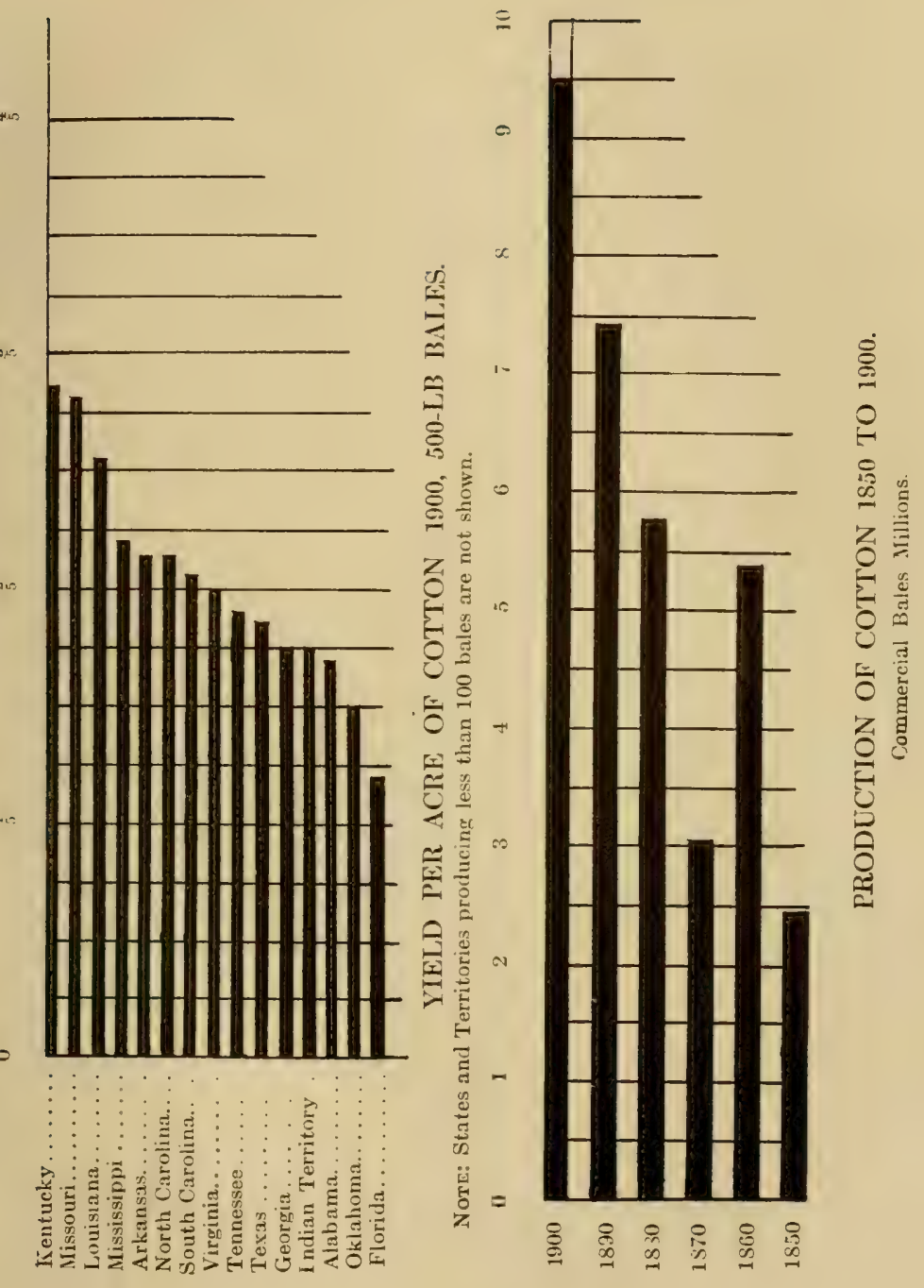




\begin{tabular}{|c|c|c|c|c|c|c|}
\hline \multicolumn{7}{|c|}{ WORLD'S PRODUCTION OF COTTON. } \\
\hline \multicolumn{2}{|c|}{ COUNTRIES. } & $\begin{array}{l}1904-05 . \\
\text { Bales. }\end{array}$ & $\begin{array}{l}\text { 1903-0.4. } \\
\text { Bales. }\end{array}$ & \multicolumn{2}{|c|}{$\begin{array}{l}1902-03 . \\
\text { Bales. }\end{array}$} & $\begin{array}{l}1901-02 . \\
\text { Bales. }\end{array}$ \\
\hline \multicolumn{2}{|c|}{ 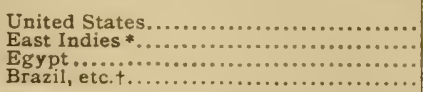 } & \begin{tabular}{r|r}
$13,420,440$ & 9 \\
$2,960,000$ & 2 \\
$1,187,000$ & 1 \\
215,000 &
\end{tabular} & $\begin{array}{r}9,841,671 \\
2,634,400 \\
1,275,754 \\
307,516\end{array}$ & $\begin{array}{r}10,511, \\
2,737 \\
1,148, \\
329\end{array}$ & & $\begin{array}{r}10,380,380 \\
2,475,230 \\
1,292,443 \\
265,896\end{array}$ \\
\hline \multicolumn{2}{|l|}{$\begin{array}{l}\text { Total .............. } \\
\text { Consumption } 52 \text { weeks.. }\end{array}$} & \begin{tabular}{l|l}
$17,788,440$ & 14 \\
$15,506,225$ & 14
\end{tabular} & $\begin{array}{l}14,059,341 \\
14,010,428\end{array}$ & \multicolumn{2}{|c|}{$\begin{array}{l}14,746,687 \\
14,436,589\end{array}$} & $\begin{array}{l}14,413,919 \\
14,414,908\end{array}$ \\
\hline \multirow{2}{*}{\multicolumn{2}{|c|}{$\begin{array}{l}\text { Surplus from year's crop............. } \\
\text { Visible and invisible stock: } \\
\text { September } 1 \text { beginning year... } \\
\text { September } 1 \text { ending year.................................. }\end{array}$}} & $2,776,185$ & 48,913 & \multicolumn{2}{|c|}{290,098} & $a 959$ \\
\hline & & $\begin{array}{l}3,011,079 \\
5,287,264\end{array}$ & $\begin{array}{l}2,962,166 \\
3,011,079\end{array}$ & \multicolumn{2}{|c|}{$\begin{array}{l}2,672,068 \\
2,962,166\end{array}$} & $\begin{array}{l}2,673,027 \\
2,672,068\end{array}$ \\
\hline \multirow{2}{*}{\multicolumn{7}{|c|}{$\begin{array}{l}\text { * Includes India's exports to Europe, America and Japan, and mill consumption in } \\
\text { India increased or decreased by excess or loss of stock at Bombay. } \\
\text { † Receipts into Europe from Brazil, Smyrna, Peru, West Indies, etc, and Japan } \\
\text { and China cotton used in Japanese mills. } \\
\text { a Deficiency in the year's new supply. } \\
\text { The above statement indicates in compact form the year's supply of } \\
\text { cotton (not including Russia) in each of the four years, the amount con- } \\
\text { sumed, and also the extent to which visible and invisible stocks were } \\
\text { increased or diminished. }\end{array}$}} \\
\hline & & & & & & \\
\hline \multicolumn{7}{|c|}{ COMMERCIAL CROP BY STATES. } \\
\hline & $\begin{array}{c}\text { 1904-05 } \\
\text { Bales }\end{array}$ & $\begin{array}{c}1903-04 \\
\text { Bales }\end{array}$ & \multicolumn{2}{|c|}{$\begin{array}{c}1902-08 \\
\text { Bales }\end{array}$} & & $\begin{array}{l}1901-02 \\
\text { Bales }\end{array}$ \\
\hline Alabama.... & $1,470,000$ & $1,000,000$ & \multicolumn{2}{|c|}{$\begin{array}{ll}0 & 1,050,000\end{array}$} & & 200,000 \\
\hline Arkansas.... & 905,000 & 705,000 & \multirow{2}{*}{\multicolumn{2}{|c|}{$\begin{array}{r}1,000,000 \\
55,000\end{array}$}} & & 820,000 \\
\hline Florida..... & 89,000 & 55,000 & & & & 54,000 \\
\hline Georgia......... & $1,975,000$ & $1,325,000$ & \multicolumn{2}{|c|}{$1,470,000$} & & 525,000 \\
\hline Louisiana....... & $1,100,000$ & 824,000 & \multicolumn{2}{|c|}{884,000} & & 880,000 \\
\hline Mississippi ...... & $1,777,000$ & $1,387,000$ & \multicolumn{2}{|c|}{$1,404,000$} & & 375,000 \\
\hline N. Carolina, etc. & 775,000 & 563,000 & \multicolumn{2}{|c|}{575,000} & & 550,000 \\
\hline South Carolina.. & $1,200,000$ & 825,000 & \multicolumn{2}{|c|}{950,000} & & 925,000 \\
\hline Tennessee, etc... & 691,000 & 451,000 & \multicolumn{2}{|c|}{509,000} & & 359,000 \\
\hline Tex. \& Indian Ter & $3,584,000$ & $2,876,000$ & \multicolumn{2}{|c|}{$2,831,000$} & & 993,000 \\
\hline Total crop, bales & $13,566,000$ & $10,011,000$ & \multicolumn{2}{|c|}{$10,728,000$} & \multicolumn{2}{|c|}{$10,681,000$} \\
\hline
\end{tabular}

COTTON STATISTICS.

(Courtesy of Latham, Alexander \& $\mathrm{Co}$ ) 
STATISTICS WHICH SHOW THE DEVELOPMENT OF COTTON GROWING

I do not know that in any way we can get the subject more clearly before the reader than to give herewith the statistics of production by years for seventy years past, and the acreage and average yield by years since 1888:

ACREAGE AND YIELD SINCE 1888

\begin{tabular}{|c|c|c|c|c|c|c|}
\hline Season & Acres Planted & Crop Pounds Net & $\begin{array}{c}\text { Net } \\
\text { Pounds } \\
\text { per } \\
\text { Acre }\end{array}$ & Bales in Crop & $\begin{array}{c}\text { Net } \\
\text { Weight } \\
\text { per } \\
\text { Bale }\end{array}$ & $\begin{array}{c}\text { Bales } \\
\text { Per } \\
\text { Acre }\end{array}$ \\
\hline $1888-89$ & $19,362,073$ & $3,260,996,300$ & 168 & $6,938,290$ & 470 & 036 \\
\hline 1889-90 & $20,171,896$ & $3,472,861,786$ & 172 & $7,311,322$ & 471 & 036 \\
\hline 1890-91 & $20,809,053$ & $4,092,678,381$ & 196 & $8,652,597$ & 473 & 041 \\
\hline 1891-92 & $20,714,937$ & $4,273,734,267$ & 206 & $9,035,379$ & 473 & 043 \\
\hline 1892-93 & $18,067,924$ & $3,182,673,375$ & 176 & $6,700,365$ & 475 & 037 \\
\hline 1893-94 & $19,684,000$ & $3,578,613,258$ & 182 & $7,549,817$ & 474 & 038 \\
\hline $1894-95$ & $21,454,000$ & $4,792,205,484$ & 223 & $9,901,251$ & 484 & 046 \\
\hline $1895-96$ & $18,882,000$ & $3,414,054,042$ & 181 & $7,157,346$ & 477 & 038 \\
\hline $1896-97$ & $22,341,000$ & $4,177,548,828$ & 187 & $8,757,964$ & 477 & 039 \\
\hline 1897-98 & $24,071,000$ & $5,398,397,108$ & 224 & $11,199,994$ & 482 & 047 \\
\hline 1898-99 & $23,572,000$ & $5,513,396,760$ & 232 & $11,274,840$ & 489 & 048 \\
\hline $1899-00$ & $22,583,055$ & $4,757,062,942$ & 210 & $9,436,416$ & 479 & 044 \\
\hline $1900-01$ & $25,558,000$ & $4,958,252,000$ & 198 & $10,383,422$ & 485 & 041 \\
\hline 1901-02 & $27,532,000$ & $5,176,016,000$ & 188 & $10,680,680$ & 483 & $\begin{array}{ll}0 & 39\end{array}$ \\
\hline $1902-03$ & $27,450,000$ & $5,188,050,000$ & 189 & $10,727,559$ & 483 & 039 \\
\hline 1903-04 & $28,907,000$ & $4,885,283,000$ & 169 & $10,011,374$ & 483 & 035 \\
\hline $1904-05$ & $31,730,371$ & $6,695,108,281$ & 211 & $13,565,885$ & 491 & 043 \\
\hline
\end{tabular}


CROP, EXPORTS AND PRICES FOR SEVENTY YEARS

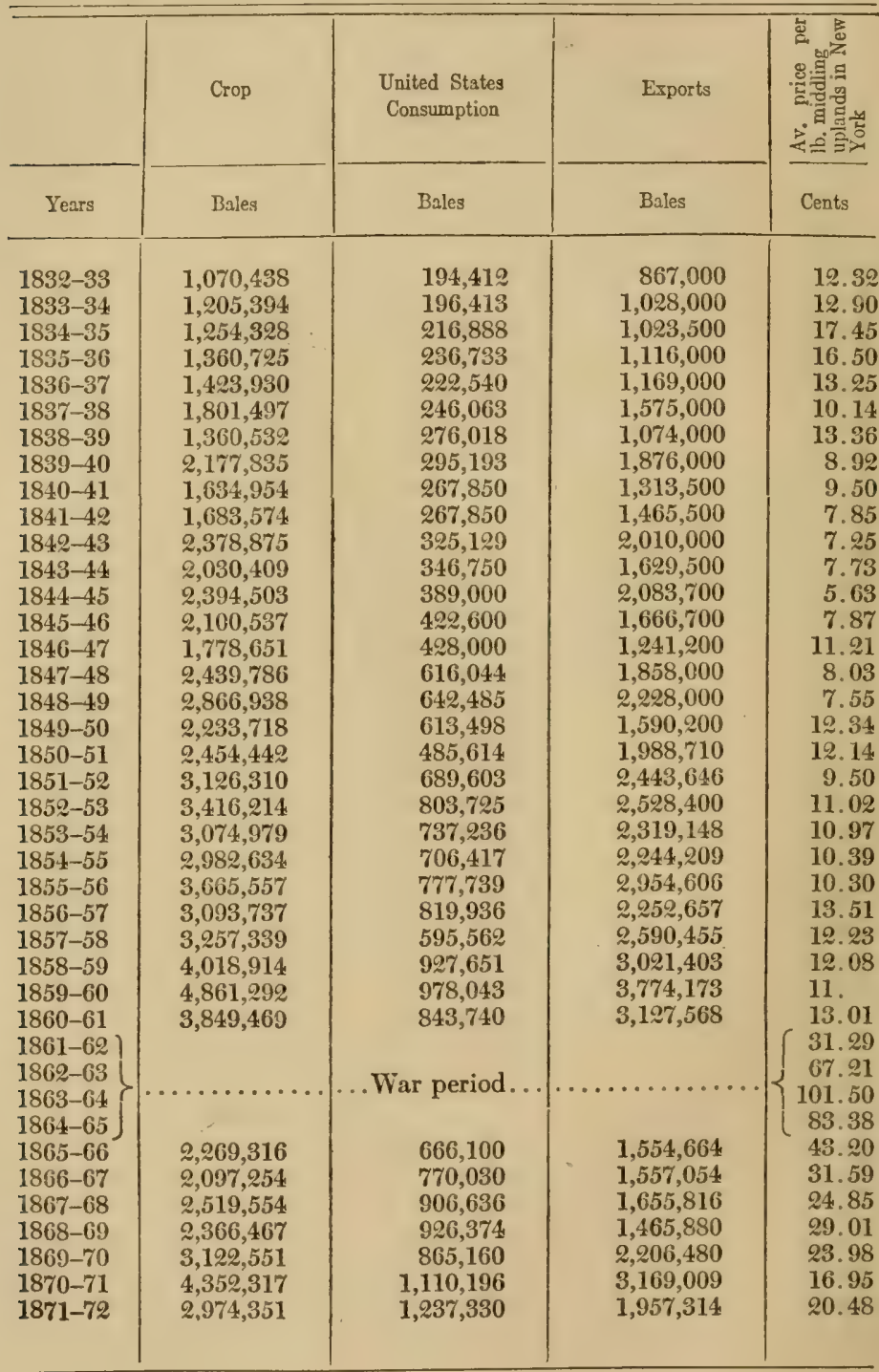


CROP, EXPORTS AND PRICES FOR SEVENTY YEARS

(Continued)

\begin{tabular}{|c|c|c|c|c|}
\hline & Crop & $\begin{array}{l}\text { United States } \\
\text { Consumption }\end{array}$ & Exports & 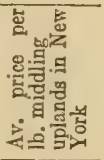 \\
\hline Year & Bales & Bales & Bales & Cents \\
\hline $1872-73$ & $3,930,508$ & $1,201,127$ & $2,679,986$ & 18.15 \\
\hline $1873-74$ & $4,170,388$ & $1,305,943$ & $2,840,981$ & 17. \\
\hline $1874-75$ & $3,832,991$ & $1,193,005$ & $2,684,708$ & 15. \\
\hline $1875-76$ & $4,632,313$ & $1,351,870$ & $3,234,244$ & 13. \\
\hline $1876-77$ & $4,474,069$ & $1,428,013$ & $3,030,835$ & 11.73 \\
\hline $1877-78$ & $4,773,865$ & $1,489,022$ & $3,360,254$ & 11. 28 \\
\hline $1878-79$ & $5,074,155$ & $1,558,329$ & $3,481,004$ & 10.83 \\
\hline $1879-80$ & $5,761,252$ & $1,789,978$ & $3,885,003$ & 12.02 \\
\hline $1880-81$ & $6,605,750$ & $1,938,937$ & $4,589,346$ & 11.34 \\
\hline $1881-82$ & $5,456,048$ & $1,964,535$ & $3,582,6 \mathcal{2} \mathcal{2}$ & 12.16 \\
\hline $1882-83$ & $6,949,756$ & $2,073,096$ & $4,766,597$ & 10.63 \\
\hline $1883-84$ & $5,713,200$ & $1,876,683$ & $3,916,581$ & 10.64 \\
\hline $1884-85$ & $5,706,165$ & $1,753,125$ & $3,947,979$ & 10.54 \\
\hline $1885-86$ & $6,575,691$ & $2,162,544$ & $4,336,203$ & 9.44 \\
\hline $1886-87$ & $6,505,087$ & $2,111,532$ & $4,445,302$ & 10.25 \\
\hline $1887-88$ & $7,046,833$ & $2,257,247$ & $4,627,502$ & 10.27 \\
\hline $1888-89$ & $6,938,290$ & $2,314,091$ & $4,854,573$ & 10.71 \\
\hline $1889-90$ & $7,311,322$ & $2,390,959$ & $4,996,543$ & 11.53 \\
\hline $1890-91$ & $8,652,597$ & $2,632,023$ & $5,783,101$ & 9.03 \\
\hline $1891-92$ & $9,035,379$ & $2,876,846$ & $5,868,545$ & 7.64 \\
\hline $1892-93$ & $6,700,365$ & $2,431,134$ & $4,410,524$ & 8.24 \\
\hline $1893-94$ & $7,549,817$ & $2,319,688$ & $5,360,318$ & 7.67 \\
\hline $1894-95$ & $9,901,251$ & $2,946,677$ & $6,926,025$ & 6.50 \\
\hline $1895-96$ & $7,157,346$ & $2,50+, 972$ & $4,751,384$ & 8.16 \\
\hline $1896-97$ & $8,757,964$ & $2,847,351$ & $6,088,521$ & 7.72 \\
\hline $1897-98$ & $11,199,994$ & $3,443,581$ & $7,674,065$ & 6. 22 \\
\hline 1898-99 & $11,274,840$ & $3,589,494$ & $7,452,116$ & 6. \\
\hline 1899-00 & $9,436,416$ & $3,665,412$ & $6,055,874$ & 8. 69 \\
\hline $1900-01$ & $10,383,422$ & $3,588,501$ & $6,639,931$ & 8.96 \\
\hline 1901-02 & $10,680,680$ & $3,988,501$ & $6,715,793$ & 8.75 \\
\hline $1902-03$ & $10,727,559$ & $4,161,374$ & $6,766,378$ & 10.27 \\
\hline 1903-04 & $10,011,374$ & $3,946,219$ & $6,109,755$ & 12.42 \\
\hline $1904-05$ & $13,565,885$ & $4,445,650$ & $8,767,180$ & 9.11 \\
\hline
\end{tabular}


THE LIMITS OF PROFITABLE COTTON PRODUCTION IN THE SOUTH

Stretch a line from Norfolk to Memphis, Little Rock and Dallas, and you have the Cotton Belt fairly outlined-though cotton has been grown to some extent north of this line. It was first cultivated in Virginia. One hundred and twenty years ago it was found on farms in parts of Delaware. "At the time of the Revolution the home-grown cotton was sufficiently abundant in Pennsylvania to supply the domestic needs of the State." Three Maryland counties grew the crop largely up to eighty years ago. In Civil War times Nevada and Illinois also figured in cotton production.

Of late years, however, the production of cotton in all States beyond the borders of the old Southern Confederacy has steadily diminished. Kentucky, Missouri, Tennessee and Virginia each showed a declining yield for the last census decade as compared with the preceding decade.

For fifty years now the median point of production has been within a radius of about $\mathbf{7 5}$ miles from Jackson, Mississippi,-in the earlier period northeast of Jackson, but in the last twenty years carried northwest by the increase of the Texas crop and the opening up of new lands in Oklahoma and Indian Territory. The cotton section west of the Mississippi grew 34 per cent. of the crop in 1879,38 per cent. in 1889 , and 43 per cent. in 1899. The next census will probably show the center of production as having for the first time crossed beyond the Father of Waters. 


\section{CHAPTER III.}

DOES FOREIGN COMPETITION THREATEN THE SOUTH'S SUPREMACY?

The figures we have already quoted and the tables of statistics we have given leave so little to be said about the subject of acreage and production in the South that we now proceed directly to the inquiry which is doubtless uppermost in the minds of most of our readers:

Is the South likely to maintain its present supremacy as the world's chief source of raw cotton?

For it is really the South against the field, and all the countries that now make cotton on a small scale are interesting in this respect only as we regard them as a combination which might eventually rob America of its prestige.

ENGLAND'S EFFORTS TO BECOME INDEPENDENT OF SLAVE-MADE COTTON

It is not a new subject. Before us now is a bulky, time-worn volume, bearing on its title page the legend, "Cotton is King: and Pro-Slavery Arguments," and one of the weighty problems which engrossed the attention of its compilers was the effort England was making to free herself from dependence on slave-made cotton. I have also dis- 
covered in this musty volume some extracts from the London Economist of 1859 which-except for their direct references to slavery:-might well have appeared yesterday. The Economist Editor comments on the fact that Brazil, Egypt and the West Indies all grow cotton and might grow more, "but as an immediate and practical question of supply, it is confined to America and British India."

To India, however, he looks very hopefully. The situation, he says, "invests the subject of Indian cotton growing with enormous interest.

conditions of supply from India differ very much from those which attach to and determine the supply from America. In India there is no limit to the quantity of labor. There may be said to be little or none to the quantity of land. The obstacle is of another kind; it lies almost exclusively in lack of cheap transit." Therefore he finds new hopes in the "railways which are being constructed . . . . to bring in the abundant labor of millions of our fellow subjects in India to cheapen and increase the supply of cotton." No English consul or cotton manufacturer in our own time has had a severer attack of Mulberry Sellers optimism than did this Economist writer of fifty years ago.

\section{"HOPE SPRINGS ETERNAL"}

Writing later in 1859, the Editor of the Economist lauded in the highest terms the continued efforts to make England independent of Southern cotton. "We cannot well conceive of stronger considerations than those which are moving Englishmen to action in this particular," he says; and this time he also lays stress on the opportunities in 
Africa. Missionaries from various sections also believed that West Africa and the Niger countries would relieve the situation; and Lord Palmerston shared the enthusiastic faith that Great Britain would "find on the West Coast of Africa a most valuable supply of cotton . . . . . . cotton districts . . . . more extensive than those of India."

If Alexander Pope were alive to-day he could ask no stronger confirmation of his famous dictum that "hope springs eternal in the human breast" than the persistence with which English manufacturers still hug the delusion that Africa and India will enable them-as their fathers and grandfathers fifty years ago hoped it would enable them - to get a large part of their raw cotton from Old World districts.

WHAT HAPPENED WHEN THE CRUCIAL TEST CAME

We all remember how on one occasion Uncle Remus was telling the Little Boy of one of Brer Rabbit's hair-breadth escapes. The pursuer was almost upon Mr. Cottontail and in another moment might have had him in his furious grasp. "And right then Brer Rabbit he clumb a tree," said Uncle Remus.

"But rabbits can't climb trees," protested the Little Boy.

"Never mind," replied the old darkey, "Brer Rabbit this time was obleeged-jest obleeged-to climb the tree-en' he clumb it."

Well, in 1862 the English spinner reached the same inexorable crisis that confronted Brer Rabbit -the time when he knew he was "jest obleeged to climb the tree." 
And he didn't climb it.

SOME STATE'S EVIDENCE

Let the British edition of the Encyclopaedia Britannica tell the story. Let us hear this piece of State's evidence as to the crisis which came when war so nearly stopped cotton production in the South:

"This great source of supply, when apparently most abundant and secure, was shortly afterwards suddenly cut off, and thousands were for a time deprived of employment and the means of subsistence. In this period of destitution the cotton-growing resources of every part of the globe were tested to the utmost; and in the Exhibition of 1862 the representatives of every country from which supplies might be expected met to concert measures for obtaining all that was wanted without the aid of America. The colonies and dependencies of Great Britain, including India, seemed well able to grow all the cotton that could be required, whilst numerous other countries were ready to afford their cooperation. A powerful stimulus was thus given to the growth of cotton in all directions; a degree of activity and enterprise never witnessed before was seen in India, Egypt, Turkey, Greece, Italy, Africa, the West Indies, Queensland, New South Wales, Peru, Brazil, and in short wherever cotton could be produced; and there seemed no room to doubt that in a short time there would be abundant supplies independently of America. But ten years afterwards, in the Exhibition of 1872, which was specially devoted to cotton, a few only of the thirtyfive countries which had sent their samples in $\mathbf{1 8 6 2}$ again appeared, and these for the most part only to 
bear witness to disappointment and failure. America had re-entered the field of competition, and was rapidly gaining ground so as to be able to bid defiance to the world."

AFRICAN AND INDIAN EXPERIMENTS NOT A SUCCESS

An even more vivid picture of the inducements to foreign competition which England held out during the Civil War period is furnished by the 1869 report of the Cotton Commissioner of India. So immense were the profits that the Indian cotton farmers received, he says, that they committed all sorts of absurdities: "Silver plowshares and tires of solid silver for cartwheels made their appearance here and there; fancy prices were paid for bullocks of a favorite color or possessing some peculiarities of tail, and enormous sums were squandered on marriage ceremonies." And yet in spite of the enormous subsidies (virtually) which were paid, and the energy with which the experiment was prosecuted, it was found impossible even with artificial inflation to carry the Indian crop beyond 3,000,000 bales.

As to Africa, the experiments there have never been at any time anything but inglorious failures; and it is said that the cotton made in the Niger territory has cost 50 cents a pound. A West African correspondent of the London Times says that the much vaunted "colonies of Lagos, Southern Nigeria, Gold Coast, Sierra Leone, and Gambia, under the most favorable circumstances . . . will not be capable of producing more than 350,000 bales, and these figures will not be attained for many years, if ever." 
WORLD'S DEMAND WILL GROW FASTER THAN FOREIGN PRODUCTION

It is not likely, of course, that all these attempts to grow cotton outside the South will fail utterly; but what does seem sure is that the world's demand for cotton will grow much faster than the foreign supply, and that therefore our country will be called on in the future, as heretofore, for a constantly increasing crop.

And in support of this opinion the writer will quote just three opinions, and then pass on to other subjects.

First, our own National Department of Agriculture in its Crop Reporter for December, 1905, makes this conservative statement of fact: "The organized efforts of powerful associations of cotton manufacturers in Great Britain, Germany, and France to establish and stimulate cotton production in the colonies of these countries, which began early in 1903 with a large capital subscribed for promotion, have so far resulted in no perceptible addition to the world's cotton crop, and there are no present indications of a competition of new fields of production which will materially affect the foreign market for the upland cotton of this country for many years."

LOWER SOUTH AMERICA ALONE CAN COMPETE WITH THE SOUTH

Even more interesting is the opinion of the late Edward Atkinson, as given in an article in the Manufacturers' Record in 1903. During the Civil War Mr. Atkinson imported cotton from India, Egypt, China, West Africa, Peru and Brazil, and his conclusion is that nearly all the foreign cotton 
is as unsatisfactory in quality as it is deficient in quantity. None of the countries mentioned, he says, have a congenial climate such as ours. The Indian fiber is "short, rough and unsuited to any but the coarsest fabrics;" the Chinese fiber he found "only about a quarter of an inch long;" the cotton from West Africa "wholly unfit for use as a substitute for America;" and he did not think Peru or Brazil could compete with the South. Summing up, Mr. Atkinson declared that while he should like to believe otherwise, he was forced to the conclusion that the South would have a virtual monopoly for fifty years. "There is but one section of the earth's surface, where, in my judgment, there can be competition with our Cotton States in growing cotton of equal quality, and that is on the high pampas of the Paraguay and Parana Rivers, sufficiently elevated to be free from tropical conditions, endowed with a soil of wonderful fertility and capable of unlimited crops of cotton and wheat Therefore our Cotton States have an unwholesome but practical monopoly of the cotton of commerce. They are not, therefore, under the wholesome stimulus of prospective want, and therefore their method as a rule, subject to conspicuous exceptions, in dealing with their land, their cotton and their cotton bale, is as bad as it can be, as I have often said when face to face with my friends in the South."

ENGLISH AUTHORITIES FINALLY ADMIT THE SOUTH'S SUPREMACY

Lastly I come to the most striking testimony of all-direct evidence given by "our friends, the enemy." It is the report of the Commissioners sent 
out by the British Government to investigate the cotton-growing possibilities of East Africa; and with this parting shot we shall drop the question of possible foreign competition with the Southern States:

"All efforts to raise cotton successfully elsewhere than in the Southern part of the United States have failed. This is the home of the cotton plant, and if it will grow and fruit elsewhere to the extent that the staple have a substantial commercial value, the fact is yet to be demonstrated. It was experimented with under different suns during and after the American Civil War, and all the experiments failed. Providence has given the Southern farmer a monopoly of the indispensable cotton crop, and he need not take fright when the price soars and there are heard threats of turning Africa, Egypt or other countries into cotton fields and making them furnish the world's supply." 


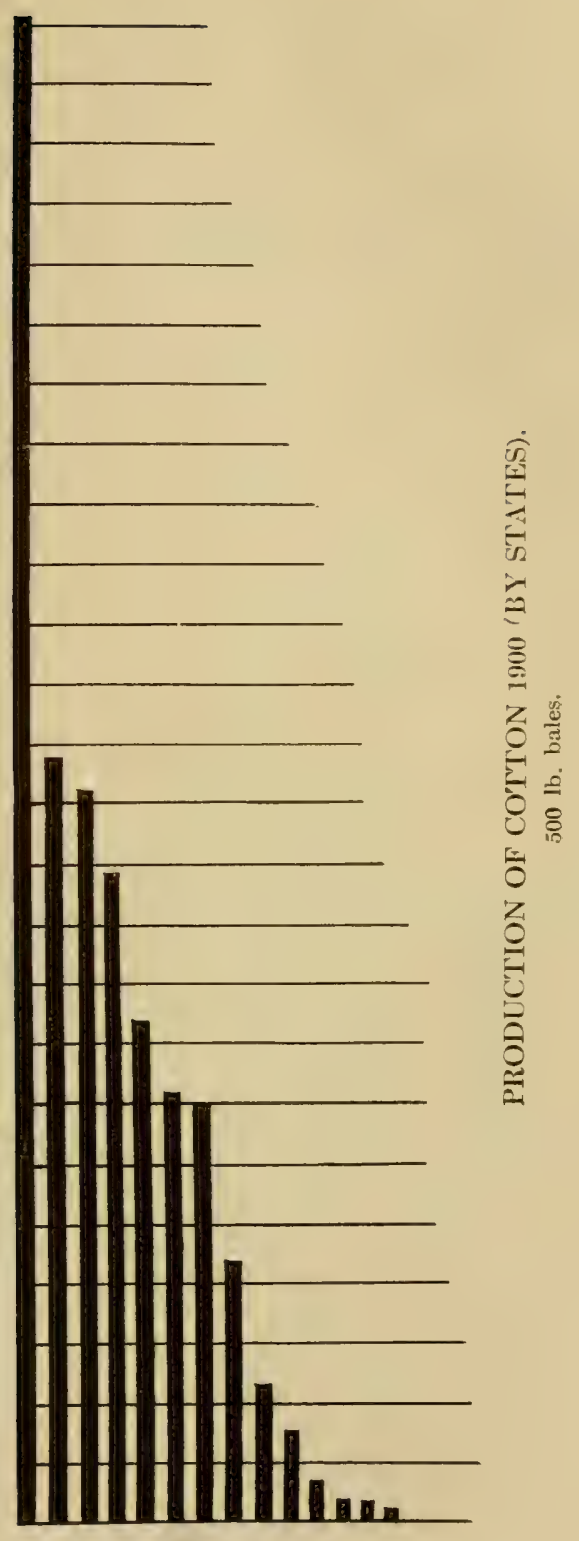




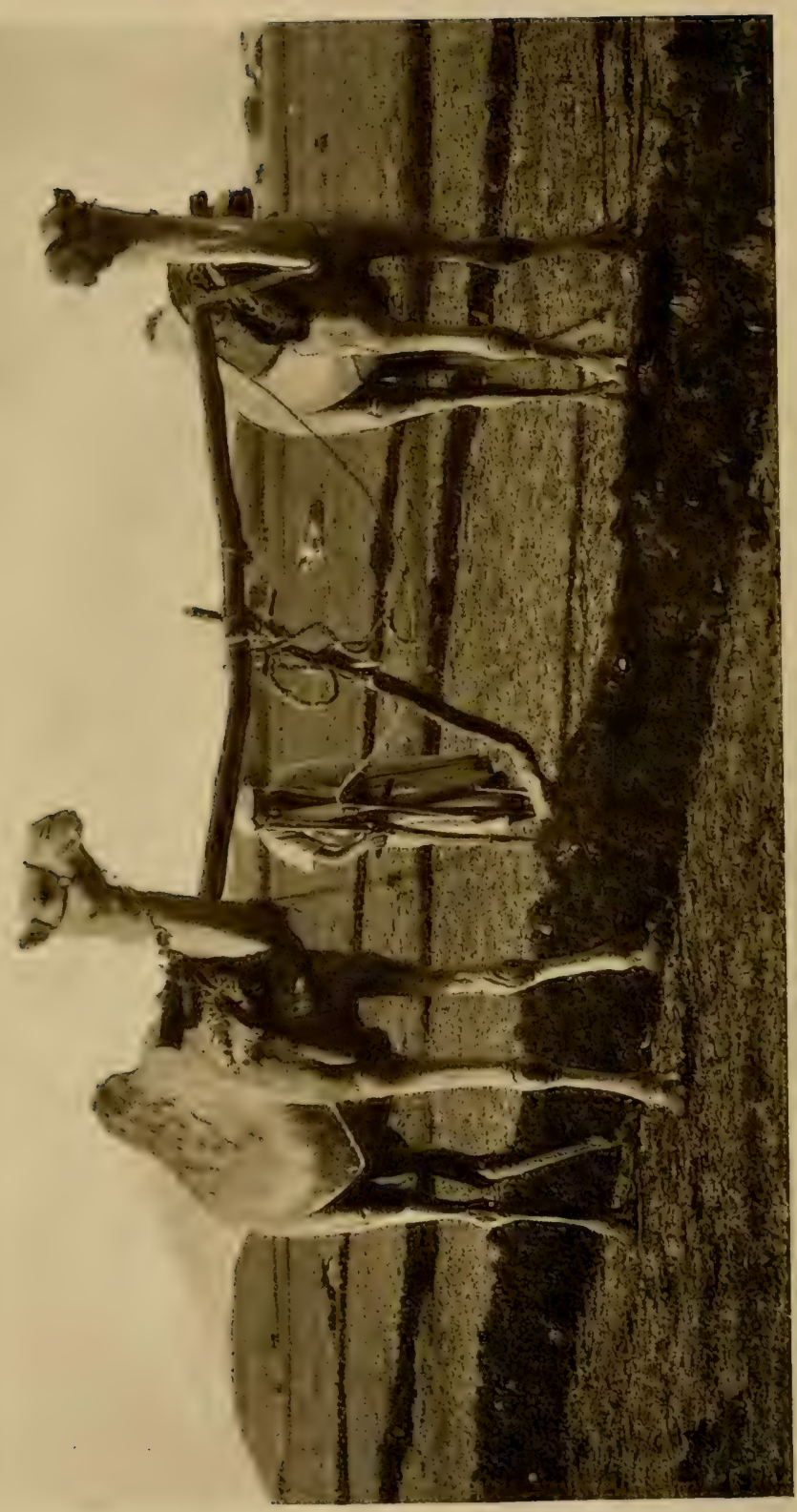

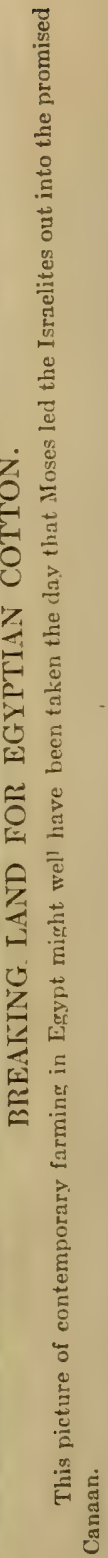




\section{CHAPTER IV.}

THE MEN WHO MAKE COTTON: WHITES AND BLACKS; PLANTERS AND TENANTS

Unique in many other features already mentioned, cotton is also unique among American staples in that it is the favorite crop of the negro farmer and that in its production a larger number of tenants are employed than in any other crop.

WHY THE NUMBER OF TENANTS INCREASED IN 1890-

\section{0}

Of the farms in the ten Cotton States in $\mathbf{1 9 0 0}$ 48.3 per cent. were operated by owners, 20.3 per cent. by cash tenants, and 31.4 by share tenants-showing a decrease for the decade of 15 per cent. in proportion operated by owners, a gain of 12 per cent. in the proportion worked by share tenants, and a gain of 33.1-3 per cent. in percentage operated by cash tenants. Of share tenants there are several classes. Some rent land only, paying therefor one-fourth of the farm product; others are furnished land, stock, tools, and one-half fertilizer, and receive one-half the crop, while still others are content to furnish labor only for one-third the yield.

The relative decrease in number of farms operated by owners during the last census decade must be attributed to the emigration of farm owners to 
towns, as a result of the depression in cotton prices. Sir Guilford Molesworth estimates that between 1872 and 1894 prices of general commodities fell 50 per cent., while cotton prices declined 70 per cent. With the turn in the tide in prices, one now finds abundant evidence of a similar turn in the tide of migration.

NEGRO'S IMPORTANCE IN COTTON PRODUCTION PROBABLY OVERESTIMATED

As to the negro in cotton production there are probably conflicting impressions and delusions. "A regular" cottontot" as he has been called, the negro, the mule, and the cotton patch are inseparably linked together in the public mind. In 1899 little more than half of the Southern white farmers grew cotton, while 84 per cent. of the negroes were faithful to their favorite staple.

And yet it is more than likely that the average reader has overestimated the negro's importance as a factor in cotton-growing. It is so picturesque to have the black negro in the white cotton field that in about ninetynine per cent. of our book, magazine, and tourist pictures it is the son of Ham and not the white man who is laboring with the fleecy staple. As a result of all this, the average Northern reader would probably be surprised to learn of hundreds of thousands of small white farmers with their families who make cotton from planting to picking almost or entirely without negro labor. On many farms a negro is never employed; on many others, negroes are called in only for a few days' work in the height of the busy season. 
Of the 1,418,000 cotton farms reported in 1900 , 849,000 were operated by whites. White farmers cultivated 14,616,000 acres, and negro farmers, $9,650,000$ acres. (Of course, though, much negro labor was hired to assist in cultivating the white farms.)

\section{THE SHIFTLESS NEGRO TENANT FARMER}

Of the negro farmers more than four-fifths are tenants-or about 500,000 of the nearly 600,000 negro farmers. "Clearly the central feature of the Southern farm life of the negro race," says Prof. W.E. Du Bois, "is the tenant class-this half million black men who hire farms on various terms, and a large proportion of whom stand about midway between slavery and ownership."

One hardly knows whether to say that the negro's indifference, his contentment with this lot, makes the situation more or less tragical. "Take ye no thought for the morrow - what ye shall eat, nor yet for your body, what ye shall put on," is one Bible commandment which the negro literally obeys. And his other favorite commandment is like unto it: "Multiply and replenish the earth"-taking equally little heed for the morrow of the niggerkins themselves, unless Topsy-like, they "just grow." As an old negro whom the writer used to know would say, "If I've got a peck of corn meal in the bar'l, I ain't got nothin' to worry about."

"The one-room cabin" says Prof. Du Bois, "is still the typical farm home of the negro," and as for his food and disposition:

\footnotetext{
“Oh, I gits my stren'th from white side meat,

I sops all de sorghum a nigger kin eat,

I chaws wheat bread on Saddy night

En' I ain't no han' to run f'um a fight."
} 
Let us look for a minute at our typical negro tenant. He moves in December to a new farm, we will say - for he has a roving instinct that prevents his remaining long at any place. He probably rents horse, land and tools from the farm owner, taking half the crop for his labor, and the farmer stands his security for supplies at the nearest store. Or he may rent land only, paying one-fourth the crop for the land, and mortgage his unplanted crop to the merchant for advance supplies. At any rate, the negro's recklessness, coupled with the exorbitant "time prices" charged, leads him perhaps to buy more than his crop pays for-so that the merchant's reckoning when the negro brings in his three or four bales of cotton in the fall, has been pretty accurately set forth in the popular couplet:

"Naught's a naught, figger's a figger,

All for the white man, and none for the nigger."

Heretofore it has been true in most cases perhaps that the negro actually ended the year owing the merchant a balance on the year's supplies-the merchant not allowing the balance, however, to become more than just large enough to insure the negro's becoming his bondservant for another year.

If, however, the negro finds himself burdened with an unexpected cash surplus after paying his debts, he probably relieves the burden aforesaid by buying an organ (which no member of his family can play) or a calendar clock (the dates of which he can barely read) or a magnificent range (on which his wife will experiment with side meat and corn bread until she becomes disgusted and goes back to the family fire-place). 

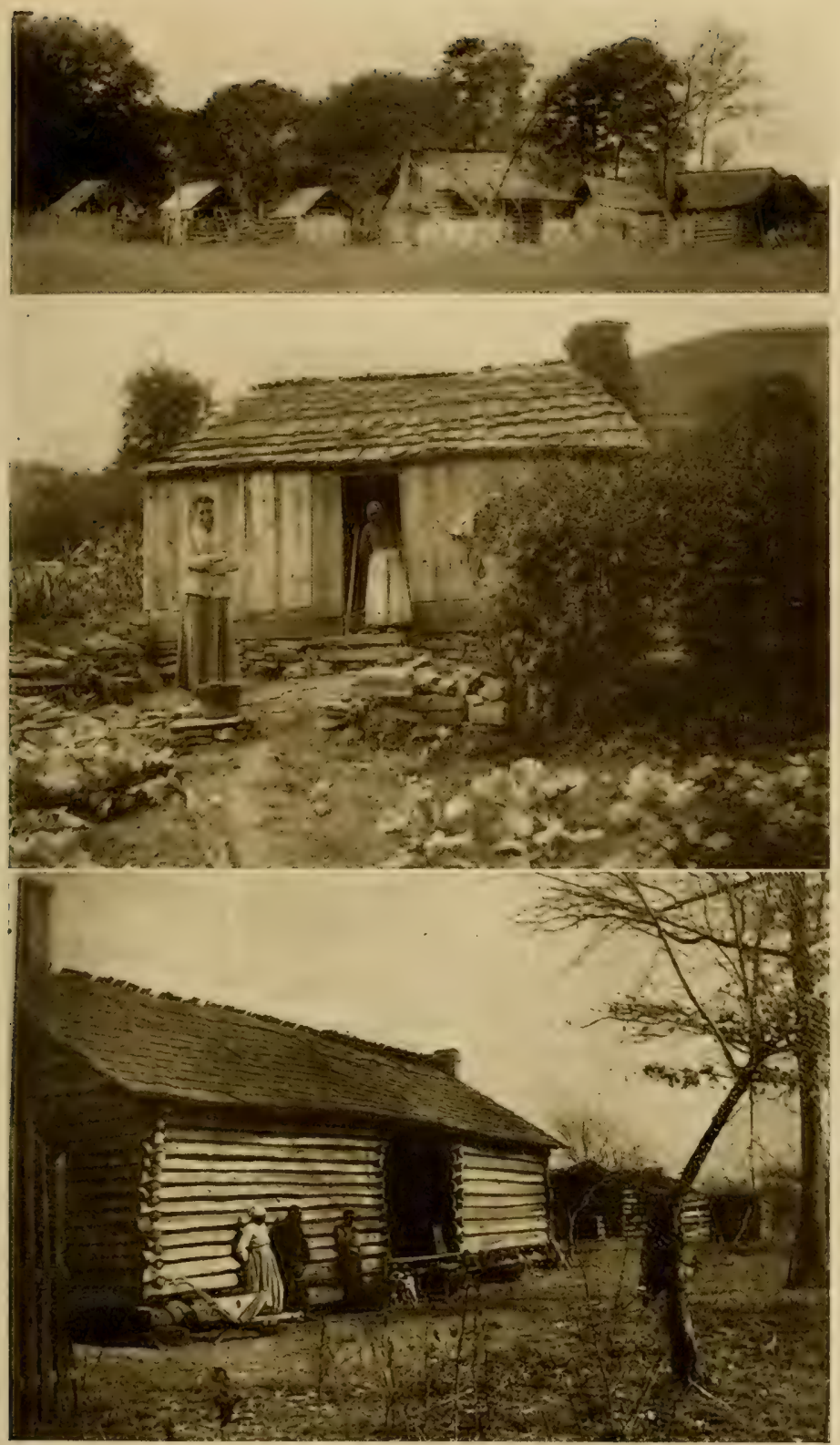

HOW THE NEGRO TENAN'TS LIVE.

The pictures show typical homes of negro croppers and renters of the poorer class. The houses, however, are being steadily improved. 

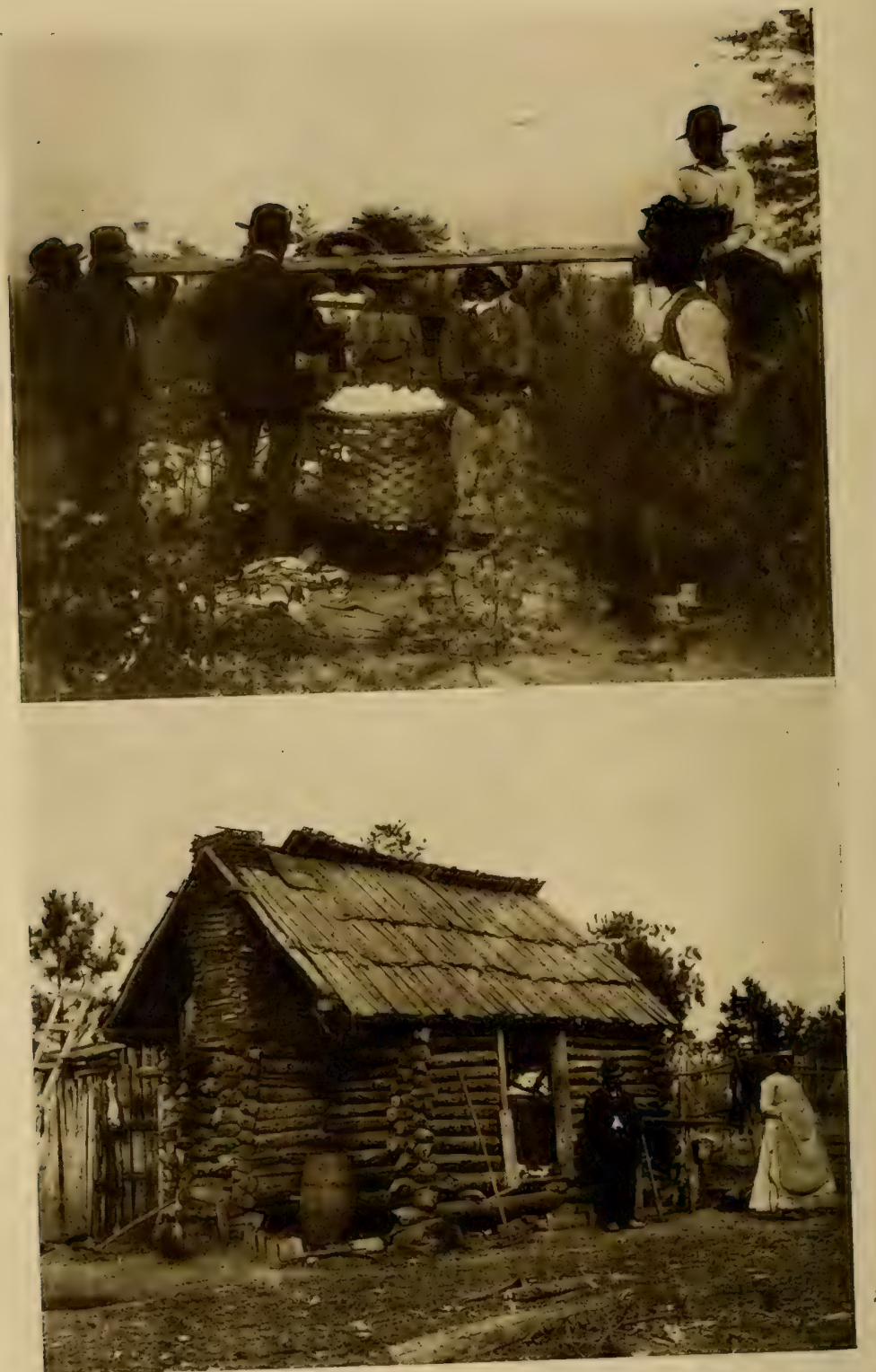

NEGRO PICKERS AT WORK AND AT HOME.

Favorite method of weighing the day's harvest, the basket supported by a (A) Favorite method of weighing the day's harvest, cabin.
fence rail borne on the shoulders of two men. (B) a negro cabin. 
A DIFFERENT TYPE OF NEGRO FARMER

Such is our typical negro-_"light-hearted, goodnatured and aisily lynched," as Mr. Dooley saystypical, but not the only type. A by no means inconsiderable number of negroes are acquiring property, building better houses, and adopting improved methods of farming. Many negroes once tenants have bought portions of the farms where they formerly worked. For example, take Deal Jackson, a Georgia negro cotton grower, who every year for seven years past has beaten every one of the 110,906 white farmers of his State in getting the first bale to market. Less than twenty years ago Deal was a tenant. He borrowed $\$ 1,000$ to buy a run-down farm, mortgaging the place as security. Then like that proverbially modest mar. who wanted each year to buy just the land "j'inin' his," so Deal continued to buy adjoining tracts until he has 2,000 acres of fertile land, operating, with his tenants, forty-five plows.

WHEN LOW PRICES CRUSHED BOTH WHITES AND BLACKS

Nor should we forget that it is not the negro alone who has struggled year after year, Sisyphuslike, with the burden of debt. Thousands of white tenants, and of white farm owners as well, have had the same experience. In fact, unless the farmer carried some surplus savings into that long perind of low prices from 1891 to 1901 , such an experience was almost unavoidable. With any reasonably high standard of living, cotton was then below the cost of production. No wonder farm owners moved 
to towns and mortgages became almost as common as they were in the West in the days of low-priced corn. Ten-cent cotton then seemed an iridescent dream, and men talked of it as the feature of some Golden Age gone never to return.

\section{CHANGES RESULTING FROM HIGH-PRICED COTTON}

Of course, with the coming of higher prices for cotton, important changes are taking place. The mortgage and the crop lien, with all except the hopelessly shiftless class, are disappearing like snow before a summer sun-unless we except the mortgage given by the aspiring tenant in his ambition to become a land-owner himself.

As to the future, one must not predict too lightly, for it is easy to see that the present high price of cotton will make itself felt not in one direction only, but in counter currents.

As one result, more tenants wish to buy lands for themselves; as another result, land is increasing in value so that it requires greater savings to buy it. On the whole, however, it is now relatively easier to become one's own landlord, and with high prices the tenant class is likely to decrease.

As one result, too, more people are attracted by the old plantation system; as another result, laborers find it so profitable to work for themselves that labor is much more expensive than it used to be. But as the negro works better in groups, the large plantation has at least this advantage in its struggle to reassert itself.

With high prices then, the one sure thingwhether the proportion of tenants increase or decrease, whether the plantation system decline or 
flourish-is that a larger proportion of white people will engage in cotton production. If labor can be had few town occupations are more profitable. And as for the man who has his own labor, who must have his own children at work, how much better for health, safety and comfort, as well as profit, to have them on the cotton farm instead of in the cotton factory!

Already many cotton mills are beginning to suffer for labor because the tide is turning back to the farms. 


\section{CHAPTER V.}

A 25,000,000 BALE CROP: WILL THE SOUTH BE READY WHEN THE WORLD DEMANDS IT?

Thirty years ago the South grew only $4,000,000$ bales of cotton; twenty years ago $6,000,000$ bales; ten years ago, 8,000,000 bales; the last three crops have averaged more than $11,000,000$.

And the end is not yet. Cotton is not only supplanting other fabrics (we have seen how rapidly wool production is decreasing), but the demand for the great Southern staple is increasing as a result of the constant raising of our standards of living and of comfort, and as a result of the advance of civilization among peoples heretofore barbarous. The time will soon have passed when "the lady in middle Africa may cavalierly inform the agent of the American cotton mill that clothes are of doubtful propriety amongst the aristocracy of the Congo Valley anyhow."

THE WORLD WILL DEMAND 42,000,000 BALES

"It is estimated," says the United States Depart-. ment of Agriculture, " that of the world's population of $1,500,000,000$, about $500,000,000$ regularly wear clothes, about $\mathbf{7 5 0 , 0 0 0 , 0 0 0}$ are partially 
clothed, and 250,000,000 habitually go almost naked, and that to clothe the entire population of the world would require $42,000,000$ bales of 500 pounds each. It therefore seems more than likely that the cotton industry will go on expanding until the whole of the inhabited earth is clothed with the products of its looms."

And it is the opinion of the authors that the South will increase her production just as fast as the world increases her demands. We have yet a shamefully low average yield; we are depending yet on fearfully mistreated soils; we are yet planting miserably selected seed; and we have very inefficient tools and machinery. Necessity, that mother of invention, will help us reform these abuses-just as necessity brought about the new inventions in cotton spinning, and just as necessity brought about Whitney's cotton gin. When it becomes necessary for her to furnish the world $25,000,000$ bales of cotton, the South will furnish it.

\section{OF SOUTHERN LANDS ONLY ONE ACRE IN SEVEN- TEEN NOW IN COTTON}

Even if we were not going to double the yield (and unless the boll weevil interferes, men now living may see that result), we have enough available idle land to make $30,000,000$ bales with the present low average yield per acre. Of the twelve Cotton States only one acre in seventeen is now planted to the fleecy staple, and only one acre in eleven of the cotton-producing counties. Only two-fifths of the farm lands of the South are yet improved for any sort of crop.

The great trouble is that we have so long allowed the bulk of our cotton lands to be butchered by 
negro slaves and negro tenants that we do not yet appreciate the marvelous possibilities of scientific cotton farming. Just take the bald statement of Dr. H. J. Webber: "The average yield of cotton in the United States is only about 190 pounds of lint per acre, while on many large tracts carefully cultivated a yield of 500 to 800 pounds per acre is frequently obtained." Here in itself is material for a book of sermons.

SEED SELECTION MAY INCREASE YIELD 30 TO 50 PER CENT.

For one thing, the seed for the cotton crop are probably selected with less care than are seed for any other farm crop that men grow. Your cotton farmer will carefully select the largest and bestformed ears for his seed corn; he will pay high prices for improved seed or oats; even his watermelon seed are selected from the most luscious and reddest-meated specimens of last summer. But when it comes to seed for his cotton crop he is strangely careless. The average farmer gets his seed haphazard from the general supply at the gin - good, bad, indifferent; early, late, medium; tall, bushy, and ordinary, varieties all mixed.

With such conditions there is indeed abundant reason for believing that the average cotton yield per acre could be increased one-fourth by only five years' wise selection of seed. We know a farmer now who by selecting seed from the most thrifty stalks and having the seed ginned separately, in two years so improved the crop from the selected seed that the improvement was easily noted and became a matter of comment by persons passing on 
the road. We know another farmer who by a few years' seed selection has increased the yield of cotton thus improved from 400 to 600 pounds while seed selected in the old way grown on similar land and under similar conditions still makes its bare 400 pounds an acre. Fifty per cent. increase from four years' selection of seed!

Of course, where a special type of cotton has been nurtured and improved through a long period of years' seed selection has increased the yield of cotresults can be obtained than with ordinary farmbred seed; and when our farmers come to a proper appreciation of this fact, a long step toward the doubled yield will have been made by this one reform. Thus one of our State Departments of Agriculture, speaking of a five-year test of cotton varieties (with practically the sameconditions of soil,

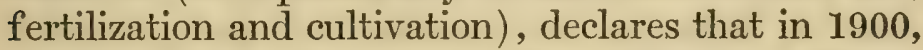
in a test of eight varieties the difference between the variety yielding the largest amount of seed cotton per acre, and the one the smallest, was 565 pounds; in 1901 and 1902 in tests of seven varieties each, the differences were 520 and 790 pounds respectively; in 1903, 662 1-2 pounds when nine varieties were incorporated; and 725 2-5 pounds difference in 1904 in a test of twenty-one varieties.

In other words, one man uses intelligence in seed selection; another man does not; both work equally hard; both have land of equal value; both expend the same amount for fertilizers-but the scientific cotton farmer gets from 500 to 700 pounds more per acre than the thoughtless clodhopper.

So much for what we may accomplish by seed selection alone. 
CORN SEVEN TIMES, WHEAT TWICE, AS EXHAUSTIVE AS CO'TTON

But it is not alone in our reckless disregard of the ancient laws of breeding that we have succeeded in bringing down the yield of cotton far below what it should be; like a Prodigal Son, wasting his substance in riotous living, we have also been guilty of inexcusable folly in dealing with Nature's greatest gift to the farmer-the soil itself. Land-starved for ages, our forefathers came from Europe to our Southern States and reveled in mad intoxication in the seemingly unlimited areas of virgin soils they found. Before the Civil War it was customary to clear up land, grow a few crops of cotton on it, then "turn it out" to broomsage and gullies, and clear up more new lands for the cotton crop. The old fields of the South probably cover an area as large as five of the New England States. So it was not mere poetic sentiment, but the deep recognition of a damning economic sin that moved Sidney Lanier to say:

\footnotetext{
"Upon that generous rounding side With gullies scarified

When keen Neglect his lash hath plied

Yon old deserted Georgian hill

Bares to the sun his piteous aged crest And seamy breast,

By restless-hearted children left to lie

Untended there beneath the heedless sky,

As barbarous folk expose their old to die."
}

Really, as we shall see further on in this book, there is less reason for the abandoned field in cotton growing than in any other kind of farming. An average crop of wheat requires twice as much plant food as an average crop of cotton, and an average crop of corn nearly seven times as much. 
Or to put the matter in even more striking form, it appears that if through feeding and manuring, the wheat straw, corn stover and cotton seed of these three crops respectively are each returned to the soil, wheat requires nineteen times as much of the great fertilizing elements as cotton, and corn thirty times as much.

Sooner or later the Southern farmer will learn to apply this doctrine; the farm paper, the agricultural text-book in the public school, the agricultural college, the Farmers' Institute workers, all are hammering away at the idea. And then when the cotton farmer gets this double-jointed idea: first, that he has the finest stock food in the world; second, that with this by-product properly utilized he has the crop that is of all crops the kindest to the soil-and a practical monopoly of this crop-why, then, we shall have a new era in Southern agriculture; and as Dr. B. T. Galloway says, "a system of landrobbing will give way to a system of land-building."

\section{THE MECHANICAL COT'TON-PICKER}

But, some one reminds us, in this day of laborsaving machinery cotton is still the one crop most fully dependent on hand labor. It is said that within fifty years the time of human labor required to produce a bushel of corn has decreased from four hours to shirty-four minutes, and for a bushel of wheat from three hours and ten minutes to ten minutes, while it is doubtful if the time of human labor required to produce a pound of cotton has been diminished even one-third. What then-when the world has begun to demand $25,000,000$ bales of the South, even though we have so improved our seed 
and so built up our lands as to find no difficulty here, shall we not nevertheless be hopelessly balked by lack of labor for chopping and picking the crop?

This problem, in our opinion, is another one that is likely to solve itself when inexorable circumstance demands that it do so.

As for hoeing the cotton, that problem is already solved. Within two miles of where this book is written, some of the finest cotton in the county was grown last year entirely without hand-choppingsimply by the right use of the peg-tooth smoothing harrow and the cultivator. The cotton was thinned and kept free from grass entirely by these tools. And instead of the average yield of 200 pounds of lint per acre, this land made 700 pounds of lint per acre!

A much more serious problem is the mechanical cotton-picker. There are many lions in the path. Cotton does not open all at once, but irregularly through a period of several weeks. Cotton does not have the uniformity of corn or wheat in size or position, but is irregularly placed in the rows, its limbs grow all over it, and the plants vary hopelessly in size; the limbs furthermore are easily broken. Finally, the lint should be free from dirt and trash, and many have thought that only the human hand could select the lint from the open bolls without adding a ruinously large quantity of dead leaves and dirt.

Clearly, therefore, the making of a mechanical picker is a hard task, and yet so fertile is the human imagination and so enormous are the rewards awaiting the man who succeeds in making an effective picker-the wealth of Croesus may be his-that we expect it to come, and to come not very many 
years hence. Writing of this matier in a farm paper early in 1904, we said: "The present labor crisis in the Cotton Belt is certain to bring the matter to the attention of inventors. We have long thought of the cotton picker as an impossibility, because the bolls are irregularly placed, ripen irregularly, and must not be mixed with limbs and leaves in picking. But the suggestion now made puts the matter in a new light. Instead of a harvesting machine on a big scale such as we have for grain, a small machine carefully guided and watched over by an operator, would be put to the task of taking the cotton from the open bolls. It does not look as if this should be wholly impossible. And as there are millions in it for the man who succeeds at it, it is likely to be done if it can be done."

\section{THE LOWRY COTTON PICKER DESCRIBED}

Within the last few months the South has seen this "small machine carefully guided and watched over by an operator, . . . . . . put to the task of taking the cotton from the open bolls." It is the Lowry Picker, and its mode of operation has been fully described as follows; the photographs given herewith making the matter still plainer:

"The machine is not entirely automatic, as the arms that carry the little wheels which gather in the fleecy staple must be directed by human hands to the open bolls. The arms carry a chain with hooked teeth, adjusted like the chains of a bicycle. When the machine is in operation this chain revolves rapidly and the curved hooks gather up the staple the instant it touches the open boll, and 
carries the cotton upward until it is deflected off into a receptacle, by a revolving brush. The machine carries four operators and a driver, for each of whom a comfortable seat is prepared. There is no necessity for any bending or stooping on the part of the operator, and all he is required to do is to direct the well-balanced and nicely-adjusted arms of the machine. It is claimed by the inventor that when finally perfected each arm should gather up one boll per second, at a very low rate of speed, making 480 bolls per minute for the four operations, or 28,800 per hour. As the bolls early in the season average 60 to 80 in the pound, one machine could pick from 3,600 to 4,800 pounds per day of ten hours. One of these machines with four boys and a driver could do the work of twenty average pickers."

Some who have seen the Lowry Picker ask: "And what shall it profit the cotton farmer to have this machine, since even with it the human hand, or what is virtually an extension of the human hand, must be directed to each individual boll?" The advantage lies in the fact that the man who operates the mechanical hand at least saves (or should save) the time required in bending over each new stalk and the time required in drawing his hand back and forth in putting each separate handful into his picking-sack-and this is more than half the time required in picking.

Others who think Mr. Lowry has invented a practical device for picking the cotton say that he has hampered its success by putting it in connection with a motive power which is not satisfactory: in other words, he is sacrificing a good invention 


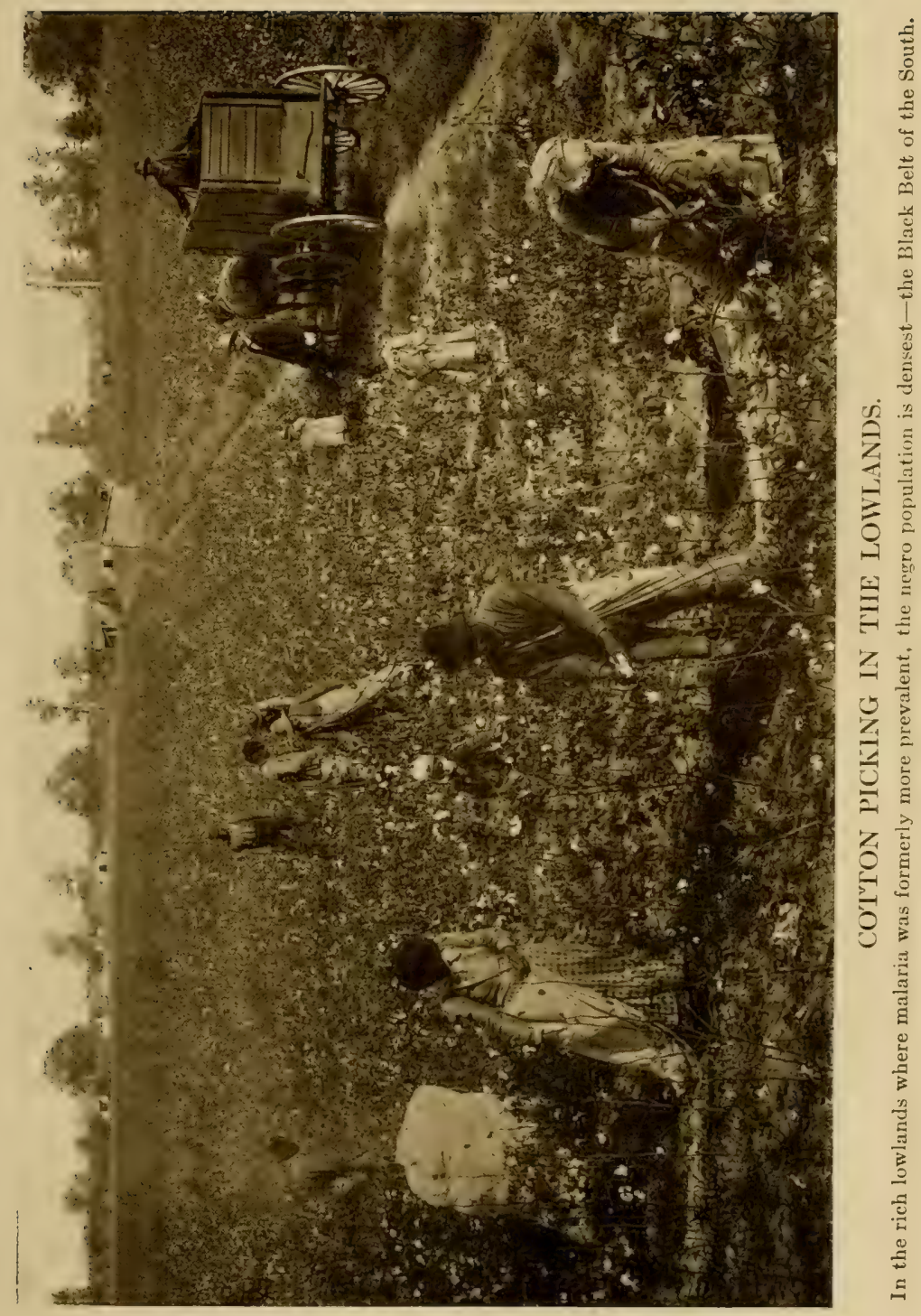




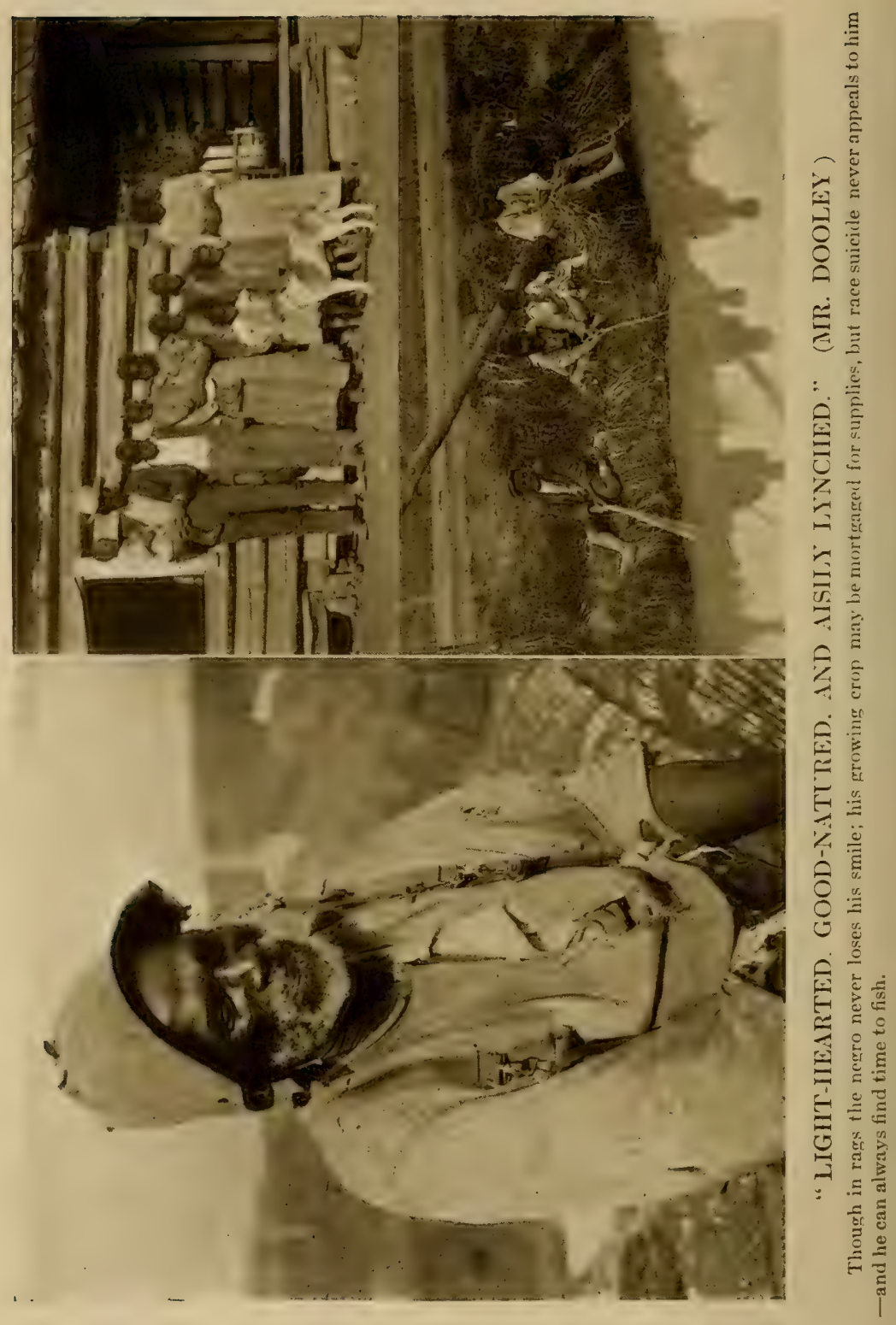


of great possibilities by yoking it with a motivepower invention absolutely worthless.

Whatever the difficulties, we may be sure that if Mr. Lowry's basic principle is right, it will sooner or later be separated from all entangling alliances and set to the service of a great need. And suppose it succeeds simply in doing the work of four men? Or suppose it reduces the cost of picking by just half? Picking now costs $\$ 100,000,000$ a year-think of saving just $\$ 50,000,000$ annually to the South! Or to put it differently, "To pick a crop of $11,000,000$ bales, at an average of 150 pounds of seed cotton a day per picker, means that for a picking season of three months, consisting of twenty working days each, somewhat over 1,830,000 people must be kept at work. Hence the basis for the claim that a picker doing the work of four men would reduce 1,500,000 people to other industries for a fourth of each year."

Indeed, there are millions in it!

Noте.-Of course many other pickers besides the Lowry have been brought before the public, but the Lowry is clearly the one that now gives most promise of success. We know an old man who twenty years ago invented a picker and still has faith that his idea will work into a success. An incorporated company, the Dixie Cotton Picker Co., of Chicago, is also at work upon the problem, and we are indebted to them for the pictures of their machine appearing herewith, and for the following description of how it works:

"The two large wheels of the machine travel in the furrows between the rows, the plants being gathered into the front of the machine between the two points of the gatherers; and, as the bushes strike the apron, they are gently bent over to the ground so that the picking spindles enter the same while the plants are beld between the skirts running parallel with the machine. There is continually entering the bushes during the progress of the machine forward about 60 revolving picking fingers. It is evident, also, that much cotton will be picked even though it be lying upon the ground, because these picking fingers with every vertical thrust downward reach clear to the ground. Each of these picking fingers, while in the plant, makes 22 revolutions and continues revolving about their own axes until they have disappeared into the machine; at which time they cease revolving, and a stripping wheel 
cleans the cotton by traversing the full length of each spindle. This stripping wheel is better termed a slotted wheel which revolves rapidly in the opposite direction to that which the spindle or picking fingers are traveling; and after clearing the cotton frum the fingers, it is carried up to a point where a set of doffer wheels clears the slotted wheel of its load of cotton, throwing the same into a basket which rides on the rear of the machine. The machine weighs about 1200 pounds, has a raising and lowerng device upon it which is essential in getting in and out of the cotton field as well as in turaing around." 


\section{CHAPTER VI.}

COTTON: WHAT IT MEANS AND WILL MEAN TO THE SOUTHERN STATES

\section{Cotton!}

To every boy born and bred in the Southern States it is a magical word from the time he is big enough to roll in its billowy heaps in the "cotton house" or go out into the June cotton field to find the first white bloom for his father, or ride to the gin on the big two-horse wagon-bed which the hands have packed with the snowy fleece new-gathered from the autumn fields. White or black, if his father is not of unusual wealth, he early learns to labor with his own hands in making the crop; and the entire process of cultivation is familiar to him.

\section{EVERY SOUTHERN BOY KNOWS COTTON FARMING}

Long before he leaves off knee pants he learns to plow the cool, fresh earth in early spring; helps haul out the great loads of manure from the barn; brings in the malodorous loads of fertilizer from the nearest village; helps "roll" the planting seed in wet ashes, so that the dry lint may not hold them together in bunches. For planting time is now at hand: the dogwoods are blossoming; the first "turtle-dove" has been heard; the fisherman has begun to tell of satisfactory catches in the nearby streams; "Uncle Isaac" and "Black Bob" dispute wisely as to whether this phase of the moon portends warm 
or cool weather, wet or dry. For the cotton seed must be ready to "come up" as soon as all danger of frost is passed; and now the rows, ridged and waiting, are opened, and fertilizer and seed distributed. Then the long green line of two-leaved plants, bursting the hard seed-covering they have pushed above ground-and the grass that will not let them be and that we have always with us. Chopping then-white and black, old and young, everybody strong enough to handle a hoe. And the plants flourish under the summer sun; now "hoehands" report that some plants have "seven leaves," then that limbs have come, and squares-and finally the anxiety as to which farmer in the neighborhood shall report the first bloom, or which one in the county shall send the first one to the editor of the county paper. Weeks, then, of budding and blooming and growing, the thrifty branches bedecked with white blooms that opened this morning and red blooms of yesterday, and becoming heavy now with green and growing bolls. Then on the lowest stalks the bolls begin to open-and who now will gin the first bale? The women in the towns begin to tremble for their negro cooks, and employers of colored men also begin to scent danger. For the coronation of King Cotton is at hand; and all the sons and daughters of Ham must dance attendance. Cotton-picking has an irresistible attraction for all negroes, especially when the picking is done in groups, and though they stay in town even through the watermelon season, cotton picking is likely to lure them back to farms.

"The real depth of feeling," as some one has said, "the sheer abandon and the proper stage setting does not come until September has touched the cotton fields, and the great hearts of the maturing bolls 
burst with joy. That is the supreme moment, and the beautifully blended voices of the negro cotton pickers of the South is a sound, once heard, never to be forgotten. One cannot find any adjective to express the wild untutored beauty of it. It is a chant of inexpressible rhythm, with a note of sadness and mingled hope and regret, and one cannot stop without burdening it with that indefinable qualification-and calling it weird . . . these days and nights filled with song and laughter, and the nimble plying of fingers set to music that is perhaps a lone relic of a long-forgotten Congo."

\section{IN DIXIE COTTON IS REALLY KING}

All this the Southern man knows from his youth up; it is his inheritance and a part of his life. For whatever it may or may not be to the rest of the world, in "Dixie" cotton is really king. Here cotton is the life blood of commerce, its condition, the thermometer of trade. Every man talks cotton; every man has an opinion as to the size of the crops; the weather conditions in Texas and throughout the Cotton Belt are subjects of general interest; the Government crop report is read with more interest than anything else a newspaper prints.

When cotton prices drop, every Southern man feels the blow; when cotton prices advance, every industry throbs with new vigor.

We can see then what it means to the South when we say that for the last five crops for which the figures may be given, she has received nearly $\$ 1,000$,000,000 more than for the preceding five cropstwice as much money as is invested in all our American cotton mills. For the crop of 1904 and 1905 she received $\$ 341,000,000$ more than for the crop 
of 1899-which sum if equally divided, would give a surplus of $\$ 240$ to each of the 1,418,000 farms growing cotton, of $\$ 21$ each to every one of the $16,000,000$ inhabitants of the Cotton States.

\section{ASTOUNDING SOUTHERN PROSPERITY}

Small wonder that Southern railways report heavier increases in earnings than lines in any other section of the country.

Small wonder that the assessed valuation of Southern property is now increasing three times as rapidly as in the decade 1890-1900.

Small wonder that savings and bank deposits in the Southern States from 1900 to 1905 increased more than 100 per cent. while the increase for the rest of the United States was only 50 per cent.

Small wonder that it is no extraordinary affair a Sampson County, North Carolina, farmer reported to us when he said last week that a farm he bought four years ago for $\$ 57.50$ per acre would sell now for $\$ 100$; another farm bought then for $\$ 3,000$ was recently sold for $\$ 8,000$; land values in his county have increased 33 1-3 per cent. within a year, a total increase of a million dollars for this one cotton county. ( We know of two South Carolina cotton farms, one of which in three years has increased in selling price from $\$ 3,000$ to $\$ 8,000$ and another from $\$ 7,000$ to $\$ 20,000$.)

Small wonder that Dr. Walter H. Page declares in the World's Work that we "are in sight of the time when the cotton grower in the old Slave States will become the most prosperous tiller of the earth."

It is, in fact, a new South that we have. The factory, the bank, the church, the school, the newspaper-all are benefited by the increase in prices 

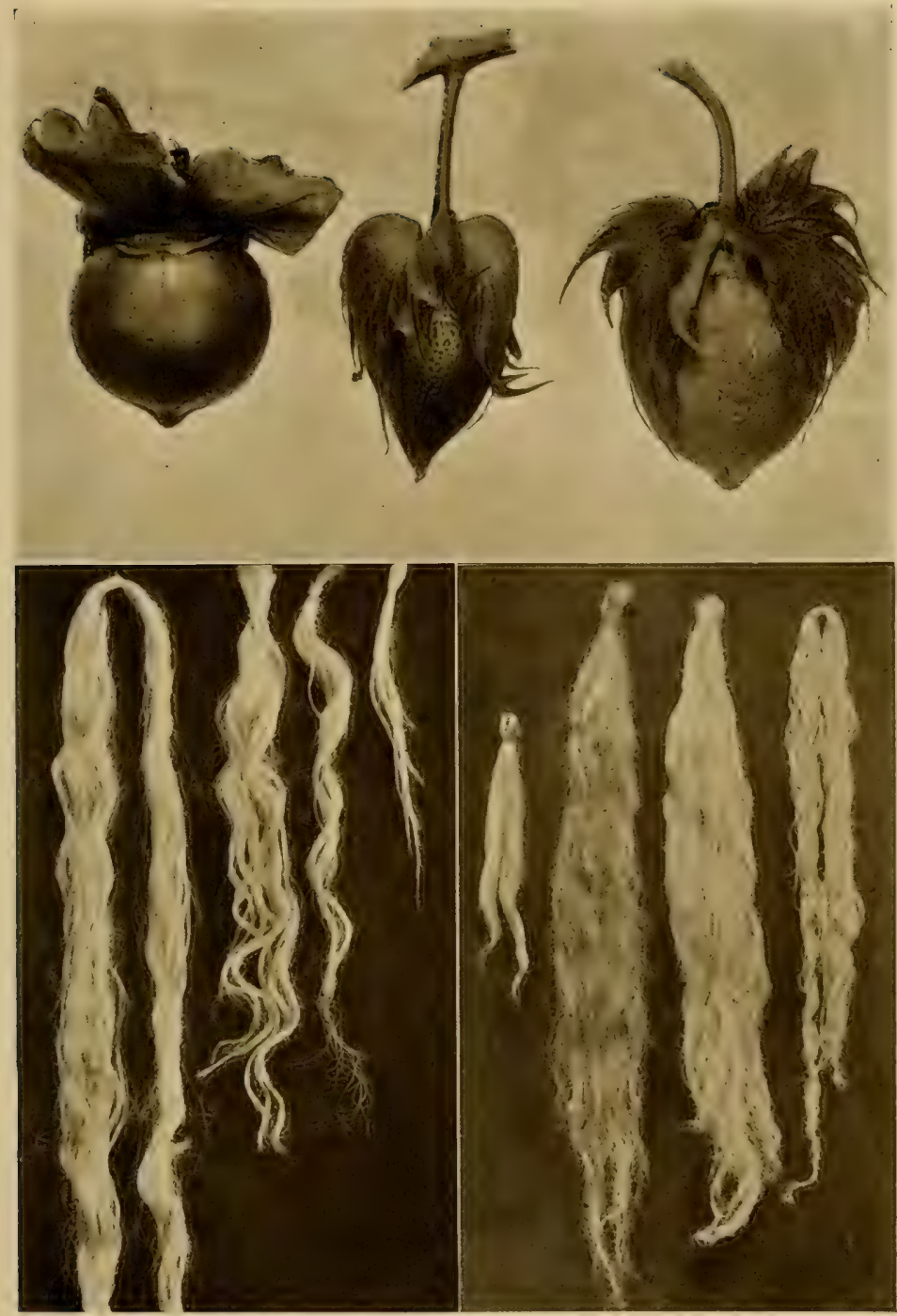

COTTON BOLLS: FIBERS OTHER THAN COTTON.

The bolls are typical (1) Asiatic, (2) Sea Island, (3) American Upland; (B) rep. common hard fibers other than cotton; (C) soft fibers; flax, hemp, and jute. 


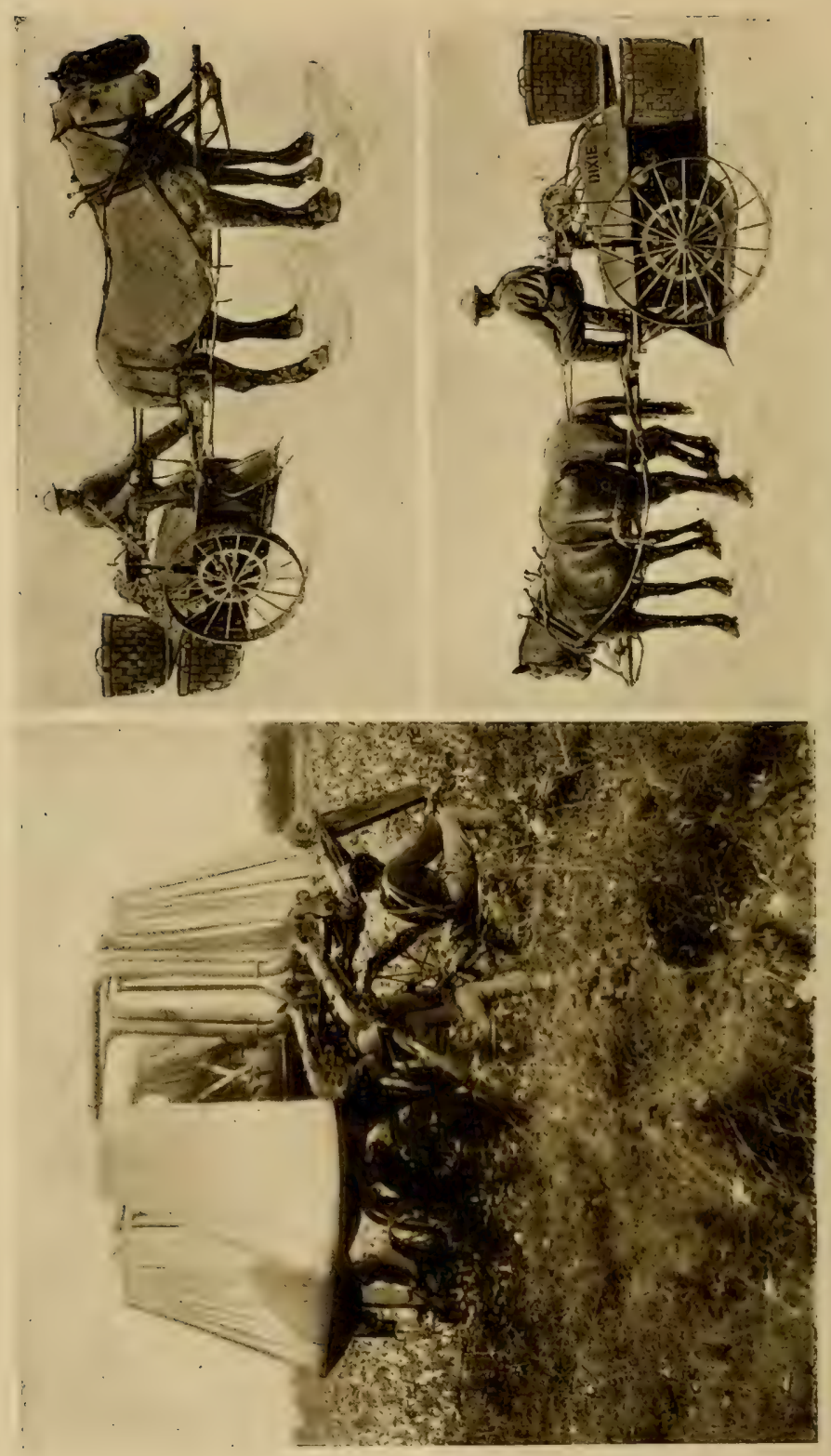

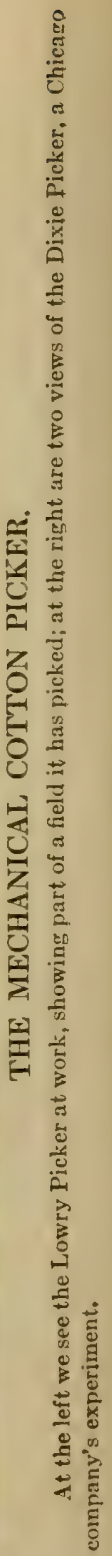


paid for the South's great staple crop. The architect will tell you that he is building better houses than erer before; the furniture dealer will tell you that he is shipping more furniture than ever before; the manufacturer of implements and machinery will acknowledge that Southern progress astounds him; the schools report record-breaking openings; the newspaper subscription gains threaten to overtake the circulation manager's estimates; and even the preacher joins in with the story that for once his salary is paid promptly and in full, and that a sermon on foreign missions is now unprecedentedly effective.

\section{IT MEANS THE COMING OF THE NEW SOUTH}

These things cannot fail to have the most farreaching influence upon every phase of Southern life. Prosperity will bring more education, more travel, greater contentment, more liberal thoughtin fact as Sidney Lanier said nearly thirty years ago:

"One has only to remember that whatever crop we reap in the future-whether it be a crop of poems, of paintings, of symphonies, of constitutional safeguards, of virtuous behaviors, of religious exaltations -we have got to bring it out of the ground with palpable plows and with plain farmer's forethought, in order to see that a vital revolution in the farming economy of the South, if it is actually occurring, is necessarily carrying with it all future Southern politics and Southern relations and Southern art, and that therefore such an agricultural change is the one substantial fact upon which any really New South can be predicted." 


\section{CHAPTER VII.}

THE ORGANIZATION OF COTTON GROWERS AND WHAT IT MAY ACCOMPLISH

"The great secret of success," said Lord Beaconsfield, "is to be ready when your opportunity comes."

One might go far and not find a better illustration of the truth of Disraeli's assertion than is afforded by the career of Hon. Harvie Jordan, President of the Southern Cotton Association. His opportunity came in December, 1904, when the Government ginners' report, indicating a crop of $12,000,000$ bales, startled the country-electrified the bears, and hopelessly dazed the bulls. Cotton prices went toppling, dropping two cents a pound almost immediately.

WHEN HARVIE JORDAN'S OPPORTUNITY CAME

For severalyears Jordan had been fitting himself for a time like this. At the head of the nominal Cotton Growers' Protection Association which he had organized and which his personality had largely kept together, his voice had been as that of one crying in the wilderness; and always, Raven-like, his song had borne one burden-the need of a farmers' organization for the purposes of self protection. When the crash came, and turned everything in the Southern States topsy-turvy, serene Harvie 
Jordan sounded the same bugle-note which Southern farmers had hitherto refused to heed.

Now they heard him.

A call was issued for a great mass meeting in New Orleans January 24-29, 1905.

One of the most pathetic pictures in history is that of the faithful remnant of the old French nobility crowding around poor King Louis when his star had almost set, thrilled again by a deep loyalty to the ancient throne then tottering, and passionately swearing allegiance once more to their hapless king, while the touching strains of "Richard, My Richard, All the World is Leaving Thee!" floated through the ill-fated Parisian palace.

It was with some such earnest loyalty, but with confidence the exact opposite of the French despair, that the followers of King Cotton met in New Orleans that January day. What they said and did it is not our purpose to record here in detail. They did resolve that the South should reduce her acreage 20 per cent. as compared with the previous year, and they organized the Southern Cotton Association to carry this resolution into effect.

With a manifest overproduction, with cotton selling at the time for six or seven cents, and with five-cent prices confidently predicted by the bear leaders of the New York Cotton Exchange, it took considerable courage for the New Orleans Cotton Convention to declare that the remainder of the 1904 crop should be held for ten cents.

Such a resolution, however, was almost unanimously adopted. And within six months the ten cent figure was reached-largely as a result of the success of the movement for reducing the cotton acreage. 
It is easy to say, of course, that cotton prices having become unsatisfactory, the cotton acreage would have been reduced without the aid of the Cotton Association; but it would certainly not have been reduced to such an extent. For if the farmer in the Carolinas had felt that the farmer in Texas was reducing his acreage on account of low prices, the Carolina farmer would have thought it a good time to increase his own crop-and vice versa. For "that air same Jones" who figures in Sidney Lanier's poem is but the type of thousands and thousands of cotton growers; and we all recall how he read the arguments for reducing cotton acreage and diversifying crops-

And presently says he: "Hit's true;

That Aisley's head is level.

Thar's one thing farmers all must do,

To keep themselves from goin' tew Bankruptcy and the devil!

"More corn! more corn! must plant less ground, And mustn't eat what's boughten !

Next year they'll do it : reasonin's sound :

(And cotton 'll fetch 'bout a dollar a pound,) Tharfore, I'll plant all cotton!"

With Texas and Carolina alike pledged to a 25 per cent. reduction, however, and with each section feeling in honor bound not to take treacherous advantage of its neighbor's fidelity, the cotton farmers of the South were moved by a common purpose, worked together earnestly to a common endand succeeded. When we attended the meeting of the Southern Cotton Association in Asheville in the fall of 1905 , not ten cents, but eleven cents, was fixed as the price of the crop then maturing. 


\section{DEMORALIZING CHANGES IN PRICES}

If it had no other object the organization of the cotton farmers would find ample justification in the opportunity it affords for co-operation in keeping the cotton acreage limited to the apparent demands of commerce.

Very large and very small crops are alike demoralizing to every cotton interest. These lead to fluctuations in value which make the manufacturer's hair turn gray as he tries to fix a fair price for his product, and which make the cotton farmer the prey of speculators and the sport of chance.

Take the difference between seventeen-cent prices in May, 1904, and seven-cent prices in January, 1905, eight months later, meaning on a 10,000,000 bale crop the difference between $\$ 350$,000,000 and $\$ 850,000,000$.

The remedy for all this lies in a more systematic plan of marketing - the entire cotton crop must not be rushed pell-mell upon the market in the ninety days of the picking and ginning season. Almost invariably prices the following spring are very much better than during the fall; and this is natural, -in fact, inevitable.

BUYERS MAKE FALL PURCHASES ONLY WITH ODDS IN THEIR FAVOR

If he must buy during the picking season before the size of the crop becomes known, the spinner buys on the assumption that the larger estimates of yield are correct-and he must then allow himself a full margin of safety, else it were better to keep his money employed in something else and buy later with less risk and with less outlay. 
In a word, it would be bad business, an unsound economic policy, for buyers to take cotton while the size of the crop is uncertain except upon the basis of the maximum reasonable estimates-which must in any given series of years be materially higher than the correct estimates.

Selling in the fall, therefore, the cotton farmer must dispose of his crop with the knowledge that the odds are against him, and that the buyer could not afford to take a supply of millions of bales in excess of his immediate needs, if the odds were not in the buyer's favor.

MORE REGULAR MARKETING SURE TO COME

Whatever plans may be discussed, the one essential, fundamental thing in marketing is more regular distribution of sales; and even if the warehousing system does not become general, cotton growers are likely to break away very rapidly from the old plan of selling cotton as fast as harvested. In the first place, every "lien farmer," every farmer with a mortgaged crop, has had to put his cotton on the market immediately. This class, as has been said, is now rapidly decreasing. Then, too, other farmers, hard pressed by adversity in the period of low prices, were unable to hold their product, even if confident of a rising market later on. With better prices, therefore, inevitably comes greater freedom and more gradual marketing:

LEAVING COTTON EXPOSED TO THE WEATHER

If there is anything more foolish than the policy of rushing the entire crop upon an unwilling market in the ninety days of the ginning season, it is the way we handle the little cotton we decide not to sell during these ninety days. It has been said- 
and with too much truth-that the average farmer takes no more care of his baled cotton than if it were a grindstone. "But," said Mr. J. T. Dargan, of Atlanta, at the New Orleans Cotton Convention, "the farmer is not so big a fool as you think in leaving his cotton out in the open on the farm. It is not only safe there under his eye, but, if it rains too much, he can put it under a cheap frame shed instead of taking it to town to pay storage charges to the warehouseman, unless he can get more benefits than now exist with the average cotton warehouse. What is more important to the cotton grower is, he has long since known that a bale of cotton will lose some ten or fifteen pounds by drying out if stored in a warehouse in comparison to when it is left in the open with a few planks under it to keep it out of the mud. Then, again, bright sunny weather as a rule prevails in the South until about Christmas, by which time most of the cotton grower's cotton has been sold to the spot cotton buyers intown. Thefarmerdoes not mean to act fraudulently by letting his cotton remain in the open to absorb moisture, but as some farmers do it, others are in self-defense compelled to follow suit, and I don't blame him for it at all, for he increases thereby the weight of his cotton and saves storage charges."

This assertion of Mr. Dargan's, however, does not affect our contention as to the folly of leaving cotton out in the weather; it only shifts the folly from the farmer's shoulders to those of the buyer who does not take the dampness and damage into his reckoning when buying the staple.

More and more, however, buyers are now coming to an appreciation of this fact; and the advantages 
of storing cotton in dry places is recognized by the payment of higher prices-both on account of the better fiber and on account of the fact that with the dry cotton the buyer knows he is purchasing cotton, while in the latter case, it is a mixture of cotton with an cxtra quantity of moisture. A Charlotte paper, we believe, recently estimated the season's loss to its farmers by reason of damaged cotton at $\$ 25,000$ -and this on a comparatively small market.

NOT A LOW PRICE, BUT A STABLE PRICE, NEEDED BY THE MANUFACTURER

The organization of cotton farmers, therefore, means chiefly a better regulated acreage and a better regulated system of marketing; and greater stability in prices is the chief good to be derived from each of these. To have cotton prices ranging from five to fifteen cents in a decade, is manifestly demoralizing to every interest dependent upon the staple; a uniform price of ten cents would be vastly more helpful to all of them. To the cotton manufacturer it matters little whether the prices are high or low; his profits are perhaps greater when cotton is fairly high. But what he does need is a fairly stable price so that he may take an order for manufactured goods months ahead with some idea as to what price he must ask in order to have a fair margin of profit. With the price of raw material ranging from seven to seventeen cents in eight months, as we have seen that it actually did a short time ago, it is of course impossible to make such an advance calculation with any degree of accuracy. 


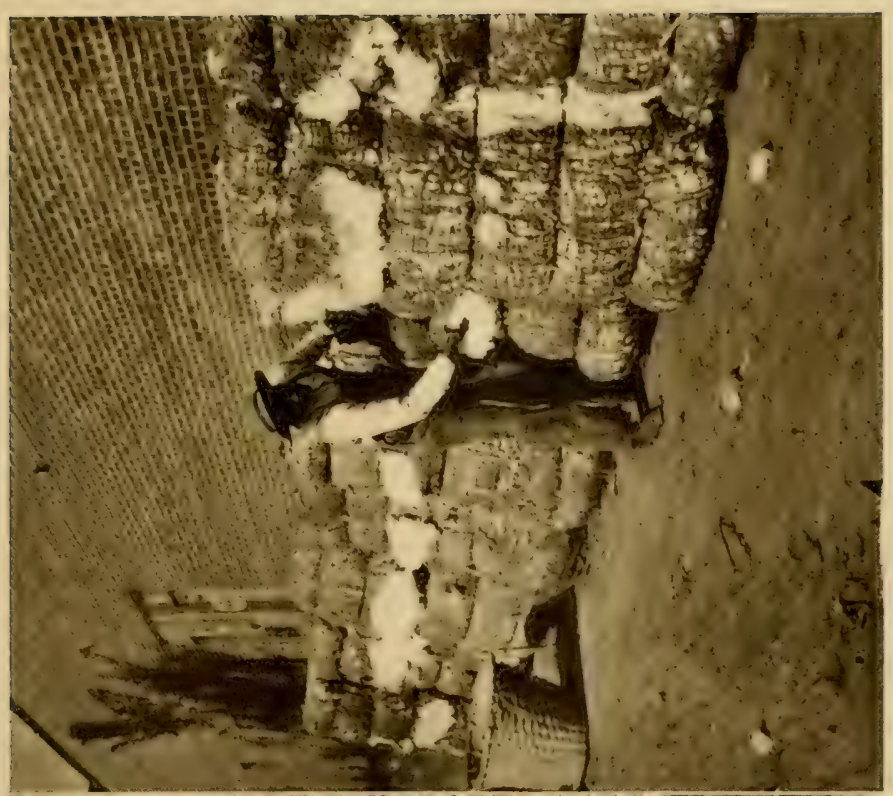

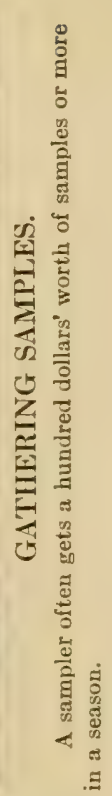

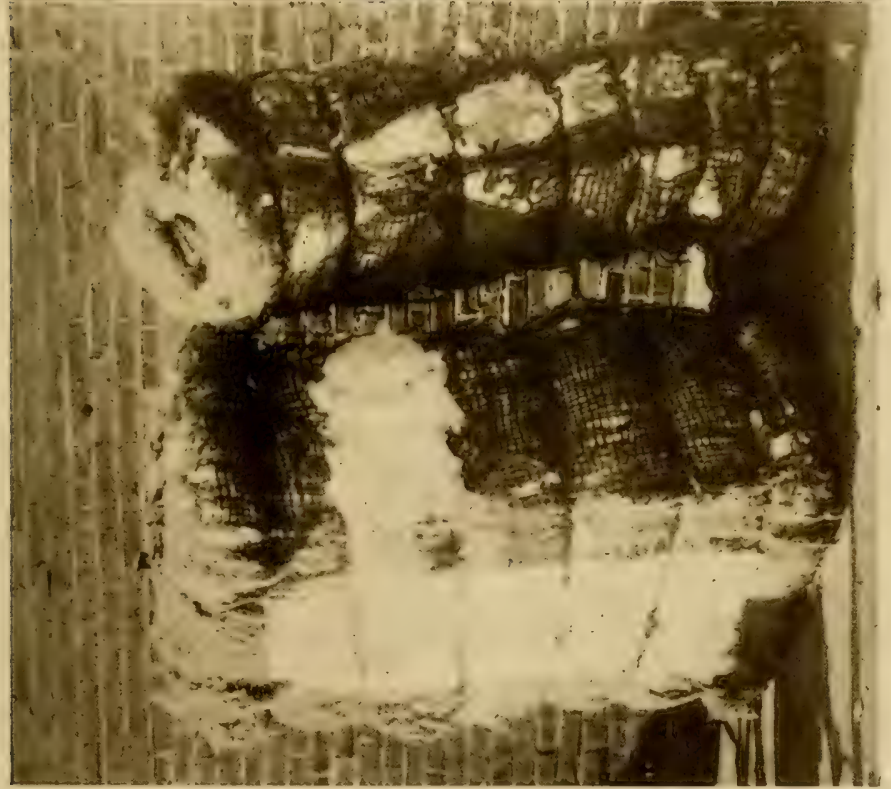

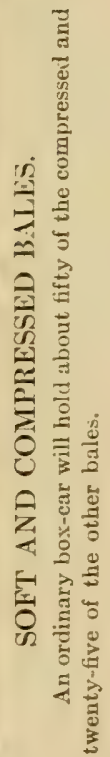




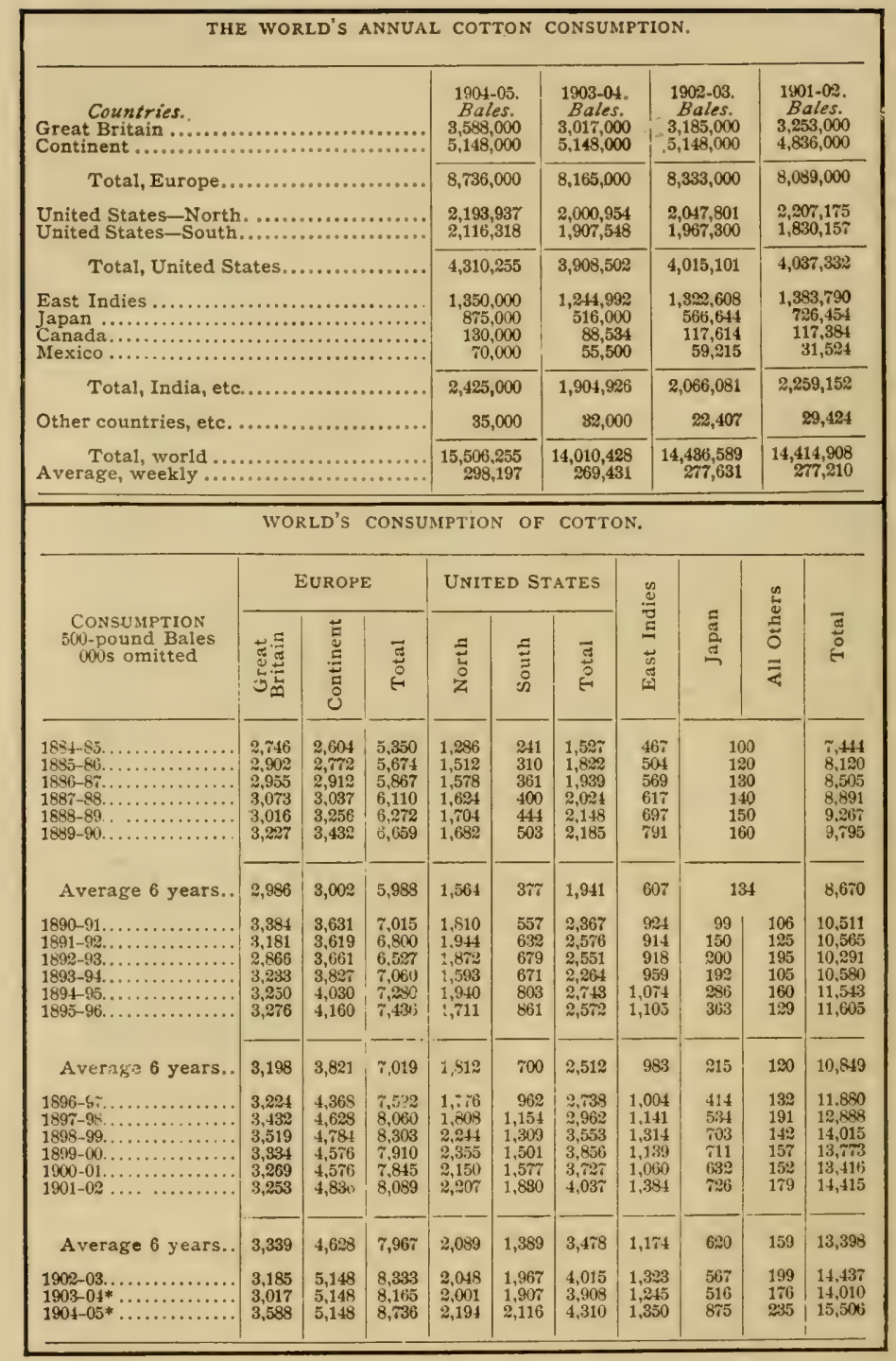

\section{COTYYON S'TATISTICS.}

(Courtesy of Lstham, Alexander \& Co. ) 
On the whole, the cotton farmers' organization does not seem inclined to be unreasonable in its demands. Attending its meetings, we have been most impressed by the marked conservatism of its members generally. President Harvie Jordan is on record as saying:

"It will be the part of wisdom for all cotton producers to discourage speculative interests that would tend to drive the price of spot cotton above twelve cents a pound, just as it is imperative that no farmer should ever again sell a pound of middling cotton under ten cents per pound. Let us not encourage inflated prices that will hamper the mills, curtail consumption of cotton, and encourage the growth of this staple in foreign fields. We hold a complete monopoly of the cotton industry of the world up to twelve cents a pound, and at that price good profits to the producer can be realized."

This quotation may seem to be at a variance with Mr. Jordan's advice late in 1905, urging farmers to hold the remainder of their crop for fifteen cents, but Mr. Jordan declares that he was consistent in that the average price for the entire crop would still have been less than twelve cents, and this on a short crop.

REDUCING PRODUCTION OR INCREASING DEMAND?

Another way in which the South's cotton growers may accomplish much good for themselves through organization, is by working together to develop our foreign markets. Civilization demands, as we have seen, that the world consume $42,000,000$ bales 
of cotton. The prices of wool and silk are prohibitive. Only cotton can fill the requirements of cheapness, and the world is yet only half clothed. Says Lieut. Richmond Pearson Hobson:

"I have had a great many Chinamen who worked under my directions, and whose work I inspected from day to day, while they were building gunboats, and if they were doing that work for you, I would judge the wages of such hard-working men to be about forty to fifty cents a day. Now I investigated this matter thoroughly, and as far as I could get any information, I found the real wages of these men to be about five cents a day. Their families are large, and, of course, they can't afford too much for food, clothing or anything else; and what is the result? The average Chinaman wears about half a suit of clothes. They are cotton, for they don't wear silk over there. It's a mistake to say it is silk, for only the Mandarins can wear silk. Now there were many of these coolies, who would come down from the interior, whom I saw working on these gun-boats, and pretty soon I would see one come down with a whole suit on. That wasn't all. It got a little colder, and I found that same coolie before long would come down with two suits of clothes on, the second pulled over the first. Later, he would come down with three, four, five, six and seven, the last suit (the sixth or the seventh) made of cotton, so that when you saw him coming down the street, helooked like a walking cotton bale."

When China wakes up, therefore, we are likely to find an enormously increased demand for our cotton crop in this one country. Properly civilized, China alone, says Lieut. Hobson, with its $430,000,000$ people, would consume the present 
cotton crop of the world. Or to put it more forcefully, we may quote the now famous remark of Mr. Wu Ting Fang to Senator McLaurin of South Carolina: "If my people wore cotton like they do in America, and every Chinaman should add one inch to his shirt it would consume the entire cotton crop of the South."

And China is not the only country where there are vast opportunities for increasing our cotton trade. We should decrease our cotton supply, when it becomes necessary, but a worthier task is to try to increase the demand, and thereby help civilize and uplift other nations as well as benefit ourselves. 


\section{CHAPTER VIII.}

\section{STOPPING THE LEAKS IN COTTON PROFITS}

It is not true, as a distinguished authority has charged, that our general methods of growing and handling cotton are "as bad as can be;" but it is true that they are susceptible of vast improvement, and that enormous leaks in cotton profits are yet to be stopped. Perhaps the most serious menace to cotton farming at this time is the boll weevil, but as that subject is reserved for a later chapter, $I$ shall not discuss it here.

One of the greatest leaks that any industry has ever known was the utter waste of cottonseed for a hundred years. Cottonseed used to be regarded as of so little use, in fact so much in the way, that cotton gins within the last two generations have been built over streams in order that the seed might be easily washed away! In some States laws have actually been passed requiring ginners, for the sake of the public health, to remove the rotting piles of waste seed!

$\$ 100,000,000$ FROM A PRODUCT ONCE THOUGHT WORSE THAN WORTHLESS

Now the raw cottonseed are worth nearly $\$ 100$, 000,000 , or about one-fifth the value of the cotton 
crop, and so rapidly are we finding new uses for them-all of which will be considered at greater length in other chapters in this book-that Mr. Edward Atkinson was probably not far wrong when he declared that it would be worth while for the South to grow great crops of cotton, even if the plant made no lint at all but seed only. How varied are the uses of cottonseed-meal, oil, hulls and linters--has been suggested in the Introduction to this volume.

The great trouble is that in the new awakening to the enormous value of cottonseed as a fertilizer, we have not yet come to a proper appreciation of their value as a feed also; for, in fact, we may feed them and still get three-fourths of their fertilizing value in the manure from the animals. How unusually nutritious they are as a food may be guessed from the fact that for feeding purposes 100 pounds of cottonseed equals in value 116 pounds corn, and 100 pounds cottonseed meal equals 175 pounds corn. Cottonseed at 25 cents a bushel or cottonseed meal at $\$ 25$ a ton is as cheap as corn at 40 cents a bushel.

The folly, therefore, of burying this most valuable of cattle feeds-burying it unused to rot in the soil-must be apparent to all. What should we think of using wheat bran or corn meal as a fertilizer for cotton without first having our live stock extract its feeding value? Yet in the one State in which the authors live, about $\$ 3,000,000$ worth of cottonseed meal is used as a fertilizerwhich means that $\$ 2,500,000$ in feeding values goes to nothing, and is a dead loss to our agricultural interests. 
FEEDING VALUE OF COTTONSEED NOT YET

\section{APPRECIATED}

Moreover, we are learning more and more each year of the feeding values of cottonseed meallearring how to combine it with other feeds and feed in larger proportions to different classes of stock. In fact, its use as a human food has been seriously contemplated, a thoughtful journal recently declaring that "if cotton grew in Michigan, Battle Creek would be marketing a hundred thousand tons of the cottonseed meal mixed with wheatflour and put up in pound packages. Itwould be advertised, and with truth, as the only complete ration for the human race. A pound of cottonseed meal contains all the elements necessary for wholesome, nutritious bread; it contains three times as much digestible protein as the highest grade of wheat flour or the best oatmeal; it contains twice as much oil as oatmeal and ten times as much oil as wheat flour."

Whether or not we shall ever have cottonseed meal breakfast food, the fact remains that in using it as a fertilizer we are wasting millions in animal feeding values every year-and this is one great leak in cotton profits we shall eventually learn to stop.

WASTEFUL TO BUY NITROGENOUS FERTILIZERS

We are also wasting millions of dollars for the purchase of nitrogenous fertilizers, when the cow pea might be made to keep our Southern soils abundantly supplied with this most costly of all fertilizing ingredients. Making a rough guess we should say that the farmers in the Carolinas and 
Georgia spend at least $\$ 8,000,000$ a year for commercial nitrogen, when a proper system of rotation, including leguminous crops, would abundantly supply the soil with this ingredient.

And this is Leak No. 2 which we can stop and thereby transfer millions to the credit side of King Cotton's ledger.

THE BARBAROUS SAW GIN DESTROYS MILLIONS IN

\section{COTTON VALUES}

There has been no noteworthy improvement in the cotton gin since the new-born idea was first worked out by Eli Whitney; and our baling methods are also notoriously inefficient. "It is contended," says Mr. Thomas P. Grasty, "that the saw gin actually wastes or destroys over 6 per cent. of all the cotton raised in the Southern States-meaning the destruction each year of nearly $\$ 40,000,000$ worth of property belonging to the farmers of the South." By its rough handling it is also asserted by the highest authorities, that the saw gin destroys over 40 per cent. of the initial strength of the cotton fiber. No wonder one of our American cotton specialists is on record as declaring cotton to be "the most barbarously handled commercial product in the world." Besides the waste, the destruction of fiber, and the lack of uniformity in size of bales, gins at present are able to pack cotton at the average density of only fourteen pounds per cubic foot. Every bale not sold to local mills, therefore, must be sent to some cotton compress and the size reduced two-thirds before it can be exported.

A fortune awaits the man who will invent a compress requiring small horse power, so that the 
bales with one handling at the gin may be compressed tightly enough for export purposes; just as a fortune awaits the man who will invent a roller gin for upland cotton or any other economical plan by which the present wastes and the barbarous laceration of the fiber may be obviated.

With American inventive talent put to this task, we may hope before many years to stop this drain on the wealth of the cotton farmer.

\section{MARKETING AND EXPORTING THE CROP}

Another waste in former days was in marketing the crop, but here there has been in recent years a marvellous gain in directness and economy. Formerly the farmer sold to his merchant at the county seat; the merchant at the county seat sold to the commission merchant at the State capital; the commission merchant sold to the dealer at the seaport; the seaport dealer sold to the New York exporter; the New York exporter sold to Liverpool, and Liverpool sold to Manchester. Now all this is changed - how greatly changed will be seen from the report of a cotton exporting house which handles more than 300,000 bales each season. "The cotton is now bought on the plantations or at the railway stations throughout the whole Cotton Belt by the representatives of large exporting houses and by the mills," said the manager of this house to us the other day. "Our firm employs more than 100 buyers for this purpose, and the cotton is shipped daily to the port where it is expeditiously sampled, classified, weighed, compressed and loaded upon ships for foreign ports with almost incredible swiftness. We have had a train loaded with cotton fifty miles from port at 7 a.m., and at 7 p.m. of the same day it has been 


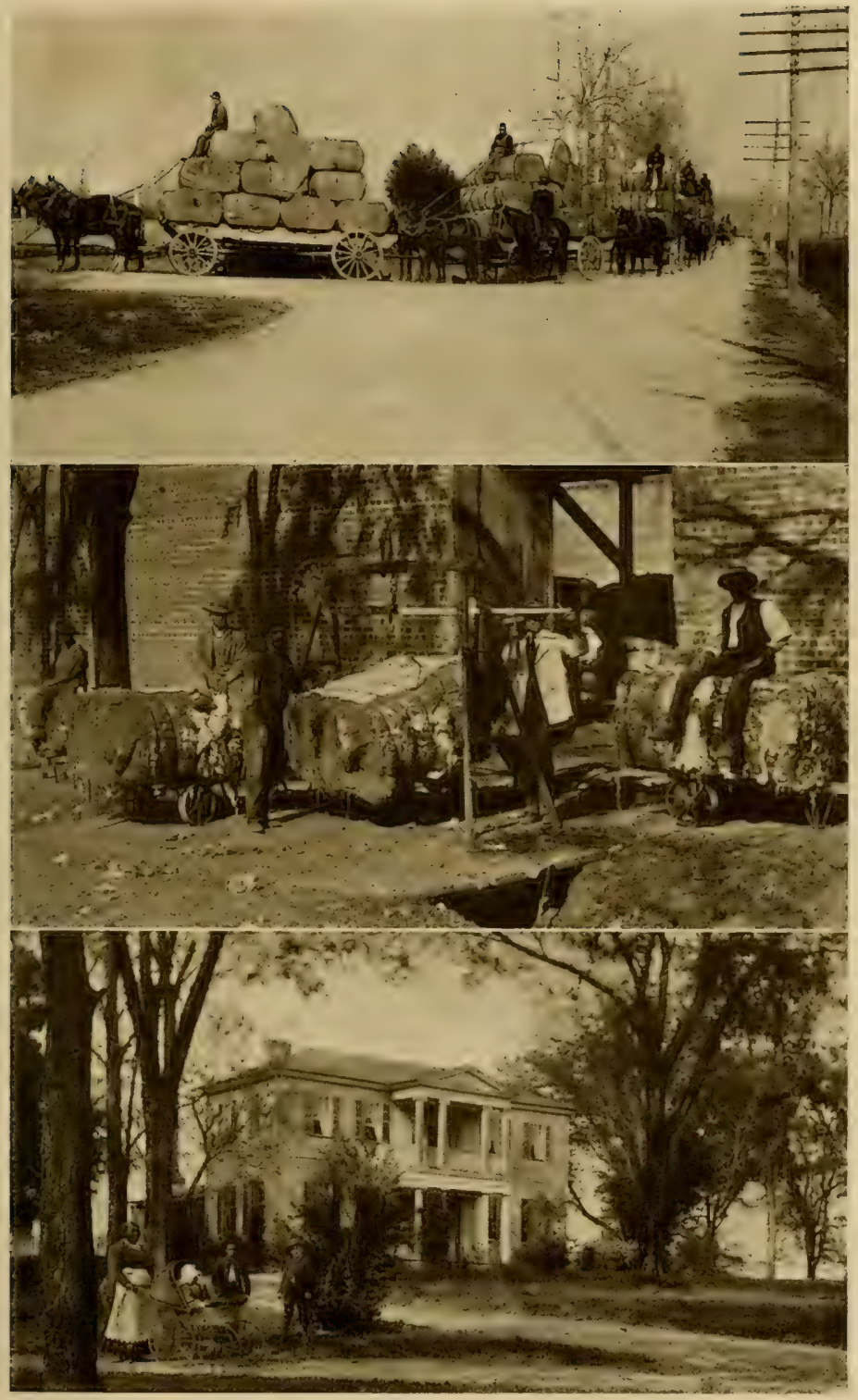

SOUTHERN VIEWS.

Good roads make cotton transportation easy; the second picture indicates the negro's easy habits; the third view is that of a typical old-fashioned Southern "Bighouse." 

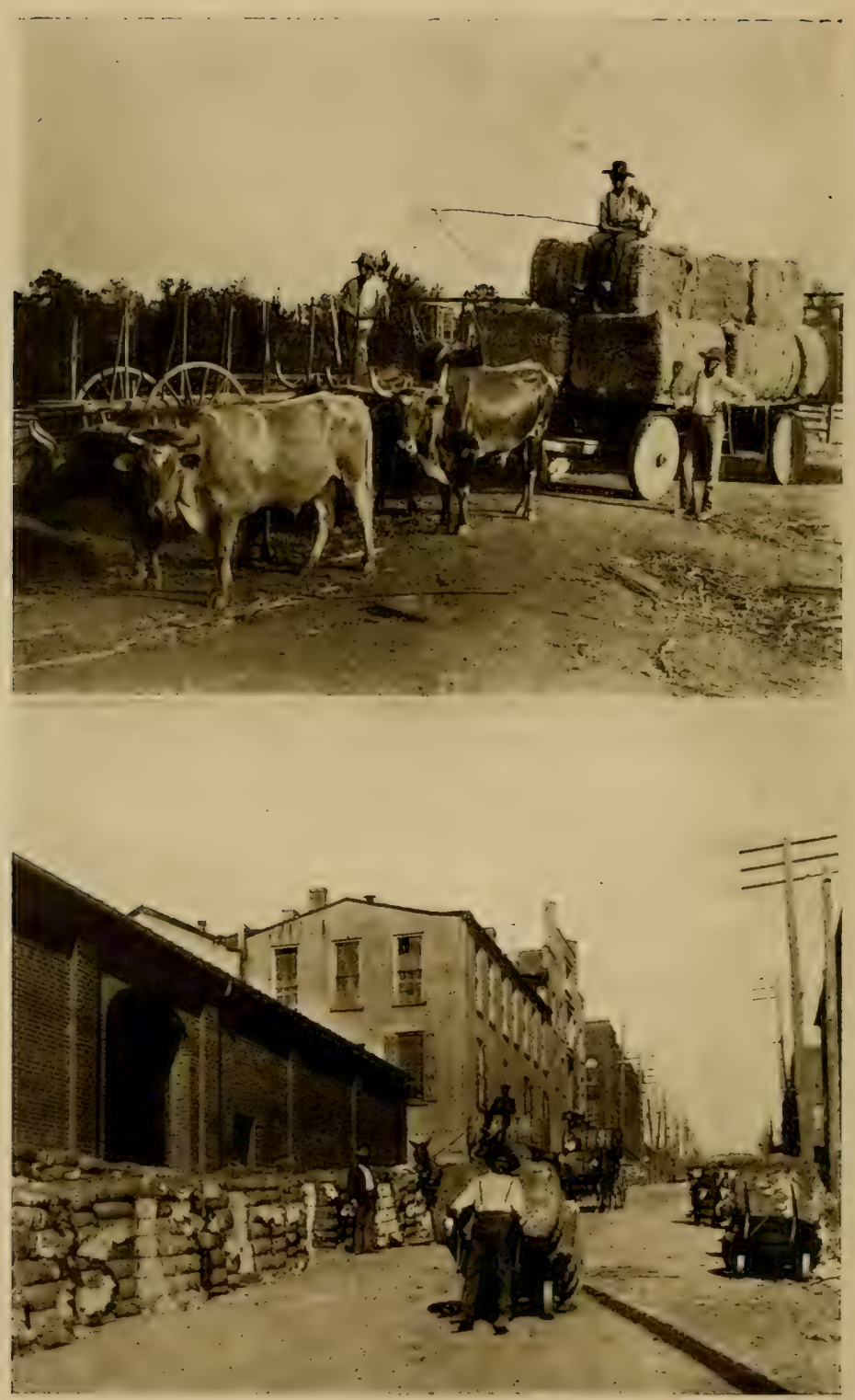

MORE SCENES FROM DIXIE.

The patient ox has not been entirely discarded, as the top picture testifies; the second is a warehouse view. 
stored on board a foreign ship and bills of exchange drawn and negotiated!"

In view of these facts we may regard this leak in the export trade as belonging to the past rather than to the present.

\section{SHIPPING $60 \%$ OF OUR COTTON TO EUROPE}

Lastly we come to what is perhaps the greatest leak of all-not to the cotton farmer solely, but to the Cotton Belt. We are still shipping 60 per cent. of our cotton to Europe-almost as uneconomic, as has been said, as it would be to ship our iron ore instead of turning it into the finished product here.

And in view of the leaks we are to stop and the great resultant savings that are to enrich the South, and in view of the prospective remedying of this last great leak, we cannot better conclude this chapter than by quoting an extract from an address by Mr. Richard H. Edmonds, of the Manufacturer's Record, delivered in New York City a few months ago - not a mere day dream, a flight of fancy, but a prediction of what actually bids fair to come to pass within the lifetime of most of those who read this article:

"It is not to be expected that the South will ever manufacture its entire cotton production, for, when it has reached the point where it consumes in its own mills the 10,500,000 bales which now measure its average crop, the world will be demanding of it, and it will meet the world's demands for, probably $20,000,000$ bales. But the utilization in its own mills of $10,000,000$ bales would mean the employment of 1,000,000 operatives, the investment in mills, textile machinery, building plants and kindred enterprises, of not less than $\$ 2,000,000,000$ 
and the annual output would be worth $\$ 2,000$,000,000 .

"Then, indeed, would the Sout', without monopolizing the world's cotton manufacturing interests, be the dominant factor, the center of the world's cotton mill business, producing 20,000,000 bales and consuming at home in its own mills $10,000,000$ bales.

"Both will come about in due time. The South sees before it this prize, rich beyond words to describe, creating wealth beyond anything which this section or any other section has known, and this is the prize - a prize great enough to enrich an empire-for which it has entered the race. That it will win admits of no question." 


\section{SECTION II.}

\section{THE COTTON PLANT-HOW IT GROWS \\ AND IS GROWN}





\section{CHAPTER IX.}

\section{STRUCTURE AND BOTANICAL RELATIONS}

The several species of every plant or animal known to man have been properly classified and grouped. It has required untold labor and pains through years and centuries to make this important contribution to the total sum of knowledge, but the result is well worth the effort it has cost.

A discussion of the causes that have entered into the production of families, species and varieties would not be in place here, but some of them are so interesting and so intimately concerned with the development and improvement of the cotton plant as to make it necessary to consider them briefly.

The cotton plant is a member of the Malvaceae or mallow family, and to scientists is known by the generic name Gossypium. The plant is given to much variation, and a very large number of varieties are the result. Differences in soil, in climate, and in environment have been the primary factors in producing these variations.

\section{INFLUENCE OF HEREDITY}

In the perpetuation of any plant or animal the importance of heredity is recognized by all. It is, in fact, the keeper of all that has gone before. Good or evil, helpful or harmful, its influence is to 
hand dorn to the future race all the life of the past. Like surely begets like. Offspring of either plant or animal inherit the essential characteristics that were a vital part of the parental stock. These inherited characteristics, however, are always subject to change as a result of change in environment.

If any plant or animal were confined to a particular soil, feeding on the same food, and with unvarying climatic conditions, then all members of the tribe or species would grow more and more similar in type, form, and quality. Only in nonessentials would differences appear.

The American deer, for example, grown under the same conditions of habit, food and climate, for so long a time, has developed the most remarkable uniformity. Only the most careful observer is able to note individual peculiarities of form, color, or outline.

Let the American breeder take this same animal and place it under a new environment, and a change will be noticed very early in his breeding operations. This change of environment gives the law known as variation an opportunity to show its power and influence.

The cotton plant has been subjected to this change in environment. We can neither tell you when nor how it happened. Mere conjecture would suggest only a starting point. Still the fact remains that cotton was early known in India, Egypt, Corea, China, South America, and the Lesser Antilles. How the plant got to any of these countries no one knows, and possibly no one will ever know. The important fact is this: there are great differences in soil, climate, and environment between China and South America, between India and the South Sea Islands, between Egypt and 
China; and these very differences have given rise to the many kinds and varieties of cotton we know to-day.

Besides the factors above considered as influencing the tendency to variation, the cotton plant responds perhaps more freely than any other cultivated plant to ameliorated conditions of soil, climate, and cultivation.

\section{THE COTTON PLANT}

To understand its characteristics you must know the cotton plant itself. Its weed, flower, fiber, seed and growth are interesting-each and every one.

In growth the stalk assumes a herbaceous, shrubby, or tree-like form. None but these herbaceous, shrub-like forms are grown to any extent in this country. You will find the larger and treelike varieties grown occasionally, but only as curiosities, since with them the low mean temperature of the Cotton Belt is unfavorable to the production of lint of any commercial value.

The cotton plant of the Southern States is a small annual shrub from two to four feet in height, always branching extensively. The limbs are longest at the bottom of the stalk, and short and light at the top, this top growth in all parts of the South usually being arrested by frost. The flowers are white, or pale yellow or cream colored the first day, become darker and redder the second day, and fall to the ground on the third or fourth day, leaving a tiny boll developed in the calyx. This boll develops and enlarges until maturity when it is not unlike the size and shape of a hen's egg. When matured, the boll cracks and opens the three to six apartments which hold the seed and the 
fibrous wool known as lint that is now to be gather ed, ginned, and baled. This lint, when separated from the seed becomes the cotton of commerce.

\section{COMMERCIAL TYPES}

The types of cotton chiefly known in a commercial way are Gossypium Barbadense or Sea Island Cotton, Gossypium Herbaceum or Upland Cotton, Gossypium Hirsutum, also Upland Cotton, Gossypium Arboreum or Tree Cotton, and Gossypium Neglectum or Indian Cotton.

\section{SEA ISLAND COTTON (Gossypium Barbadense)}

This species is one of the most important grown and is cultivated most extensively along the coast of South Carolina, and in Georgia and Florida, and the off-lying Islands.

The amount of lint produced is less than from Upland Cotton, but it sells for a higher price on account of its longer staple and better quality.

"Yarns having the finest counts, as they are called, are all spun from Sea Island." It has been shown that a single pound of Sea Island Cotton can be spun into a thread 160 miles in length. The acreage devoted to this species is small, consequently Sea Island Cotton influences the market yield but little.

\section{UPLAND COTTON (Gossypium Herbaceum)}

This is of Asiatic origin, adapted to upland, and has its botanical name from the character of its growth.

India is supposed to be the original home of the herbaceous type, but it has spread extensively until it is known in China, Arabia, Persia, and Africa. 


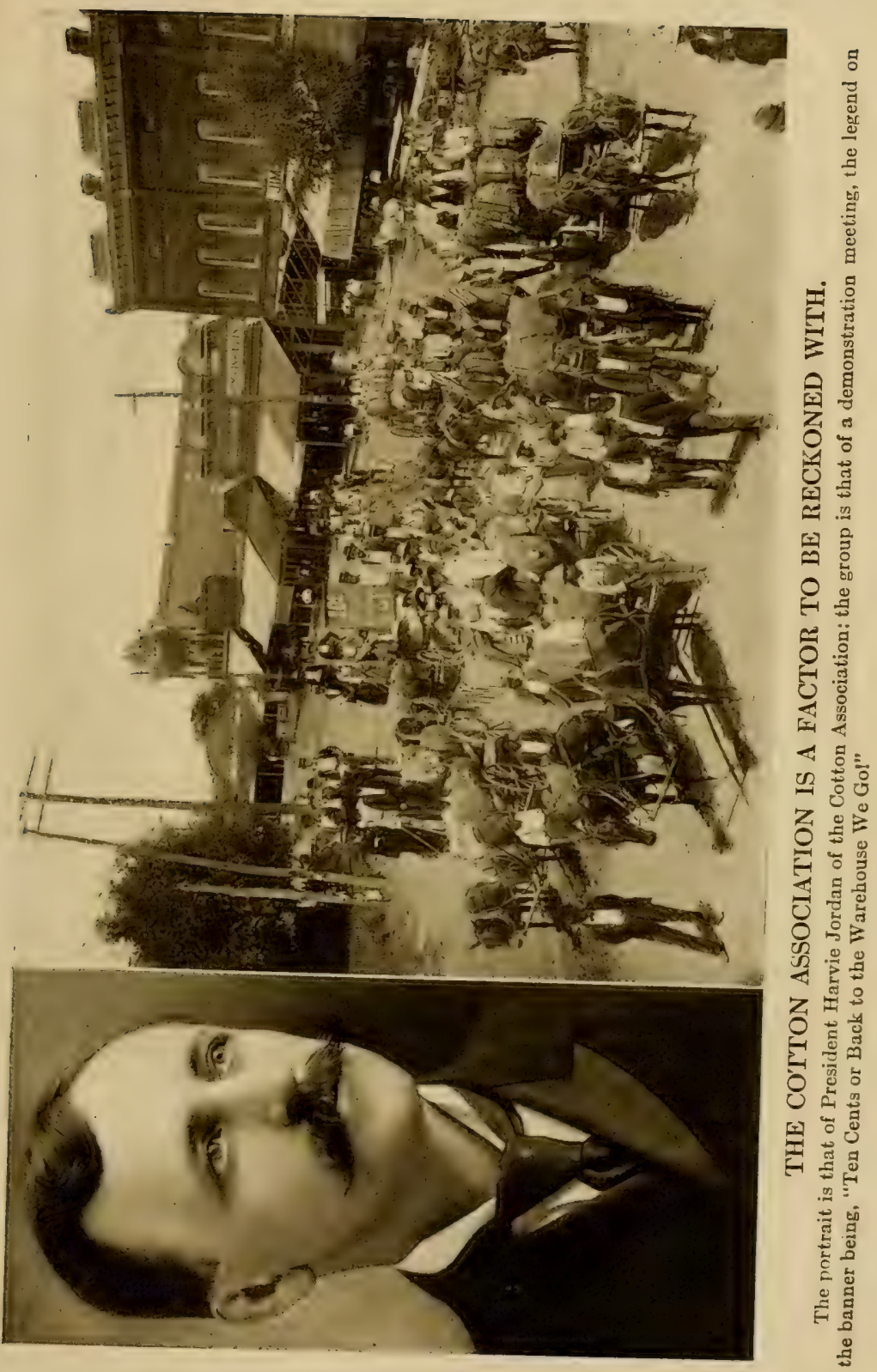




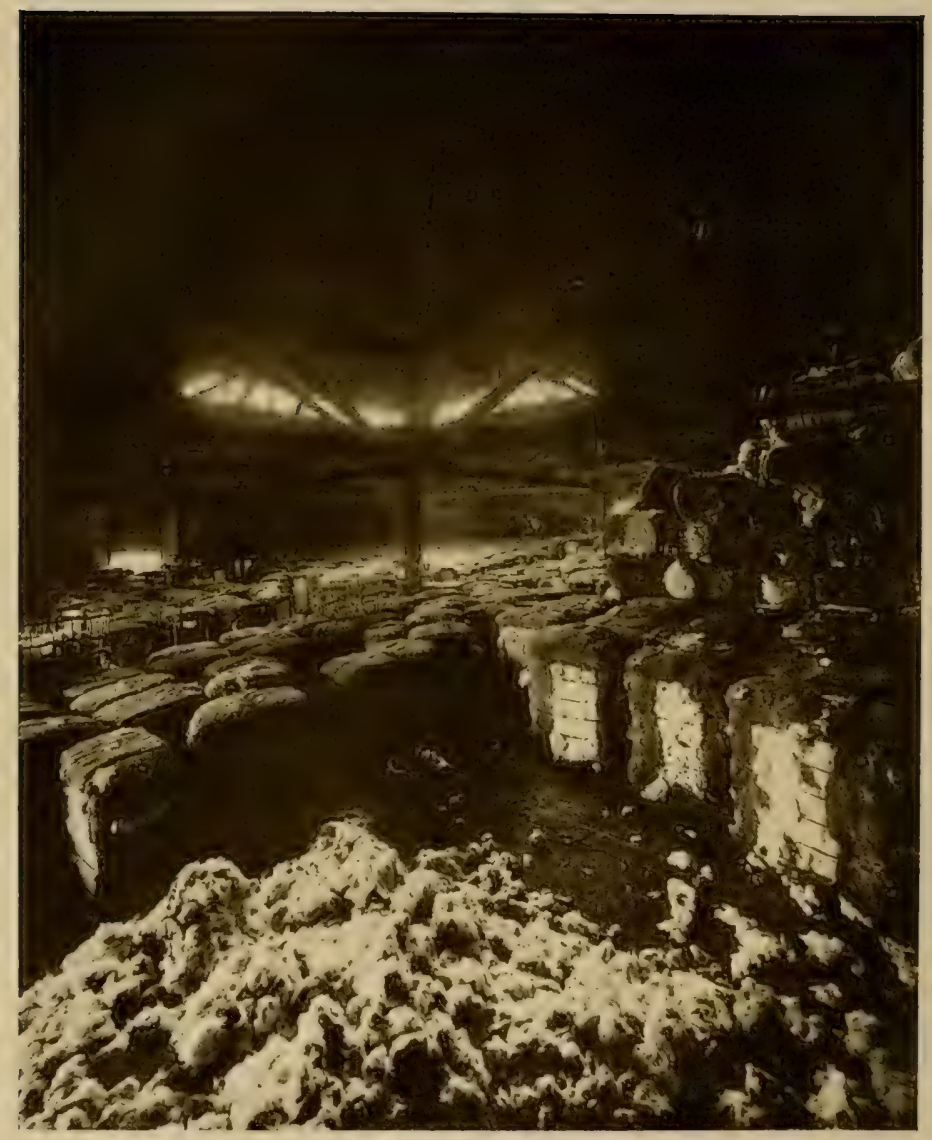

HOLDING FOR BETTEIR PRICES.

Many farmers now refuse to sell in the rush of ginning season, but store and hold in the hope of getting better prices. Many of the storage warehouses are of enormous capacity. 
The vine cotton of Cuba belongs to this species, and is peculiar because of its large pods and excessive number of seeds. The Long Staple Upland Cotton grown in America belongs to this species.

\section{UPLAND COTTON (Gossypium Hirsutum)}

The hairy nature of every part of the plant gives this species its name.

It is not greatly different from the Sea Island group of cotton; in fact it is claimed by some to be an offspring of the Sea Island. Generally thought to have originated in Mexico, it has now been carried to all parts of the world. In a sense it is a Short Staple Upland Cotton, and to this species belong nearly all the American types.

\section{TREe cotton (Gossypium Arboretum)}

Its tall-growing and tree-like proportions suggested the name for this India-bred species. In height it is often as much as twenty feet. The fiber is short and fine, and clings very tenaciously to the seeds.

No varieties of this kind are grown on this continent for commercial purposes, and not even in India, where it is principally cultivated, is it a very valuable type of cotton. There it is said to be perennial, lasting five or six years or more, and is never used as a field crop.

INDIAN OR BUSH COTTON (Gossypium Neglectum)

This species is also indigenous to India where it is extensively grown as a field crop. The boll is 
small in size and contains only a small number of seeds.

It is said that the beautiful Dacca Cotton, from which the famous muslins are made, is of the Neglectum type, and so are the varieties from which the long cloth of Madras is manufactured.

\section{THE COTTON FIBER}

The commercial grading of cotton depends almost entirely on the ripeness, length, and fineness of the cotton fiber. The long, fine, silky fibers of the Sea Island varieties command the highest price, while the native Indian and Short Upland staple of America represent the lowest market values.

The following table arranged by Evans shows the average length and average diameter of the staple of some of our best known varieties:

LENGTH AND DIAMETER OF PRINCIPAL COTTON FIBERS

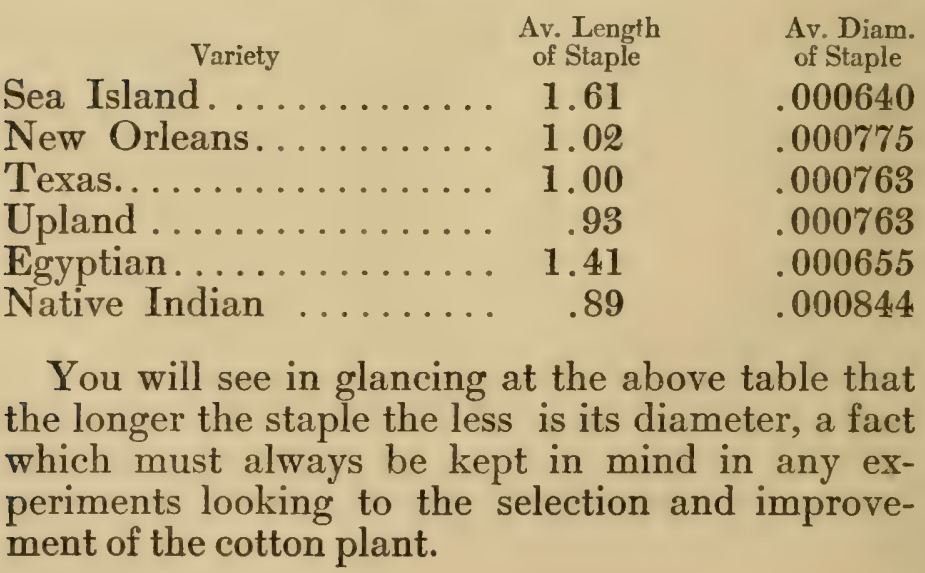


When the cotton fiber reaches maturity it assumes a tubelike appearance, somewhat irregular and flattened.

Three classes of fibers are always found in every picking - unripe, half-ripe, and ripe. Of course the time of picking influences the relative percentages of each, though late picking of seed cotton will not entirely overcome the difficulty, since these three are differences in maturity of the filaments on different parts of the same seed.

Unripe cotton is thin and transparent, has little or no twist, and has little use in manufacture. This explains why cotton picked too early commands a lower price at the warehouse.

\section{THE COTTON BOLL}

The boll is the house of seed and lint. In it are from three to five apartments or cells (often more than five in improved types) which hold the commercial product from the earliest formation of the lint after blooming until it is picked in the fall.

As the seed and lint increase in size and quantity, the boll likewise enlarges to accommodate its growing interior. When maturity is reached the doors of the apartment rooms open, lint and seed expand, and present the beautiful white, silky wool that is soon to be gathered and stored.

It is a picture indeed, the full cotton field, white with its open bolls and ready for the harvest hands. The plant and the planters have almost ended their work, and the world now awaits the result not without interest. The pickers are in the field, early and late, gathering the white "tree wool" as fast as their hands can pluck it from the bolls. Here and there all about the picked territory, are 
seen the snowy piles of gathered product, ready for the owner to weigh and store in some sheltered place. Cotton picking time has come again, and spinners and consumers in every quarter of the earth listen with eagerness for news of the South's great annual harvest! 


\section{CHAPTER X.}

VARIETIES OF COTTON AND THEIR CLASSIFICATION

In a previous chapter we have discussed the tendency of all plants and animals to vary from normal characteristics when removed to new fields, different climates, and changed conditions of environment. The cotton plant is especially susceptible to all influences, to such an extent, in fact, that in our country alone there are now more than one hundred and fifty varieties listed. Of course not all of these are true varieties. Often a variety will have one or more names even in the same territory. This state of affairs is confusing and undesirable, but it is not peculiar to the cotton crop. With corn and wheat, in fact with all the prominent crops grown in America, we have the same difficulty, the same multiplicity of names.

This condition usually arises from the fact that a new character, differing from the normal, is seen in the plant, leading the grower to think that he is justified in giving the variety a new name. With the cotton plant the change may lie in the direction of increased length and fineness of fiber; increased yield of lint, or seed, or both; early or late maturing qualities; a superior character in boll, or a change in physical growth. Still it matters not how superior a new character may be, a local name is not justified until that special 
feature is fixed as a different characteristic of this species in the cotton race. When that fact has been established it is altogether proper for the new variety to have a new name, just as we should give a new name to a new kind of apple.

\section{A SIMPLE CLASSIFICATION}

The simplest classification of Upland varieties that we have seen has been made by Professor Duggar of Alabama. He makes seven distinct groups as follows:

1. Cluster, or Dickson Type.

2. Semi-Cluster, or Peerless Type.

3. Rio Grande, or Peterkin Type.

4. Short Limb, or King Type.

5. Big Boll, or Duncan Type.

6. Long Limb Upland, or Petit Gulf Type.

7. Long Staple Upland, or Allen Type.

Such a grouping as this enables us to place a given variety as readily as we class horses into draft, coach, or roadster types. General characteristics in this manner may be readily fixed without confusion or difficulty.

\section{GROUPS OF COTTON}

Following the classification of cotton into these seven groups we find characteristics more or less peculiar to each. Of course it is not to be expected that classification will provide for striking lines of demarcation for every variety. It does not do this for horses. The heavy coach horse blends into the type of the light draft on one hand and into the roadster on the other. So we should expect some varieties of one group of cotton to merge into 
another group by imperceptible gradation. But in a general way the several types may be described as follows:

\section{CLUSTER-DICKSON TYPE}

No long limbs at base; bolls tend to grow in clusters; plants tall, slender, and erect; base limbs often 'long; and seed usually small; seed covered with thick fuzz, usually white in color; early maturing; percentage of lint from 32 to 34 .

\section{Important Varieties of Group:}

Dickson

Wellborn
Jackson

Wellborn's Pet

\section{Jackson's Limbless}

\section{SEMI-CLUSTER-PEERLESS TYPE}

Base limbs of medium length, and above these along main stem are very short limbs; stalk erect; bolls more or less in clusters; seed of medium size, well covered with fuzz which may be whitish, greenish or brownish; early to medium maturing; percentage of lint from 29 to 35 .

\section{Important Varieties of Group:}

Peerless

Boyd

Cummings

Drake

Deering

Norris
Hawkins' Prolific

Hawkins' Jumbo

Herndon

Herndon's Select

Minor

Tyler 


\section{RIO GRANDE-PETERKIN TYPE}

Plants well branched and medium in size; bolls small; seed black, quite small and bare of fuzz except at tip end; medium maturing; percentage of lint large, usually 35.

\section{Important Varieties of Group:}

Peterkin

Peterkin's Limb Cluster Excelsior
Texas Wood

Wise

Texas Oak

\section{SHORT LIMB-KING TYPE}

Plants small and well branched at both base and top; limbs short; bolls small; seed medium in size and thickly covered with fuzz of brownish (and sometimes of greenish) shade; quite early maturing; percentage of lint from 32 to 34 .

\section{Important Varieties of Group:}

King Lowry
King's Improved No. 1 King's Improved No. 2

\section{BIG BOLL-DUNCAN TYPE}

Plants large, heavy and strong; well limbed at base, but upper limbs short; bolls very large; seeds large and covered with thick fuzz, whitish in color; 
late maturing generally; percentage of lint from 29 to 34 .

Important Varieties of Group:

$\begin{array}{ll}\text { Duncan } & \text { Culpepper } \\ \text { Banks } & \text { Culpepper's Improved } \\ \text { Christopher } & \text { Grayson } \\ \text { Truitt } & \text { Russell } \\ \text { Thrash } & \text { Lee } \\ \text { Strickland } & \text { Lee's Improved No. 1 } \\ \text { Strickland's Improved Lee's Improved No. 2 } \\ \text { Coppedge } & \text { Scroggins }\end{array}$

VI. LONG LIMB UPLAND - PETIT GULF TYPE

Plants very large; limbs long and straggling; bolls medium in size and covered with fuzz of various shades; late maturing; percentage of lint 30 to 32.
Important Varieties of Group:
Petit Gulf
Cheise
Gunn
Ellis

Ellis's Big Boll

VII. LONG STAPLE UPLAND-ALLEN TYPE

Plants large and heavy and require good moist soil; lower limbs very long and open; bolls medium in size, but long, slender and tapering; seed medium to large, covered with whitish tint of fuzz; late maturing; staple long; percentage of lint from 25 to 29 . 
Important Varieties of Group:

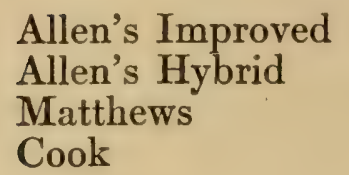

Allen's Improved Matthews Cook
Doughty

Griffin

Cobweb

Moon

\section{SELECTING A VARIETY}

You must exercise care and judgment in selecting a variety of cotton for seed purposes. A variety which yields well in one place may not do so well with you where perhaps it may have a different soil and climate. A variety may stand at the very head one year in a comparative test with other varieties, but fall toward the foot the very next season. Seasons are not all the same, and they materially affect the yield of the same variety from year to year. You must bear this fact in mind and not jump at conclusions hastily.

It is the largest quantity of seed cotton you are seeking, and a variety that yields uniformly well from year to year is a great deal better than a spectacular one that shines meteor-like when the season is just right.

An honest, average yielder is always safe and reliable, and can be improved by selection and care to suit your soil and climate and environment. In the end, too, it will become better and better because it has had time to adapt itself to the home life you have provided for it. It will reward you for this attention by obeying every reasonable demand you make. And these demands you have in mind should include:

(1) A longer staple; (2) uniformity in length of 

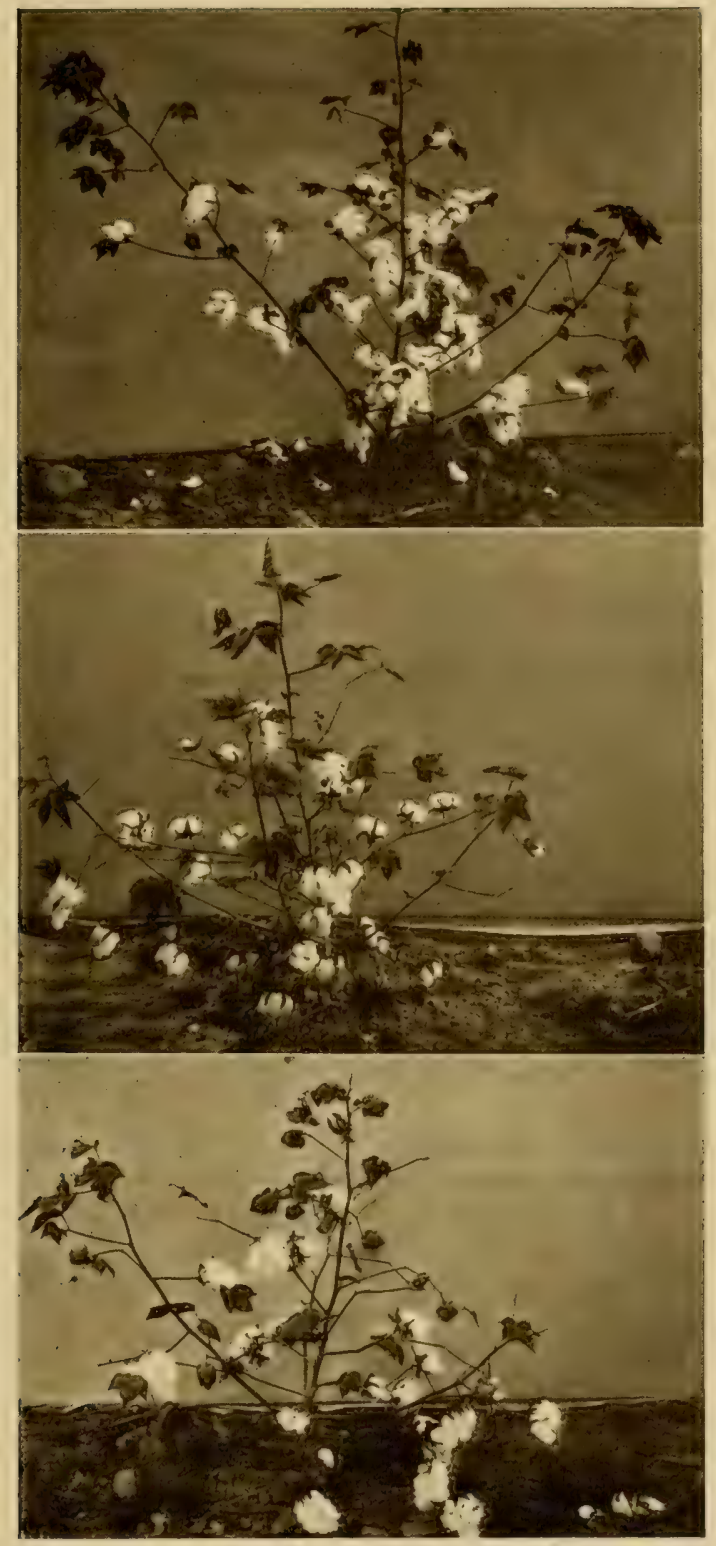

VARIETIES OF CO'TTON.

(A) Peer'ess group; (B) Peterkin Cotton; (C) Duncan group; The Peterkin is one of the best known varieties; the Duncan group is very large bolled. 

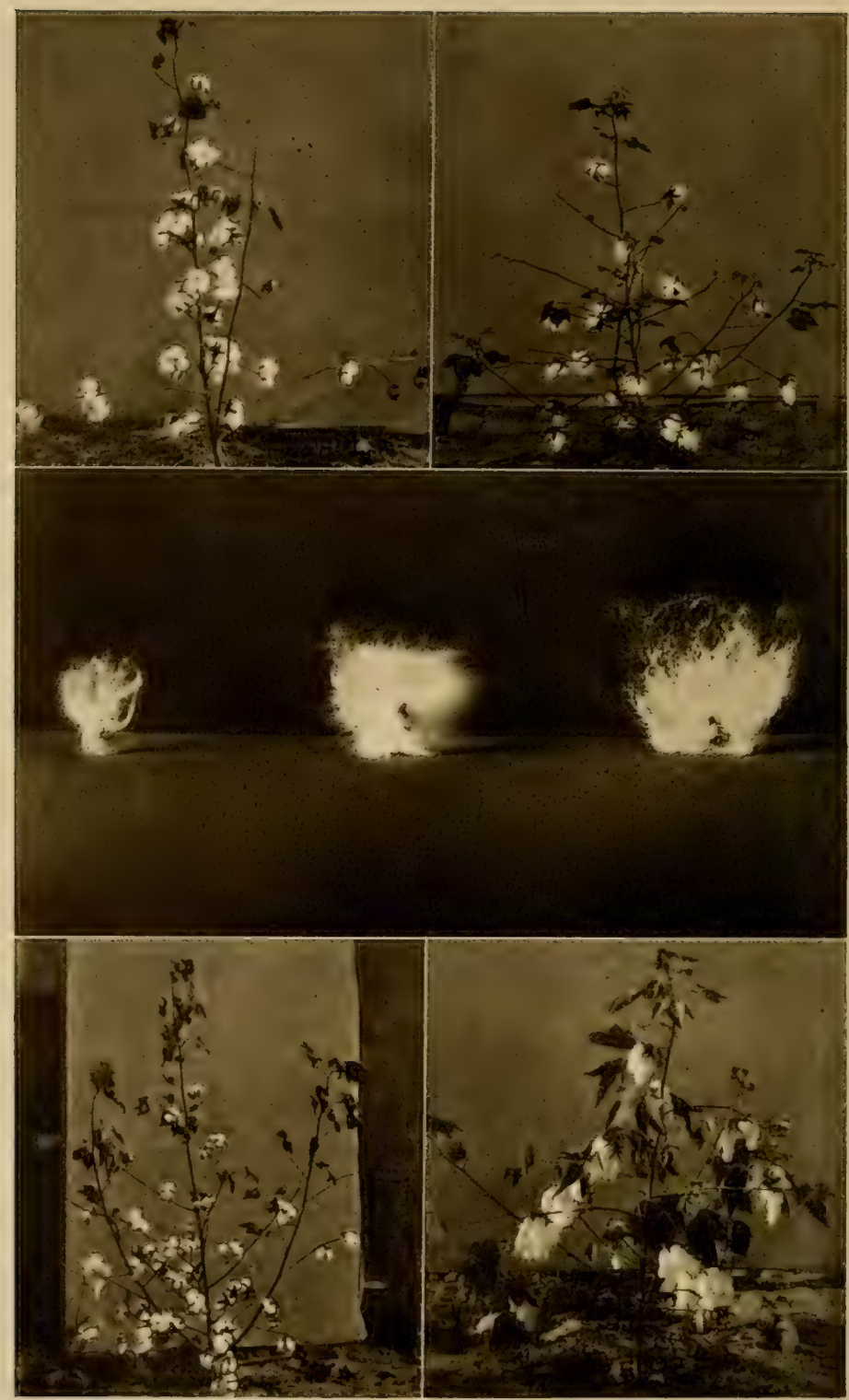

VARIETIES OF COTTON

(A) Dickson type; (B) King type: (C) show: seed and lint of Sea Island Cotton; (D) Allen Long Staple; (E) Petit Gulf. 
fiber; (3) strength of fiber; (4) a greater yield in lint and seed.

\section{THE STAPLE SHOULD BE LONG}

If you examine the staple in several bolls of any variety, you will find a certain degree of variation in length. We all know that the longer the staple is, the better price we get for it. Hence, every cotton grower should endeavor to grow a longer staple. This can be done by going into the field and carefully examining bolls of the most promising appearance, selecting for seed purposes such as have greater length of staple than the average. This practice should be followed year after year, whatever the variety you are growing.

\section{FIBERS SHOULD BE OF UNIFORM LENGTH}

Cotton, like wool-indeed like any fiber of commercial importance-is graded according to its evenness and uniformity of length. And this practice of grading is not limited to fibers, but goes out in all directions and includes corn, wheat, and other field crops.

Consequently seed cotton should be so selected that the tendency to produce fibers of uniform length may be bred in the plant.

\section{FIBER SHOULD BE STRONG}

Not only length, but strength of fiber also, is a most desirable quality, and should be considered in every operation that pertains to the improvement of any variety of cotton. The Sea Island type is especially noted for the quality of strength, 
and has been selected after years of careful tests made to develop a variety required for cloth of durability and strength.

RELATIVE PERCENTAGE OF FIBER SHOULD BE

LARGE

An essential quality for every variety of cotton to possess is the ability to produce a high quantity of lint in proportion to seed. This quality is fundamental, for lint yield is usually the first trait considered by any grower. In fact, a particular variety is selected, as a rule, because of the claim that it is a heavy yielder.

Careful attention, then, at the time of gathering and selecting seed-making constant effort to improve by selecting from plants with this tendency to increase the yield-will prove one of the most satisfactory ways of adapting the variety to your environments, and of rendering it reliable as the breed for your special purposes. 


\section{CHAPTER XI.}

\section{BREEDING UP THE COTTON PLANT}

The average yield of cotton in the United States is about 190 pounds of lint to the acre. At ten cents per pound the gross income from a cotton crop then, is only $\$ 19.00$ per acre plus the value of seed. This is certainly none too much when you consider the cost of necessary fertilizing materials and the labor involved in all operations from planting to marketing. Now to increase the gross income, but two ways are open to us: either (1) increase the market price for raw cotton or (2) increase the number of pounds of lint and seed per acre.

The latter seems to be most reasonable from an economic standpoint. Ten cent cotton, under good labor and crop conditions, is an equitable price to both producer and consumer. A price less than ten cents is unwise because it means hard living for growers and laborers.

HOW IMPROVEMENT MAY BE BROUGHT ABOUT

The problem before us then is to increase the production of cotton per acre. How shall this be done?

The following five reforms will help:

(1) Improve the soil.

(2) Get a variety suitable to your environments. 
(3) Use improved tools and implements for all operations.

(4) Manure in such a way as to promote the physical improvement of the soil.

(5) Use seed that has been improved by selection, and continue the selection that more improvement may follow.

Let us discuss the last named suggestion first, since seed stock is always of primary importance.

None of us can deny the influence of good breeding. It is only the well selected, carefully bred trotter or pacer that ever makes a record on any race track; even in beef for our tables, a scrub makes a tough, insipid product; and in the dairy, profit comes only with carefully chosen milk cattle.

Blood tells in men, in animals, in plants. It tells in cotton-in yield of seed and lint; in length, in strength, in all other desirable features of the fiber.

Not to select seed with care and according to some definite plan, therefore, is wasteful, costly, unprofitable.

\section{A PROBLEM FOR THE INDIVIDUAL FARMER}

The day when any cotton planter can afford to plant just any variety of any sort of seed has truly passed. Grood farm management in cotton growing, as in any kind of plant or animal production, calls for the use of good seed only, seed possessing qualities desired by commerce, and the ability to display these qualities under the individual grower's special soil, climate, and conditions.

But to get best results, you will have to investigate for yourself. The Agricultural College and Experiment Station can determine fundamental 

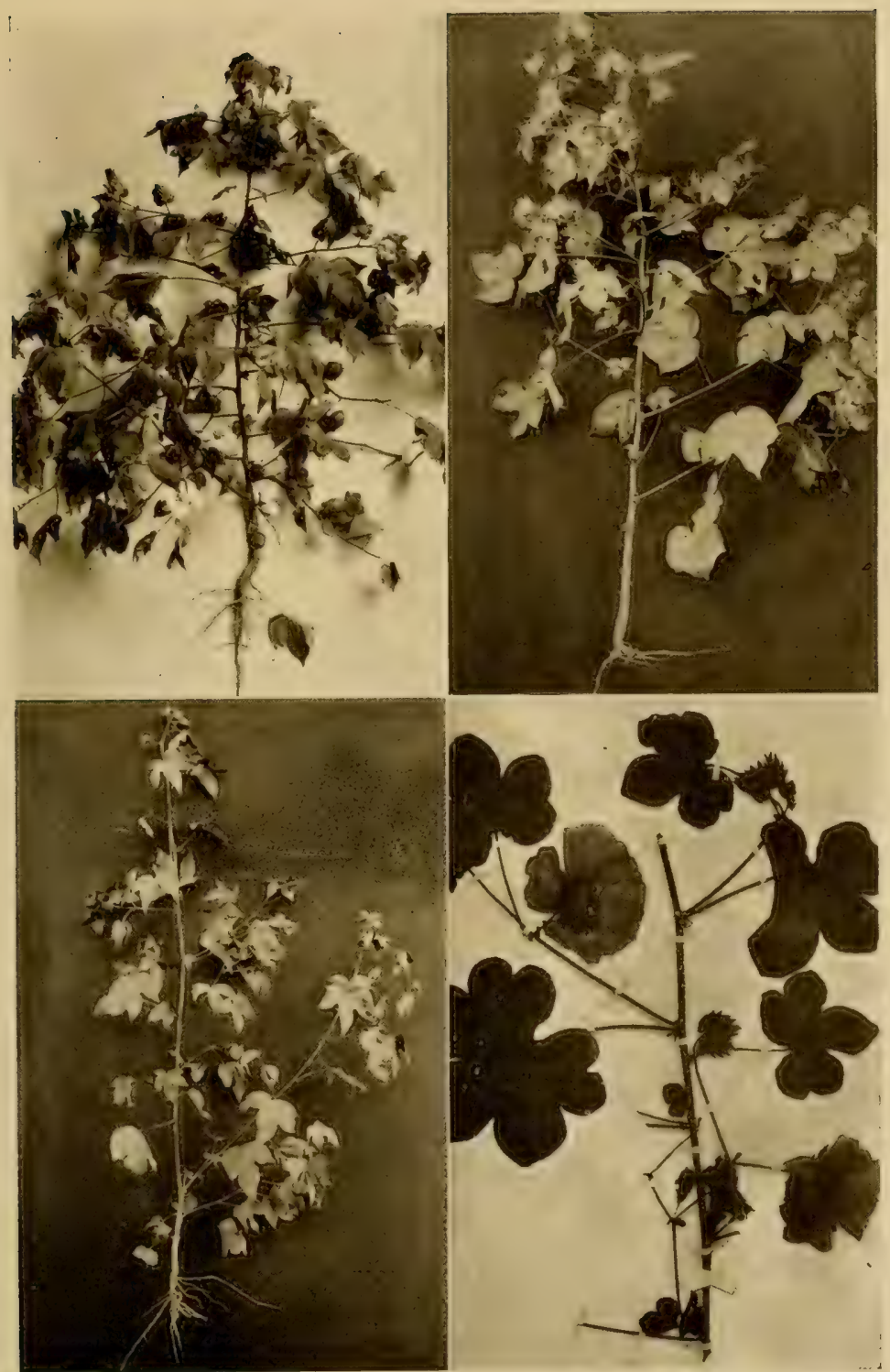

VARIETIES OF COTTON.

(A, B) American Upland, Southern types; (C) Sea Island (Long Staple) Cotton; (D) Asiatic Cotton. 

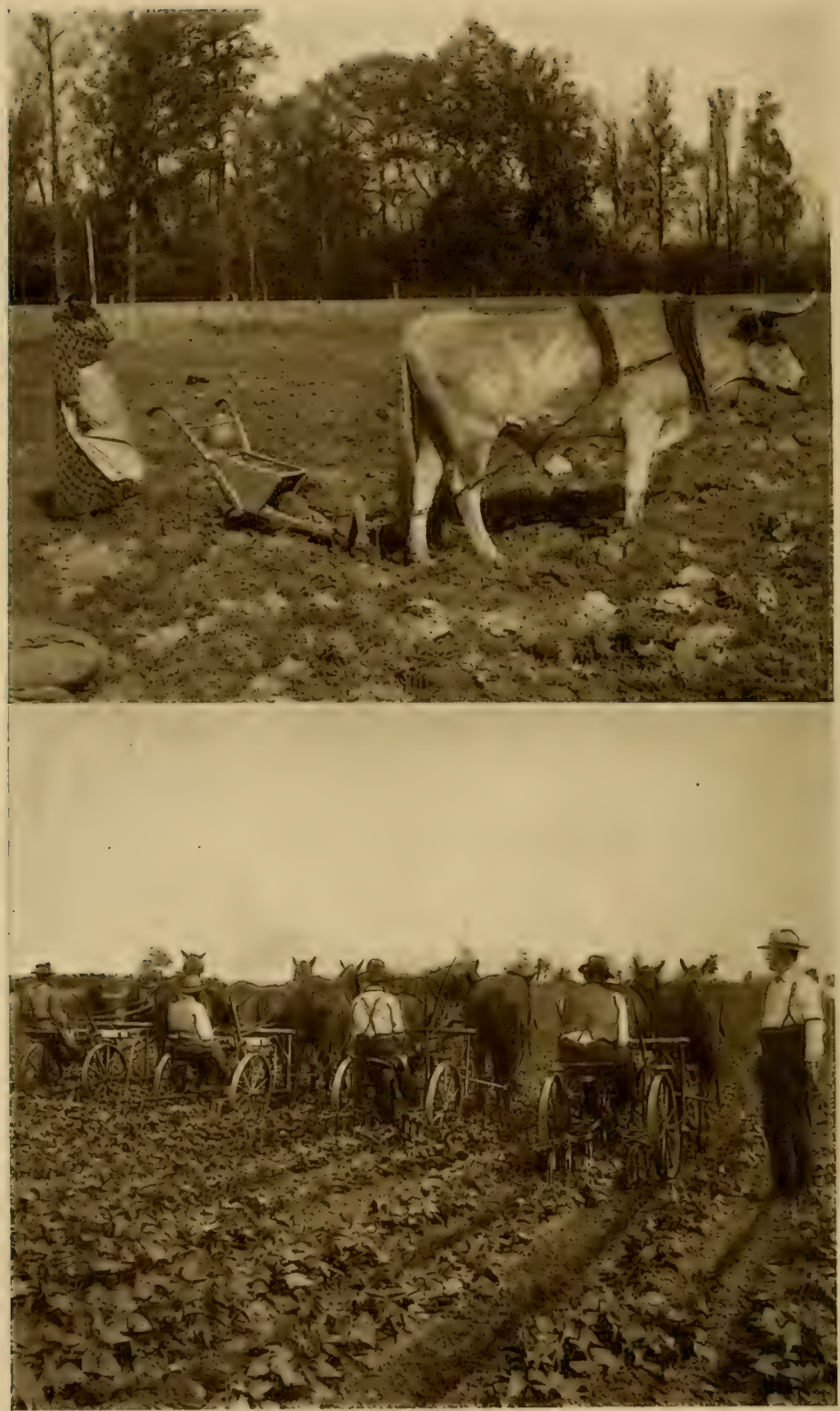

ECONOMICAI AND EXPENSIVE COTTON MAKING.

The first picture is that of planting with a slow ox- "free nigger farming" it is cailed; in the second picture we have cost of cultivation reduced to a minimum by' improved implements. 
facts only. Their application must be worked out by each individual planter on his own individual farm.

Nor is this difficult. You must put out of your mind the idea that seed selection is costly, or that it involves unusual labor. An axe that is sharpened is an improved axe; a plow that turns a deep furrow and pulverizes the soil in an efficient manner is better than one that does not; a hog that reaches maturity on a given amount of food in nine months is superior to one of any breed or class which uses an equal amount of food and requires ten months for maturity. So a particular cotton plant which shows a larger number of desirable characteristics than other stalks under the same soil, climate, and other influences is an improved specimen; and it is simple waste, as has been said, not to use its powers to the full extent in furnishing seed for the next year's crop.

\section{SEVEN POINTS OF IMPROVEMENT}

But what are desirable qualities to be sought? We discussed some of these qualities in a previous chapter. There are, in all, the following:

(1) Better yield of fiber

(2) Greater length of staple

(3) More uniformity in length

(4) Greater strength in fiber

(5) Ability to resist disease

(6) Increased yield in seed

(7) Greater effort to make the plant at home.

These characteristics are important, all of them. They must be kept in mind with every effort to improve the seed.

And next we have only to remember that the 
laws at work in seed production are the same as those at work in animal breeding:-heredity and variation.

All horses have some characteristics in common; in certain respects all cattle are alike; hogs are never confused with sheep; each species has its own special characteristics; birds have feathers, bills, and wings.

Heredity establishes features common to each class. We class horses into breeds. Some are heavy-muscled, short-limbed and strong. They make the draft breeds and appear similar in form, type, and outline. But some horses are longlimbed, long and lithe in form and muscle, and swift in speed. They form the roadster type.

Why do we find these extreme types? The answer lies in the fact that they have been bred to do special work and have acquired distinct characteristics that they may do that work more easily. The change from the normal form or type began because peculiarities are not absolutely fixed or made stable by heredity except along essential lines, and even these are subject to change.

This change in variation is quite noticeable when you observe minor characteristics. All horses look alike, yet no two horses are exactly the same. They differ in a hundred ways. So with plants. So with cotton.

Varieties of cotton are similar in essentials. The root, the stem, the leaf, the bloom, the boll, the fiber, the seed, are not to be mistaken. You may not be able to name the variety, but you know the plant. In all varieties of cotton these characteristics are similar, and you are not deceived.

The variation that concerns you most is in the amount of seed or lint, the length, strength and 
uniformity of staple-qualities which count in the market place. And as you grow cotton for the market you must produce what the market demands.

DO ONE THING AT A TIME

You will make a mistake if you attempt the improvement of your cotton in all directions at one time. It would be too big a task to undertake, even though you should devote your whole time to the work. Work in one direction, therefore: the one most important to you. When your effort here has resulted in improvement and becomes fixed and stable, begin work in another direction, but on the stock you have so far improved.

Remember it does not require money or much extra labor to work in one given direction. What you do expend in this way comes back to you with rewards a hundred fold. Set yourself to improve your cotton in one particular quality: always select plants that will produce most of marketable lint and seed. This you can readily determine by a thorough field examination.

\section{HOW TO SELECT SEED}

The most productive plants in any given variety are those that have the largest, best-formed, and most numerous bolls. The eye will readily detect these plants. Select one hundred of the choicest bolls from superior plants for your initial work the coming season. From this quantity you will secure from 3,500 to 4,500 seed, which will be sufficient for planting a seed plot of at least a quarter of an acre, and this should produce some- 
thing like fifteen bushels of seed at picking time. This quantity in turn will give selected seed for fifteen acres the following year.

Continue to select one hundred of the choicest bolls each year for your seed plot of the succeeding year.

Such a system of seed selection should be perpetually practised by planters throughout the South, and should of course improve the seed stock to a high degree, greatly increasing the productiveness and greatly accentuating all the desirable qualities of the plant.

\section{THE SEED PLOT}

Locate your seed plot on a soil offering conditions similar to those of the rest of your cotton area. To locate your plot on a sandy soil, for example, if the main crop is to be grown on a rich, heavy, clay formation, would be manifest folly.

Select a type of soil, then, like that on which the general crop is to be cultivated, but enrich it; for you will get the best and most vigorous seed from plants well nurtured and grown under most favorable conditions. You will make no mistake in fertilizing well and following with thorough cultivation throughout the growing season.

\section{STUDY INDIVIDUAL PLANTS}

By a study of individual plants you can carry the selection of your cotton still further. No two plants are alike in every detail. They vary in a hundred and one ways. They vary in their ability to transmit superior qualities to their progeny. And this is an important consideration. 
The animal breeder calls this quality prepotency. It represents the faculty of transmission of parental qualities to offspring. Some animals do this to a remarkable degree. Some plants do.

Study your individual cotton plants so that you may know which plants are pre-potent and which ones are not. Where this transmitting power is weak, you will have less desirable breeding stock, and this you should discard. Preserve seed from plants only that are able to propagate their individual qualities and merits; otherwise your progress will be slow.

Now as to the best way of putting this principle into effect: suppose you have selected one hundred bolls and these have come from several plants. You can label the seed at planting time, from every boll, or at least those from particular plants, and determine the transmitting power. This makes more work, but it greatly facilitates the breeding operations.

\section{SELECTION IS NOT SLOW}

Nor is the selection of seed a slow process for increasing yield of lint and seed. Its practice will show results even the first year. A good farmer of our acquaintance last year grew cotton at the rate of one thousand pounds of seed per acre from seed of three years' selection, while the ordinary seed under the same conditions as to soil, fertilizers etc., produced only 700 pounds per acre. Similarly, in your field in any growing season there are doubtless plants which will yield at the rate of five hundred pounds of seed cotton per acre; others, a thousand pounds; still others will produce at the rate of fifteen hundred or 2500 pounds of seed cotton per acre. 
Why this difference?

They are grown on the same soil; moistened by the same rains; brightened by the same sunshine; they have enjoyed the same tillage, fertilization and culture; and yet they differ in many ways.

The solution of the problem is heredity. Like begets like.

We expect much from civilized races of men; but less from the untrained, the child-like. In the vegetable world we can readily apply the same principle. We will not use for seeding purposes the small yielders, the little doers.

But this elimination must be done in the field at picking time. We can do no mixing. We must sccure seed from the superior plants and keep it separate from the general lot. It must be ginned separately, too, else our pains and labor will come to naught.

By discarding seed from poorly producing plants, and securing it only from the best, the process of improvement will work quickly and surely, and will reward the planter even more liberally than he might expect.

This means, furthermore, that we shall abandon the practice of getting seed for planting at the gin except from cotton previously gathered from selected plants and set aside for planting purposes.

\section{SELECT MORE THAN ONE PLANT}

The plan of selecting more than one plant for breeding stock is a good one, since it gives you better opportunity for the study of the transmitting power of each individual; and this increased number of plants for breeding purposes also aids you greatly in approaching the special type you are endeavoring to evolve. 

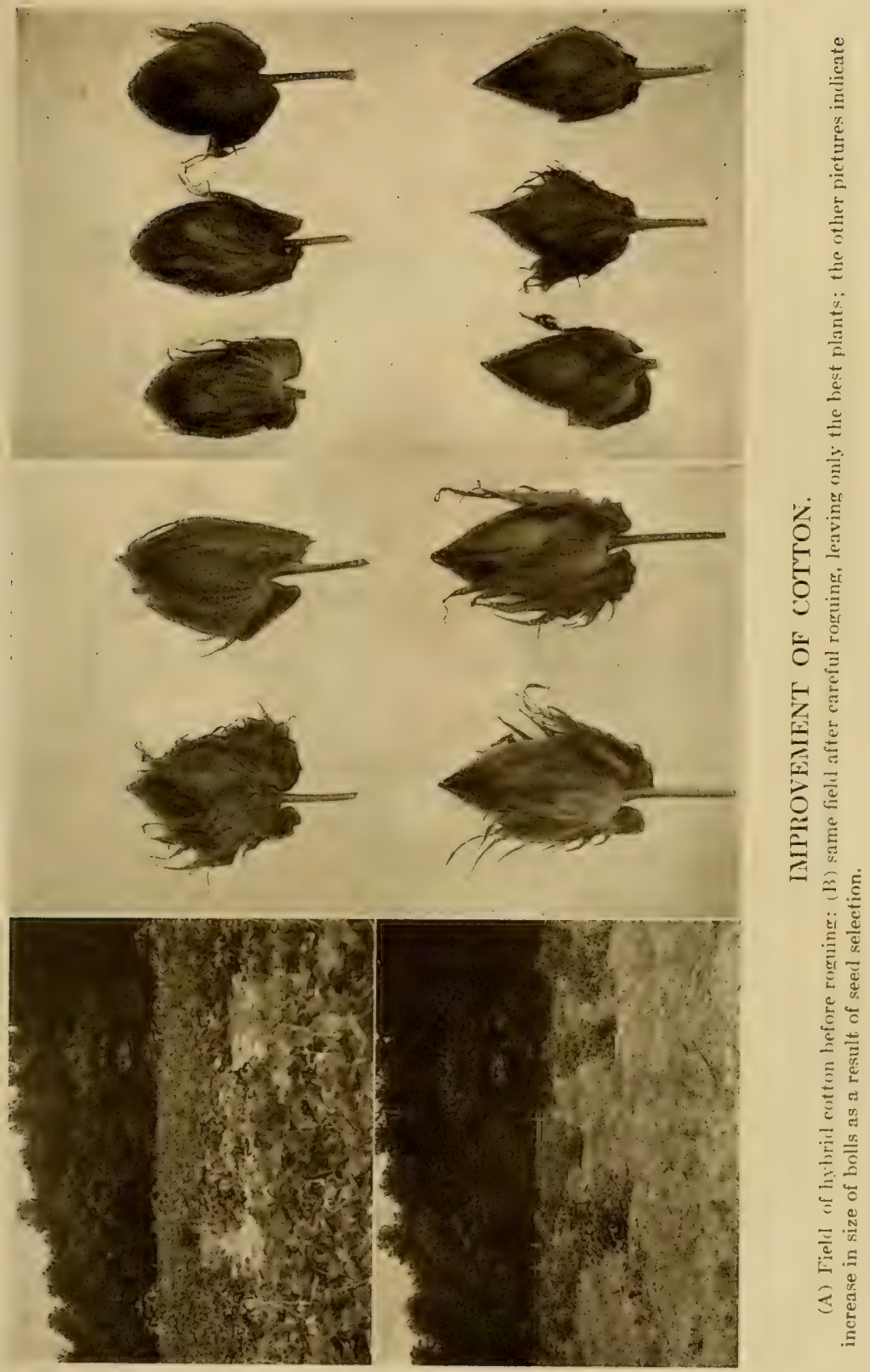


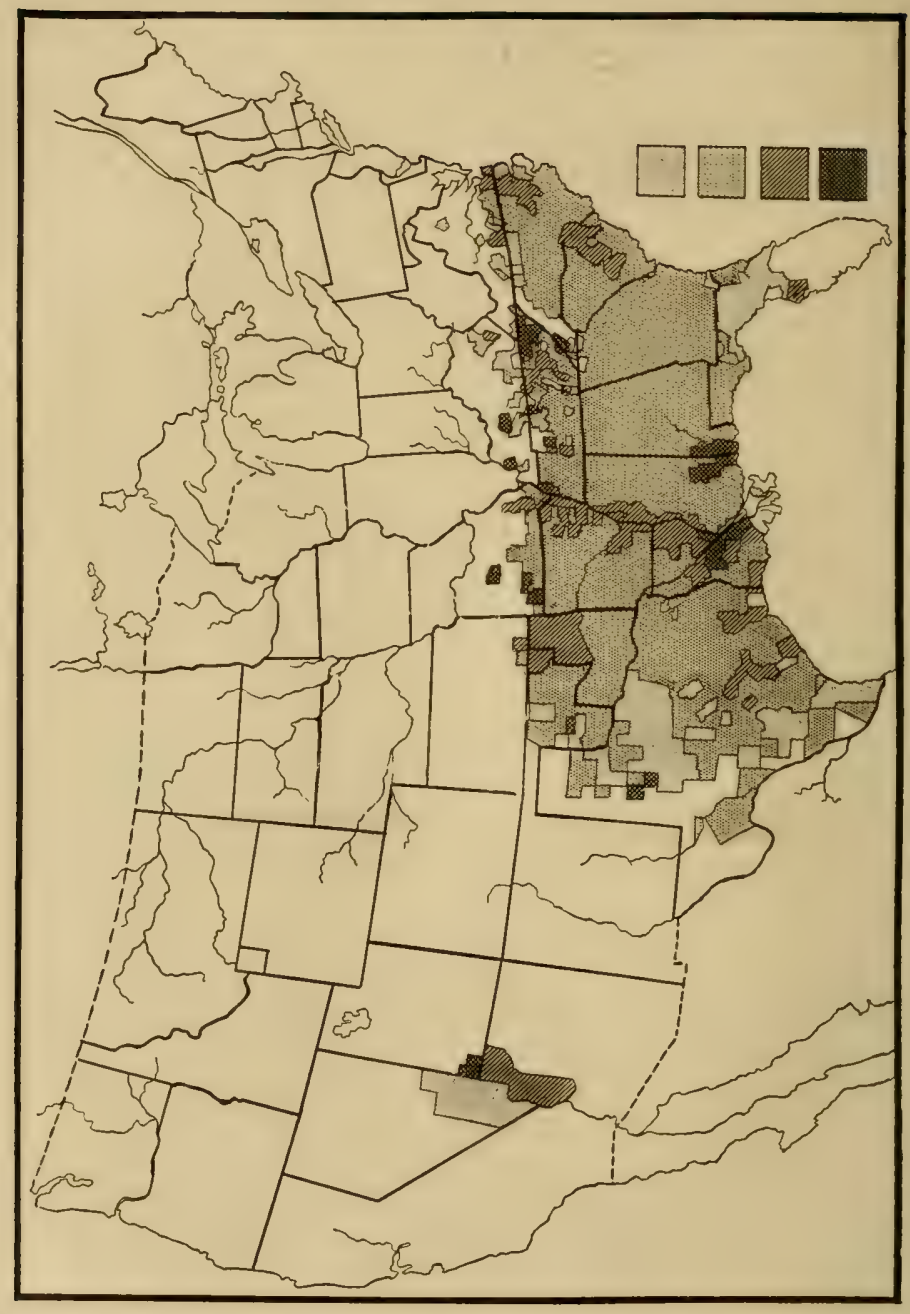

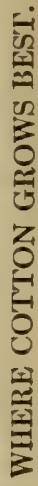


A plan suggested by Dr. Webber of the U. S. Department of Agriculture, shows the simplicity of breeding cotton, and is illustrated in the diagram below:

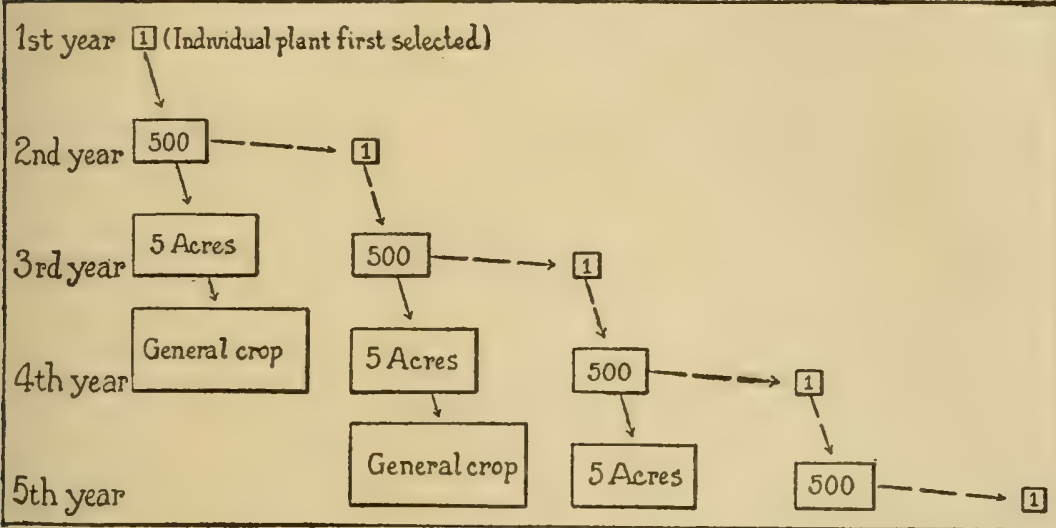

Diagram Illustrating Method of Selecting Cotton

PEDIGREED STOCK

The Sea Island planters on the islands off the coast of South Carolina follow a method of selection almost exactly like the plan advised by Dr. Webber.

When first introduced into this country from the West Indies, Sea Island cotton was a perennial and quite unsuited to our climatic conditions. A plan of selection, faithfully executed with the purpose of using only early-maturing plants, has resulted in making the Sea Island variety thoroughly at home in its new environments - so much so that to-day this variety stands foremost in length and fineness of staple.

Cotton bred with a definite purpose in the breeder's mind; selected from year to year because of 
merit and worth; adapted to soil, climate, and methods of fertilization and culture, is "highly bred" cotton in name and in fact, and in every sense is pedigreed stock.

Such strains are worth many times their cost, and give ample reward for any additional labor that needs to be given them.

\section{BREED COTTON TOWARD AN IDEAL}

The animal breeder has succeeded in producing marvelous strains of various classes of farm animals. He has succeeded because he worked toward an ideal. Some standard of excellence is no less surely needed that the cotton planter may be guided in the improvement of his crop.

And in working toward such an ideal, as has already been suggested, those traits which count for much in the sale of the commercial product, must be given first consideration. Those factors are:

An abundance of bolls

A boll of large size

Heavy yield in lint

Fiber of good length

High percentage of lint

Fiber that is fine

Fiber of good strength

Fibers uniform in length.

With these factors and their relative importance in mind we suggest a score card as follows:

A PROPOSED SCORE CARD FOR COTTON
A. Number of Bolls
(Large, 15 points
15 points Small, 5 points 


\section{COTTON}

A PROPOSED SCORE CARD FOR COTTON

(Continued)

B. Size of Boll 15 points $\left\{\begin{array}{l}\text { Large, } 15 \text { points } \\ \text { Medium, 10 points } \\ \text { Small, } 5 \text { points }\end{array}\right.$

C. Yield of Lint 15 points $\left\{\begin{array}{l}\text { Heavy, } 15 \text { points } \\ \text { Medium, } 10 \text { points } \\ \text { Light, } 5 \text { points }\end{array}\right.$

D. Length of Fiber 15 points $\left\{\begin{array}{l}2 \text { inches, } 15 \text { points } \\ 1 \frac{3}{4} \text { inch., } 12 \text { points } \\ 1 \frac{1}{2} \text { inch., } 8 \text { points } \\ 1 \frac{1}{4} \text { inch., } 5 \text { points }\end{array}\right.$

E. Per cent. of Lint $\left\{\begin{array}{l}35,15 \text { points } \\ 30,10 \text { points }\end{array}\right.$

15 points 25,5 points

F. Fineness of Lint 10 points $\left\{\begin{array}{l}\text { Fine, } 10 \text { points } \\ \text { Medium, } 7 \text { points } \\ \text { Coarse, } 5 \text { points }\end{array}\right.$

G. Strength of Fiber 10 points $\left\{\begin{array}{l}\text { Strong, } 10 \text { points } \\ \text { Medium, } 7 \text { points } \\ \text { Weak, } 5 \text { points }\end{array}\right.$

H. Uniformity in Length $\left\{\begin{array}{l}\text { Good, } 5 \text { points } \\ \text { Medium, } 3 \text { poin }\end{array}\right.$

5 points (Poor, 1 point 


\section{CHAPTER XII.}

THE KING'S REALM, THE LAND OF SUNSHINE

The great cotton producing section of the United States lies a little below latitude $37^{\circ}$. This nearly coincides with a line drawn from Norfolk, Virginia, to Cairo, Illinois, and marks the northern limit of profitable cotton culture. (Of course, the cooler mountain region of this section must be eliminated.)

Here then is the Cotton Belt of America, and to this region the world looks for its annual supply of raw cotton. New areas, favorable to cotton production, will be developed, as time goes on, but for all time to come the present cotton-growing States will likely furnish the greater portion of the world's needs.

\section{PECULIAR CLIMATE OF THE COTTON BELT}

The Cotton Belt has a somewhat variable climate. From its geographical situation it is naturally of moderate extremes, and favored by the winds that sweep over its territory. That equable temperature which characterizes the zone of Gulf Stream influences has promoted the growth of the various agricultural and horticultural industries. Orchards and vineyards thrive in the genial climate; trucking crops are nowhere better favored; one can 
grow (and with profit) any agricultural plant indigenous to America in almost any State in the belt. But though other crops are grown, cotton here is indeed king, and with improved soil conditions and wiser cultural methods will become recognized as the most powerful plant monarch in all the world.

For profitable production, cotton requires:-

A relatively high temperature

A long growing season

A moderate and well-distributed rainfall throughout the growing season.

A small amount of rain at maturing time

A great deal of sunshine.

These conditions are found in the Cotton Belt to a greater degree than anywhere else in the world. When they are prominent as features of any season a maximum yield is produced. But let the growing season be short, the rainfall excessive, the amount of sunshine small, or the summer cool and cloudy, and the whole world will know in advance of the harvest that a small crop has been produced.

\section{RELATIVELY HIGH TEMPERATURE REQUIRED}

Broadly speaking the mean temperature is from 15 to 20 degrees higher in North Carolina, Georgia, Alabama, and Texas than in Massachusetts, Pennsylvania, Ohio, and Illinois.

In winter the mean temperature is from 20 to 25 degrees higher in the South and in summer from 10 to 15 degrees higher. This climatic condition is especially favorable to cotton culture, since it means a long season free from frost or low temperatures. Cotton enjoys a warm atmosphere, or even a hot atmosphere provided it is moist and reason- 
ably constant. A sudden change in temperature bringing on a cold spell is objectionable, for it tends to check the growth of the plant, ripen its fruit, and influence its final yield unfavorably.

\section{A LONG GROWING SEASON}

At first cotton grows slowly. In a sense it is a tender plant. A light frost may do little injury; still it shortens the season and this is an undesirable risk. An ideal situation with regard to frost is to have the last spring frost no later than April 1st, and the earliest autumn one no earlier than November.

The Cotton Belt provides the much desired long growing season better than any other area of the earth's surface when other essentials and controlling influences are taken into account.

\section{RAINFALL PLAYS A PART}

More rain also falls in the Cotton Belt than in the northern section of the country. This excess varies from 30 to 50 per cent. The total rainfall, and the time rain falls, have much to do with successful cotton production.

A moderately well-distributed rainfall is necessary during the growing season. A small amount is preferable to an excess, since grass is the bane of the cotton farmer; and grass is favored by much rainfall. When present it adds greatly to the cost of culture. The slow growth of cotton while the plants are young allows grass and weeds to make rapid headway, and unless costly labor is constantly furnished, the tender cotton plants will be choked out in the race for growth and sunshine. 
In fact, among planters nowadays, there is a tendency to delay the planting period because of this grass menace returning with each planting season. Where early maturing characteristics are bred into the plant this practice will prove desirable, since it favors grass and weed destruction by reason of the general cultivation given before the crop is planted.

The use of harrows and weeders immediately after planting, and for some weeks later, will materially assist in the battle which must be constantly waged against grass-against "General Green," as the Southern phrase has it.

During the early growing period of the plant, not heavy storms, but rain in frequent showers, preferably at night with much sunshine during the day-is the sort of weather in which cotton rejoices.

Dry weather during the maturing period, is especially favorable to cotton production, and happily for the farmer, this dryness is peculiarly prevalent throughout the Cotton Belt in late summer and early fall.

It is probable that the first half of the plant's life is the more important half. In the latter half, drought, excessive rains, insects, shedding of bloom and bolls, and even other troubles we have constantly. Still if the plant and the crop reaches July safely and in thrifty growing condition, the planter is reasonably sure that an average crop will be gathered.

\section{SUNSHINE OF PRIME IMPORTANCE}

Cotton grows only in warm lands where there is a great deal of sunshine. It is truly a sun plant, 
the darling of Apollo. Wet, cloudy, and rainy days, except in so far as they are necessary to supply the comparatively small amount of moisture required, have no place in its calendar, and are unfavorable to vigorous, abundant growth and to the yield of seed and lint.

The blossom itself tells us this. In the morning of a bright, clear, warm day, it opens to its full extent to drink in the sun, but as soon as the damp evening approaches, it closes as if it would keep cold and dew wholly without. In every way the plant shows its nature and its longing for warmth and sunshine. Its green leaves even appear to turn to the east in the morning, waiting for the sun to rise, and seem, in a measure, to follow it in its course until it sets in the west; then they droopas if the day's work were finished-and await the coming of the sun again.

Climate has much to do with cotton. A native of tropical lands, it does its best in temperate climates, and seems unable to venture beyond the limits of its adopted home. No other staple field crop in our country is so circumscribed. Other than grass, corn (our leading crop by acreage and production) has gone to every part but our westernmost limits: wheat, oats, rye, though all somewhat choice of soil, yet fear neither heat nor cold; but cotton, wedded to the Southern sunshine, pines away and, Rachel-like, will not be comforted, when taken from its Dixie home. 


\section{CHAPTER XIII.}

\section{SOILS AND HOW TO HANDLE THEM}

There is no soil typical of the Cotton Belt. Cotton is grown alike on light sandy soils, on loams, on heavy clay soils, and on strong bottom lands, though naturally not with equal success on all of these varieties of soil.

In a general way we may group the cotton lands into two great divisions - the uplands and the bottom lands. The former may be sub-divided into light sandy soils, and red and gray clay soils; while the latter embrace river-bottoms, basins and banks of small streams, the prairies and canebrakes, and the valleys of the Mississippi and its branches.

These soils vary greatly in origin, in composition, in productive power. Like other lands, they are subject to change; and respond to good treatment or suffer from inattention and neglect.

In all parts of the South one sees cotton soils once abounding in fertility, but now so exhausted that they grow crops hardly worth the cost of seed, fertilizers and tillage. On the other hand, other cotton soils which inherited poverty through generations of thriftless ownership, are now noted for their high productive power.

Every soil helps its owner in proportion to the (109) 
owner's ability to help it. High pedigree, if one may use this term in this connection, counts for little, if a poor farmer owns the land. Just as the canvas reveals the training and the power of the artist, so the cotton soil testifies as to the intelligence and skill of the owner.

THE SUPREME TEST OF THE PLANTER

Power to make the soil produce remunerative crops is the supreme test of cotton farming. Without this power, good prices for the staple, an ideal climate or situation, a propitious season, are of as little agricultural value as "sounding brass or tinkling cymbals."

What then is needed?

This is needed: Knowledge of the soil and its management. The cotton farmer must so know his soil and its proper management that he can make it yield better crops; that he can permanently improve it for the generations that are to come after him; that he can make not two, but five pounds of lint or seed grow where one grew before. These happy ends can be achieved only by the most intelligent cultivation, and by the application of every principle of improvement revealed by modern science.

\section{HELPING NATURE}

The soil we know was once rock. Through countless years this primitive rock has been disintegrating and making soil. The great forces of nature through ages and ages of recurring summer and winter have been at work on it. And soil building never stops. Our cotton soils are being made to-day. But you must help nature in her effort to make your own soil more productive. You must 
neither check nor discourage her. She wants your helping hand. If the soil has been robbed of its humus, you must return this important element; you must add chemical manures when needed; you must plow deeply and effectively that a good seed bed be provided for the tender plants; legumes must be grown that their strong, deep-growing roots may add nitrogen and also penetrate and loosen the sub-soil, and bring to the upper layers the rich plant food of the fertile mines beneath.

\section{GOOD TILLAGE NEEDED}

Our Southern soils possess great possibilities for improvement. They are not exhausted and dead as generally supposed. Good tillage will help many of them as it helps soils devoted to other crops.

The plow will do much to restore virgin fertility. It will assist nature in making plant food available for the tiny fibrous roots. The plow will let air and moisture into the soil that they may do their share in rendering hitherto locked-up plant food available for the plant.

Good tillage means more than turning a three or four inch furrow, as is the usual practice through most of the Cotton Belt. It means the gradual deepening of the root bed until ten or a dozen inches are turned to the air for purification and rejuvenation.

\section{CROP ROTATION NEEDED FOR COTTON LANDS}

Not only do our cotton lands need more thorough tillage, but through the greater part of the Cotton Belt the one-crop system is practiced. From its very nature it is a ruinous system, leading inevitably to the deterioration of the land. 
Why is this true?

Because it does the following things:

1. It injures the texture of the soil by making light soils loose and open, and heavy soils dead and lifeless.

2. It destroys the humus of the soil; and no soil can remain fertile if it contains little or no organic matter.

3. It influences unfavorably the water content of the soil: light sandy soils with little vegetable matter are loose and open, and soon lose the moisture in them; heavy clay soils robbed of their vegetable matter quickly dry out and bake.

4. It influences unfavorably the amount of available plant food in the soil. Vegetable matter itself contains plant food and when used up, with no additional amount to replace it, the loss is soon felt. Plant food is lost also by leaching away in loose soils or by becoming insoluble in stiff heavy lands.

5. It draws too constantly on that special ratio of fertilizing ingredients most needed by the cotton plant. A crop following after one requiring a somewhat different proportion of nitrogen, potash and phosphoric acid, does much to restore the proper balance required for the most profitable cotton production.

Continuous culture of cotton on any land, then, is undesirable. Its harmful influence may be overcome only by a system that involves a change of crops.

Such a change of crops is suggested by nature herself. Cut a forest growth and a change of trees comes on. Pasture lands give way to many weeds and thistles; bluegrass and Bermuda drive out the clovers and timothy. Crops do better when fur- 
nished new land and soil new to them. Just as an animal likes variety in food and a change of pasture, so the cotton plant wants occasionally, a new and fresh feeding ground.

\section{A SUGGESTED SCHEME OF CROP ROTATION}

In arranging an order of crop rotation that shall serve best your system of farming, it is well to bear in mind that plants vary:-

1. As to taste in kinds and quantity of plant food.

2. In feeding habits.

3. In the power to add humus to the soil, or (because of culture) to use it up.

4. In the ability of some, like cowpeas, alfalfa, and the clovers, to add nitrogen to the soil.

These are only general rules but should be employed whenever possible because their use will aid materially in the rapid improvement of cotton lands. An example of such a rotation is given herewith:

\begin{tabular}{|c|c|c|c|c|c|}
\hline \multicolumn{2}{|c|}{ First Year } & \multicolumn{2}{|c|}{ Second Year } & \multicolumn{2}{|c|}{ Third YeAR } \\
\hline Summer & Fall & Summer & Winter & Summer & Winter \\
\hline Corn & $\begin{array}{l}\text { Cow- } \\
\text { peas* }\end{array}$ & Cotton & $\begin{array}{c}\text { Oats or } \\
\text { Wheat }\end{array}$ & $\begin{array}{l}\text { Cow- } \\
\text { peas }\end{array}$ & $\begin{array}{l}\text { Rye or } \\
\text { Clover }\end{array}$ \\
\hline
\end{tabular}

*Planted in corn at last cultivation.

If you examine this three-year-course rotation you will find that it includes two nitrogen crops (cowpeas and clover) for soil improvement and hay; two cultivated crops (corn and cotton) for physical 
improvement of the soil and to kill weeds; two grain and fiber crops (oats or wheat and cotton) for money crops; and two stock feeding crops (corn and clover or rye) for pasture, ensilage or stover.

\section{USE LEGUMES AND COVER CROPS}

Good soil management calls for some legumes to assist in keeping the land fertile and full of humus. The cowpea accomplishes this purpose best of all our legumes in the Cotton Belt, because it grows on every kind of soil, in wet or dry seasons, and in hot or warm temperatures. Rather than allow any land to lie idle as a "rest" year, sow it to cowpeas so as to furnish both hay for the work stock and humus and nitrogen for the soil.

A cover crop like clover, oats, or wheat is also a great help, since it prevents washing of land during the winter months. We are confident that more soil fertility is lost by the washing and leaching of exposed soils during the winter season than the cotton crop removes from the land during the whole six months of its growth.

The cotton farmer should include, therefore, cover crops and legumes in his system of crop rotation, that these important agents in soil improvement, may do the great work they always stand ready to do for him. 


\section{CHAPTER XIV.}

\section{BRINGING EXHAUSTED SOILS BACK TO LIFE}

We have few cotton soils that are really worn-out. We merely call them so. We have treated them badly; so badly that they have become unresponsive to our calls. Some of these were good once, others were less valuable, but bad treatment, cruel neglect, and thoughtlessness of their comfort, have contributed to making them what they are to-day.

What shall we do with them?

We can do three things:

(1) Turn them over to weeds and gullies.

(2) Make forests out of them.

(3) Bring them back to productiveness and beautv.

Of course, we have no desire to give them over to weeds and gullies. We have already enough of each. Weeds come as nature's blessings to those abandoned fields, but the gully leaves only ruin and desolation to mark its track.

Perhaps there are many areas where hills and rocks abound that might be used to better advantage if turned over to forest growth. Timber lands are becoming valuable, and with the coming years, will be still more valuable. Hence, lands difficult of tillage and cultivation might be better employed 
in bringing on new crops of timber for future generations that are to need them.

Still, the greater part of these so-called worn-out lands may be reclaimed and brought back to the fructuous state they were in before the soil-robber came.

The first step is this: Clean them up and give them the advantage of good appearance. If clothes make the man, good looks make the field. If fields could think, they would doubtless act like animals and men: to show their value they would wish to look well. But to be covered with brush and thickets and gullies and the like is enough to make them shameful and little-doers.

\section{AMPLE REWARDS IN RECLAIMING WORN-OUT SOIL}

Treat these lands liberally and they will brighten up and respond gloriously. For every cent you spend on them in the way of better appearance and clean faces they will return many. Every gullied wrinkle you remove will bring hope and earning power to them, and to you; the care and attention expended in grooming with axe and plow will produce marvelous changes in appearance, productive ability, and commercial value.

Possibly you have many acres of this kind of land. If so, reclaim them as you can. Five acres, ten or fifty: work in this fashion as far as you are able. Winter is the time, and there is none better. You are not busy with details of work: your men, your tenants, have many, many idle days; your teams are inactive because winter is on, and no pressing work is to be done. Make work: employ men and teams in these old fields. Cut the thickets, mow the briers and brush; plow the soil deeper 

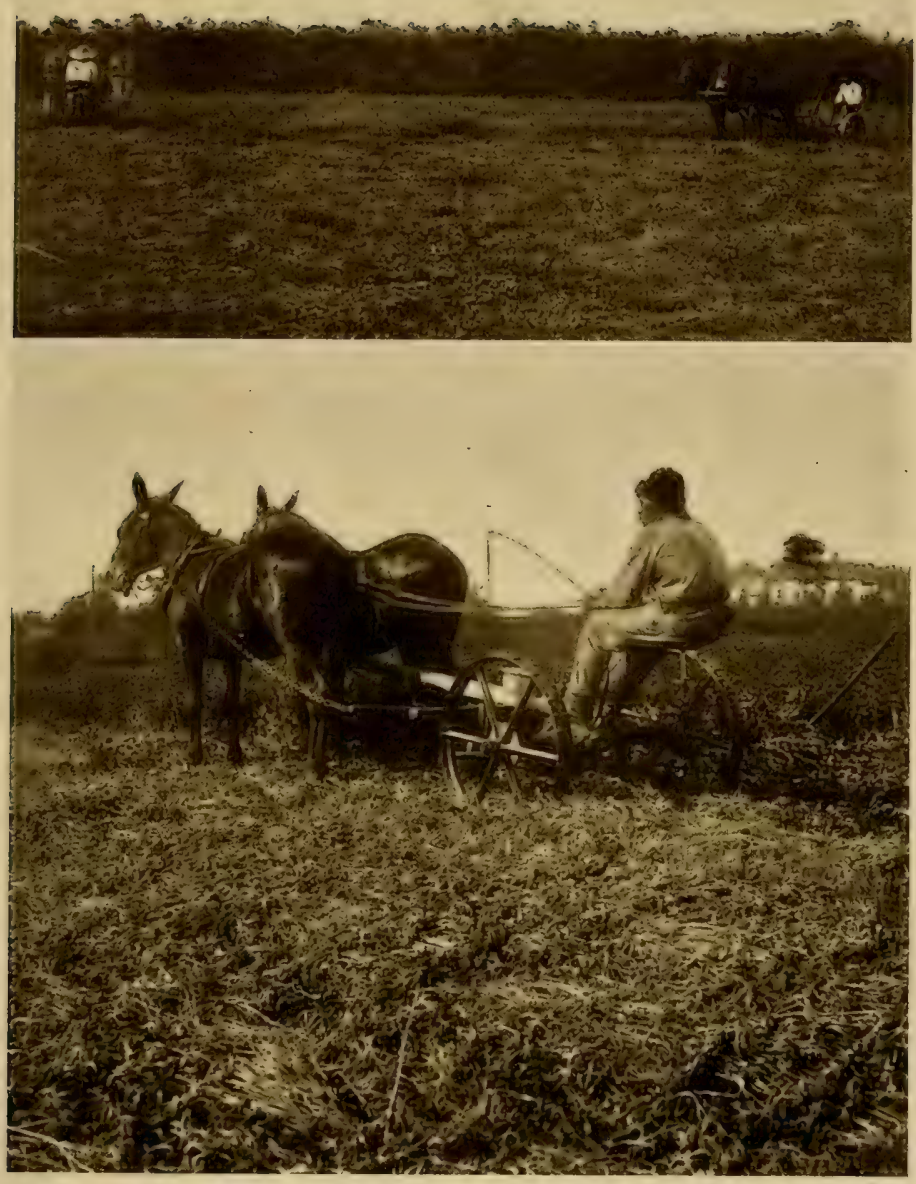

GETTING FERTILIZER FROM THE AIR.

Growing clover or any other leguminous (nitrogen-gathering) crop in rotation with cotton is the most satisfactory way of keeping up the fertility of cotton lands. 

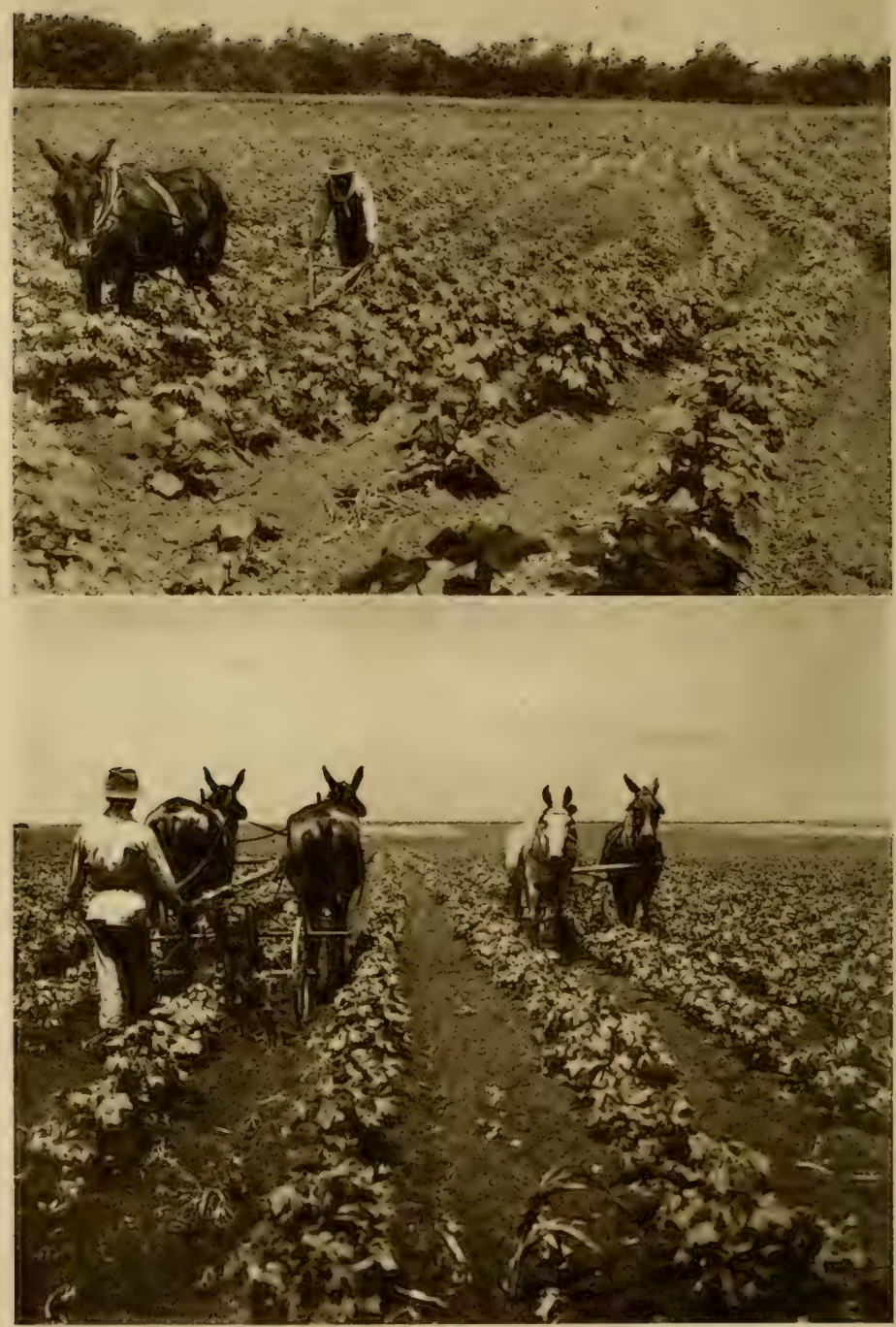

CUITIVATING THE CROP.

The old ridging system of cotton cultivation is going out of fashion. In the first picture we have the mule and the one-horse plow; in the second the more modern-and more economical-two-horse cultivator. 
than you have ever done before. Let the onehorse plow alone. It is useless in these old fields. A larger, heavier one is needed and two horses or mules will be required for the work. If you are able to do this during earlier winter the clay subsoil turned up will do no harm. Freezing and thawing, air and rain, will get things ready for the crop and no harm will be done.

Have you ever done this work? Have you ever tried it on your old fields? It may surprise you. It has surprised us.

THE COWPEA AS AN ALLY IN SOIL RESTORATION

You are now ready for the spring to come. Of course you will use the cowpea. It will do the work if any plant in all the world can do it. It will send its roots down deep into the subsoil below; it will put nitrogen into the land, humus will be added; the texture will be improved; the soil will come to life. You may get only a small growth of cowpeas the first year. It will depend on how badly the soil is deteriorated; on how much it is worn out. You can pasture the cowpeas or make them into hay, or leave them to mature and die. Suit yourself in this respect.

And now winter comes on again. Go into another field. Clean it up in the same way as you have done the one we have just been considering. And last year's section-you must not forget it. In winter plow it again and put it to peas a second time and then a third time. That makes the field. It lives! it is restored to life. Though weak and tender, still it will go to work bravely and willingly. 
Let cotton come; the old field is ready, there is no weariness now; no dragging of feet because famished by hunger or thirst; no sullen soil in which the cotton plant must send its unwelcome roots in search of food; no empty larder from which it is to turn away disappointed.

\section{FOUR THINGS TO DO}

Be reasonable with this soil from this time on. If you over-work it, evil results are sure to follow. Treat it properly and it will grow stronger and better. It will never despair again.

These four things you must do: two

(1) Grow a legume of some kind every year or

(2) Use cotton only in some rotation

(3) Plow deep and cultivate thoroughly

(4) Keep humus in the soil.

Fertilizers usually can be employed to advantage in soil restoration. Much plant food is not available. It is present in the soil, but not in forms that plants can use. Time, tillage and thoroughness only will wake this plant food from its sleep and rest that plants may use it abundantly, and when they have need for it. Until that time phosphorus and potassium may be added to the soil to help the cowpea. Nitrogen is not needed, since the cowpea attracts the bacteria that build nitrogenous store-houses on its roots.

This mutual arrangement is especially helpful to the cowpea, since it is a ravenous nitrogen feeder and finds an abundance of nitrogen within reach of mouth and hand. So chemical nitrogen is not needed as a fertilizer for cowpeas. A mixture of sixteen hundred pounds of acid phosphate, 
and 400 pounds of kainit makes a good combination of which from 150 to 300 pounds may be used per acre.

A good growth of cowpeas means the addition of a great deal of humus and nitrogen to the soil. It means the employment of the most economical methods for providing the nitrogenous part of the cotton fertilizer.

And not only does it furnish the most costly element of fertilizer; it also furnishes humus which is the back-bone and the life of the soil, 


\section{CHAPTER XV.}

\section{COTTON UNIQUE:A SELF-SUPPORTING CROP}

Cotton, like other plants, gets its food for life and growth from the soil, the water, and the air. Strange as it may seem on first blush, it is from air and from water that all plants are chiefly derived. From the air carbon enters the leaves and there forms the so-called carbonaceous matter of the plant. Cotton lint is pure cellulose, a material made from the carbonic acid of the air. From the air, too, comes a large part of the oxygen which, next to carbon, is the predominant constituent of the dry matter in the cotton plant, as well as in other plants. Other elements found in cotton are hydrogen, nitrogen, sulphur, calcium, sodium, magnesium, chlorine, iron, aluminum, potassium, phosphorus, and silicon.

\section{WHAT IS A FERTILE SOIL?}

A fertile cotton soil must contain all the elements of plant food in sufficient quantities and in available form to produce productive crops. As a rule, the soil elements are present in sufficient quantities to produce paying crops. Nitrogen, phosphorus and potassium, however, may be deficient, and if so, must be added through other means, or the crop will manifest its loss by making small growth and 
diminutive returns in seed and lint. By a deficiency is meant, in this case, an insufficient amount of plant food available for the use of the plants.

Really, as we have already seen, there is no such thing as worn-out cotton soils. There are poor cotton soils, unproductive cotton soils, infertile cotton soils, but they are so because of improper management; because the humus has been destroyed; shallow plowing has been followed; plant food has been lost or locked up.

Tillage and humus-and these alone-unlock the door to this treasure-house of old Mother Earth. The addition of nitrogen, phosphorus and potassium in chemical forms is only a temporary arrangement to make better crops for the time being. No permanent improvement of the soil will result unless tillage and an abundant amount of humus become the basis of such improvement. Chemical fertilizers are to be used, therefore, as supplementary helps, rather than as primary conditions.

We are now ready to consider the feeding demands of the cotton plant in reference to the forms of plant food usually purchased - nitrogen, phosphorus, and potassium.

But first, let us divide the cotton plant into its parts that we may clearly know the relative quantities of each.

PARTS OF AN AVERAGE COTTON PLANT Part

Per cent.

Roots.................... 8.80

Lint. . . . . . . . . . . . . 10.56

Bolls...................... 14.21

Leaves. . . . . . . . . . . . . . . 20.25 
PARTS OF AN AVERAGE COTTON PLANT

(Continued)

Part

Per cent.

Seed. . . . . . . . . . . . . . . 23. 03

Stems. . . . . . . . . . . . . . . 23.15

Total. .............. 100.00

Elsewhere it has been stated that 190 pounds of cotton lint is the average annual yield per acre. If we use thefollowing table of percentages, therefore, we find that an average crop of cotton contains:

190 pounds lint;

157 pounds roots;

256 pounds bolls;

364 pounds leaves;

414 pounds seed;

416 pounds stems.

\section{QUANTITIES OF PLANT FOOD REQUIRED}

In ascertaining the demands of the cotton plant in respect to nitrogen, phosphorus, and potassium, we can go to the plant itself for the information. Professor McBryde has analyzed a great many cotton plants, and from his work the amount of plant food used by each part is readily calculated. In this discussion, the reader must observe that only nitrogen, phosphorus, and potassium are considered, since they are the only elements purchased in commercial forms, the others being usually available in sufficient quantities in the soil. These facts are shown in the following table: 

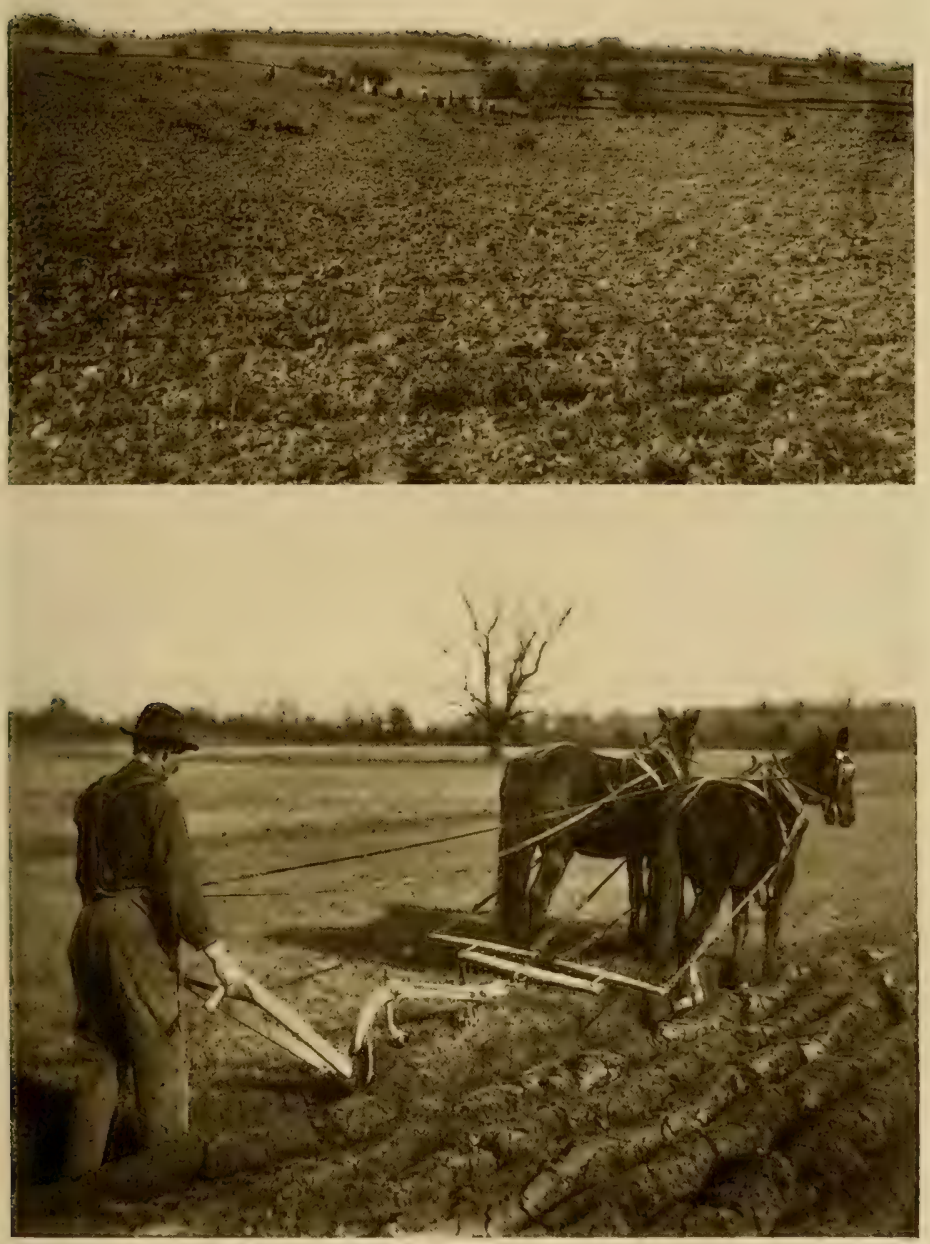

THE RESCUE OF OLD LANDS.

Gradually deepening the seed bed-the pasture ground of the roots-is one of the most effective ways of getting more wealth from cotton. 


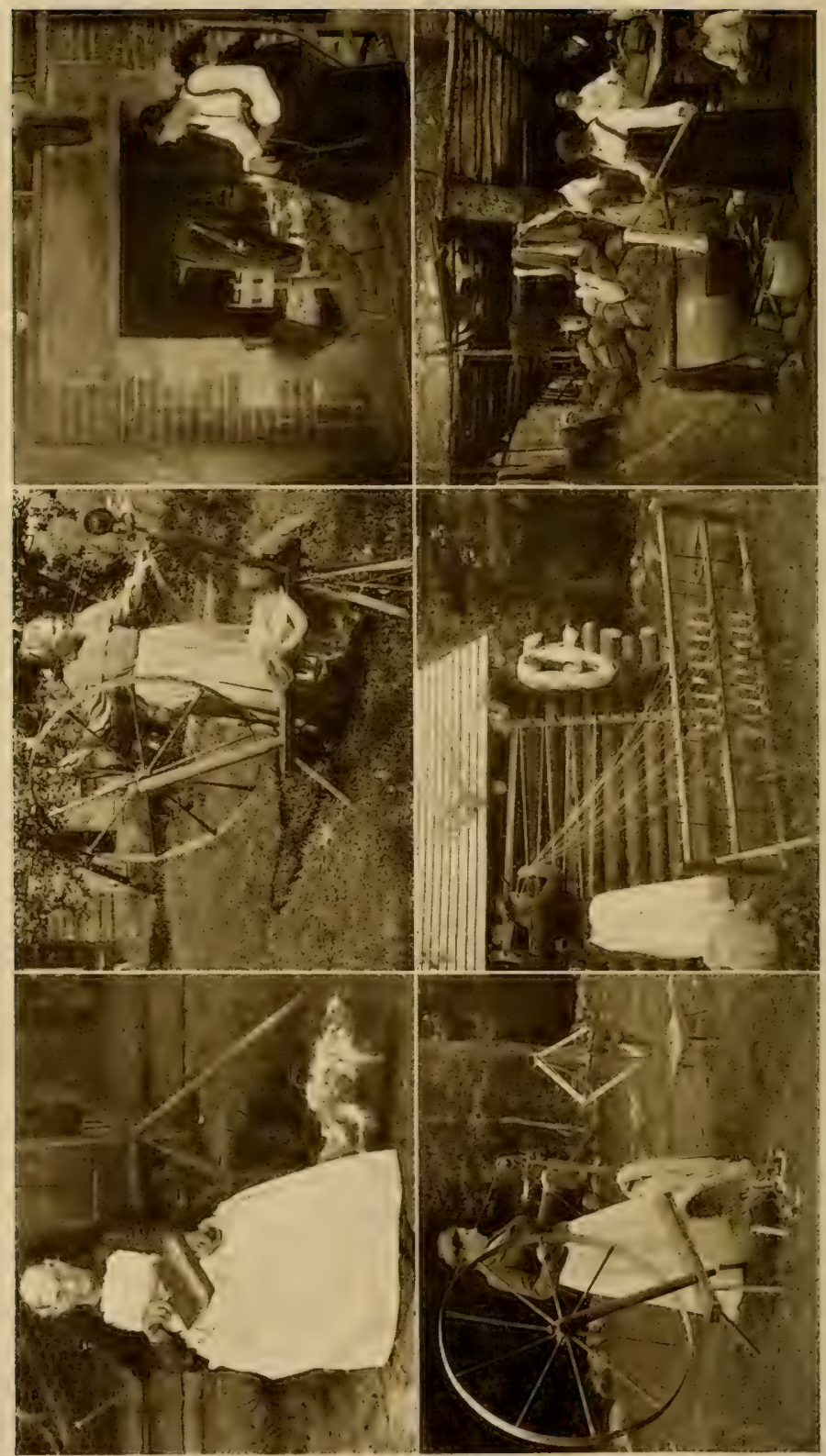

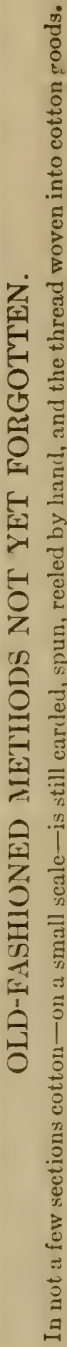


PARTS AND DEMANDS FOR YIELD OF AVERAGE

ACRE

\begin{tabular}{|c|c|c|c|}
\hline Quantity and part & Nitro. & Phos.' & Potas. \\
\hline 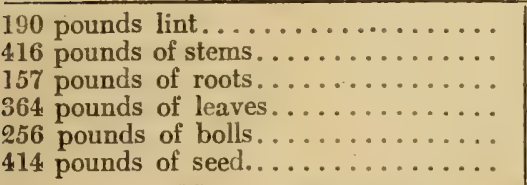 & $\begin{array}{r}.65 \\
6.08 \\
1.44 \\
11.70 \\
6.51 \\
12.96\end{array}$ & $\begin{array}{r}.19 \\
2.45 \\
.81 \\
4.33 \\
2.47 \\
5.26\end{array}$ & $\begin{array}{l}.87 \\
5.87 \\
2.01 \\
6.57 \\
4.64 \\
4.84\end{array}$ \\
\hline Total........ & 39.34 & 15.51 & 24.80 \\
\hline
\end{tabular}

Here we find the average cotton crop of 190 pounds of lint draws from the soil 40 pounds of nitrogen, 16 pounds of phosphorus, and 25 pounds of potassium. But stems, roots, leaves, and bolls are returned to the soil, and are therefore not really taken from the land at all. Lint and seed are taken away, and are removed from the land. Now what draft is made on the soil ? Let us see, and at the same time compare with corn and wheat on the basis of the average yield of each crop per acre.

We have the following facts:

\begin{tabular}{|c|c|c|c|c|}
\hline Crop & Nitro. & Phos. & Potas. & Totals \\
\hline $\begin{array}{l}\text { Cotton } \\
190 \\
414\end{array}$ lbs. lint. $\ldots \ldots \ldots$ & $\begin{array}{r}.65 \\
12.92\end{array}$ & $\begin{array}{r}.19 \\
5.26\end{array}$ & $\begin{array}{r}.87 \\
4.84\end{array}$ & \\
\hline Total.... & 13.57 & 5.45 & 5.71 & 24.73 \\
\hline $\begin{array}{l}\text { Corn } \\
29.4 \text { bus. grain. . . . . . } \\
4000 \text { lbs. stover...... }\end{array}$ & $\begin{array}{l}32.14 \\
41.60\end{array}$ & $\begin{array}{l}12.36 \\
11.60\end{array}$ & $\begin{array}{r}7.06 \\
56.00\end{array}$ & \\
\hline Total.... & 73.74 & 23.96 & 63.06 & 160.71 \\
\hline $\begin{array}{l}13.95 \text { bus. grain. . . . . . } \\
2300 \text { lbs. straw. . . . }\end{array}$ & $\begin{array}{l}10.75 \\
13.57\end{array}$ & $\begin{array}{l}7.44 \\
2.76\end{array}$ & $\begin{array}{c}5.1 \\
11.73\end{array}$ & \\
\hline Total.... & 33.32 & 10.20 & 16.83 & 60.35 \\
\hline
\end{tabular}




\section{COTTON A FAR LESS EXHAUSTIVE CROP} THAN CORN OR WHEAT

This table shows several interesting things. The most striking fact brought to our attention is this:

Of the three great staple crops of America, cotton is by far the least exhaustive.

Wheat requires more than twice and corn nearly seven times as much plant food as does cotton.

Nor is this all. We will suppose that cotton seed, corn stover and wheat straw are used on the farm, and in the end find their way back to the soil. The plant food they contain will be returned to the land from whence it was taken. We will now find a still greater difference in reference to the demands on the soil made by each crop, as is shown in the table below:

\begin{tabular}{c|r|r|r|r}
\hline \hline \multicolumn{1}{c|}{ Crop } & Nitro. & Phos. & Potas. & \multicolumn{1}{c}{ Total } \\
\hline 190 lbs. lint ... & .65 & .19 & .87 & 1.71 \\
29.4 bus. corn. & 32.14 & 12.36 & 7.06 & 51.56 \\
13.95 bus. wheat & 19.75 & 7.44 & 5.10 & 32.29 \\
\hline
\end{tabular}

In respect then to the amounts of nitrogen, phosphorus and potassium required for average acre yields of cotton, wheat and corn in the United States, wheat calls for 19 times as much of these elements as cotton, and corn calls for 30 times as much as cotton.

RETURNING COTTONSEED TO THE SOIL ESSENTIAL TO ITS PRESERVATION

The greatest demand on the soil by the cotton plant is for seed production. For the average 
yield 13 pounds of nitrogen, 5 pounds of phosphorus and 6 pounds of potassium are used.

If seed are sold, cotton is an exhaustive crop, but still only moderately so. When a rational system of farming is followed so that seed (or its equivalent in meal) may be used by live stock on the farm, and returned in manure to the land, cotton becomes the least exhaustive of all field crops. The demands on the soil are slight, indeed, when lint is the only product that goes from the farm. Wise is the farmer who realizes this, and blessed is he whose farming methods recognize this practice. 


\section{CHAPTER XVI.}

BUYING FERTILITY FOR THE SOIL

The small yield of cotton per acre over the greater part of the Cotton Belt is due to poor management in maintaining fertility, small quantities of homemade manures, sale of cotton seed from the farm, poor tillage, the limited growing of leguminous crops, an ill-planned tenant system, and the lack of systematic crop rotation in the management of cotton farms.

All these factors have contributed to the small returns in yield and to the constantly increasing demands for commercial fertilizers.

Where attention is given to all these details cotton growing becomes at once the most profitable of all kinds of farming in the whole world.

The small farm, as well as the large plantation, is ever confronted with new phases of management; the owner is successful in proportion to his ability to meet these new phases and so adjust them to his work that they will conduce to his profit and advantage.

The use of commercial fertilizers has assumed gigantic proportions in cotton production and calls for constant discussion.

We have mentioned elsewhere that of the fourteen chemical elements demanded by the cotton plant, nitrogen, phosphorus and potassium are the only ones likely to be deficient in old soils, and, 

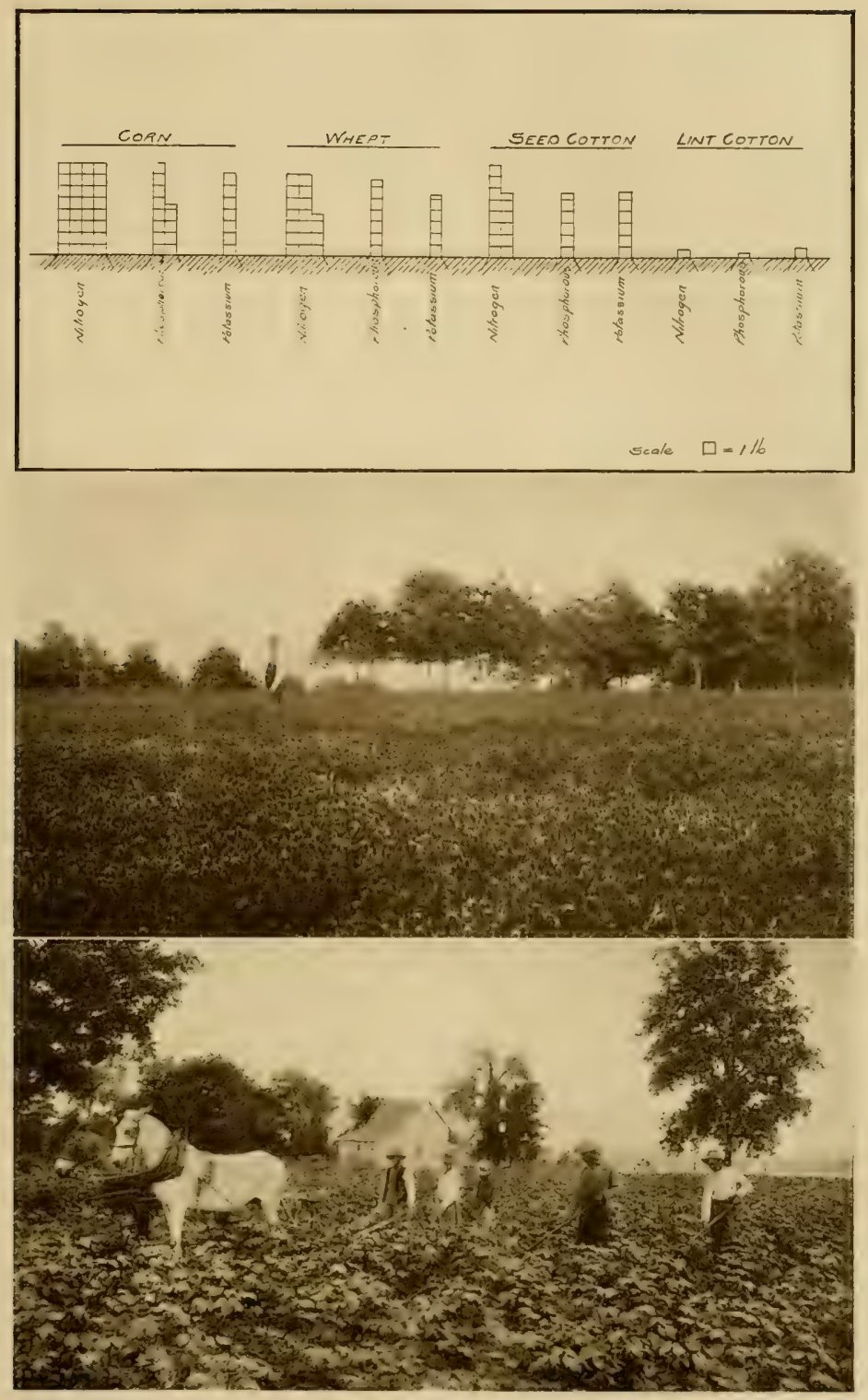

(Courtesy of Gray's Studio.)

The diagram at the top shows the relative quantities of nitrogen, potash and phosphoric acid required for the production of an average yield (per acre) of corn. wheat, seed cotton and lint cotton-strikingly illustrating the light draft on soil fertility when cotton seed or their equivalent are returned to the soil. The middle picture shows crimson clover; at the bottom we see cotton cultivation in its final stage. 

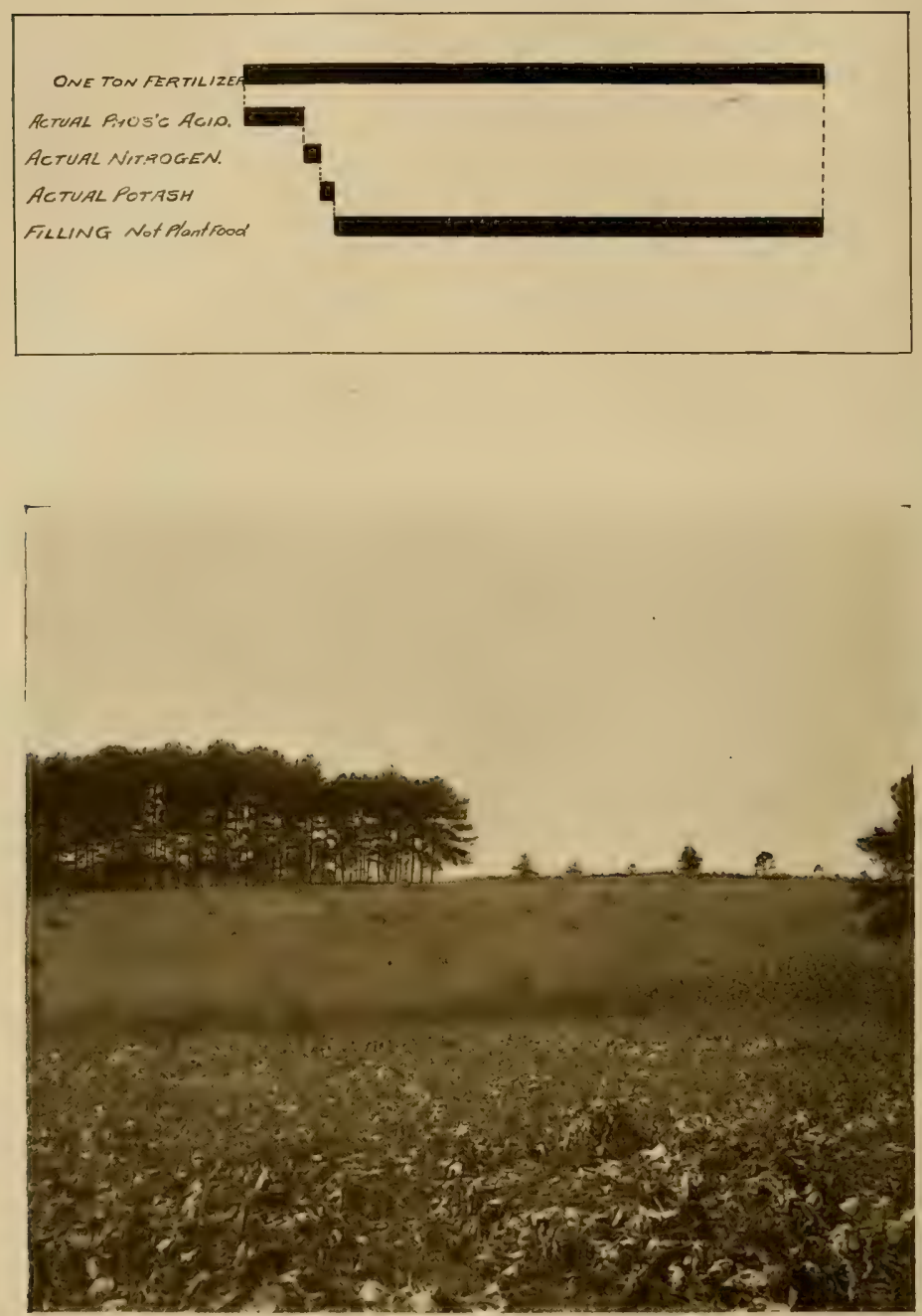

\section{TWO WAYS OF FERTILIZING}

A common fertilizer formula is the "8-2-2"; the diagram shows its relative quantities of actual nitrogen, phosphoric acid and potash. The second way shows the cheapest and easiest way of getting nitrogen and humus into the land. 
hence, must be furnished if satisfactory yields are to be obtained.

How to furnish these elements-in what forms; at what time; and in what quantity - are problems, which, like the poor, we have always with us.

That fertilizers pay is attested every year on nearly every farm and with most emphatic proofs. That they are often, if not usually, employed without the attention due their importance is also certainly true.

The judicious use of fertilizers demands that every farmer make not only a study of sources and relative values, but also a study of his own soil and crop conditions. Fertilizers show their greatest profit where the farmer practices thorough prepparation of land and careful tillage. Here it is, too, that they can be used in greatest quantities with most economical results.

\section{NITROGEN}

Nitrogen is the most costly element of plant food that we buy, and for this reason its production by means of home-made manures and legumes should be carefully considered.

Four-fifths of the atmosphere is made of nitrogen, but unfortunately this atmospheric nitrogen is in a form not available for plant use. There is a compensating influence, however, in the fact that nitrifying bacteria seek out the leguminous crops, and on their roots store up nitrogen in small tubercles, ready for use by the growing plant.

\section{SOURCES OF NITROGEN}

In commercial forms and factory-mixed ferti- 
lizers, we find several materials for supplying nitrogen:

Nitrate of Soda or Chili Salt-peter is a white solid which is mined in the rainless districts of South America, especially in Chili and Peru. When prepared for commercial use it contains from $15 \frac{1}{2}$ to 16 per cent of nitrogen or 320 pounds to the ton.

Nitrate of soda dissolves easily in water, and rapidly distributes itself through the soil where plant roots can make use of it. The plants take their nitrogen from the soil in the form of nitrate, regardless of the source of supply, hence this material is the most immediately available form of plant food found in commercial substances. When used in large quantities there is danger of loss because of the ease with which the material becomes soluble.

Sulphate of Ammonia:-This substance contains about 20 per cent of nitrogen or 400 pounds to the ton. While quite available it must be changed first into nitrate form before being used by plants.

Dried Blood:-Contains from 8 to 12 per cent of nitrogen and 7 to 14 per cent of phosphoric acid, and is the richest substance coming from animal products.

Tankage:-A by-product of the slaughtering house, contains from 4 to 8 per cent of nitrogen and 7 to 14 per cent of phosphoric acid. It slowly decomposes in the soil, but is a valuable material for cotton fertilizers.

Dried Fish Scrap:-This substance is a byproduct of the fish oil and canning factories. It contains both nitrogen and phosphorus, there 
being from 6 to 8 per cent of the former and 7 to 9 per cent of the latter.

Cotton Seed Meal:-Contains 7 per cent of nitrogen, or 140 pounds to the ton, and is the most important of the vegetable products used in commercial fertilizers. It decays very rapidly but lasts for a considerable length of time. It is much less quickly available than nitrate of soda or sulphate of ammonia, and more promptly available than tankage.

\section{PHOSPHORUS}

Experiments tend to show that phosphorus is the chief element demanded by most cotton soils. As is true of nitrogen, so phosphorus is necessary to the full and complete development of all parts of the plant, but its usual use is in fruit and seed production. Being a mineral substance, a deficient supply in the soil can be reinforced only through artificial means.

\section{SOURCES OF PHOSPHORUS}

Phosphatic Rock:-These are mined in North and South Carolina, Tennessee, Georgia, and Florida. They must be ground finely before being used, and even then are slow to decay. Best results are obtained by treating the ground rock with sulphuric acid to make the phosphoric acid available.

These materials make up the bulk of the phosphorus supply in cotton fertilizers. They contain from 12 to 16 per cent of available phosphoric acid.

Bone Fertilizers:-Bone was early used as a fertilizer and is still popular today. "Ground 
bone," "fine ground bone," "bone dust," "bone meal," "dissolved bone," are terms to indicate the mechanical treatment and physical condition of the fertilizer. Ground bone contains from 2 to 4 per cent of nitrogen, and 20 to 35 per cent of phosphorus; steamed bone from 1 to 2 per cent of nitrogen and 25 to 30 per cent of phosphorus; and dissolved bone 2 to 3 per cent of nitrogen and 12 to 14 per cent of available phosphorus.

\section{POTASSIUM}

Potassium, the last of the elements likely to be deficient in the land, seems to be less urgently in demand by the soils of the Cotton Belt than are nitrogen and phosphorus. Its best use is in connection with phosphorus.

The principal commercial materials that furnish this element are obtained from potash mines at Strassfurt, Germany. Potassium either in kainit or muriate of potash is rapidly soluble in water and equally available to the cotton plant.

Kainit:-This substance is the one most commonly used as a potassium carrier for cotton. It contains $12 \frac{1}{2}$ per cent of potassium or 250 pounds to the ton.

Muriate of Potash:-This is a purified substance of the potash mines, and is one of the richest materials supplying potassium. It contains fifty per cent of potassium or $\mathbf{1 0 0 0}$ pounds to the ton.

BUYING COMMERCIAL FERTILIZERS

Commercial fertilizers make up the bulk of our purchased cotton manures. They are sold under hundreds of names, but are valuable only in proportion to the amount of plant food they contain.

Of course, one should always be guided in 
buying factory mixed goods by the guaranteed analysis and not by any particular name or brand.

Nitrogen is usually about three times as costly as phosphorus and potassium. The prices of these elements vary from year to year, but in a general way one can place the commercial value of nitrogen at fifteen cents per pound and phosphorus and potassium at five cents per pound.

In computing relative values of different fertilizers you should bear in mind that 1 per cent means one pound in a hundred, or twenty pounds in a ton. It is also a good plan to base your estimate on the lowest percentage figure, since these more truly represent the true value; the higher ones are usually put there to deceive the purchaser.

To show the manner of estimating fertilizers, I will use two brands commonly sold on the market:

\section{No. 1. Guaranteed Analysis.}

Nitrogen 1.60 to 2 per cent.

Phosphoric acid 7 to 8 per cent.

Potash, 2 to 2.75 per cent.

Cost, $\$ 30.00$ per ton.

When these percentages are multiplied by 20 we obtain the number of pounds in a ton, and when further multiplied by the value per pound, we obtain the value on the basis of a ton.

This is shown below:

Nitrogen 1.60 by $20=32$ lbs. $@ 15$ c. $=\$ 4.80$

Phosphorus 7 by $20=140$ lbs. @ 5c. $=7.00$

Potassium 2 by $20=40$ lbs. @ 5c. $=2.00$

Commercial value per ton....... $\$ 13.80$ 
No. 2. Guaranteed Analysis.

Nitrogen 2 to 2.75 per cent.

Phosphoric Acid 9 to 11 per cent.

Potash 2 to 3 per cent.

Cost per ton, $\$ 28.00$.

Let us calculate its value as in the case of No. 1:

Nitrogen 2 by $20=40$ lbs. $@$, 15c. $=\$ 6.00$

Phosphorus 9 by $20=180$ lbs. @ 5 c. $=9.00$

Potassium 2 by $20=40$ lbs. @ 5c. $=2.00$

Commercial Value per ton....... $\overline{\$ 17.00}$

In purchasing commercial fertilizers your aim should be to obtain the largest amount of plant food at least cost. In the first fertilizer $\$ 13.80$ worth of plant food would cost you $\$ 30.00$ while in the second $\$ 17.00$ worth would cost you but $\$ 28.00$. The difference between commercial value and selling price is due to the cost of manufacture, profits, agent's commissions, etc. With the first this difference is $\$ 16.20$ while with the second it is but $\$ 12.00$, - a clear saving of $\$ 4.20$ per ton, and No. 2 superior to the other in every way, since you secure 8 pounds more of nitrogen and 40 more of phosphorus.

You will often find printed on fertilizer bags analyses as follows:

Ammonia 2 to $3 \frac{1}{2}$ per cent.

Available phosphoric acid 8 to 10 per cent.

Total phosphoric acid 11 to 14 per cent.

Actual potash 10 per cent.

Sulphate of potash 18 to 20 per cent.

This reduced to its true meaning should read as follows:

Nitrogen 1.65

Phosphorus 8

Potassium 10. 
In most States, however, it is now unlawfuland properly so-for the fertilizer manufacturer to use the "sliding scale" in his printed analysis; only guaranteed minimum figures are allowed.

Ammonia is used in fertilizers because it sounds as if a little more nitrogen was used, but values are estimated on basis of nitrogen content. Remember it is nitrogen you are after. Ammonia can be reduced to terms of nitrogen by multiplying by .824. In other words, one pound of ammonia equals .824 pound nitrogen. 


\section{CHAPTER XVII.}

FARM-MADE MANURES: SAVING FERTILITY FOR THE SOIL

There is an old saying that runs,

"No grass, no cattle,

No cattle, no manure,

No manure, no grass,"

which contains so much good sense in a few words that it should become a memory gem in every rural school in the land. And it is especially applicable to cotton growing, for cotton lands need manure even to a greater extent than grass does. Next to tillage and good seed, farm-made manures are the crying needs of the Cotton Belt. These manures will do these things for the soil:

(1) Add plant food

(2) Unlock stored-up quantities of plant food

(3) Increase the humus content

(4) Improve the mechanical condition of the land.

The importance of these factors in promoting the crop-producing efficiency of soils has been shown in previous chapters, and will be considered here only as they pertain to the production and use of farm-made manures, for we are concerned now with the use of additional plant food in potential and active forms. 


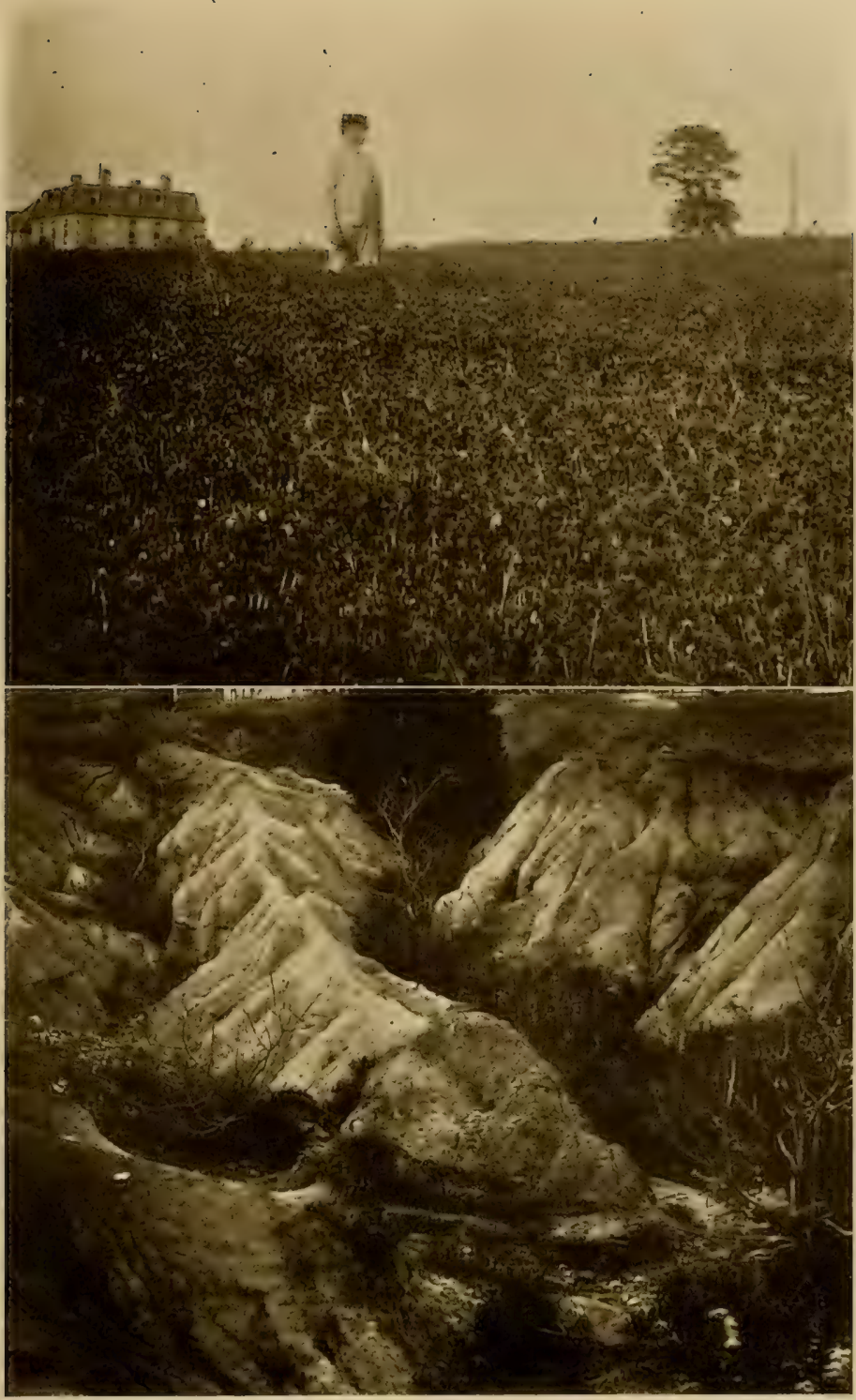

SOILS AND THEIR IMPROVEMENT:

A guilied old field at the bottom; at the top a field which has kept its virgin tertility through proper rotation and the growth of legumes. 


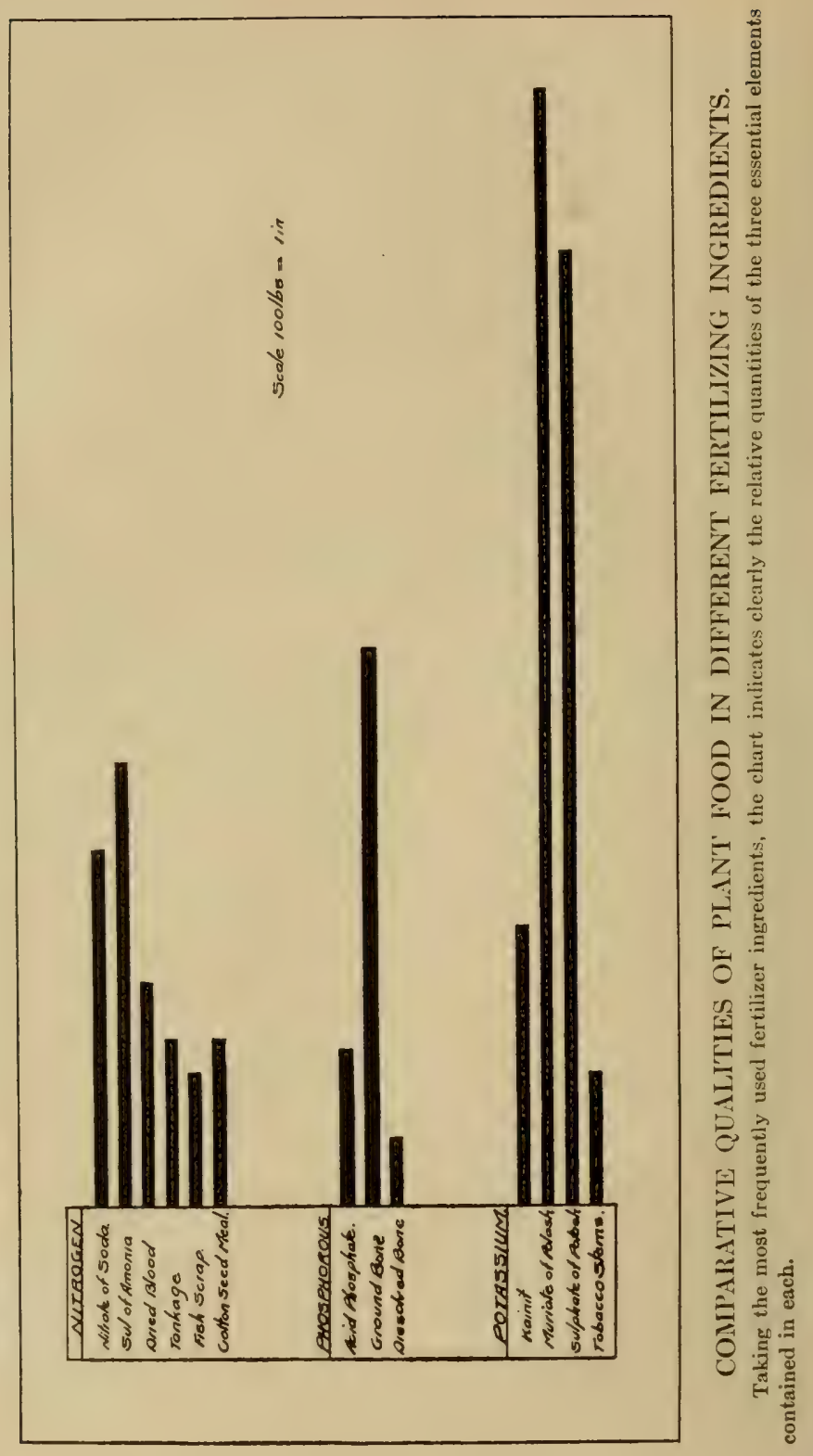


Naturally every farm produces some manure. But as the factory-farm is ordinarily run, only a small quantity is annually produced. Too little is made to meet the wants of the cotton farm. Something is wrong with the factory management, else more manure would be made.

Live-stock increases the efficiency of the factory. We will go further and say that live-stock combined with any system of farming will lead not only to permanent improvement of the land but to the highest efficiency in the management of the whole plant as well. This suggests much. It means diversification; it calls for a rotation of crops; it increases the animal stock on the farm; it demands greater skill in management; it means business farming. And with it all, it means manure.

What becomes of cotton seed now? You bury them in the soil for fertilizer, or you sell them; but how few cotton farmers feed them, and thereby get two profits - one from feeding and one from fertilizing! And by neglecting to save one of these profits the Southern farmer annually wastes enough for a King's ransom.

Plant food is always disorganized material. Decay must come before plants can feed. Animals on the other hand, can use only organized material. Hence, is it not better to feed cotton seed or their equivalent in meal, and get the feeding value out of them? After this they may be returned to the soil in the form of manures. By this practice nothing is lost and much is gained. We like to buy fertilizers in the form of feeding stuffs, pass them to the cattle, and from them back to the soil. 
They provide a double value for us, and it is only business to take it.

The cotton farm should be open to live-stock, then, and the seed or meal produced on the farm should be consumed there by animals raised on the farm. At present the Cotton Belt sends cotton seed meal to all parts of the world, which is just another way of saying it ships away plant food or Cotton Belt soil to all parts of the world. Such a practice leads to soil depletion. It may be followed for a great many years without bringing its full penalty on the heads of those who practice it, but in the end it means death and destruction to the land.

\section{YOU CAN MAKE FARM MANURES}

You are making some home-made manures, but are you doing your best in this respect? What are your teams doing during the winter months? To be sure, most of them are idle. But they need no rest. Keep them going the whole winter long, some here, some there, gathering vegetable matter wherever it is to be found. Haul this in and pile it deep under horse and cow, and keep up the work. It is the medicine the cotton soil needs. No tonic will produce a change so quickly; no prescription will so rapidly vitalize and build up the soil system.

\section{THE COMPOST PILE}

You can make a compost pile, if you like. Thousands of farmers believe in it. Thousands do not. It is one of the knotty questions on the farm. Perhaps there are two sides to the question; 
at least we are willing to admit that there are. Still we prefer a direct application to the field.

When you consider the labor necessary for extra hauling and mixing, it is considerable after all. How much better it is to use that labor in the woods, getting and hauling other quantities of leaves and pine straw for the various pens, stalls and yards at the barn.

We prefer to haul manure direct to the field and have it mixed in the soil, so its decay can take place there, because as a result of chemical action it will rot the soil as it rots itself.

\section{SAVE THE MANURE}

The American farmer has not yet become skilled in saving manure. He is rather wasteful in most things and especially so with farm manure. Liquid from the stable and yards runs away, because of too little bedding material, is leached away in the rain, and is lost never to be recovered. Again, stables are cleaned, manure is dumped out of window or door, exposed to sun and rain, and gradually burned up or washed into the stream.

Do you believe this? Your own observation will be proof enough.

The remedy lies in but one direction: Save homemade manures and make more the following year. If you have no covered barnyard or other covered place to keep it, haul direct to the fields.

This offers many advantages:

It enables you to keep the stables clean.

You can do the hauling in the winter when men and teams have little else to do.

The soil itself is benefited by the decay of manures and is inclined to make active its insoluble plant food. 
Where this method is practiced, it combines easily with winter or cover crops like clover or rye, and as plant food is released it is stored in stem, root, and leaf of the growing plant, thus leaving a wealth of plant food and humus in the soil for other crops that come later.

\section{GREEN MANURES}

A green crop plowed under offers another quick way of improving the productive power of the soil.

For this work you can use clover, rye, or cowpeas. Clover and cowpeas are preferred, since they add humus abundantly, and at the same time gather atmospheric nitrogen and store it in the soil. 


\section{CHAPTER XVIII.}

HOME-MIXING OF COTTON FERTILIZERS: SAVING THE MANUFACTURER'S PROFIT

Home-mixing of fertilizers deserves much more attention than it receives. The fact that standard brands may cost from five to fifteen dollars a ton more than the commercial value of the several ingredients of plant food; the fact that fertilizing materials are standard articles of trade and may be purchased as such; and the fact that the many manufactured brands are only composed of materials such as the farmer may purchase himself, all suggest the wisdom of farm-mixing rather than factorymixing.

The claim has been constantly advanced, but principally by agents of factory-mixed goods, that home-mixing is not advisable and that the work here cannot be done properly. This claim is altogether untrue, so far as the principle of homemixing goes. That some fertilizing materials have been mixed hastily and poorly on some farms, we have no doubt: but so has plowing on some farms been poorly done; so have seeds been improperly selected; and so has culture of the growing crop often been neglected, or the wrong principles followed. But shall we abandon tillage and seed selection because someone else is thoughtless or because hefails? Rather, if the principle is cor- 
rect, if the practice has proved reasonably successful and if it is a money-saving method for the farmer, it should not only be considered carefully, but put into operation as quickly as means may be found.

The first step in home-mixing is the selection of the materials to be used. Then these must be brought together, mixed and bagged. Now you can do this work, receive big wages for your labor, and save money besides. Often many farmers join together and make their purchases. A better rate is usually obtained, as the cost for freight is less for a large lot shipped at one time than if several lots are separately billed.

\section{WHEN AND HOW TO MIX}

The winter season is usually the best time for mixing fertilizers, since it enables you to get your materials together and do the work when labor is available and before you get into the rush and hurry of the plowing and planting season.

This time is suggested, not because of the great amount of labor involved, or time required, but because it may then be done well without haste or carelessness.

To the fertilizing phase of cotton growing you should indeed give the same consideration, in reference to all details, as you give to seed, or labor, or soil preparation. Hence you should take it up, study it carefully, and be ready when the time for action comes.

An excellent place to do this fertilizer mixing is a tight barn floor. There are times in winter when this can be given over a few days to this work without greatly interfering with feeding or any of the other uses of the barn. You will, however, 
find the wagon box as suitable, and many people prefer it.

In mixing, spread the materials over the floor to the depth of five to ten inches, putting the bulkiest fertilizer first; on top of this, spread layers of the remaining materials; and then mix thoroughly, shoveling over several times. When a great many tons are to be mixed this operation will need to be repeated often and the material bagged as mixed. In case you find any unmixed material has become hard and lumpy in the sacks, first put it in a separate pile and break up finely with a maul or shovel. This done, it is ready for the mixing pile to be handled as described above.

\section{WHAT KINDS TO USE}

You will, of course, decide what materials you wish to use, and in doing this you should be governed by the commercial value rather than by the name. The State Experiment Station will assist you in suggesting a formula to use and the materials to buy.

Here are a few general suggestions it is well to bear in mind in doing the work:

1. Nitrate of soda is immediately available when mixed with the soil. Therefore it should furnish no more than one-third or one-half of the nitrogenous part of the fertilizer.

2. Sulphate of ammonia is open to the same objection as nitrate of soda, but to a smaller degree.

3. Cottonseed meal decays slowly, and at the price for which it can be bought at present, may be used with economy as a nitrogen carrier. 
4. Acid phosphate is usually our most economical carrier of phosphorus.

5. Muriate of potash is an economical carrier of potassium.

6. Kainit, which contains only one-fourth of the quantity of potassium found in muriate, is usually preferred in cotton manures because it is believed to be beneficial in warding off rust.

7. Nitrogen is especially concerned with the growth of leaves and stems. If your cotton leaves and stems have been small, therefore, and the nitrogen supply in the soil has not been increased by the growth of some leguminous crop, it would be well to increase the nitrogen content of the formula you select. On the other hand with marked growth of leaf and stem, the quantity of nitrogen in any formula may be decreased or altogether abandoned.

8. When cotton follows clover, cowpeas, or other legumes, little or no nitrogen will be required in the fertilizer.

9. When stem and leaf growth are abundant, but yield of seed and lint below what it should be, phosphorus and potassium-especially the former -are needed.

10. In a general way, on average cotton soils the best results are obtained when nitrogen, phosphorus, and potassium are combined in the proportion of about three or three and one half parts phosphorus, one part nitrogen and one part potassium-unless the nitrogen be already supplied by leguminous crops.

THE FORMULA TO USE

It is impossible to suggest a formula, or even 
many formulae, that will meet all conditions of soil and culture. You must work out this problem by personal investigation and experiment if you desire to solve it with any degree of satisfaction. Formulae should differ with different seasons, different soils, different farms. Only the general average can be considered here.

\section{COMPOST MANURES}

No. 1. Green Cotton Seed..... 100 bushels Stable Manure....... 100 bushels Acid Phosphate...... 2000 pounds

No. 2. Barnyard Manure..... 1750 pounds Acid Phosphate....... 200 pounds Kainit............ 50 pounds

2000 pounds

No.3. Barnyard Manure..... 1225 pounds Cotton Seed......... 400 pounds Acid phosphate....... 300 pounds Kainit............ 75 pounds

2000 pounds

HOME-MADE CHEMTCAL MANURES

No. 1. Acid phosphate....... 1100 pounds Cotton Seed Meal..... 700 pounds Kainit............ 200 pounds

Total.......... 2000 pounds 
No.2. Acid Phosphate....... 1000 pounds Cotton Seed Meal...... 600 pounds Nitrate of Soda........ 100 pounds Kainit............ 500 pounds Total........... 2000 pounds

No.3. Acid Phosphate....... 850 pounds Fish Scrap............ 700 pounds Kainit............ 450 pounds

Total.......... 2000 pounds

The quantity of fertilizer to use per acre will depend upon the following conditions:

Producing power of the land

Preparation that has been given the land

Kind of crop grown the previous year

Richness of fertilizer

Previous treatment of the soil

Kind of season.

By your own judgment you will have to determine the quantity to use per acre. Learn your soil by careful observation, study and experimentation year after year. All the way from 200 to 1000 pounds of fertilizer are now used per acre. What is best for your soil and conditions lies doubtless within these limits.

Try the following plan of questioning your own land, and the answers will be far more valuable to you than any foreign advice:

Choose a small area that is reasonably typical of 
your land, and which will contain ten rows of any length desired.

On rows 1 and 2 , use 200 pounds per acre.

On rows 3 and 4, use 400 pounds per acre.

On rows 5 and 6 , use 600 pounds per acre.

On rows 7 and 8 , use 800 pounds per acre.

On rows 9 and 10, use 1000 pounds per acre.

In cultivating, treat all soils alike and give each the same treatment as you give the remainder of the field. Carefully observe the plots during the growing season and at picking time estimate yields. The results cannot fail to be helpful in deciding what kinds of plant food your land needs and in what quantities each element is needed.

\section{WHAT WE MUST DO}

So much is involved in fertilizing land that each of us will have to study his individual problems year in and year out, that help may come to each of us in knowing how to manage lands and how to maintain their fertility, wisely and judiciously.

That we may have a few general principles to guide us along our immediate course, the following general suggestions are offered:

1. Judicious fertilization increases the profitableness of cotton farming.

2. Fertilizers wisely used hasten the maturity of the crop.

3. Fertilizers pay best on land in good mechanical condition.

4. Fertilizers respond best for cotton when used in connection with leguminous crops.

5. A complete fertilizer pays best on old lands. Where legumes are used or stable manure, the nitrogen content may be decreased or omitted entirely. 
6. When fertilizers are used in small quantities, apply in the drill and mix well with the soil. When 500 to 1000 pounds are used, apply broadcast or make two applications.

7. Home-mixing of fertilizers is the wisest practice to follow.

8. Adjust the quantities of nitrogen, phosphorus and potassium as the soil calls for change due to better tillage or as increased quantities of humus and organic matter are added to the soil.

9. Broadcast barnyard manure on winter-growing crops or compost with cottonseed, acid phosphate, and kainit.

10. Experiment with your own soil and forget not its teachings. This will help you with every crop that follows. 

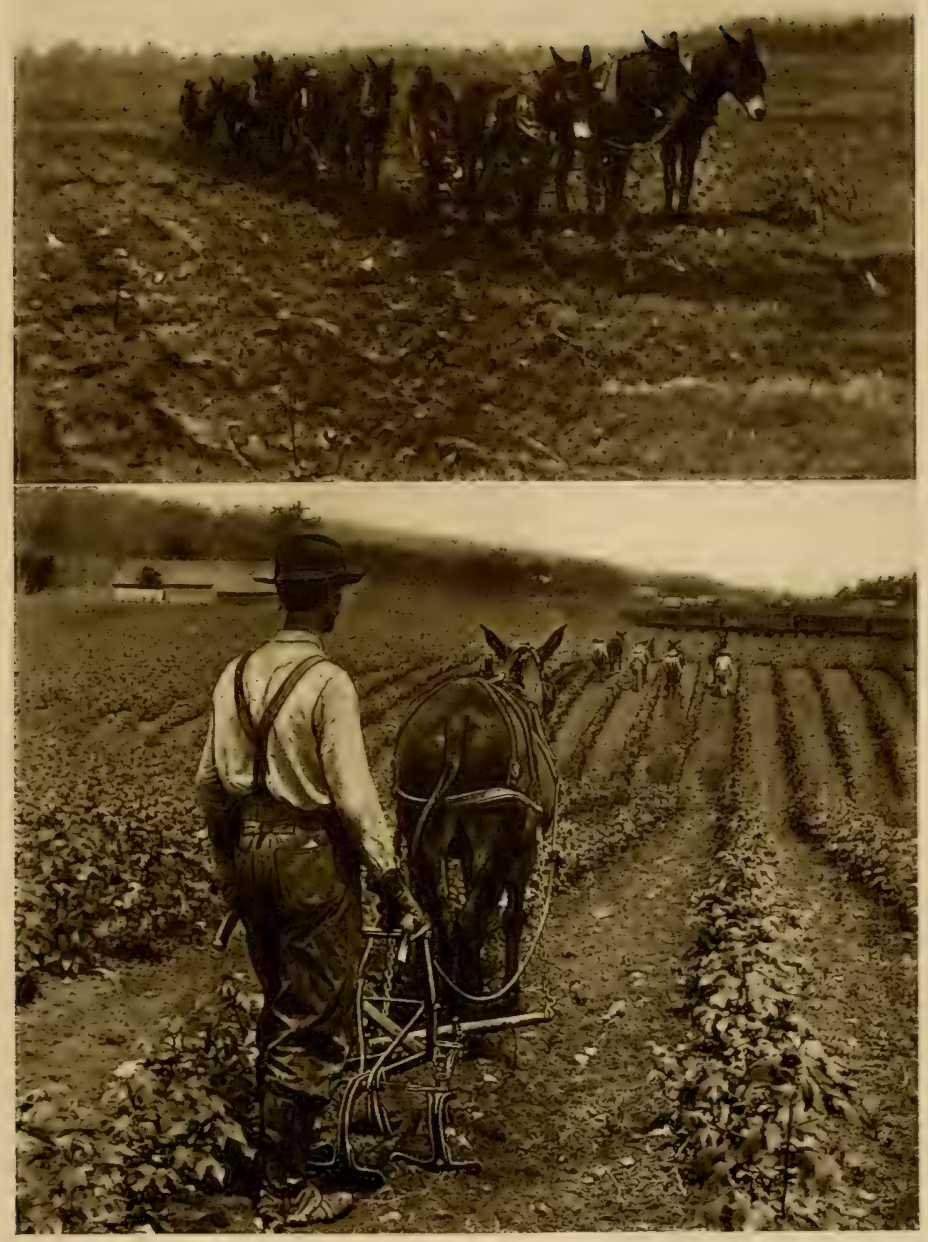

MODERN COTTON MAKING.

Breaking the land with three-horse plows, and shallow and level cultivation of a growing crop. 


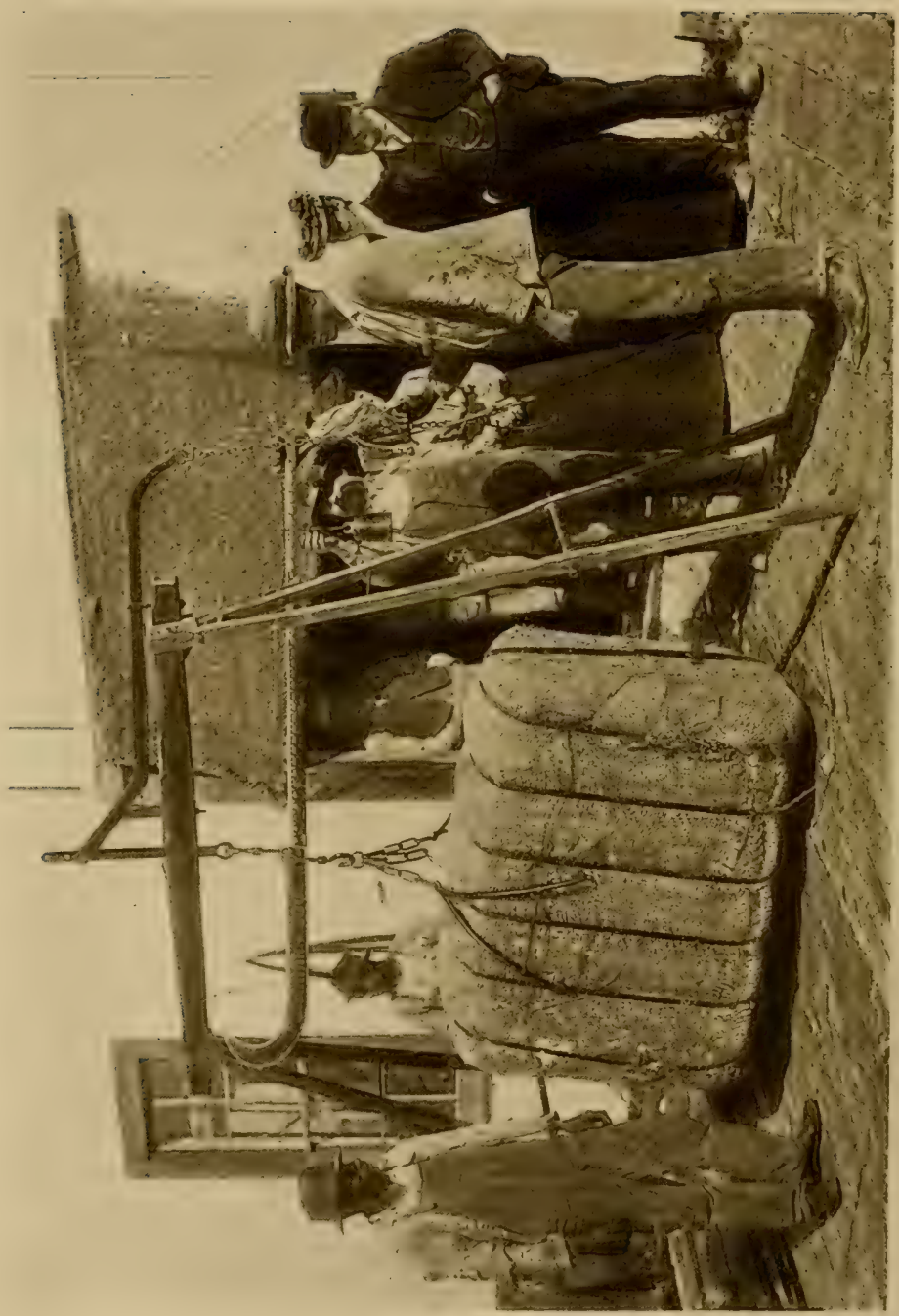

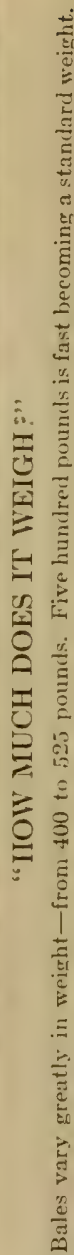




\section{CHAPTER XIX.}

THE COTTON FARMER'S EQUIPMENT OF TOOLS

It is doubtful if any factor has contributed more to the advancement and progress of American agriculture than the improvement of farm implements and machinery. When one contemplates the enormous yields of American corn, wheat, cotton, oats, potatoes and other crops, he is struck with wonder and amazement. What a record our farmers have made! But have you thought of the debt we owe to inventors and to makers of tools and implements, without which these tremendous yields would be impossible?

Unfortunately for him, the cotton farmer has not had such advantages as his brother farmers in the use of labor-saving machines and tools. On far too many farms their use is limited indeed, and often we find only the one-horse plow and the hoe. Cotton farming can never be profitable where this is true. The use of inefficient tools also means an economic policy at variance with the advancement and progress of civilization, since it restricts the possibilities of land and labor, and decreases their potential contribution to the human race.

But where these old fashioned methods exist, they are now fast giving way to improvements, making the culture of cotton less laborious, less costly, and 
the field at the same time more productive, thereby making cotton growing far more remunerative.

Cotton farming calls for the same variety of labor-saving tools and devices as does the production of any other kind of crop. As a rule, the principal difference in the equipment of large and small farms is in number of tools, rather than in kind, size, or efficiency.

For the information of the reader unacquainted with terms commonly used in the Cotton Belt, let us say that "one-horse farm" or "one-horse farmer" is not meant to express derision of the individual, nor does it refer to social standing. The term means, on the other hand, just what it says: a one-horse farm on which all labor is done by a single animal. The owner may be a one-horse farmer, and at the same time stand high in the community, and have a good store of worldly goods. But the value in land and equipment of a ten-horse farm in cotton production is just ten times that of a one-horse farm.

And of what does this equipment consist? Land, feed, stock, tools, implements, etc. Since the one-horse plow is the important implement of the one-horse farm, and since it is so commonly used on both small farms and large plantations, it may be called the typical tool of the Cotton Belt. To be sure, two-horse and even three-horse plows are used; the sub-soil plow occasionally has work to do; the disk harrow, the roller, the cultivator, are now generally known, but the "Dixie" plow is the one tool that in a measure does the work of all these and which finds employment on every farm, regardless of its size or the wealth or standing of its owner. It serves as soil-breaker, soil-pulverizer and cultivator for weed destruction and winter 
plowing, and is known in all States and sections where cotton is grown.

In spite of the popular favor in which this tool is held, it neither merits it, nor is its use in keeping with the progress now manifestalong other lines of cotton culture.

\section{THE KIND OF PLOW WE WANT}

In the first place, the effective plow must so throw the slice ripped from the furrow as to cover all manure, trash or green crops on the land. Todo this it must turn the slice entirely over or set it well on edge. If it does either of these things for you the first aim is achieved.

In the second place, the plow should go deep into the ground. This must be done for two reasons: First, deep plowing enables the soil to drink in and hold more water against a day of drought; second, deep plowing gives cotton roots a wider pasture.

In the third place, the effective plow must pulverize the slice it throws out. It is not enough that your plow turn the soil; it must break, fine and mellow it.

A plow that does not do these things is a poor plow. Measure your one-horse plows by this standard and you readily see why the greater number of them should be thrown with your pile of scrap iron, and from there carried to the junk shop to be melted and remade into larger and more effective tools.

The one-horse plow is sometimes defended on the ground of economy. Really, however, it is not an economical plow. The two-horse walking plow will not only prepare cotton lands better, but will 
do as much work as two one-horse plows and thereby save you the labor of one man.

Where money is scarce or where labor is also scarce or insufficient, it is always economy to use the best tools on the market. The two-horse walking plow or the two-horse sulky plow ought soon to find a place on even the smallest farms. The disk plow has already been used on some cotton farms. It pulverizes well, and covers in an effective manner, and goes deep into the soil. It is not practicable, however, for use in stony lands.

TOOLS FOR COMPLETING THE SEED BED

The harrow follows the plow. Commonly this tool is used in connection with the roller to complete that pulverization of the soil which has been begun by the plow. And this is necessary. You have observed that the cloddy spots, even in fertile fields, make a poor harvest. In these places bad mechanical condition of the soil forbids it holding moisture, hardens up plant food, and so brings about lack of fruitfulness. The harrow and the roller will correct this trouble. A single kind of harrow will not do for all soils nor for all seasons of the year.

A fine peg-tooth smoothing harrow should find a place on every cotton farm. It levels the land and disintegrates the larger particles of the soil. You may use it also to advantage in harrowing cotton after planting.

The spring-tooth harrow you should have also. It comes in nicely where you have leveling and smoothing to do, or where a heavy rain has compacted the surface too much just before planting time. 
In addition to these you should have either a disk or cutaway harrow, for crushing and for completing the pulverization begun by the plow.

Where clods are left on top of the soil, the wooden drag or roller will be the next implement to use. The wooden drag grinds the clods and lumps, and is also a good implement for leveling purposes.

The fertilizer distributor is another economical tool, doing its work evenly and satisfactorily.

Following the fertilizer distributor comes the cotton planter, and drops the seed in a continuous chain. While our planter as now used serves its purpose, it is far from being ideal. It must do better work. It is not enough to drop the seed; it must drop the right quantity and in the place where wanted. When this end is achieved, seed will be tested for vitality and germinating power, and the planter regulated for dropping seeds to suit the requirements of each particular soil.

This will largely do away with "chopping," now a laborious and costly burden to the cotton farmer.

The cultivating tools required in cotton culture serve three purposes: they kill weeds, provide a mulch so as to conserve the moisture in the soil, and release plant food.

The old one-shovel plow is fast giving a way to the shallow cultivator with several shovels.

And the one-horse plow-do you use it for cultivating purposes? Up and down the row it goes, breaking roots, increasing labor bills, lessening profits. Let us again express the hope that improved cultivating tools will soon replace it throughout the South.

For the early work of cultivating young cotton plants, perhaps no implement is more useful than 
the weeder. It runs shallow; its many teeth destroy or cover all weeds; it thins the cotton; its complete soil-stirring makes a fairly effective mulch. You can use the weeder two or three times in cultivating the cotton crop, and if you do not have it, then use the smoothing harrow.

We have many kinds of cultivators: some single, others double; some are shallow-goers while others creep along the surface slightly deeper. All of our improved cultivators are good. Do not hesitate in securing such as are needed, for they will quickly repay their cost in increased returns.

And finally, the hoe: is it needed?

Once it was thought that every gentleman needed a sword, then a pistol. We may have use even today for the pistol and sword, but not for every-day clothes. So we have use for the hoe in cotton culture, but not until after the weeder and fine-tooth harrow have done their work. In some fields, some seasons, the hoe may be needed until the perfect planter comes; until cultural methods are more studied; then the hoe may go, with knighthood and chivalry, and be one of the things of memory. 


\section{CHAPTER XX.}

CULTURE FROM SEED TO BOLL

In the romance of cotton the climax is reached in that scene which has to do with its culture. All that has come before is concerned with stage settings properly to introduce the chief actor, and what follows in the disposition of the crop is but the natural conclusion expected before the final curtain falls. In this growing scene the seeds awake from their sleep in the soil, the tiny twoleaved plants peep through their surface screen and come forth into sunlight and growth, now to engage the attention of a vast army of men and women through long months of watchfulness and care.

\section{THE BED IS MADE}

Sometime before planting time the land is "bedded up" as a final preparation for the seed. This custom seems to be almost an universal practice, wherever cotton is grown. While it involves extra time and labor, its warming influence on the soil, especially in cool or wet weather, is sufficiently helpful to modify any objection to the practice.

The plan of bedding up is this: the row is opened and in it the manure is placed (or if a fertilizer drill is used, the work is done by a single operation); then the plow is run back and forth, 
heaping the top soil to the center, which leaves the row two to three inches higher than the soil on either side of and between the rows.

In bedding up many people who grow cotton wisely include simple tillage operations as well. It is not enough to make the bed only; the entire surface of the soil must be plowed and then harrowed and re-harrowed until the idealseed bed is obtained. Only when this is done are you ready for bedding up the land. A week, perhaps a longer time, now passes before seeds are planted. But what of weeds and grass? Now don't deceive yourself, for they are the ever present enemy of cotton, and unless you wage war early and fiercely, your cotton crop will be sorely troubled, if not permanently injured. Your best weapon for some time on will be a light, fine-tooth harrow or weeder. This will not only destroy millions of weeds and grass seed that are germinating and fast gaining foothold at the surface of the soil, but will prove the very tool needed for conserving the moisture in the land. Team labor expended at this time of the year is hand labor saved later on in the season.

\section{DISTANCE BETWEEN ROWS AND PLANTS}

You already know that rich lands require less seed and a fewer number of plants than do thin and infertile soils. Why? Because fertile soils naturally produce heavier and larger cotton stalks, which naturally call for fewer plants to the acre, and greater distance between them in the row.

Four feet is the usually accepted distance between rows, although on the lighter kinds of 
soil three or three and a half feet are popular distances.

The distance between plants in the same row may be safely placed at twenty to twenty-four inches for good soils, and twelve to sixteen inches for poor ones. Where either the variety or the soil tends to make larger cotton stalks, thus requiring more space, rows may be widened to five feet and the row space extended to from twenty-four to thirty inches.

\section{WHEN TO PLANT}

Nearly three months are included in the planting limit for the Cotton Belt. Each section has its own extremes. These are influenced by conditions of soil and climate, and consequently vary materially. The table below suggests the commencement of planting time:

Southern Texas,............March 1

Eastern Texas, ............March 15

Louisiana, ..............March 15

Southern Mississippi,........ March 20

South Carolina Coast, ........ March 25

Mississippi Bottoms, ......... April 1

Middle Texas, ............April 1

Arkansas, ..............April 5

North Carolina, ............April 20

South Carolina, ............April 20

Georgia,............... April 20

These dates suggest when planting may commence, but represent one extreme. The limited variation of every section is sufficient properly to plant the crop. When the ground becomes warm enough to favor germination, and is properly prepared, you may begin your seeding. Earlier 
than this, while the ground is cool, or before the season has advanced far enough for the cotton plant to bask in its loved sunshine, the crop will make little progress, even if germination itself is not seriously hindered by the low temperature. Some good farmers prefer to fertilize rather heavily, delay planting, and wait for decidedly warm weather, so as to rush the crop ahead of grass and weeds. If for this or any other reason you should postpone seeding until toward the end of the planting season, however, it will be safer to plant seed somewhat deeper, and if weather is dry, you should roll the land as well.

Early maturity of the crop does not depend so much upon time of planting as it does on the early-maturing qualities of the variety. Even with late planting, if you have proper fertilization and good preparation of soil, you will secure better results than where the opposite conditions have prevailed.

\section{PUTTING FERTILIZERS INTO THE SOIL}

When two or three hundred pounds of fertilizers are used, seed may be planted without mixing the fertilizer with the soil. Where more than this amount is used, it seems desirable to apply it in the bed or mix it with the soil by means of the scooter plow.

Heavy applications justify a different procedure. If placed in the center furrow, the fertilizer should be incorporated thoroughly with the land. Experiments seem to indicate that where as much as a thousand pounds are applied, it is preferable to side list or broadcast at least one-half of the quan tity, 
using the remaining half in the center furrow. Double doses of fertilizers pay only where considerable quantities are used. For the dose as usually given, a single application is sufficient and this is best applied in the bedding-up process.

\section{THE FIRST CULTIVATION}

A few months ago we visited a cotton plantation which had received considerable local mention because of its excellence. About one hundred acres of the plantation were devoted to cotton, and at the time of our visit the crop indicated a yield of nearly two bales to the acre.

"When did you begin the culture of this cotton?" we asked the owner.

"Well, sir, I began to cultivate that cotton before it was planted," he quickly replied.

"The crop is certainly a fine one," some one remarked, " and not only that, but I see it is grown on very ordinary land. How do you account for the better appearance of your cotton as compared with all these other fields around here?"

"Simply by good tillage (for I never use a onehorse plow); by making use of all vegetable matter I can find in the woods and on the farm; by careful selection of seed; and by careful cultivation throughout the whole growing season, and especially before the crop is planted."

The excellence of the crop truly was manifest. We have heard since that this good farmer had produced even more than his estimate that day - -he made a total crop of two hundred and twenty-four bales.

His philosophy is in keeping with the facts suggested by the study and research of our cotton 
investigators. $\mathrm{He}$ is successful, of course. $\mathrm{He}$ follows modern methods, and reads about and studies his business.

\section{AT CHOPPING TIME}

The imperfect method of planting cotton makes work with the hoe necessary in order to secure a proper stand and correct the excessively large number of plants to the acre. The present-day planter drops seed in a continuous chain, using from ten to fifteen times as many seeds as are needed. To get rid of these extra plants and so to thin them in the row that the desired number only shall be left, calls for the practice of "chopping."

As young cotton plants slowly come out of their beds in the ground and raise their little bodies into air and sunlight, the laborer comes into the field "to chop" the cotton and arrange it in an orderly manner for the growing campaign now before it.

As a rule now, all planters chop their cotton, but when a more perfect planter comes this will not be so necessary. A few good farmers, even now are depending less on the hoe and more on the weeder and harrow for this work. Either one or both of these tools when run a couple of times crosswise across the rows do rather effective work in thinning the crop; and at the same time the practice warms the soil, mellows the surface, destroys weeds and grass, and puts the land into good physical condition for the growing crop.

The first step in cotton culture then is this early work with the weeder, or peg-tooth harrow. It is, in fact, the most important ever made, surpassing in value all subsequent workings. 


\section{OTHER STEPS IN COTTON CULTURE}

While cotton moves slowly during its early stages of growth, when it once takes root firmlyand it always means business if the soil is right and warm and moist-its roots go eagerly into the ground, searching in all directions for plant food and water. While the roots are thus foraging around, growing, spreading, and lengthening, the plant above the ground is not standing still. We grant that at times, especially when the land is not congenial because of poor preparation, coldness, or much rain, cotton plants seemingly hesitate, or at least move but slowly in their upward course. And yet can you blame them? Do you wonder they move so slowly,--tender and weak as they are with dangers all about them? Opposed to cold by nature, they suffer. Then, too, greedy weeds and grass continually menace and threaten them throughout the entire season; so unless you care for them while young and tender, and even stay closely by, they lose courage and fail to meet your expectations at harvest time.

When plants are about three or four inches in height, the cultivating plow may be started. The hoe may now be laid aside, and the cultivator pressed into service to do what work is left until the maturity of the crop.

You will act wisely if you get good tools for cultivating. The modern cultivator with its many shovels does the work well, and cheaply.

But the plow-the one-horse plow-is not the tool for the cultivating season; better leave it under the apple tree or in the stable for the chickens to roost upon than bring it into the cotton field; for it is not a cultivating tool for cotton or for any 
other crop where inter-culture is necessary. One objection to the one-horse plow is that it runs down into the soil where the feeding roots are, and there it does positive harm, for it injures some roots, ruins a great number of others, and consequently lessens the feeding ability of the plant.

But that other phase: that important question of labor! Have you thought how expensive the onehorse plow is as a cultivating tool? A man and a horse! Up and down the row, once, twice, three times, and even four times, to do work which might be done-and done well-in half the time and with half the labor if a really good cultivating tool were employed.

\section{HOW DEEP SHALL WE CULTIVATE?}

The point in this: Roots serve as supports for the plant and hold it in the soil; they get the moisture and food for its growth. All are needed for work. In the life of the plant the surface-feeders have their work to do, work of just as great importance as that done by those which creep down into lower depths, where harm is further removed.

But suppose you cultivate deeply, as is the common practice. What then? Just what we have already said - the roots are torn away and the feeding ability of the plant is lessened and permanently injured.

It follows then that cultivation should be shal. low. One inch or two, just deep enough to do good work, is what we want. If you think you must cultivate more deeply than this, let the work be done in the season while the plants are still young and before their roots have extended out in all directions. 


\section{WHERE YOU FIND THE LATERAL ROOTS}

An examination of cotton roots as they grow in the field will indicate many things helpful during the cultural season, and show how essential it is not to go deep into the soil with the cultivator. The growing habits of cotton roots have been given a good deal of study, and this knowledge ought to be used to advantage in the culture of the crop. In South Carolina, for instance, "it has been observed that most of the lateral roots commenced about three inches below the surface, and never went below the upper nine inches of soil." At the Alabama Station similar observations were made. "In a soil of sandy drift and pebbles" a young cotton plant three and one-fourth inches high was found having a lateral root over three feet in length, the end of the root being only three inches from the surface. The position of the roots suggested to this experimenter that "the usual deep cultivation would have destroyed four-fifths of the lateral roots which extended at right angles to the row."

Many experiments made in respect to inter-culture make out a strong case as to the superiority of shallow over deep cultivation. These tests extend over a period of several years, and have to do with conditions in several States. Only two instances are on record in which shallow culture failed to afford a larger yield than deep culture.

\section{HOW OFTEN TO CULTIVATE}

Early culture, if well done, plays havoc with grass and weeds. And since to rid land of these is the first of the reasons why we cultivate, it follows that if they are kept in check early in the season, 
less effort and labor later on will be required to complete the work. Then culture is given also to break the surface crusi that forms after each rain, so as to conserve moisture and blanket the ground with a mulch of fine dry soil. If rains come often, we need to cultivate often; if weeds and grass persist in presenting themselves, then we must keep the cultivator going, in order to disappoint them and prove ourselves masters of the situation. Then too, if dry weather becomes the rule, the cultivator must be kept at work so as to hold the water in the soil as far as possible for growing plants.

The best tool for this purpose, as has already been suggested, is a light cultivator with several shovels. If you will use this tool once every week or ten days, going once or twice in every row, you will have little difficulty in keeping cotton free from weeds and grass and in providing suitable cultivation for these other purposes.

\section{TOPPING THE PLANTS}

A practice more widely followed in former years than now is "topping cotton." This operation consists in the removal of a few inches of the extreme top of the cotton stalk late in summer. The idea is to check the growth of the leafy upper part of the plant, and thereby favor the fuller development of the bolls already formed.

Tests as to the advantages of topping have been made at a number of places, including several at our Experiment Stations, but fail to indicate any benefit from the practice; in fact, some of these tests have been quite unfavorable to it. In the face of these results and in view of the labor required, 
topping is evidently unwise and makes an unjustifiable increase in the cost of growing the crop.

\section{THE LAST CULTIVATION}

The art of cultivation becomes very gentle and delicate toward the end of the growing season. Many men have caught the spirit of cultivating work for the early stages, but few indeed for the last.

This last cultivation is but the final touch of the brush to complete the picture. The top crust only is to be broken; the few straggling weeds that have heretofore escaped are to be caught, and then the work is done.

No breaking of roots, no ripping open of soil, no hilling of land, is needed in this gentle, delicate and final cultivation. Rather, every leaf, and root, and every favorable soil influence, must be directed to help the plant in the tremendous effort it is making to fructify.

\section{CULTURE IS POWER TO HELP}

Finally, it may be said that the work of culture is to furnish assistance to the plant that it may the better do its work.

The soil is stiff and hard, so we must open it that roots may enter; plant food is slight, so we must provide additional quantities; land is poor in texture, meaning a poorer water supply, so we must add humus to the land; weeds are hardy, vigorous and greedy feeders on water and food, also infringing on the rights of the plant, so we must get rid of them; the soil favors capillarity, losing its moisture in dry weather, so we must cultivate fully 


\section{4}

\section{COTTON}

that it may be blanketed in,-all these we do to help the plant in its struggle and its journey toward maturity. 


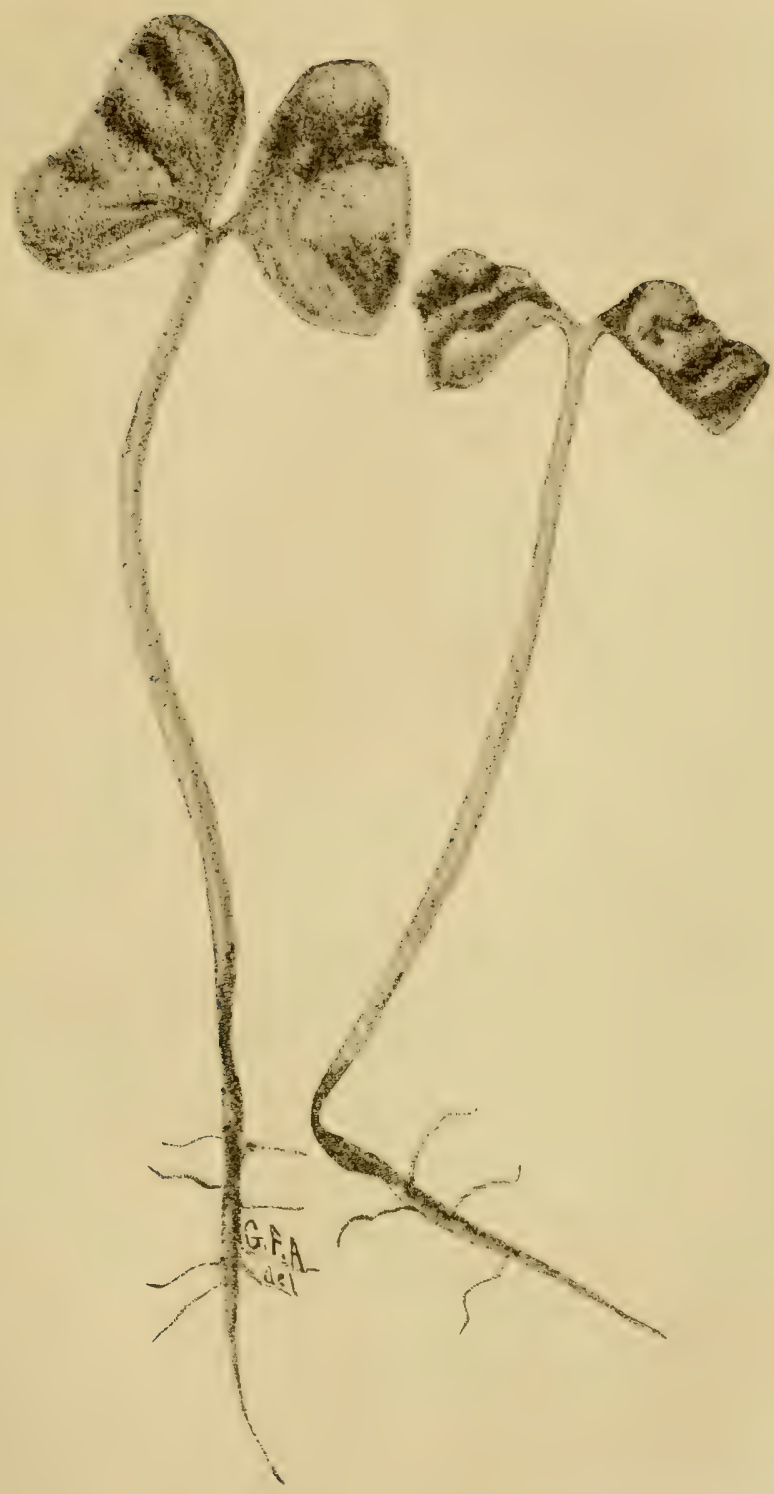

YOUNG PLANTS JUST AFTER GERMINATION 


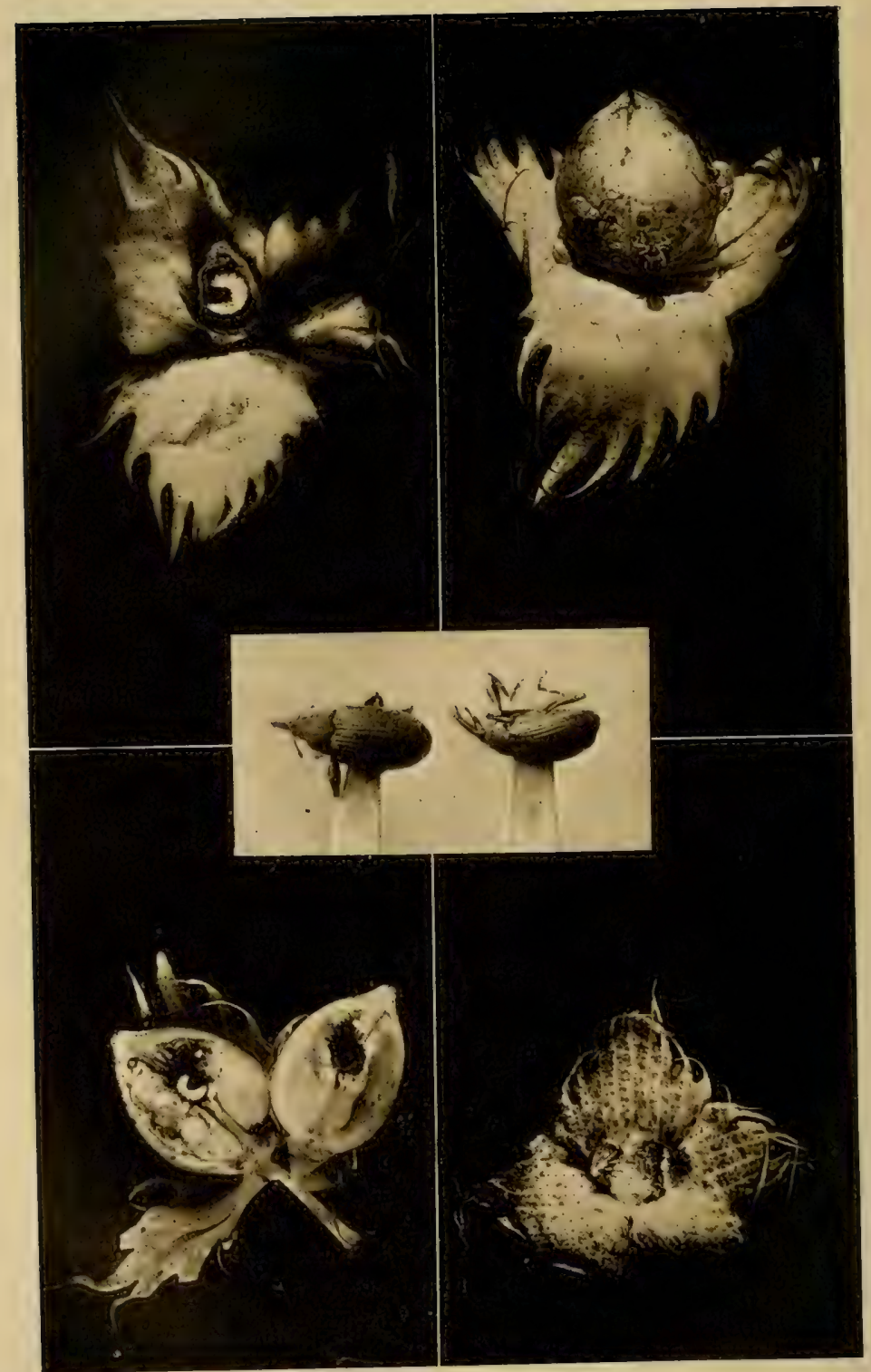

AS DESTRLCTIVE AS AN INVADING ARMY.

The pictures show the boll weevil and bolls blighted by its attacks. The cotton lost any year as a result of its ravages would be enough for a king's ransom. 


\section{CHAPTER XXI.}

THE ILLS THAT COTTON IS HEIR TO

From our general knowledge of diseases it seems not unnatural that any plant grown to any extent on the same areas year after year, subject to the same treatment, living under the same environments, should in time be attacked by diseases peculiar to itself. Doubtless many of our common plant diseases have been present for considerable periods of time, but have been developed and recognized only with the development and application of science to agriculture. It is reasonable to suppose that we have had for sometime many of the maladies that now affect cotton. Doubtless many of these have been recognized by practical occurrence, but until a pathological study was made they were not definitely described and the range and extent of their ravages not clearly known. It is scarcely correct therefore to say that the common maladies of the cotton plant in the United States are of recent occurrence; rather they have been with us to a greater or less extent for a long time, but have become more prevalent in recent years, since cotton production has become a more centralized industry and its culture more intensive.

It is natural to suppose that where planted spar(165) 
ingly, or grown under some plan involving a constant change of crops in which cotton appears only once in four or five years, there would be considerably less trouble from disease; for it is only in those cases where a disease gains a foothold that it causes appreciable loss to the cotton farm, and to gain such a foothold permanently cotton must be grown on the same land in fairly quick succession.

The same principle of disease as it applies to the cotton plant, or in fact to any plant, applies also in animal life. Texas fever, for instance, affects cattle only where they graze upon the same land year after year and thus give the tick time to put a new generation through the full cycle of changes each season. But if, on the other hand, cattle are withdrawn from the affected territory, and kept from it a year or two, the tick disappears as soon as the process involved in the completion of its lifehistory is disturbed, and it perishes, leaving theland entirely free from that time on. Perhaps there would be no eradication of the disease were the lands continually grazed without any period of intermission.

It is so with our cotton diseases where the crop is grown continually, as cotton usually is. There is no disturbance of the life process involved in the disease and so it comes on year after year, completing its full cycle of development.

The treatment of disease in general then should involve preventive methods rather than specific; a wise system of farming that will improve the land and make it stronger-this will mean interference in the development of the disease; this will lessen its ability to do harm, until it perishes altogether for want of necessary surroundings and satisfactory environments. 
In general the diseases affecting cotton may be divided into three classes:

1. Diseases affecting bolls:

Anthracnose

Shedding bolls.

2. Diseases affecting roots:

Root Gall

Root Rot.

3. Diseases affecting leaves or stems or both:

Anthracnose

Leaf Blight

Mildew

Damping-off

Wilt

Mosaic

Red Rust

Angular Leaf Spot.

\section{WHAT THESE DISEASES DO}

In order to clearly understand these diseases each one will be discussed separately.

Anthracnose:-The fungus causing this disease is a well known parasite of the cotton plant in all its stages of growth. It attacks the stems of young seedlings near the ground and produces the disease similar to the well known "sore-shin" or damping-off of the same plant. The cotyledons or young seed leaves also are attacked frequently. The same fungus also produces spots on the leaves and on the stems, but it is perhaps best known as the cause of the anthracnose of the boll.

When it attacks the bark of the stem, reddish- 
brown areas at first are produced, and eventually the bark dies. As a result of this injury the leaves may turn yellow, wilt, and fall from the plant; though, unlike the rust with which these symptoms often are confused, the plant rarely if ever produces another crop of leaves when affected by the anthracnose.

As a result of the boll anthracnose, very serious losses may result. A boll when attacked by this fungus assumes, particularly on the side exposed to the sun, a bronzy yellow due to the growth of the vegetative threads (mycelium) of the fungus in the walls of the fruit. If the bolls are nearly mature, especially if the weather is not very moist, no very serious damage to the bolls may result, and they may open in a perfectly normal manner. But if the bolls are attacked when young, or if the weather is rather moist, the fungus may cause the boll to open prematurely and expose the lint to rotting. The anthracnose may become epidemic, and cause very great losses. In this way it caused very serious trouble in many parts of Alabama during last season. Under such circumstances the surface of the bolls often becomes covered with a pinkish coat composed of the spores of the fungus.

At present no remedy is known, but if the ravages of the disease render such effort necessary, it may be possible to select and develop resistant strains or varieties that will be nearly immune against its attacks.

Shedding the Bolls:-This trouble has been long known and is very frequently a serious loss to the cotton farmer. Alternating wet and dry weather is the main trouble. Every farmer has noticed that during a time of excessive wet weather the ground 
is literally spotted with bolls that have dropped off. This condition possibly should not be called a disease, but rather a provision of nature to adjust the plants to their environment. When bolls are shed it leaves the plant in a better condition to mature those bolls that are unaffected. It naturally brings up the question, however, as to just where is the nice dividing line between full fruiting and overfruiting.

No treatment for this trouble is suggested further than having the soil in such condition that it may feed the plants so well as to minimize the evils of unfavorable seasons.

Root Gall:-This disease is located in the roots, and its primary cause is the nematode worm which lives in the tissue and causes the abnormal growth. It is termed a gall. This worm is white or yellow in color, and very small and threadlike in form. It has been said that each female will lay from one hundred to two hundred eggs, and that there may be seven or eight generations in a year. It is readily seen therefore that their growth and extension is rather rapid. From the very nature of this disease it appears that this worm must get into the soil from affected plants, and hence there is practically no way to combat the trouble other than by a change of crops, and using care that other important areas. may not be affected in the same way.

As a matter of fact, the direct damage from this root gall is not of so much importance as the indirect damage, in that the nematode in its injury to the root prepares the way for the entrance of the wilt fungus into the root system. Hence it is that the two troubles are often found together, and hence it is that many claim that the wilt came only 
after cowpeas were cultivated on the land. In other words the peas introduced the nematode worm, and this in turn caused the cotton plant to be readily attacked by the wilt fungus. And more than this, the most serious attacks of the wilt are found on soils known to be infected with the nematode worms.

Root Rot:-Root rot is a fungus which attacks other plants as well as cotton-alfalfa, also apples, peaches, and other trees. The disease spreads in all directions through the soil. The fungus derives its nourishment from the living substance of the root, and this naturally uses up the material in the tissues, and they shrink and decay. The life processes in the roots are also checked, and consequently they are unable to supply the plant with necessary food and water. As a result the whole plant shrinks, withers and dies.

Some one has suggested the application of salt or kerosene to the soil as a means of checking the development of this disease, but as yet the efficacy of this treatment has not been proved, and there is likely little or no value in it. Crop rotation seems to be the only method that will serve in keeping the fungus in check. Specific applications are naturally difficult to apply, even if effective. General methods that involve better management and provide a comfortable home for the plant, seem to be the way in which effective treatment or prevention must be directed. Crops like corn, millet, wheat, and oats seem not to be affected by this disease, and consequently they can readily be used in a system of rotation that will bring cotton on the same field only once every three or four years. In this way cotton will show the advantage not only of crop rotation, but will improve by reason 
of its ability better to survive or resist the fungus. Leaf Blight:-This disease, while very common in cotton is not very serious. It is a fungus that attacks the older leaves of the plants, and such others as have been disturbed in some manner so as to affect nutrition and assimilative power. You will sometimes find this disease associated with other diseases that affect the leaves and have weakened them, thus destroying their power to resist disease. The leaf blight is distinguished by the reddish circular and somewhat irregular spots surrounding a rabbit brown or white central area. As yet no remedy has been suggested for this trouble, and likely none will prove satisfactory that does not involve a better adaptation of the plant to its environments. This adaptation will enable the plant in a measure to resist this disease-or any other disease for that matter.

Mildew:-This is another fungus disease that affects the parts of the leaf limited by the veinlets. Its area of infection, thus far, has been rather limited and little harm has so far resulted from it. While it may occur in many parts of the Cotton Belt, its damage is small and unimportant. No remedy has been suggested.

Damping-off:- The terms "sore-shin" and "seedling rot" are also applied to this very common disease. It is a fungus attacking the young plant just beneath the surface of the ground. The parts affected assume a shrunken appearance, brownish or reddish in color. The time of attack is in early spring, when the cotton plant is small and delicate. Wet weather aggravates the trouble and from the nature of the disease, perhaps effective remedies cannot be applied. Any soil treatment that may be given so as to fit the plant for its environment, 
thus controlling soil conditions, will favorably influence the plant so that it can outgrow the trouble. Liming the soil to improve its mechanical condition; good tillage so as to loosen and aërate the soil; frequent cultivation in the spring so as to dry out the soil, usually after rain, and at the same time warm it up, are the best means of helping the plant when the fungus appears.

Wilt:-This disease has also been called "frenching," and extends over a considerable portion of the Southern Cotton Belt. The fungus gains entrance through the roots and thence goes into the wood tissue of the stems. The growth of the fungus in the stems naturally hinders the upward and downward movement of the plant solutions, thus interfering with the physiological processes of the plant. How the disease works may be readily seen by splitting open the stem: a brownish diseased condition will be noticed. Occasionally you find that a greater part of the leaves of the affected plant drop and the plant dies, a new growth probably appearing from the lower part of the stalk.

The only remedy lies in securing a variety or breeding a variety that will resist the disease. This is the only direction from which help can come. By going into the field and selecting seed only from plants that have lived through the plague, you can, after awhile, secure plants that will grow on infected soil.

Mosaic Disease:-The name "yellow blight" is also applied to this disease. It follows as the result of uncongenial conditions of soil and weather, and even of other diseases that seem to sap the strength of the plant. Healthy leaves, or leaves from very healthy plants, are seldom if ever at- 
tacked. The first appearance of the disease is a peculiar yellowing of the leaf which assumes a checkered appearance. As it gains ground, the leaf not infrequently curls up and falls.

The most effective remedy is to keep the plant in good growing condition. Cultivation is effective, since it warms the soil, dries the upper layer, and provides an effective mulch during seasons of drought; or an addition of vegetable matter, improving the physical conditions of the soil and thereby favoring the plant, is an effective help in carrying the plant through the danger, and enabling it to resist the disease.

Red Rust:-The reddening of leaves often noted in parts of cotton fields is the result of attacks by the red spider. As a rule, this trouble is limited in area extent, and it is not a prominent disease. Dry, warm weather favors the increase and growth of the spiders, and hence any treatment that causes vigor and steady growth in the plant is a safe and effective remedy.

Angular Leaf Spot:- This disease is largely confined to the months of June and July, and while it nowhere appears to any appreciable extent, it is found in a very large territory. It gets its name from the dark angular spots which appear on the leaves. The disease does not extend to all of the leaves, but usually only to those that are older and less active in growth. The spots are watery at first, but in time assume a blackish and then a brownish color. Those plants that are less vigorous and therefore constitutionally weak are usually the natural prey of the disease. The selection of strong seed, with careful cultivation, giving a good growing environment for the plant, is suggested as the best means of warding off the malady. 
We see from what has been said that the cotton plant falls heir to many kinds of diseases. You naturally look for some treatment that will keep your plants from disease and help them to be strong and healthy. What is the remedy? It lies along one general direction: fitting the plant to its environment. If its atmosphere, its home conditions, and life in general, are good, it will in a large measure resist all diseases.

The central thought then is to apply preventive rather than remedial measures. Get your soil deep, and well loosened; fill it with vegetable matter so as to control the warmth and moisture and plant food; rotate your crops so that no disease may gain headway; apply humus frequently and constantly to the soil, because humus is the life of the land; and select seed only from strong and vigorous plants, for these will possess endurance.

The right treatment of disease lies in these directions. Follow them and neither fungus nor bacteria can destroy your crop; follow them and your reward will be found in a plenteous harvest. 


\section{CHAPTER XXII.}

\section{INSECT ENEMIES OF THE COTTON PLANT}

You have heard about some of the troubles that come to the cotton farmer through the depredations of insects; maybe you have been troubled yourself; if so, you are altogether familiar with trouble of the real and true sort. But you, in those regions where the plague has not yet come, you had better go out to meet the foe, ere he come, rather than delay the battle until the enemy is upon you. For in either case you face a foe of no uncommon kind, determined, aggressive, often defeated, but so undaunted by defeat that it keeps on, usually winning in the end. Such, at least, has been our experience with the Mexican Boll Weevil. Slowly at first it approached, merely selecting a place for camp; but that first camp became really a fort, and in all directions its outrunners have gone, gaining in numbers, until to-day their aggressiveness and power threaten the whole Cotton Belt.

\section{I.-THE MEXICAN COTTON BOLL WEEVIL}

Monclova, Mexico, produced considerable cotton in the early half of the last century; from somewhere, in some direction, came the insect of this story. How long it encamped around this little town we do not know, but sometime between 1860 
and 1865 its ravages, gradually increasing, forced the farmers finally to abandon the culture of cotton. Cotton was not grown then for a great many years until it was thought safe to make another effort. But scarcely had operations begun anew before there appeared the ancient foe-hidden up to that time, of course, but where no one knows - and destroyed the crop. Twenty years later the insect was noticed at Matamoras, carrying on the same destructive work; but it stopped not here. In ten years it reached the Rio Grande. Checked for a moment, but not baffled, it goes on, continuing in its attempt to cross the river, which it succeeds in doing within a year or two. Once across, more bold now, it makes its campaign with quickness and dispatch, entrenching itself at Brownsville, Texas. Not waiting to subjugate completely the surrounding territory, it hurries on with darting jumps, and within a year it has fastened its hold upon San Diego, Alice and Beeville. This was in 1894. The interior does not stop it; for within a year it goes still further to the North, doing considerable damage at Floresville, and reaching even San Antonio. Likewise it pushes to the East and to the Gulf, reaching Victoria, Cuero, and sends its scouts to Wharton also. The last ten years has been a period of entrenchment and invasion to a peculiar degree. Practically all of the cottongrowing territory of Texas is now invaded; and the weevil has crossed into Louisiana, and has even threatened Indian Territory.

Its ravages have been great, and for the last four years the annual amount lost to the cotton growers of 'Texas has been approximately twentyfive millions of dollars. Including the loss to ginners, manufacturers, and other allied industries, 
the total yearly loss to the South through this insect probably amounts to a hundred million dollars.

\section{WHAT THE DESPERADO IS LIKE}

The Mexican Boll Weevil is not a ferociouslooking foe. It is only a small gray beetle, with a reddish-brown snout, and a body scarcely a quarter of an inch in length-the desperado that causes all this trouble and fright. It hardly seems possible that he could strike terror to the hearts of so many thousand people, or that he could attract so much space in the newspapers. As with men, it is not the man but the work done that calls for praise or punishment; so with the boll weevil, it is not the insect (for you have seen scores all about you that look more capable of evil) but his methods of attack, his numbers, that have alarmed the millions of people dependent upon one of the greatest industries of the world.

\section{THE LIFE HISTORY}

As the life of one man is the history of all men, so is the life of one of these insects the life of all. And clearly to understand him and his destructive work, we must follow the life history through its cycle, for it is during one of the intermediate stages that the greatest trouble is done.

Let us take him when his work for the year is over: when his evil deeds for the season are ended, and follow him sufficiently close and far enough for observation purposes, since that is the only way we can fully understand his life.

The weevil has done its work for the season. 
The cotton crop is ripe and harvested-or what is left of it after the weevil has done his work is harvested. He still stays with the cotton plant until late in December, or as long as any portion of the plant is green.

Winter approaches now, and a winter home is needed. Where shall he go? He does not like cold, and thousands and thousands of his fellows perish each year; but there are many places of protection on the average cotton farm; the open bolls, grass and weeds, brush and rubbish; even leaves in the ground furnish a home and warmth. Here he stays with all his fellows, silent and asleep, until spring comes again. The warm days of rejuvenation go on. The buds on tree and grass stalk crack and burst in their joy, and perhaps awake the sleeping beetle, which is now attracted by the joyful sounds, and proceeds to take breakfast with the happy hosts.

When cotton has grown so large that squares are made, the enemy appears, looking altogether harmless, few in numbers, and exceptionally gay. Soon the female begins to lay eggs. At first her nests are many and she puts but one egg to the square. By and by, as the number of females increases, and the squares become fewer in number, more nests must be found. The boll seems to serve the purpose well. But the shell is hard. So much the better; it will be safer there. Wise little mother beetle! she will find a way. And she does, for that snout seems especially built for digging and eating. The opening made, the egg is inserted, and the opening closed. Too precious to the little mother is that egg and the life within it for her not to exercise care, that it may not be disturbed or destroyed. She knows in some way, in some manner, and with 
some instinct, that the juice of the boll will soon glue the opening shut, and her offspring will be protected and safe. Sometimes two or three eggs are laid in each boll. In just two or three days the egg is hatched, the young larva develops, transforms to pupa, and eventually completes its cycle, this time becoming a beetle-the final stage of weevil growth.

These beetles join the hosts of other workers, and soon a vast army, scattered here and there, seek new squares and growing bolls, and they too lay their eggs, contributing their share to the new broods, and to the destructive depredations.

So then we see that there is a constant succession of generations from the time of the earliest appearance of volunteer plants until the end of the season. This description of affairs readily suggests the tremendous hosts at work, destroying the crop and blasting the hopes of the cotton planter.

The greatest enemy of the weevil is frost and cold weather. When these come late in the season the latest broods mature and seek winter quarters, in which they may hibernate during the winter months. Thus a late season is favorable. On the other hand, where frost and cold come early, the last broods are caught and nearly all are killed. The surviving beetles have secured their winter quarters either before, or do so now, and sleep silently until spring's choice days bring them back again to the strenuous life they fill so well.

\section{WHERE HELP LIES}

"Is there no hope of ridding the land of the pest?" ten thousand people ask. 
"There is," the scientific people say, "but you must give us time."

"And in what way?"

"We can tell.you, so far, only indefinitely, but several things are being tried," comes back the answer.

And many things are being done. Every suggestion having merit is considered. Experts from the Department of Agriculture at Washington, Experiment Stations, and private parties, all are exerting themselves to the utmost that this question may be answered, and some practical remedy applied.

Some one heard of an ant in Guatemala that is a natural enemy of the Boll Weevil, and parties were at once dispatched to study it and to make friends with this new-found ally.

The ant was found and brought to our shores where a hospitable welcome awaited it, but the climate was colder than it was accustomed to, and many of the specimens died. But some are adapting themselves to their new environment, and in course of time the ant may become indeed a friend and ally to the cotton planter. In the meantime we must wait and not neglect other ways of ridding the land of the fatal beetle.

"What more can be done, and how can we help?" the farmer asks.

"You can help in many ways: you can make life miserable to your enemies. See how they use your property - grass, brush, rubbish-for winter quarters: will you permit them to do this ?"

And you can disturb them much: old rubbish, grass, and brush you can burn and so destroy thousands; for in destroying their winter quarters you subject them to hardships that in the end will 

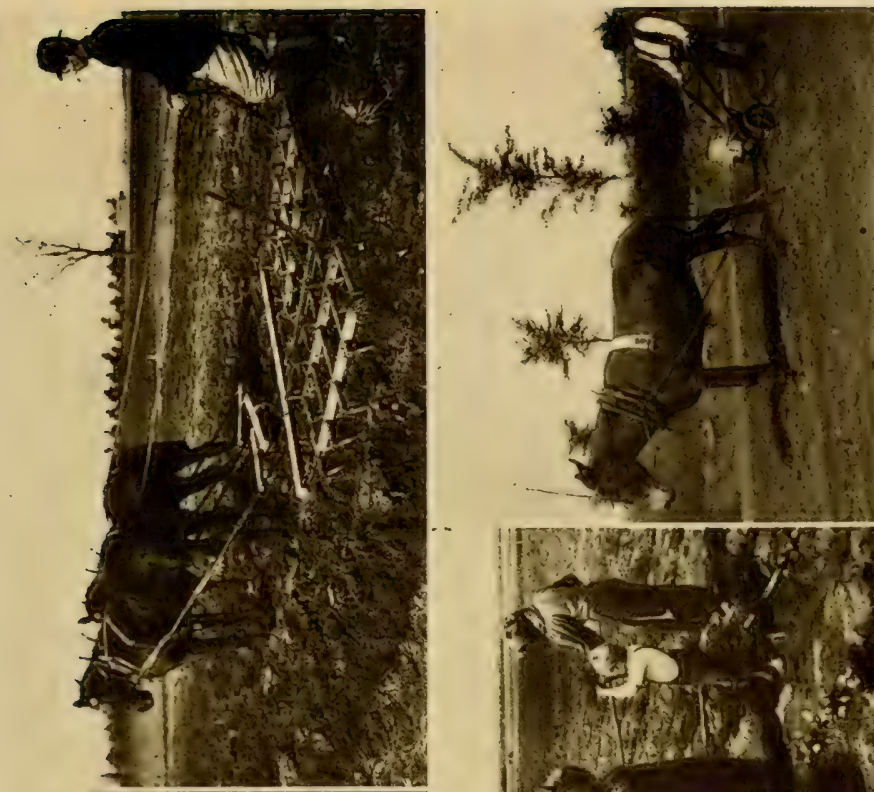

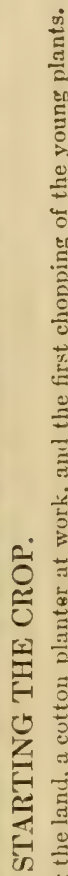
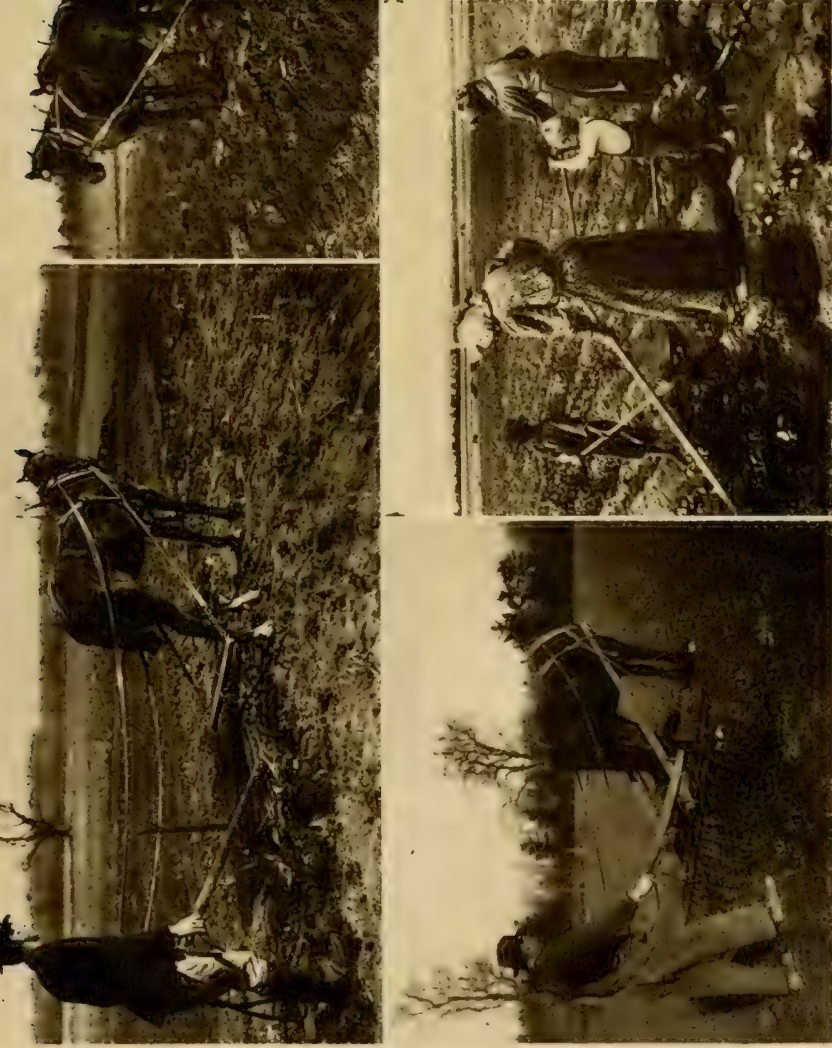


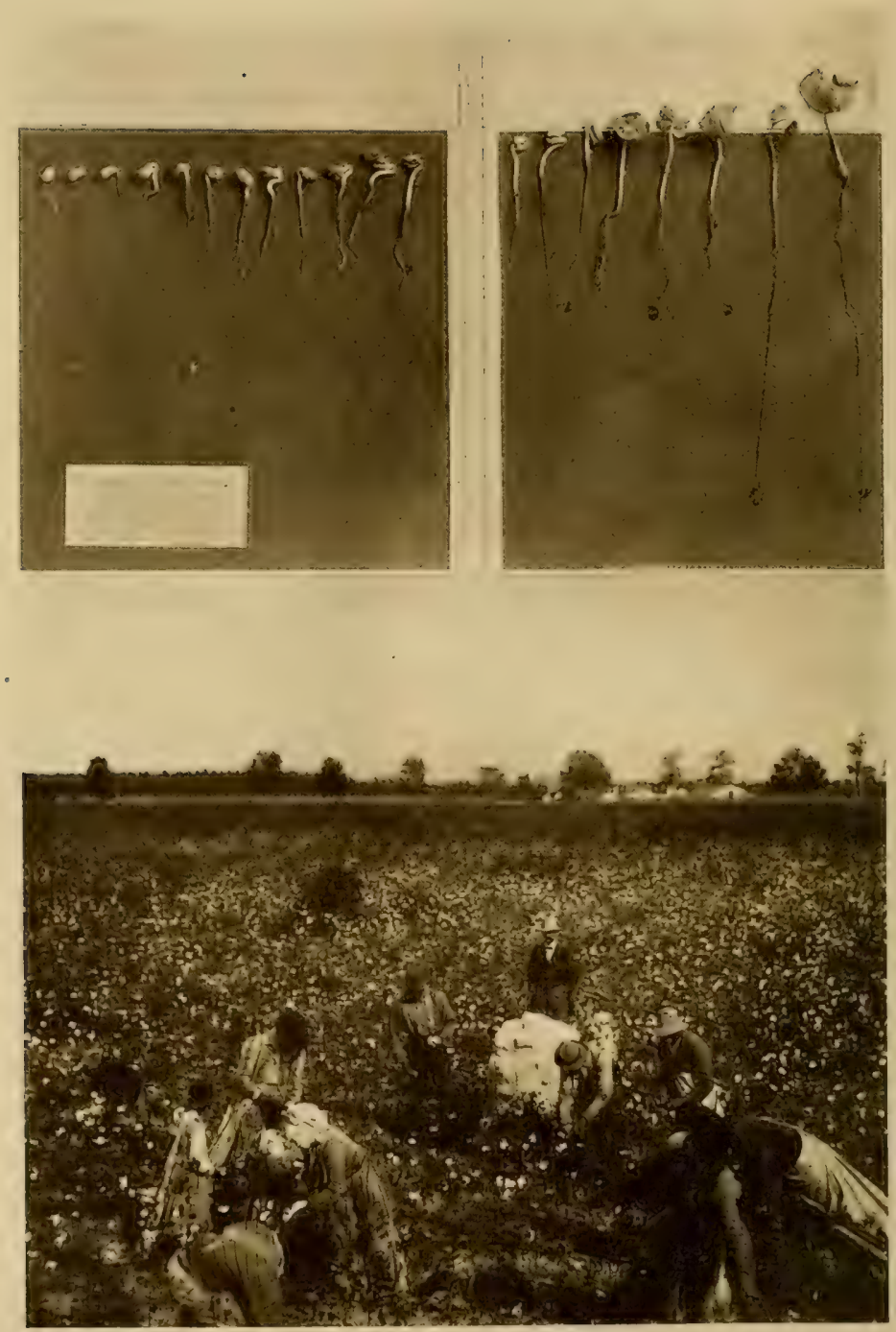

THE ALPHA AND OMEGA OF COTTON MAKING.

The picture at the top shows the growth of cotton day by day - at 21 days it is still only a tiny two-leaved plant. Compare with corn. 
mean the destruction of many. Hence it follows that all rubbish, including cotton stalks, should be burned as early in the fall as practicable, and the land turned with the plow.

Other effective remedies lie in trapping the beetle in the late fall by means of new plants left standing; by enticing with early plants those that escape and live through the winter, and then destroying them; by destroying all volunteer cotton plants-for these are natural feeding places and brooding grounds; by picking summer squares so as to check the summer ravages; and by using early-maturing seed and planting as early as possible.

In some of these methods you can now find help; by some of these methods the final battle will be waged and the victory will come to you and your fellows.

\section{II.-THE CATERPILLAR OR COTTON WORM}

This insect has a wider territory for his range, and while he still causes much anxiety and distress, he once ruled with considerable force and power.

He looks like a caterpillar: in fact that is what he is. You are thoroughly familiar with his work and that of his class. Eating seems to be his principal occupation. All caterpillars are voracious eaters. Trees are stripped of their leaves; small fruits become bare of every vestige of green; cabbages are often entirely destroyed. You are familiar with these. The cotton caterpillar is just as greedy in his cotton field. In appearance you find him a bluish green caterpillar, with small black spots, and often with black stripes down his back. This is the fellow that does the damage. 


\section{THE STORY OF HIS LIFE}

The female lays about 500 eggs, using one or more leaves for places of deposit, and usually the underside of the leaf. Since the moth is a nightflyer, eggs, as a rule, are laid at night. In the summer, these eggs hatch in three or four days, but the time is lengthened somewhat in the earlier and the later seasons of the year. The young larva on hatching from the egg, begins feeding on the leaf, starting with the underside, and biting just a bit of the layer. A little stronger, it travels about, and finally may be seen at any place on the stalk. During the caterpillar's life, the skin is shed five times; at the fifth shedding full growth is reached. It usually takes from one to four weeks to complete this part of its existence. At first the larva is yellow in color, but soon a change is seen and the greenish appearance deepens and becomes permanent, the black along the back coming out prominently, though varying in intensity with different individuals. The larva moves rapidly; in walking it brings its hind prop legs forward to its fore legs, arching its back and becoming a loop in shape. It eats greedily now, subsisting on leaves principally; but where numbers are many and food consequently scarce, the cotton boll is not spared but also contributes to the bill of fare. And should the vegetation diet become short, there is no hesitation about the stronger members feeding on the feebler and smaller individuals of the race.

\section{WHEN MATURITY COMES}

Many farmers believe that the caterpillar, when 
mature, seeks rest in the ground and passes the winter there.

I asked one who knows this insect well.

"Not so," he answered me. "In fact, the insect does not even enter the ground. Nor is the winter passed in the caterpillar stage. The fact is, an imperfect cocoon is made, usually within a folded leaf. Here a nap is taken for a week or two, sometimes even for four weeks. When its sleep is finished, it is not a caterpillar that comes out, but instead a flying moth, rather small in size and of olive green or gray color. This moth is somewhat shy of the day, usually hiding then, but with the coming of the night it takes wings, seeking food, and a nest for its eggs. From now on it is a more active creature. It flies on and on, and seldom returns to its home. In fact, it goes to the North, going from its ancestors' Southern home, and leaves its brood in a new land; these broods in turn, having a like roving disposition, seek new lands also, until the distance grows so large, it is quite impossible ever to reach the ancestral home again. This moth wanders even as far to the northward as Canada."

The number of generations each season is large. This is readily understood when we consider the fact that in just a few days after leaving the pupa state the moth begins its business of laying eggs. Thus five, six, or even more generations may be produced during a summer-so quite naturally a single individual can populate a territory of considerable extent.

Later generations of each season, drifting northward, are damaged by cold, and seldom, if ever, survive the winter. Hence all generations born outside of Southern climes are lost. New broods coming 
from the southern portions of the countryalong the Gulf each year must furnish the northern population, and so great is the number, the hosts often do considerable damage to late peaches in Kansas and ruin acres of cantaloupes as far north as Wisconsin.

\section{WHERE THE WINTER IS SPENT}

The moths that go to the north each season never live through the winter; they are too far from home to get back again, and the winter is too severe for them to endure the cold; hence they never see the coming of a new year. It is left to their relatives and their kind that abide in the warmer sections of the most southern portions of the Cotton Belt. Great numbers of these likewise perish. But of course many succeed in finding winter quarters to their liking, through the shelter of rank wire grass, and other vegetation. Exceptionally few of these survive, but their large broods quickly populate all their territory, and the caterpillars are as numerous as the season before.

\section{GETTING RID OF THEM}

The natural way to rid the land of these pests would be to destroy their winter quarters, and they would perish as they do when attacked by like unfavorable conditions elsewhere. This seems impracticable now, since the undrained territory and waste places of their winter resorts are so extensive.

\section{A COMMON REMEDY}

Where the caterpillar becomes very troublesome, 
threatening the crop, some heroic treatment is necessary. This seems to be found in the use of Paris green sprinkled on the cotton plant.

A rather ingenious method is in vogue for doing this work: two sacks, made of heavy cloth, 10 inches long and 4 inches wide, with both ends sewed, are tacked to the ends of a strip of wood $1 \frac{1}{2}$ inches by 2 inches and 5 feet long. The open sides of the bags are tacked to each of the sides of the strip of wood. A hole is now made in the end of the strip, and through this Paris green is poured by means of a funnel, and distributed by riding on horseback between the cotton rows, dusting two rows at a time. A slight jarring of the wood strip will cause the poison to pass through the sacks to the cotton plants below. With such equipment one man and one horse will dust from 15 to 20 acres daily.

\section{III.-THE COTTON BOLL WORM}

You have very likely seen this insect in some of its forms; maybe not in connection with cotton, for it is known in many parts of the world, but perhaps feeding on some plant such as corn, peas, beans, pumpkins, or squash. Its food range does not stop even here, but includes even the tobacco plant, and its fastidious palate often selects many of the garden plants such as the geranium and gladiolus, and even wild plants also.

THE CYCLE OF ITS LIFE

The egg is usually laid on the underside of the cotton leaf, but is often seen on other parts as well. You will recognize it byits whitish color, although inclined to a yellowish tint, is nearly round in shape, 
and quite similar to the cotton worm egg, though a little larger in size. From a couple of days to a week are required for incubation.

The larva is somewhat darker than the cotton worm, and assumes the same general appearance in walking. Its first feeding is done near the place where it was hatched; as it grows in strength (and this it does in a surprisingly short time), it wanders about seeking what is more acceptable to its appetite-the cotton boll. It seems that the contents of the cotion boll favor its development, since the boll worm seldom reaches full growth upon a diet of leaves alone.

When a boll is at last found, it begins its work by boring into it, feasting upon it, and then abandoning it for another boll. This is kept up day after day. This method of dieting is, of course, very destructive to the crop. Quite a number of bolls may be destroyed by each individual worm. More yet to be said against its spendthrift habits is its constant unreasonableness in atiacking premature blooms, which of course prevents them from further development, and consequently incapacitates them for fructifying. This much must be said in its favor, however; this policy is not wanton destruction, for it makes food of the stamen and pistils of the blooms in satisfying its greedy appetite.

Their feeding habits indicate that these insects are not altogether harmonious and agreeable in their pursuits, for the stronger and older ones impose constantly on the younger and weaker, even to the extent of eating them when vegetable food is scarce, or not altogether to their liking. As a rule you will find these "big fellows" appropriating the larger and more luscious bolls, and leaving 
the smaller bolls and the flower buds to the young and immature worms.

After living thus for two or three (and sometimes even for four) weeks, the larva reaches its full growth, and now, weary of the world in this form, it seeks some place for rest and change. It finds this in the very soil out of which the plant comes and upon which it is fed. It enters the ground, and out of earth it welds an oval cell, and here remains from a week to a month. At the end of its pupa life, it appears as a moth, varied in its markings and somewhat stout in body. Its dress is bright in color, shading from a dull yellow to an olive green.

An active little creature, we find it darting here and there, but usually seeking the night time for exercise, food and work. Whether it thinks it safer to appear at this time or whether it is somewhat ashamed of its deeds, does not appear; still we know it hides among the clover and the grass during the day, and with the approach of darkness comes out of its seclusion to find food and a place to deposit its eggs.

Unlike the two insects previously described, the moth seeks sweeter feeding-grounds and more appetizing foods, such as the honey found in the blossoms of the cowpea, the clovers, and other nectar-secreting plants.

\section{THE SEASON'S POPULATION}

A single female deposits something like 500 eggs at a time. The avcrage time occupied in the various changes from the egg to the adult state of the moth is from thirty-five to forty days; and since the first appearance is about the last of April or the first of 
May, there is easily time enough for five or six generations in each season. What a population for a single year! Do you wonder that their ravages are-so destructive, or their reputation for evil so extensive?

Nor do these pests limit their work to the cotton plant alone; they are just as aggressive in the fields of corn as in the cotton fields. They find pleasant feeding grounds in both tassels and growing ears. When the former have passed their edible state and the latter have become too hard for eating, the moth seeks other feeding grounds, new cotton perhaps, or a later-maturing corn somewhat farther off; maybe a tomato field lies in some other direction: if so, it will be found and appropriated for the use of the new-coming brood.

\section{WHEN WINTER COMES}

As a rule, larvæ of the latest broods seek winter homes in the ground and there remain until the warm days of spring rescue them when they issue forth as moths, soon to lay eggs preparatory to another summer's campaign. But this is not the only way the winter months are passed, for adult moths are known to seek shelter in some protected place and hibernate during the cold weather, perhaps only a few, however, in the adult or moth stage.

\section{ENEMIES OF THE INSECT}

Many birds feed constantly on worms. Naturally the cotton caterpillar and the cotton boll worm do not escape this provision by which nature seeks to keep them and other insect pests in check. The boll worm is the more favored of these two 


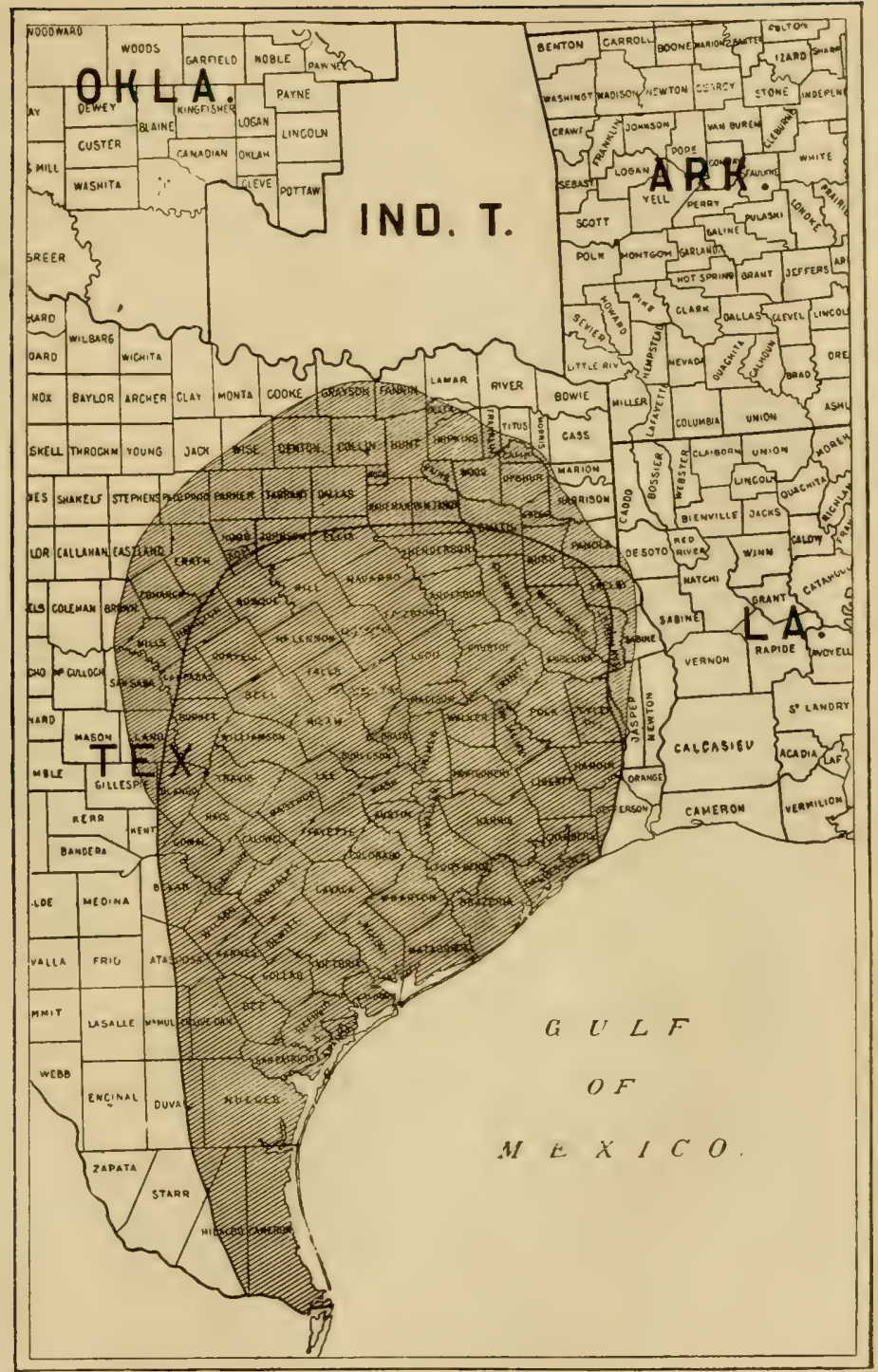

THE BOLL WEEVIL'S CONQUEST OF TEXAS.

The shaded territory shows where the boll weevil is doing the most serious damage. 


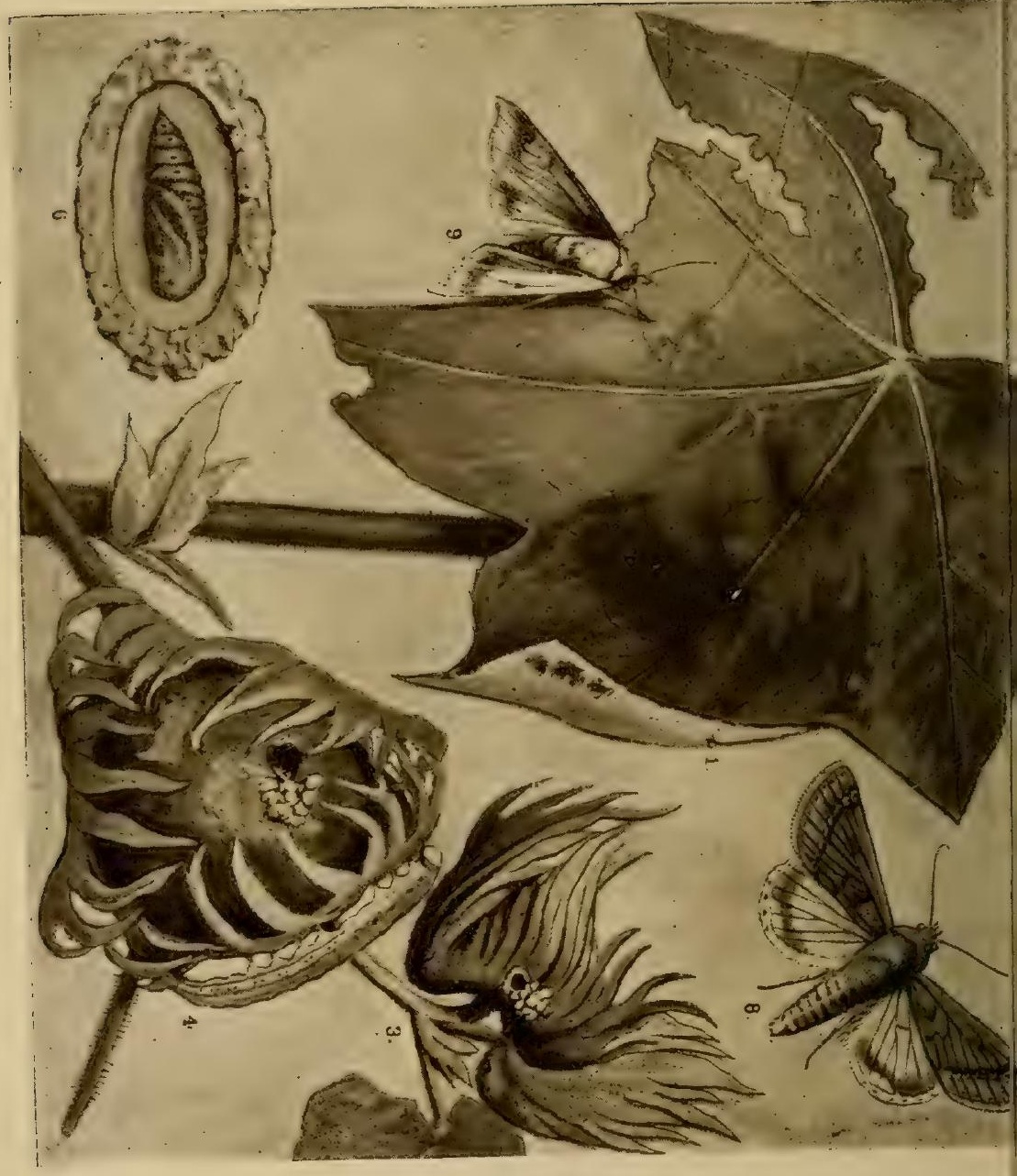




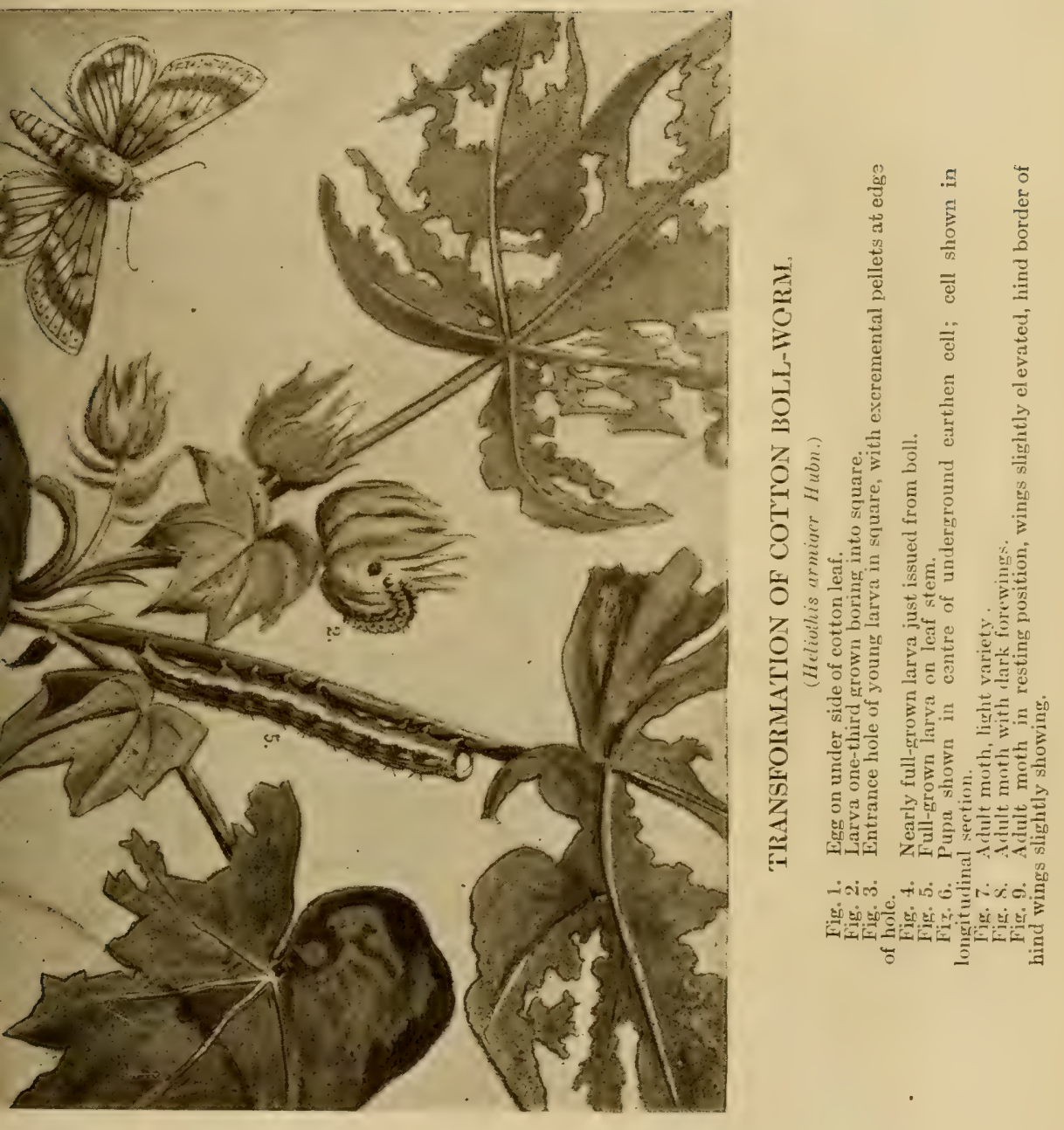



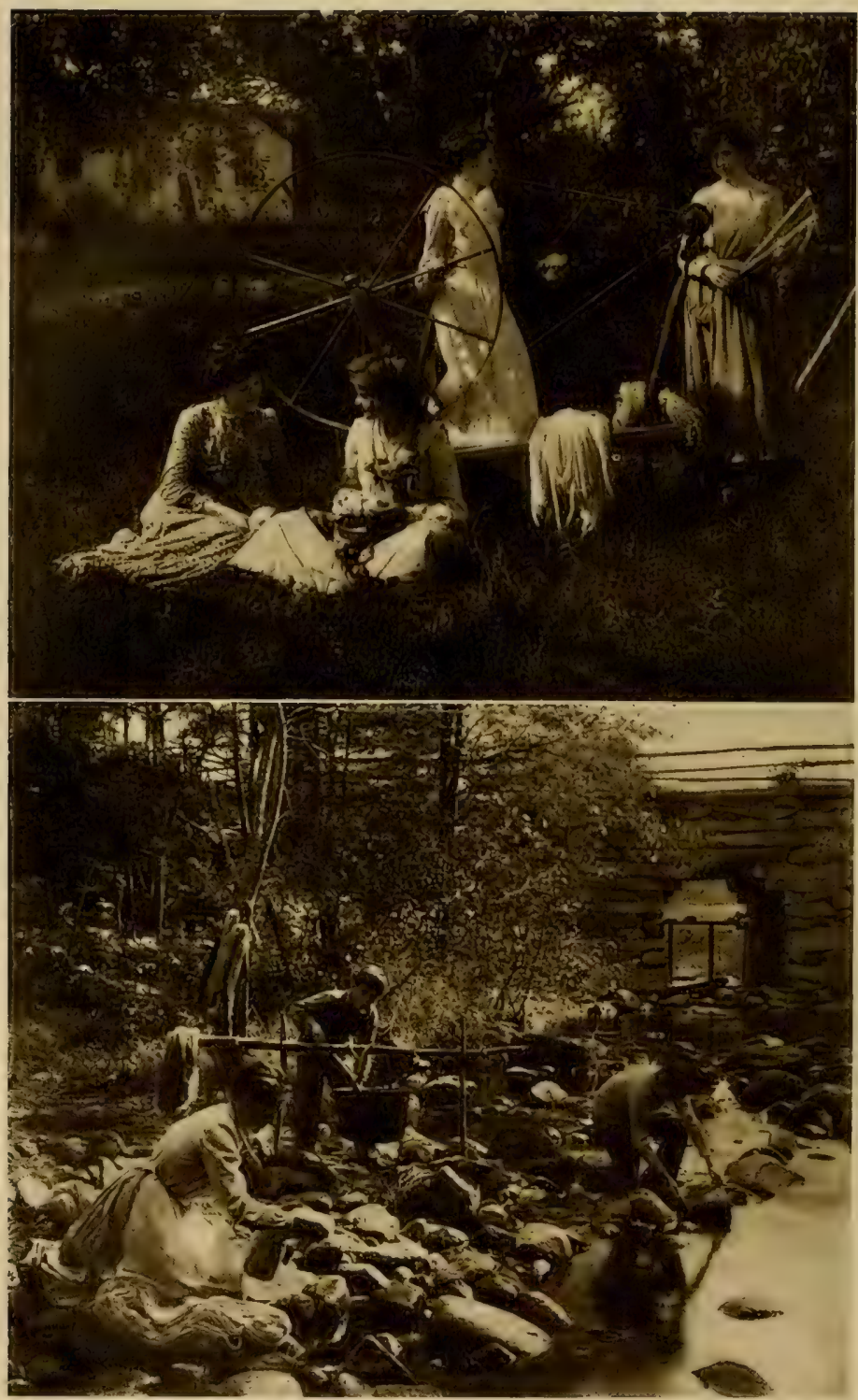

BEFORE THE FACTORY CAME.

(A) Girls wind the yarn from spools into skeins, just as our grandmothers used to do 'way down east.

(B) The skeins of yarn are washed thoroughly in both hot and cold water. 
insects, since it does a good deal of its feeding under cover of corn shucks, or within the shell of the cotton boll. while the cotton worm is usually exposed to bird enemies during the whole of its larva life.

\section{GETTING RID OF THE INSECTS}

Many kinds of traps have been devised for catching the moths. As you know, moths of all kind are attracted by lights when darkness comes on, but the expense of operation, the comparatively small number that are caught, and the large percentage of beneficial insects killed, seem to mark the moth trap as worthless.

Poison has also been tried, but with unfavorable results. It is quite impossible to destroy the cotton boll worm as we may destroy the cotton caterpillar, as the latter feeds within bolls or is hidden within the tassels or ears of corn. Nor have we been successful in attempts at enticing moths to especially prepared sweets flavored with poison and put within their range, for only a very few accept the invitation.

The most successful effort is in growing trap crops planted especially for nesting places for the moths. As soon as eggs are deposited these crops are destroyed, and the number of broods of each generation is kept at a minimum. A few rows of early but not thickly-planted sweet corn are used to surround a certain area of cotton. As the eggs are deposited on the silk the ears bearing this can be plucked and fed to live stock. A few rows of later corn may be coming on to catch later broods, thus to a certain degree, keeping the pest in check. 


\section{IV.-COTTON APHIS.}

When the first few leaves of the cotton plant have formed, you may frequently observe on the under surface many tiny, soft-bodied insects-some having wings, others wingless. Often they are so numerous on the terminals of the buds as to give these buds a black appearance. This pest is the cotton aphis. These aphides have passed the winter on various kinds of common weeds, but in spring migrate to the cotton plants. Often these tiny insects multiply so rapidly as to become very destructive, doing the damage by sucking the sap from the young leaves.

They can be destroyed by spraying with kerosene emulsion, whale oil soap, or tobacco water, but this is rarely profitable. As they pass the winter on various kinds of weeds, it is at once apparent that fall and winter plowing, by which the field is cleared of the host plants, will do much toward preventing injury from this pest.

\section{V.-CUT WORMS}

In early spring when young cotton plants are just out of the soil, the farmer when visiting the field in the morning will often find that many plants are cut off at the surface, as if some mischievous person had been trying to discover how many plants he could behead during the night. This destructive work is so familiar to every planter that he at once realizes that it is the work of cut worms. The well-known authors of these midnight raids are the caterpillars or worms. There are a number of different kinds, and the life-history of these several species varies considerably; in the case of a 
number of them it has never been accurately ascertained.

The worms are generally of a brown, gray or greenish color, often marked with longitudinal stripes and dashes. They are stout, and when full grown are often almost two inches in length. There are three pairs of regular legs on the front portion of the body besides the fleshy appendages further back on the prolegs.

Their feeding is done only at night, and for this reason their presence is usually discovered only after the damage has been done. During the day they hide near the plants, frequently entering the ground, and leaving a little hole where they went in. Some species remain entirely under ground, often pulling the plant down into the soil.

By thorough cultivation of the land in late fall, winter, and early spring, much can be done toward controlling these pests. Thus exposed to adverse weather conditions, many of them will die, while others are eaten by birds or killed by parasitic insects. Furthermore, land plowed during winter has no vegetation on it in early spring, and consequently there is no food for these worms to feed on. Frequently, of course, the farmer cannot apply these preventive measures, and when the pests then become destructive, they may be destroyed by scattering poisoned vegetation over the infested portions of the field. Bunches of grass may be immersed in Paris Green, one pound to a barrel of water.

\section{VI.-THE GARDEN WEB WORM}

In early spring we often see a great number of small caterpillars feeding on the surface of cotton 
leaves under a thin web spun over the leaf. On account of the fact that these worms are often found on "careless weed" many farmers call them "careless worms," and where the planter allows these weeds to grow unchecked, these caterpillars are always worse. When winter approaches the caterpillar enters the ground as a larva, often becoming a pupa. They emerge the following spring. The female lays about 50 eggs, putting them in several bunches on the leaves of the cotton, and these eggs hatch in a few days. These first caterpillars are miscellaneous feeders, attacking alfalfa and various garden vegetables. The second brood is injurious to cotton. In the far South there are upwards of five or six broods a year.

Clean cultivation is the most effective preventive of the development of this pest. This will destroy the weeds upon which they feed. Where they have become destructive to cotton they may be easily destroyed by dusting the plants with Paris Green or some similar insecticide.

\section{VII.-THE COTTON SQUARE BORER}

We have already considered the work of the cotton boll worm and have learned how it bores holes in the squares and bolls. We have learned the appearance of the caterpillars and feel that we shall know them every time we see them. When we go through the cotton field, however, we may see another insect doing work similar to that of the boll worm, but clearly a different insect. It is a short, thick caterpillar covered with hair, and has a uniformly green appearance. These insects are called Cotton-square Borers. The mother of these green, oval-shaped caterpillars is a dainty little 
butterfly. The eggs are laid on the leaves and stems of cotton, cowpeas, and various other plants. The larvæ feed on beans, cowpeas, hops, and peaches, but seem to prefer cotton.

It is rarely necessary that we need to apply remedies, although a thorough dusting with Paris Green will control the pests. In most cases, however, the little wasps that are parasitic upon the borers are so numerous as to hold them completely in check. 


\section{CHAPTER XXIII.}

\section{HARVEST TIME IN THE COTTON FIELD}

Every crop is interesting at harvest time; but especially is this true of cotton. Even the poorly tended field with its short stalks and open ground becomes spectacular in appearance as the bolls burst and reveal their fleecy treasures, soft, abundant and snowy white.

To this scene add hosts of workers of all shades of color, and of every size from the toddling babe to the tottering grandfather, and here and there spot the picture with mounds of white made of the picked cotton-then indeed you have a scene that will never leave the mind, and will hold the gaze until it fades away in the distance. Such is picking time in the cotton field: such is the reward of a season's endeavor.

\section{HOW PICKING IS DONE}

The only equipment necessary for cotton picking is a common sack suspended from the shoulder and open at the mouth into which the cotton is placed as it is pulled from the open bolls. It is very light work-more so than harvesting any other sort of crop. Often the best pickers in the cotton field are women and young children.' The arduous part of the picking operation is the stooping necessary 
to gather cotton from the lower bolls. The lugging of the load as picked is inconsiderable, since large baskets are kept at the ends of the rows into which the pickers empty their sacks as often as they wish.

Cotton is picked largely by colored labor; and with the negro's careless, "happy-go-lucky" nature, some loss is but a natural result. This loss principally comes from cotton falling out; from its being soiled by dirt; and from small locks being left in the bolls.

The quantity that each picker will gather in a day naturally varies, since people of both sexes and all ages do this work. Some hands gather less than 100 pounds a day, while others, where conditions are favorable, gather as much as 300 to 350 as their day's work.

HOW LARGE A CROP CAN OUR PICKERS GATHER?

The picking season extends through a period of from 90 to 100 days. This is an important advantage in cotton production. With wheat, a few days only may be devoted to the harvest, and if the harvest period is extended, the loss will be great. With our hay crops, with corn, with tobacco, the same thing is true: inevitable loss if the harvest work is not promptly done and done within narrow limits indeed.

But with cotton it is different. Some loss, of course, follows, should picking be unreasonably postponed. Some of the cotton may be beaten into the ground by rains and the rest may be injured slightly in quality; still the work may be long delayed without very serious damage. We have known crops in which the picking was not quite completed until the following spring, when the 
farmer began preparing for planting again. The full crop, we see, does not ripen at once. Again and still again harvest comes, and gives a long season for the gathering of the crop from the earliest to the latest pickings.

"But is the production of cotton limited at the present time by the quantity that could be gathered?" is a question often asked.

Here is the opinion of an expert:

"Excluding the population of towns and villages, who do a considerable share in cotton picking, and deducting one-third for children under eleven years of age, there remains an exclusively rural population in the Cotton States of over 6,800,000, all more or less occupied in cotton-growing, and capable, at the low average of 100 pounds daily, of picking more than 450,000 bales a day (or the crop of 1905 in three weeks); and if they continued picking at this rate through the whole season, they could gather four or five times as much as the largest crop ever yet made."

\section{COST OF PICKING}

Picking costs from forty cents to one dollar per hundred pounds of seed cotton-fifty cents being perhaps the usual price-and it takes three hundred pounds of seed cotton to make one hundred pounds of lint; that is to say, two-thirds of the weight of cotton when picked is seed. With an average price of seventy-five cents per hundred, the cost per pound for picking is 2.2 cents. With cotton selling at ten cents per pound, it is seen that more than one-fifth of this amount goes simply for labor of picking. As cotton sold for a number of years at six cents a pound, with the cost of picking 
only a little less than now, one can readily see what a factor in cotton production is this one item of gathering the crop. For wheat we may reckon one dollar as an average price. What would you think of 20 cents per bushel for labor in the harvest field? With cotton, too, it costs practically the same for picking whether the price is six, eight or ten cents per pound. Surely it is selling for little enough now. We read of the enormous value of the 1905 cotton crop, but it is well to remember that it cost the cotton farmer about seventy-five million dollars to gather it after the crop was grown.

\section{WEIGHING}

As the pickers fill their sacks they return to some convenient place where the sacks are emptied, and then back again they go to picking again, and thus they work for the greater part of the day. The cotton is emptied into baskets or put into piles on blankets or cloths of some sort. At night, or when the field is picked over, the owner weighs the picked cotton and either pays or credits each picker for the quantity gathered. Many of these piles are made; as many as there are individual families or pickers. It is the only way to determine the amount earned, which is then easily calculated. This cotton is called seed cotton, and after weighing, it is hauled to the barn, "cotton house," or other place of storage.

THE COTTON PICKER

As has already been indicated, the draft on cotton profits is greatest for picking. We gather 
cotton to-day just as it was done in India a thousand years ago. Hand picking, hand harvesting, is not only the rule, but it is the only method of gathering the lint.

Other crops have labor-saving devices in use in this final phase of their production. With wheat, corn, oats, potatoes, - all our leading crops, - while the cost of production has been lessened in our time, the cost of harvesting has been reduced many times. With cotton it is different. Slave labor passed; paid labor took its place. And labor cost is steadily increasing. It costs more to-day than a quarter of a century ago, more than it did a decade ago.

The great hope of the South then lies in the direction of better labor-saving devices for lessening the cost of cotton production! Some will come, of course, for better preparation for the crop, and for its better culture, thereby increasing the yield: but the greatest improvement will be found when the cotton crop may be picked with somewhat the same independence of hand labor as obtains in the harvesting of other staple crops.

You think this can never come?

We were fifty years producing the wheat harvester, and from its nature- gathering grain, cutting it, and binding it-are not as many features included and complications involved as in the harvesting of cotton?

The cotton picker will come. In its experimental stage now, it is not to be dismissed with a mere wave of the hand. It picks now. That much is certain. The time will come when it will pick profitably.

The successful cotton picker has only to do the work efficiently and cheaply. It must be built to 
pick the open cotton without injury to plant or unopened bolls.

The fact that cotton opens slowly, necessitates, as has been seen, three, four, or even five pickings, and this complicates cotton harvesting: but if rows are placed at proper distances, fields planned for horse or steam drawn tools, the cotton picker may be operated twice or three times without serious injury to plants or bolls. 


\section{CHAPTER XXIV.}

WHAT DOES IT COST TO MAKE COTTON?

You may think it is an easy matter to calculate the cost of cotton-growing and the profits that are to come. But you will do well if you put a good deal of study on this problem, and then as a final proof that your solution is correct, make actual field tests, not for one but for many years. Nor need you then feel absolutely certain of your process of reasoning.

Why do we say this?

Just remember this fact: you are dealing all the while with natural and artificial conditions, and while wise farm management endeavors to control these, it still remains true that cotton farming is dependent on natural causes which vary constantly, often to such an extent that the most careful calculations will be upset.

For proof of this proposition you need consider only the production of cotton during the last few years. The yield in bales and production per acre is shown in the table following:

YIELD OF COTTON

Year

1898

1899

$$
\begin{gathered}
\text { Production, } \\
\text { in bales }
\end{gathered}
$$

$11,235,383$

$$
9,439,559
$$

Product per acre, pounds

240

189 


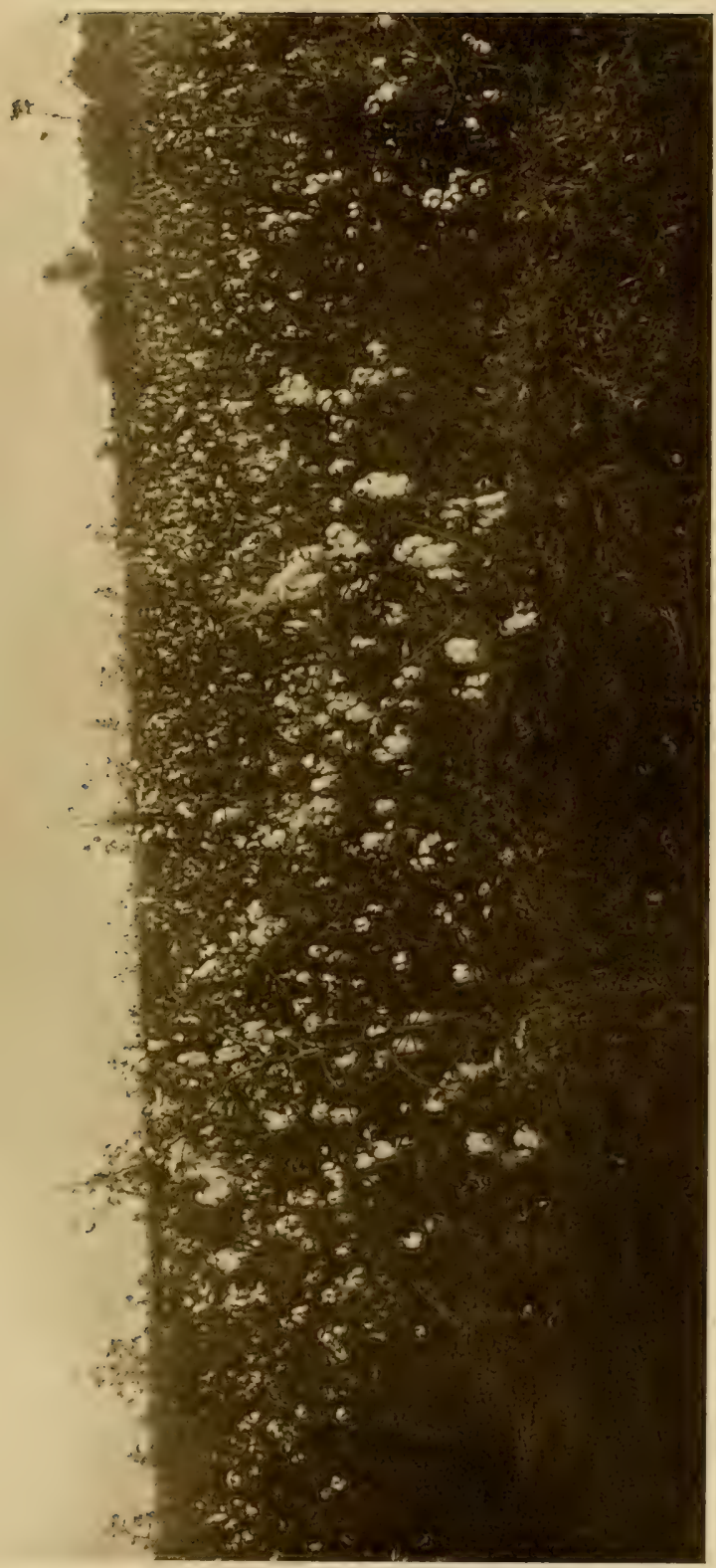

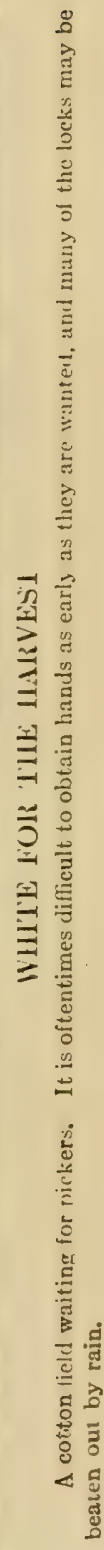



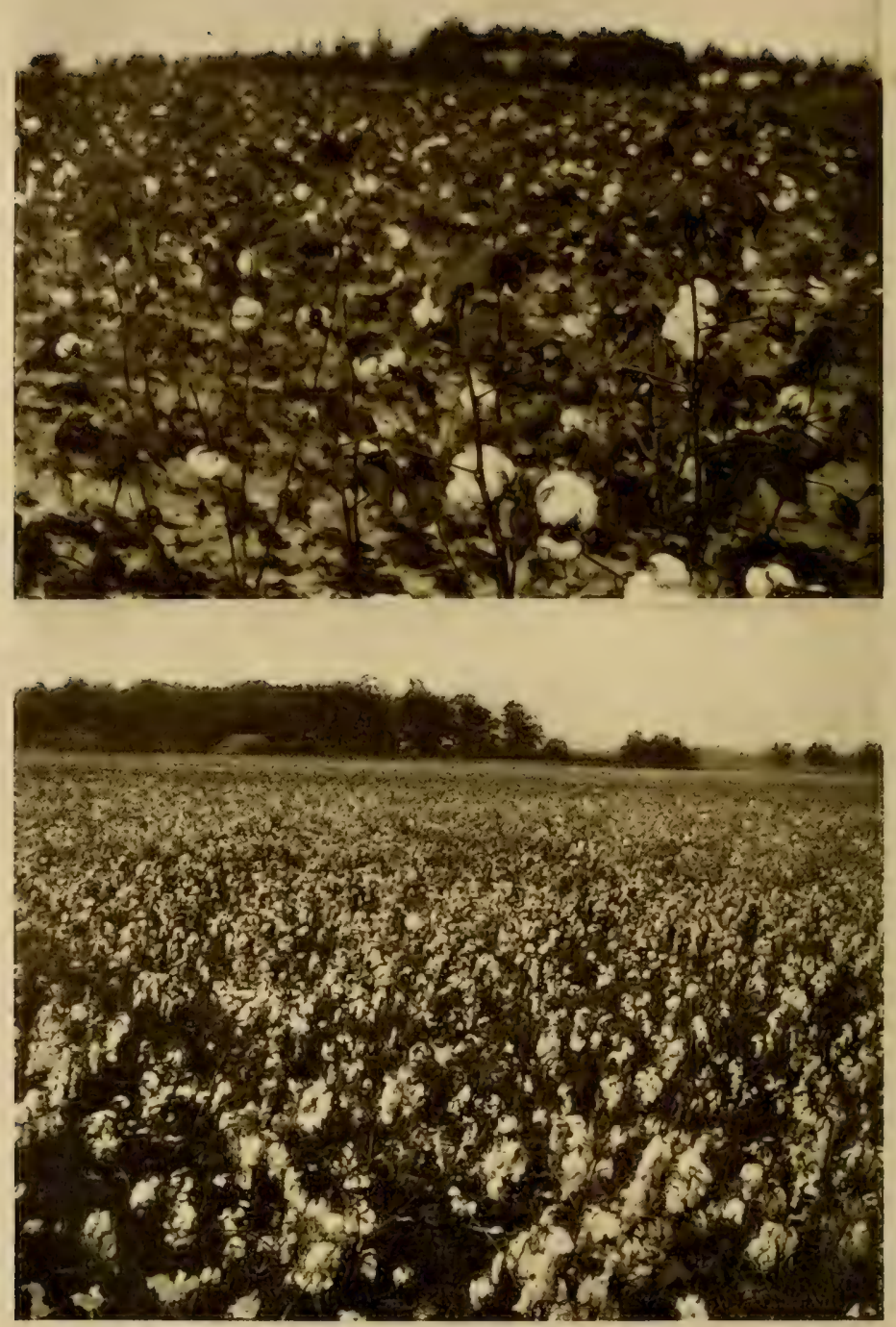

MAKING COTTON WITHOUT HAND CHOPPING.

By the use of cultivators, harrows, etc., farmers are enabled to make good crops entire.y without hand chopping-a great saving in cost. The bottom picture is that of a field in which cotton has been grown for fifty years. 


\section{YIELD OF COTTON}

(Continued)

Year

1900

1901

1902

1903

1904

1905
Production, in bales

$10,425,141$

$10,701,433$

$10,758,326$

$10,123,886$

$13,556,841$

$10,697,013$
Product per acre, pounds

193

186

192

170

207

205

No one needs to be told that these fluctuations were due to natural causes. The same farmers tilled the same kind of land, used the same kinds of fertilizers, followed the same methods of culture, picked the fiber in the same manner, during all these years. There is some fluctuation in acreage, to be sure, but we are now referring to the yield per acre. The difference in yield between 1903 and 1904, for instance, is thirty-seven pounds per acre, or a variation of more than twenty per cent. In this case acreage did not influence the yield, since it was greater the year the largest area was planted. Neither smaller productivity of the land nor the grower's carelessness in culture could possibly have influenced these results unless they acted in keeping the differences within closer limits. The same wide difference is noted when the years 1898 and 1899 are compared, only here the variation is even greater-51 pounds, or a difference of more than thirty per cent.

This inability on the part of the cotton farmer to control his output acts immensely to his disadvantage not only in estimating his yearly expenses, but in marketing his crops as well.

Quite different is it with the man who buys cotton and manufactures it. 
He is able to calculate with more accuracy. As a rule, he knows what his raw product will cost. $\mathrm{He}$ estimates what his operating expenses will be and sells his product, including his many items of expense, at a profit as great as competition will permit. While he has troubles to bother him, they are small indeed when compared with those of the farmer-troubles that begin even before the crop is started and only end when the last bale is sold.

The mere fact that the quantity fluctuates, is enough to show that the farmer deals with factors beyond his control.

Let us suppose a cotton factory produced one year $10,000,000$ pounds of product, the next year $12,000,000$ pounds, the next year $7,500,000$ pounds, and the next $9,000,000$ pounds, all unexpected results, not in the calculation of the management: do you think if such results were produced, the manufacturer could make any very close estimate on the cost of 1,000 pounds of product; or do you think he could remain long out of bankruptcy, unless his profits some years were very great indeed?

But the manufacturer may even sell his product before he makes it. If he can arrange with his labor, and purchase his raw material, he knows within close limits just what his business will do during the year. With the farmer this can never be the case. He knows not twenty-four hours ahead that some insect may not damage his crop, or that some disease may not destroy it in part; nor does he know that wet weather may not come and injure bloom and boll and plant, or give him trouble with his ever-ready enemies, weeds and grass. One day he may be glad and rejoice for what his 
crop may do for him, but on the next, hope and expectancy may have departed.

With exactness he cannot calculate-he can only anticipate, hope, plan for the best.

The point is, the cotton farmer cannot estimate at the beginning of the year just what his total outlay for his crop will be; nor can he bargain on final yields or results. This, however, the manufacturer can do, and he does so with advantage to himself .

It follows that the farmer is entitled to the right of considerable margin as to cost of production when compared with the price it shall bring on the market. These risks which he has to encounter all along the growing route are just as legitimate for use in the final calculation as waste of fiber, variation in cost of power, strikes, depreciation in equipment, etc., are essential factors in considering the final cost-estimate in the cotton factory.

\section{NATURAL CONDITIONS THAT INFLUENCE PRODUCTION}

Were it not for uncertain natural conditions cotton farming would be more stable in its ability to produce certain and constant results, and the farmer also would be able to calculate his profits on his labor and equipment in advance, and with reasonable accuracy. A few of these active, everpresent conditions are:

Variation in productivity of the soil;

Wet or dry seasons;

Diseases and insects affecting the crop adversely;

Ease of securing labor, its cost and efficiency;

Efficiency of fertilizers for different seasons;

Different tools of culture for different seasons; 
Failure of other crops incidental to our system of cotton farming ;

Uncertainty in knowledge of factors governing cotton growing ;

Fluctuation in market value.

All these and many other conditions influence the cost of production, either favorably or unfavorably, each and every year,-and to such an extent that final and sure results are still unknown until the crop is marketed.

\section{TWO PRACTICAL ILLUSTRATIONS}

We will take two cases, not fictitious, but true ones; the farms are near together, similar in size, soil, environments, influenced by the same seasons and climatic conditions, accessible to the same markets. Will the cost of producing a pound of cotton be the same on both farms?

Let the figures speak for themselves; they are the results from two prominent cotton farms:

EXPENSES IN COTTON PRODUCTION PER ACRE Items of Expense $\quad$ Farm A Farm B

Plowing $\$ 1.50 \$ 2.50$

Harrowing $\ldots \ldots \ldots \ldots \ldots \ldots \ldots . .50$

$\begin{array}{llll}\text { Bedding and applying fertilizer .. } & 2.00 & 1.00\end{array}$

Planting ...................... .50

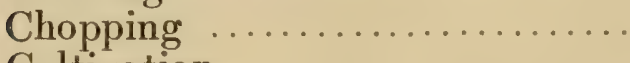

Cultivation

Seed

Fertilizer...................

Picking

Ginning

Other expenses

Totals carried forward. 
EXPENSES IN COTTON PRODUCTION PER ACRE

(Continued)

Items of Expense $\quad$ Farm A Farm B

Totals brought forward....... \$25.95 \$30.30

Less value of seed......... $5.60 \quad 5.84$

Expenses in producing lint..... $\overline{\$ 20.35} \overline{\$ 24.46}$

Yield in pounds, lint cotton..... $350 \quad 365$

Expense per pound lint cotton... $5.8 \mathrm{c} \quad 6.7 \mathrm{c}$ Market value lint at 10 cents.... $\$ 35.00 \$ \$ 36.50$ Receipts per acre above expense.. $\$ 14.65 \quad \$ 12.04$

The results on these two farms show a difference of nearly one cent a pound in cost of producing lint cotton, and here, too, rather good farming is done, since the yields obtained are nearly twice the average production for the Cotton Belt.

But let us take other examples that more nearly correspond to the average for the whole country. Like the preceding two, they are also actual results produced on three average farms :

EXPENSES IN COTTON PRODUCTION ON BASIS OF AN ACRE

Items of Expense Farm C Farm D Farm E

Plowing .......... \$1.25 \$1.00 \$1.00

Harrowing ........ .50 $\quad .50 \quad .15$

Bedding and Adding Fer-

tilizer........... $1.75 \quad 1.50 \quad 1.12$

Planting .......... .40 .25 .25

Chopping ......... $\quad .50 \quad 1.50 \quad .75$

Carried forward..... $\overline{\$ 4.40} \overline{\$ 4.75} \overline{\$ 3.27}$ 
EXPENSES IN COTTON PRODUCTION ON BASIS OF AN ACRE-(Continued)

Items' of Expense

Brought forward....... \$4.40

Cultivation ......... 2.50

Seed

Fertilizer.............

Picking . .50

3.75

4.00

Ginning........... 1.25

Other

Totals

1.00

$\$ 17.40$

Less value of seed

4.80

Expenses in producing lint.............\$12.6

Yield in pounds of lint Yield in pounds of lint cotton................

300

Farm D

Farm E $\$ 4.75$

2.00 $\$ 3.27$

2.75 .35 .25

3.00

2.00

3.00 .75

3.00

2.00

3.00

$\$ 15.85$

$\$ 14.92$

3.20

3.00

Expenses per pound of lint cotton........ 4.2c

Market value lint at 10 cents............\$30.00 $\$ 20.00 \$ 25.00$ Receipts per acre above expense ..........\$17.40 $\$ 7.35 \quad \$ 13.08$

The results as shown in these instances give us an idea of the range in expense account on farms where the yield varies from one-half to threequarters of a bale per acre. It will be seen that they represent neither extreme, and can be taken as showing about average results.

We will now carry these estimates still further by considering statistical averages from a large number of sources, representing different soils, and different climatic conditions, in our several Cotton States. The results are as follows: 
AVERAGE EXPENSES IN COTTON PRODUCTION ON BASIS OF AN ACRE

Items of Expense

Many Farms

Plowing................... \$1.55

Harrowing ................ .52

Bedding and Adding Fertilizers........ 1.65

Planting ................... . . . . . . .

Chopping ................... 1.34

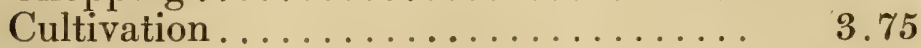

Seed......................... . . . . . . . .

Fertilizer. . . . . . . . . . . . . . . . 4.75

Picking .................. 4.55

Ginning................... 1.35

Other expenses............... 2.88

Total..................... \$23.13

Less value of seed . . . . . . . . . . 4.72

Average acre expense of producing lint... \$18.41

Average yield of lint cotton in pounds... $\quad 296$

Expense per pound lint cotton....... 6.2c

Market value of lint at 10 cents... . . . . . \$29.69

Receipts per acre above expense....... \$11.10

\section{WHAT COST MEANS}

Estimates showing "cost of production" are freely made and often are misleading, because they are based solely on items of expense incidental to producing the crop during its growing period only. The cost of production ascertained in this manner is incomplete since it leaves out of consideration many items that are necessary and legitimate and which must be included if a fair and accurate statement is to be made.

On many farms cotton is the only crop produced; even feed for work stock (and this is not uncommon) 
and the work stock itself are not home-produced, but purchased in the open market just as supplies and equipment are for the cotton factory. As a rule, work stock is permanent equipment for the cotton crop alone, and cotton must support it, just as land is permanent capital, and land is not employed during the whole of the year: there is no reason why they should be omitted in the final settlement. The investment is made and an allowance of interest must follow, teams must be fed, and the maintenance of the plant continued-all items of legitimate expense which must rightly be considered in calculating the real cost of production.

"But why charge cotton with the support of teams during the winter season?" you ask.

Who will feed them? Your neighbor will not, neither will the State. On most farms they belong to the cotton equipment. Of course, where they are employed for other purposes, a proper credit to cotton should be made, but in the winter season as a rule, both labor and teams are idle, and cotton should bear its part of this expense.

You see there are other charges to be added to the amount required for the mere production of the crop.

Here are a few that must be included:

Taxation of land, tools, and teams.

Allowances for interest on land, tools and teams.

Allowance for depreciation of tools and teams.

Maintenance of land and teams.

Taxation:-On the basis of the product of one horse or mule, we have twenty acres of land, valued at fifteen dollars per acre; one working animal valued at one hundred and fifty dollars, and tools 


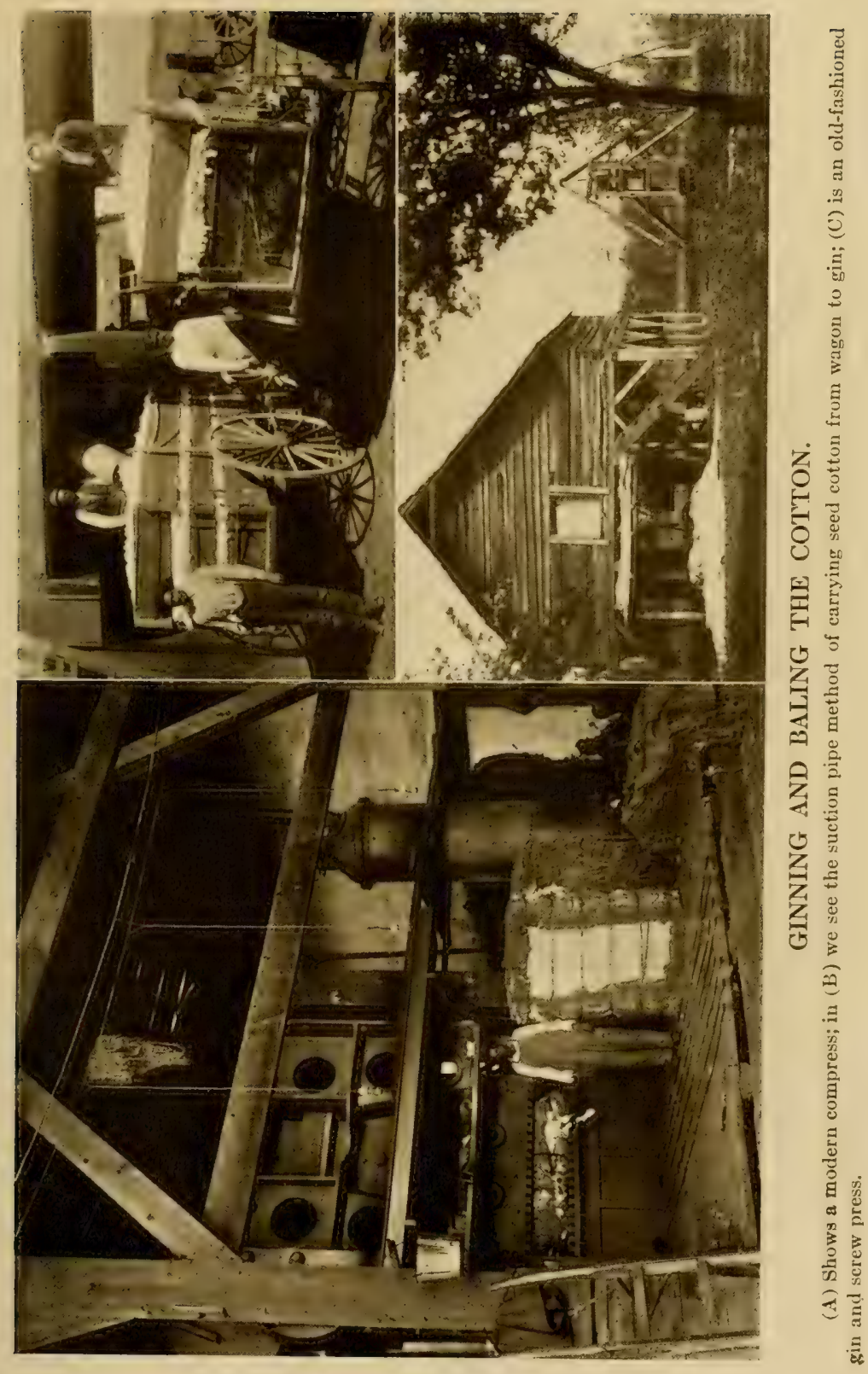



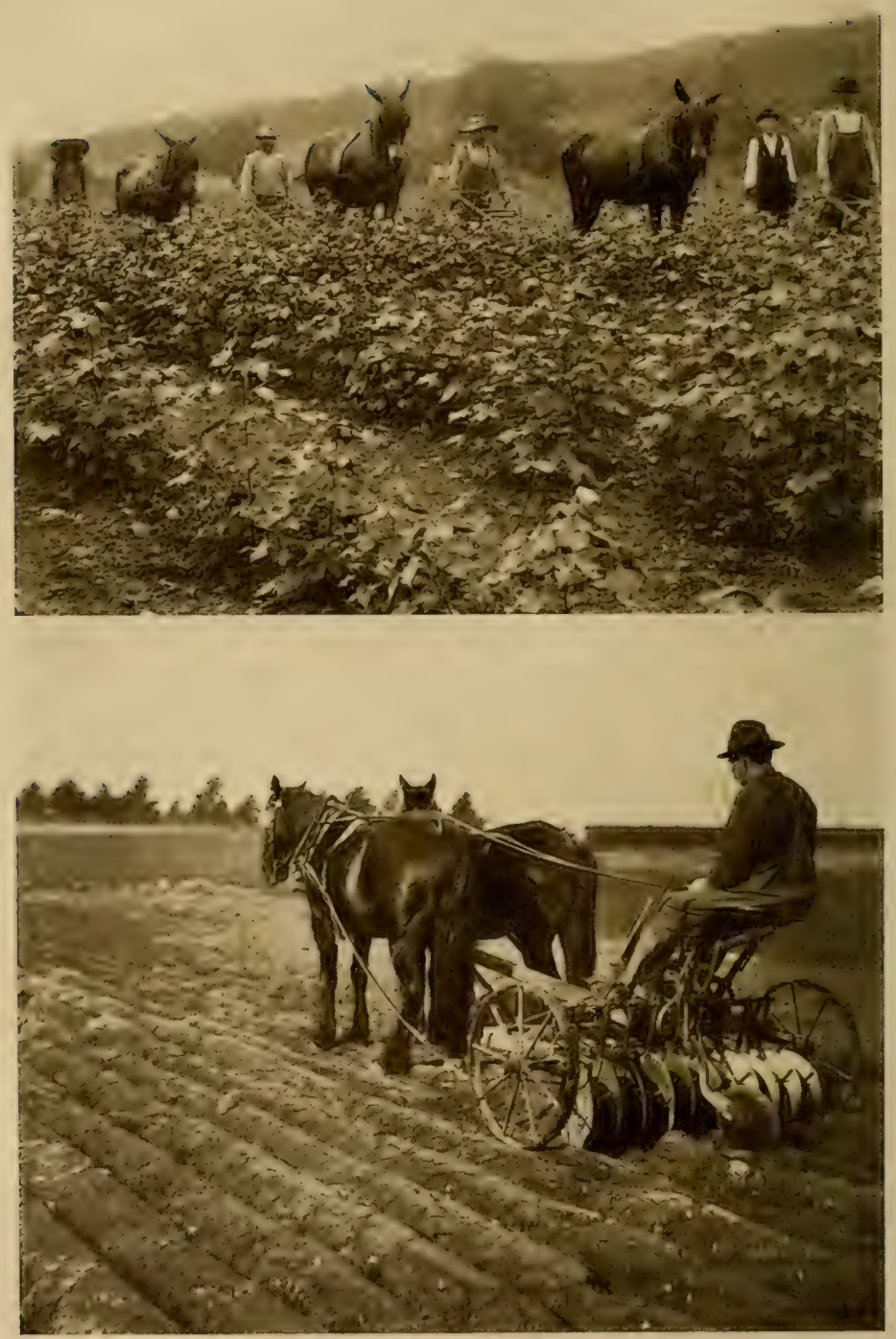

HOPE AND REALIZATION.

Disking land preparatory to planting cotton; and the final cultivation before the crop is "laid by" in July. 
valued at about seventy-five dollars; a total of five hundred and twenty-five dollars,- - a reasonably low estimate, you will admit. On this amount taxes will be three dollars.

Interest:-The investment should realize six per cent.: this is a simple business proposition with banks, as well as with all investing enterprises. This calls for a charge against cotton for thirty dollars.

Depreciation:-The average working life of a horse or mule is ten years; therefore the cotton crop here must make good an annual depreciation of fifteen dollars, and also keep in repair stock, implements, and tools, which on the cotton farm is at least ten dollars, or a total of twenty-five dollars.

Maintenance:-At least twenty-five cents per acre is expended each year in maintaining the land. Terraces must be kept up, ditches must be opened, brush and shrubs cleaned away: a cost here of five dollars annually. Then the horse must be fed throughout the year. At least half the time he is non-supporting, and cotton should pay his bill for board. The occasional use will cover his care. Hence a charge of forty dollars is to be made: a total of forty-five dollars for the yearly expense of maintenance of land and stock.

We get then the following additional amounts that must be included in the cost of cotton production:

Taxation...............\$3.00

Interest................ 30.00

Depreciation.............25.00

Maintenance............. 45.00

Total............\$103.00

Cost per acre......... 5.15 
This estimate is based on a cotton farm of twenty acres which produces an average of 200 pounds of lint cotton per acre or 4,000 pounds as a total product. These additional charges now should be added to the expense incurred during the six months of the growing season. When this additional cost, on basis of calculation suggested, is included in the expense, we have obtained a figure that reasonably represents the cost per pound of cotton production as follows:

\begin{tabular}{|c|c|c|c|c|c|c|}
\hline Cost & Farm A & Farm B & Farm C & Farm D & Farm E & Allothers \\
\hline Growing & 5.8 & 6.7 & 4.2 & 5.8 & 4.8 & \\
\hline Additional & 1.5 & 1.4 & 1.7 & 2.6 & 2.0 & \\
\hline Tota & 7.3 & 8.1 & 5.9 & 8.4 & 6.8 & \\
\hline
\end{tabular}

\section{DIFFERENCE BETWEEN COST AND MARKET PRICE}

So far in our estimate no allowance has been made for directive effort save in that of labor itself. But this the cotton farmer is entitled to, since he is both a laborer and a capitalist; when considered in connection with the value of his product, to a considerable extent, he is both. The difference remaining between the cost of production and market value of the crop comes now as profit to cover such charges as are included in superintendency, in the duties of the producer as a citizen, in the risks he runs as to profit or loss in his enterprise, and in accumulating gain.

RELATION OF OTHER EMPLOYMENT TO COTTON PRODUCTION

The cotton farmer has a perfect right to carry on 
other farming enterprises as well as cotton. But they are separate and distinct in themselves. If he can so connect them with his cotton enterprise that these and cotton work to advantage so that the cost of production is lessened, that is his right and to his credit as a business man. But cotton farming must stand on its own feet and not exist at the expense of the cow or the pig. You may be sure, in case you think you are producing cotton very cheaply, that the tenant, or cord wood, or hay, the steer, or the old hen, one or all, are contributing very materially to the pocket that pays the cotton bills.

\section{RELATION OF COST TO SELLING PRICE}

Naturally some farms produce cotton more cheaply than do others. On a basis of cost, a reasonable selling price on the average is ten cents per pound; it is mere wages when below that. Like other products, cotton sells in the face of supply and demand. When earnestly wanted the farmer's accumulative gain is greater, but not out of the range of the very supplies he constantly purchases. 



\section{SECTION III.}

\section{MARKETING AND PRICES}





\section{CHAPTER XXV.}

PREPARING FOR MARKETING: THE WORK OF THE COTTON GIN

Cotton production in the Southern States owes its great development to a simple invention which must be considered one of the greatest connected with the marvelous rise of American agriculture.

When cotton is gathered from bolls it is known as seed cotton from the fact that it contains both seed and cotton lint-two-thirds seed to one-third lint. To prepare cotton therefore for the market and for commerce, it is necessary first to separate these two products. This work is now done by means of the gin.

In 1790 but 3000 bales of cotton were produced in the Southern States: in the year 1904 more than 13,000,000 bales were produced.

Why this remarkable difference in production? Naturally the demands of the world have influenced this production; improved tillage and cultural tools have played a considerable part in lessening the cost; commercial fertilizers have increased yields without additional labor and with relatively small cost; but for an answer to our question we must go first of all to that invention which has made the name of Eli Whitney immortal.

To the cotton gin the greatest credit must be given. With seed picked by hand, cotton produc- 
tion could never have become a commercial enterprise of more than local interest. With seed picked by hand cotton manufacturing would never have developed. Some other fiber-wool or flaxmight have been King, but cotton never.

It required the cotton gin-doing the work of picking by other power than by hand,--to develop this industry, and make it rank as second to none in all the world.

\section{THE BEGINNING OF THE COTTON GIN}

Eli Whitney, to whom the world credits the cotton gin, was a graduate of Yale and a native of Massachusetts. He possessed an inventive spirit and a full knowledge of mechanical devices. Seventeen hundred and ninety-two found him on his way to South Carolina where he expected to follow teaching as a profession. But greater things were in store for him: his genius was to be directed in another way; a larger service to the race was to be his. For some reason his arrangements for teaching miscarried, and he was left without employment. He was in a strange land, he had no work to which he might go, and was without means to begin any new enterprise. Chance favored him, however. Soon after his arrival an invitation to visit a friend came to him. He accepted, and while sharing this hospitality with others who also came to enjoy the warmth of the South Carolina home, Whitney learned of the difficulties of the Southern planter, and especially of the great difficulty that stood in the way of the development and production of a great cotton crop. Just how this matter was presented; in just what form it came to his attention, 
we do not know. Whether or not the thought had its birth in his fertile mind is also a mystery. But this matters not. He became interested in the great problem of profitable cotton production. Maybe this was a problem of the plantation where he resided; maybe the thought came as a chance suggestion. Be that as it may, he made the problem his. He fitted up his shop and went to work. His educational equipment and his mechanical inclination favored him, and soon hope came, the clouds parted, the ideal became more than a fancy. Soon it was a reality, the cotton gin a material thing.

Of course it was crude, undeveloped, only partially practical at first. The next year the patent was granted and given to the world.

The germinal idea was alive, its incubation soon ended, the gin was born, soon to be a working success; soon to make an industry; soon to build an aristocracy; soon to make the fortunes of men and nations.

One of the first inventors who contributed to the success and perfecting of the gin was Hodgin Holmes of Georgia. As early as 1796 he secured a patent on his gin which represented some useful features not possessed by the Whitney patent.

THE MAGNITUDE OF THE INVENTION

The cotton gin is an example, perhaps the most remarkable on record, of the power of a single labor-saving machine to infuence the social and industrial interests, not merely of a nation, but in a great measure of the civilized world. "What Peter the Great did to make Russia dominant," says Maraulay, "Eli Whitney's invention of the 
cotton gin has more than equalled in its relation to the power and progress of the United States."

In reference to this invention and its effect on cotton manufacturing an early writer has this to say:

"Its introduction at the particular period when the completion of the brilliant series of inventions for carding, spinning and weaving cotton had created a demand for the raw material, at once directed into a new and profitable channel the agriculture of the South, and at the same time furnished the manufacturing industry of Europe and America with one of the most valuable staples, and the shipping and commercial interests of the world with an enormous trade in its raw and manufactured products. The increase in growth and exportation of new cotton which followed has no parallel in the annals of industry, save in the wonderful develop-, ment of its manufacture in Europe and America."

The effects in all their magnitude of the growth of cotton culture and manufacture in increasing material wealth, in furnishing employment to labor and capital, and in increasing the comfort of all classes, can hardly be conceived.

\section{THE EARLY GIN}

The gin in its early days consisted of a series of fine tooth circular saws fastened upon a wooden cylinder about three-fourths of an inch apart, and revolving in slits cut in a steel plate, less than a quarter of an inch wide. A mass of cotton in the seed is laid on this plate. As the saws revolve the teeth passing down between the openings, pull off the lint from the seed and carry it through with them, the openings being narrow enough to pre- 
vent the seed from passing through with the lint. On the lower side of the cylinder set with saws is a revolving brush which takes off the lint as it comes through the saw teeth, and a blast from a revolving fan carries it back through a flue into a lint room in the rear of the machine. This is the essential principle of the Whitney gin as well as of all succeeding ones that have yet been made.

\section{PRESENT DAY GINNING}

There are two kinds of gins used at the present time: roller and saw. The former, old long before Whitney's saw gin was invented, is used for ginning Sea Island cotton, while the saw gin is always used for the upland varieties. Seed of Sea Island cotton, it must be remembered, are loose in the lint, smooth and clean,-as contrasted with upland seed to which the lint is as firmly attached as barnacles to a log. Hence the need of two forms of ginning.

The cotton gin is by no means perfect yet: it leaves too much dirt and trash in the lint during the process of separation from the seed. Whether perfection in this direction is at all possible, the future only can say; but at present the waste in form of dirt, weak fibers, seed and leaf is a matter of considerable consequence. The gins now used also cut the lint badly, thereby seriously damaging it for manufacturing purposes. With the coming of improvements, cotton ginning has become an industry, almost separate and distinct in itself.

Not many years ago nearly every plantation had its own gin: but there were many items of expense which made the small gin too expensive. It was 
operated but a small part, not only of each year, as must be true of all gins, but only a small part of the ginning season; parts got out of repair, and interest on the investment amounted to much when the small returns from ginning the crop of a single plantation were considered.

Once it was thought that portable ginning outfits, like portable threshing outfits, would be practicable, but too much power was needed; there was too much expense connected with the transportation, especially where but few bales were ready to be ginned; too great difficulty in the way of securing fuel and water, and too many interruptions due to bad weather and poor roads.

\section{THE STATIONARY GIN}

The small farm gin was costly, the portable gin impracticable; and so the larger stationary gin came as a necessity as well as the solution of a vexing problem.

The numerous inventions incident to the completion of the ginning idea, the labor-saving devices in many directions, the rapidity of ginning and baling by the gins of greater capacity, have established the large stationary gin as a prominent part of the equipment of the cotton industry.

The farmer may now haul his seed cotton to the gin in an open wagon box, the suction tubes will suck the cotton up, the carrying belts will carry it to the saws, and the lint will go at once to the compress, giving the owner his cotton back in baled form in a few minutes after the wagon is emptied.

The old hand method made but a pound of lint daily: the hand gin increased the working efficiency to half a modern bale per man; the old plantation 
power gin further increased the quantity to several bales; and now the consolidated high power machine is common where 50 to 75 bales, and in some cases even as much as 250 bales, are daily ginned and baled.

This is indeed wonderful evolution.

\section{THE SUCTION ELEVATOR}

The suction elevator has done much in increasing the daily capacity of gins. 'Think of the labor required for carrying from the wagon by hand all the seed cotton produced any season-and now a simple device does it all, effectively, quickly, economically.

"What is the extent of this saving?" we once asked an expert.

"To this extent," he replied, "three hands to a gin of say 60 saws, making four hundred revolutions per minute-the speed producing the best staple-would turn out six bales in a day of 10 hours. With the suction elevators, the same number of hands with much less labor, can attend to four or five gins and turn out 24 to 30 bales in the same time."

\section{THE ITEM OF SPEED}

Cotton comes from the gin in the best condition if speed is kept within moderate limits. The tendency to run the gin at high speed increases the output but lessens the value of the lint. Here, then the interests of the farmer and ginner are at variance-unless the farmer is willing to recognize the value of cotton ginned at low speed by paying more for such service.

High speed strains and even breaks fibers, and 
allows waste matter to become mixed with the lint. The old gin, when run by horse power, was not open to this objection urged against high steam power. Then you never heard of cut or broken fibers or of crimped or knotted lint such as is now caused by the impact of the saws when the cylinders rotate at a high speed.

About four hundred revolutions per minute is considered a reasonable speed, and this leaves the lint product in fairly good physical condition.

\section{THE BALING PROCESS}

While the baling process has no direct connection with ginning, it is now a part of the gin equipment, and so may be considered as belonging to this operation preparatory to marketing.

Like the gin, the baling press has been materially improved in rapidity and in efficiency. The large compresses put a large quantity of fiber into a small bulk, thus promoting ease of transportation.

Freight rates, you know, are regulated by bulk as well as by weight. Hence, this leads naturally to the demand for a bale carrying as large a quantity of lint as possible in a given amount of space. The following data showing the average weights of bales for 100 years illustrate this:

In 1800 average bale, weight 225 pounds; 1810 , 250 pounds; 1820 , 264 pounds; 1833, 339 pounds; 1839, 385 pounds; 1849,400 pounds; 1859,445 pounds; 1869,440 pounds ; 1879,453 pounds ; 1889 , 477 pounds; 1899,499 pounds.

Cotton brokers and shippers naturally prefer a bale of great density, and of such shape as will pack easily in cars and steamboats.

As a rule, the American bale is not prepared 
with such care as its importance demands. It now comes in all sizes, varies greatly as to weight, may or may not have been damaged by rain and exposure. Then, too, it is poorly covered. Often the covering is torn, allowing the lint to drop out, subjecting the American bale to the charge that it is "the clumsiest, dirtiest, most expensive and most wasteful package in which cotton, or in fact any commodity of like value, is anywhere put up."

What do you do with your cotton when it comes back from the gin? Your neighbors put theirs under the apple tree or in the barn lot, or in some open exposed place, where rain and dust attack and damage it; even pigs are allowed access to cotton bales as places to clean their muddy backs.

This constant loss is of course the farmer's, and no one else's. Even the waste due to bagging and ties is the farmer's loss, although he seldom realizes it. The usual tare percentage is placed at six, which means a reduction of 24 pounds for a 400 pound bale, and 30 pounds for a 500 pound bale. While this feature of tare is but slightly discussed or considered in this country, it always calls for a deduction in the great manufacturing centers abroad and so has its effect on cotton prices. 


\section{CHAPTER XXVI.}

MARKETING: THE TRIP TO THE SPINDLE

Having come this far in all seriousness of spirit may we not turn now to something a little lighterperhaps even to a nonsense verse? If so,-well, you remember the old nursery rhyme, that runs:

"Jack and Jill went up the hill, To get a pail of water;

Jack fell down and broke his crown, And Jill came tumbling after."

In a large sense this expresses the situation that confronts the cotton farmer in handling his crop. You and I and every man who produces cotton must first go up the hill. Like Jack and Jill we go there for a purpose; ours is to produce a crop that shall, we hope, enable us to keep our farms in a good producing condition; our houses and barns in repair; our reading tables reasonably furnished with papers, magazines and books; our family with food and raiment; our children with the advantages of education for culture and professional efficiency. We have a right to expect these rewards. Jack and Jill no doubt knew that water was there; we at least know that the kind we want is there. But it is hard to get it. The road that leads to the top of the hill is a difficult one. That this was so with the one that Jack and Jill went up, is evidenced by, the fact that "Jack fell down and broke his crown." It was a steep, rocky road, no doubt; rough and dif(224) 
ficult of access. And isn't the road of the cotton farmer steep and rough and difficult? And so long, too. Six months and more are necessary to cover the distance; a thousand difficulties are met on the way; late frosts in the spring, and early ones in the fall before the crop matures; often unduly wet weather or unduly dry weather materially lessen the crop; insufficient and inefficient labor bother and interfere; expenses for labor, seed, fertilizers, implements, and tools, often come at the sacrifice of the legitimate comforts and needs of the family: surely the road is beset with difficulty and danger all the way we must follow in reaching the top.

For Jack and Jill the top possessed water; for the cotton farmer the top-the end of his journeyis the market. He is entitled, at least, to water while on the top, enough to take him down the hill again, a sufficient quantity for those dependent upon him at home, and in quantities sufficient to supply not only real needs, but all purposes of comfort and even those of luxury; besides this, he is entitled to enough to last him on his trip up the hill again, and to supply his family until he returns with a fresh supply.

Are you going to reject this philosophy?

Is it not the kind practiced and preached by every other industry - the railroad, the cotton factory, the coal, iron, and steel industries, by every manufacturing and industrial concern?

Are not its precepts illustrated in the tenets of every professional creed-the merchant's, the doctor's, the banker's, or the publisher's?

All accept this doctrine save the farmer-and what is more, they practice it.

Take the railroad. Its preachments are all to the effect that its capital is entitled to a reasonable 
annual reward. In practice it goes further and not only grants this on its real investment, but includes dividends on a fictitious, watered capital as well.

Take the trust. It secures not only its legitimate share of the water at the top of the hill, but through all sorts of schemes and tricks secures a great deal more.

Take the man in exchange or in business. He meets with his fellow workers; he organizes and plans that competition may be met; that he may thus secure his share of water, and further that his share shall be protected for all future years.

Then take the farmer-the cotton farmer. He meets not with his fellows; he organizes not; he goes to the top of the hill alone; his part of the road is roughest of all; and when he gets there he is alone; it is dark and only with difficulty does he find water. At other times so many others are at the source of supply, and so well organized, that they crowd him back and away.

So he takes what is offered and returns on his homeward journey.

Going still further with our nonsense verse, we also discover that "Jack fell down and broke his crown, and Jill-she tumbled after."

And here is the danger place in cotton production: the crop is produced, too much goes on the market all at once, or the market is manipulated, and over it goes. Jack fell and broke his crown. How many cotton farmers, think you, are ruined, because the cost of production - the trip up the hill-is more than the market place gives them?

But there is more to our story yet: When Jack fell down, "Jill came tumbling after." When cotton goes down, not only that man whose crop costs more than he secured for it is injured, but 
his neighbor who made a little on his crop, his banker, his merchant, his friends in other lines of work, are injured as well. But the result is even more far-reaching; the manufacturers who make the cotton farmer's clothing, his tools and implements, who supply him with all the necessities, suffer as well. The farmer falls down, and the rest come tumbling after.

\section{HELP IN THE DIRECTION OF ORGANIZATION}

It is not wrong to organize. The principle is commercially and morally correct. Organization is helpfulness. Cotton farmers need the spirit of helpfulness. They will profit by it as much as any class, for it will bring a new meaning to cotton production; it will secure, as it is doing now, reasonable rewards for the effort expended; a fuller and better life will follow for the home on the cotton farm.

Organization may direct itself along many lines; it will look to the stability of the home market; it will seek for new markets; it will regulate supply in accordance with legitimate demands; it will seek to lower the cost of production so as to increase the margin of profit. All these things come with rightly managed organization.

\section{HOW THE FARMER MARKETS HIS CROP}

Cotton is sold both in the bale and as seed cotton, although the first named method is the rule. It is the most desirable and satisfactory plan, since it necessarily leaves the seed with the farmer to whose soil it rightly belongs. While it is true that if cotton lint sells for ten cents per pound, it is easy to calculate its worth in seed cotton, still this can be 
done only with reasonable accuracy, subjecting the method to some degree of criticism. Since the gin and the press are so available now, there is no reason why every farmer should not sell his lint in the bale rather than in any other form.

\section{BORROWING ON THE CROP IS BAD BUSINESS}

An interesting economic development has come with the rise of the cotton industry. It concerns itself with cotton factors who advance money to the needy cotton grower, taking as security a lien on his crop. The usual advance is ten dollars or more on the bale, given at the highest legal rate of interest. Without this help of the cotton factor, many people would be unable to purchase seed, fertilizer, feed, teams and stock, and so produce a crop. By borrowing on the crop they are able to tide over the space of time intervening until marketing of the crop arrives. Of course, this is bad business; while it is profitable for the cotton factor, it is ruinous for the grower, and consequently injurious to the community. When the crop is harvested it may be sold at once, the factor paid, and the balance credited in the bank to the cotton grower.

This balance, during the good year, may besufficient to start the tenant or other grower the next spring, and even carry him to the close of a second crop; or it may be so small, that he will with difficulty be able to live through the winter, and begin a new crop. Often it is necessary for tenant, or the otherwise poor farmer, to begin borrowing early in the year to meet bare necessities. When good seasons come, this crop lien business is of smaller proportions, but with poor seasons such advances are great and consequently burdensome to the grower. 


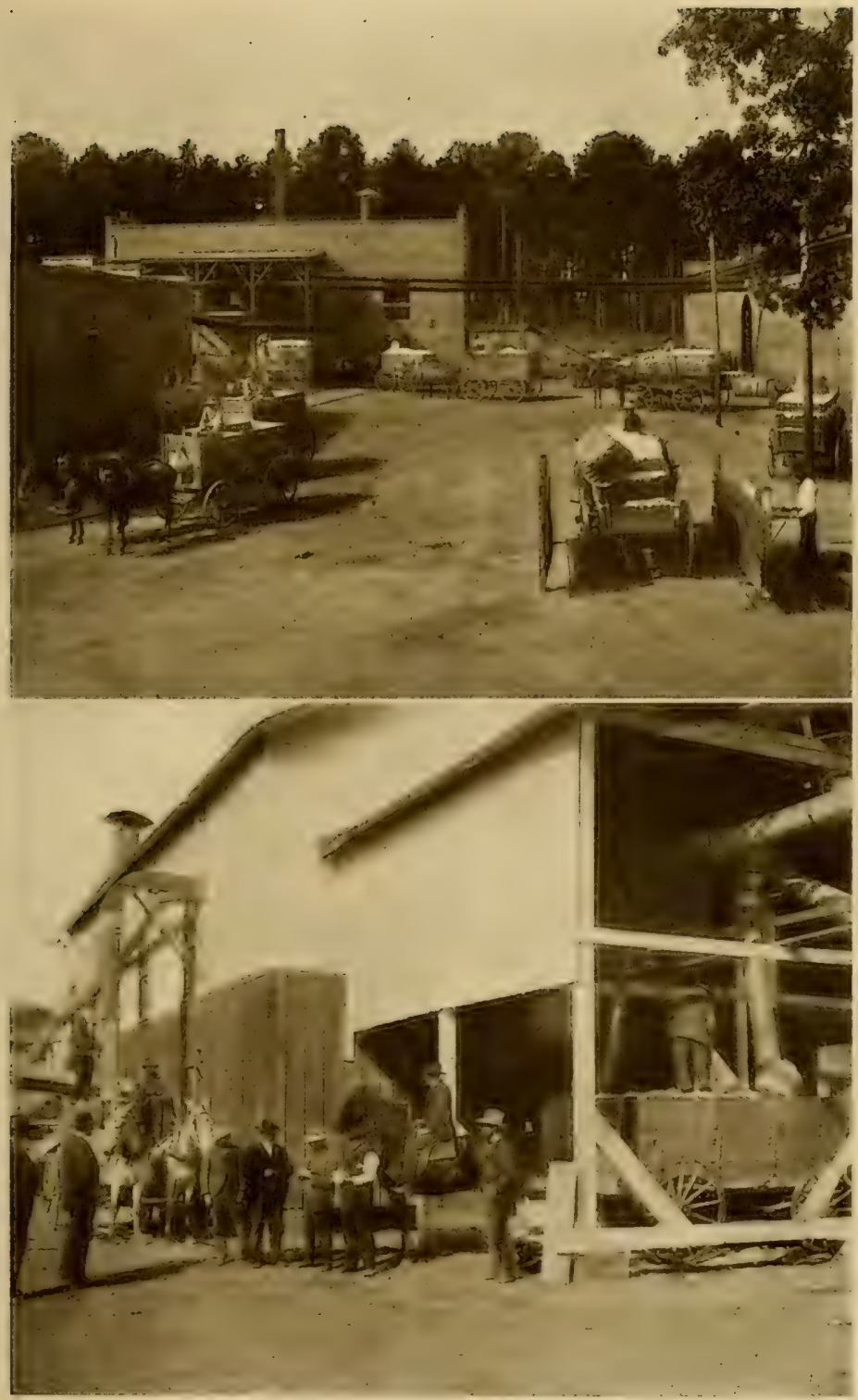

WAITING TURNS AT THE GIN.

In the busy season, October and November - cotton goes to the gin more rapidly than it can be handled. The seed cotton is then stored temporarily in bins made for that purpose. 


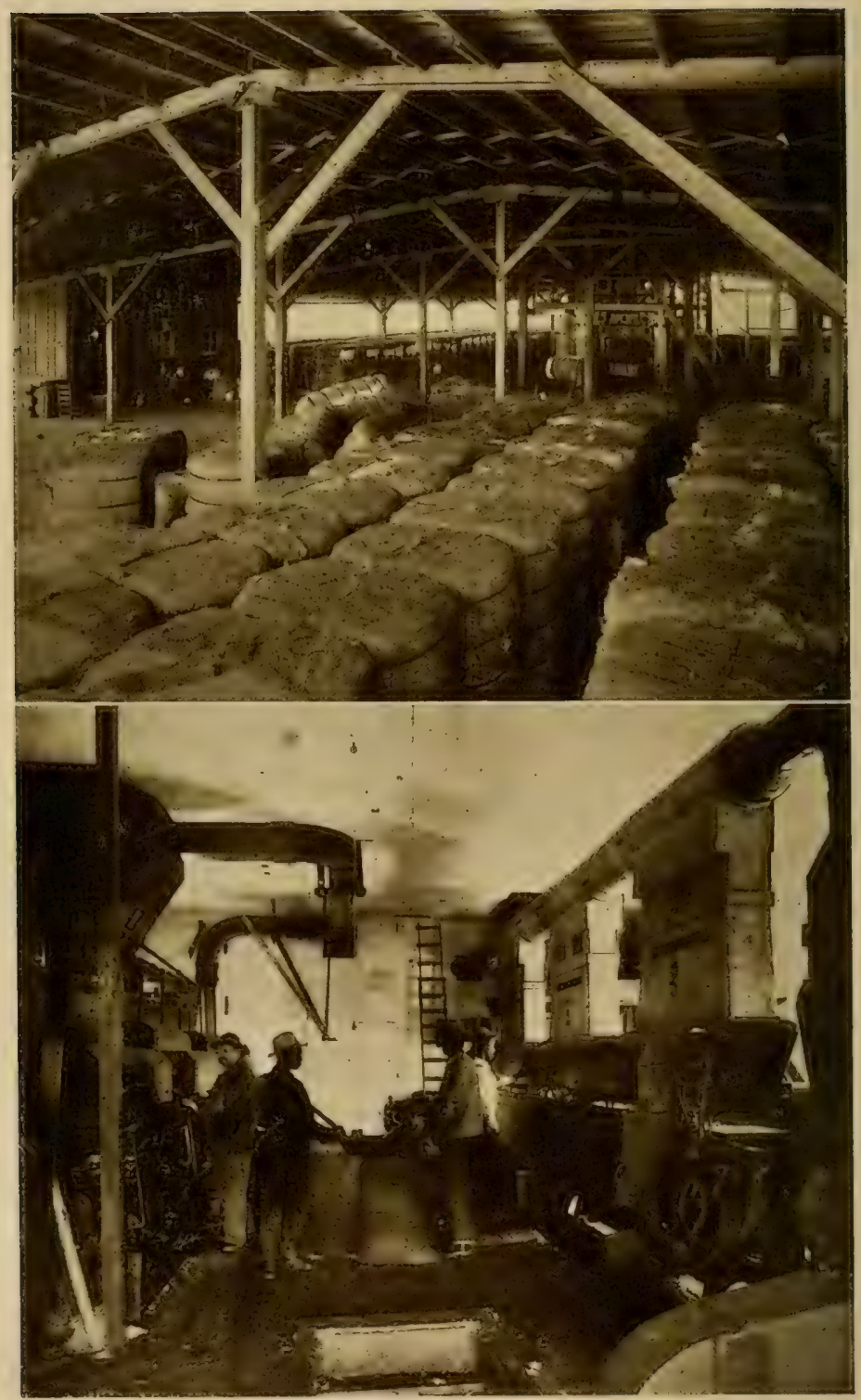

A LOOK ON THE INSIDE.

It has been said that the average farmer "takes as little care of a cotton bale as if it were a grindstone." Now, however, storage warehouses are becoming popular. In the second view we have the interior of a gin. 
With good prices the custom is now fast passing away.

STORING COTTON

At harvest time not all cotton is sold at once; some is hauled back to the farm or stored in the warehouse, and held for the expectant advance in price. The farmer who has borrowed on his crop usually stores in the warehouse that the cotton factor may have an eye on the bale. The storage cost varies from ten to fifty cents per bale, depending on the length of time it is kept in storage. Insurance must be considered as well, for much loss follows as a result of fire. The total cost for selling, storage, and insurance varies from $\$ 1.00$ to $\$ 2.00$ for each and every bale.

Where cotton is taken back to the farm, there are, of course, no storage charges, and insurance is usually at the owner's risk. While many farmers do store their cotton in places of shelter, the majority do not, but simply pile it out in the open or under the home-yard tree.

Remember that cotton, although not a perishable product, is susceptible to deteriorating influences of weather and the elements, just as other field crops are, even if in a less degree; and when long exposed to weather, the quality suffers to such an extent as to make a material difference in price. This loss, when measured for the entire cotton crop, assumes enormous porportions.

This, too, is one of the most unnecessary and inexcusable leaks on our cotton farms. If you protect your cotton thoroughly from the time it is delivered at home in the bale to the delivery time on the market, you will save enough to cover all 
rental and investment charges, and so make a warehouseman's profit for yourself.

\section{IN THE MARKET PLACE}

Cotton is often sold at the warehouse or eisewhere through an agent, whose charge is on the average of one dollar per bale. As a rule, the farmer makes his own sale, one or more buyers bidding for his product.

With the coming of cotton factories throughout the cotton-producing States, a market is provided at first-hand, enabling the producer to sell direct to the mills. Wherever this opportunity exists, it gives satisfactory results to both parties. The farmer profits, since the factory saves agents' charges for buying, drayage and freight, and this ends wholly to the advantage of the farmer or to the mutual advantage of both.

But since the greater part of the cotton crop goes North or abroad, some intermediary factors must exist in order to handle this enormous business. Usually this is done by exporting companies, which are financed by heavy capital, and whose sole business is to move the cotton from producer to consumer.

\section{MARKET GRADES OF COTTON}

Cotton as sold on the market is first classified into several different grades, and like all the products of commerce, its value is measured by intrinsic worth, merit and quality. Nor does it follow that because cotton has a market classification which includes all cotton grown, that the seller receives its true market value. While there is such 

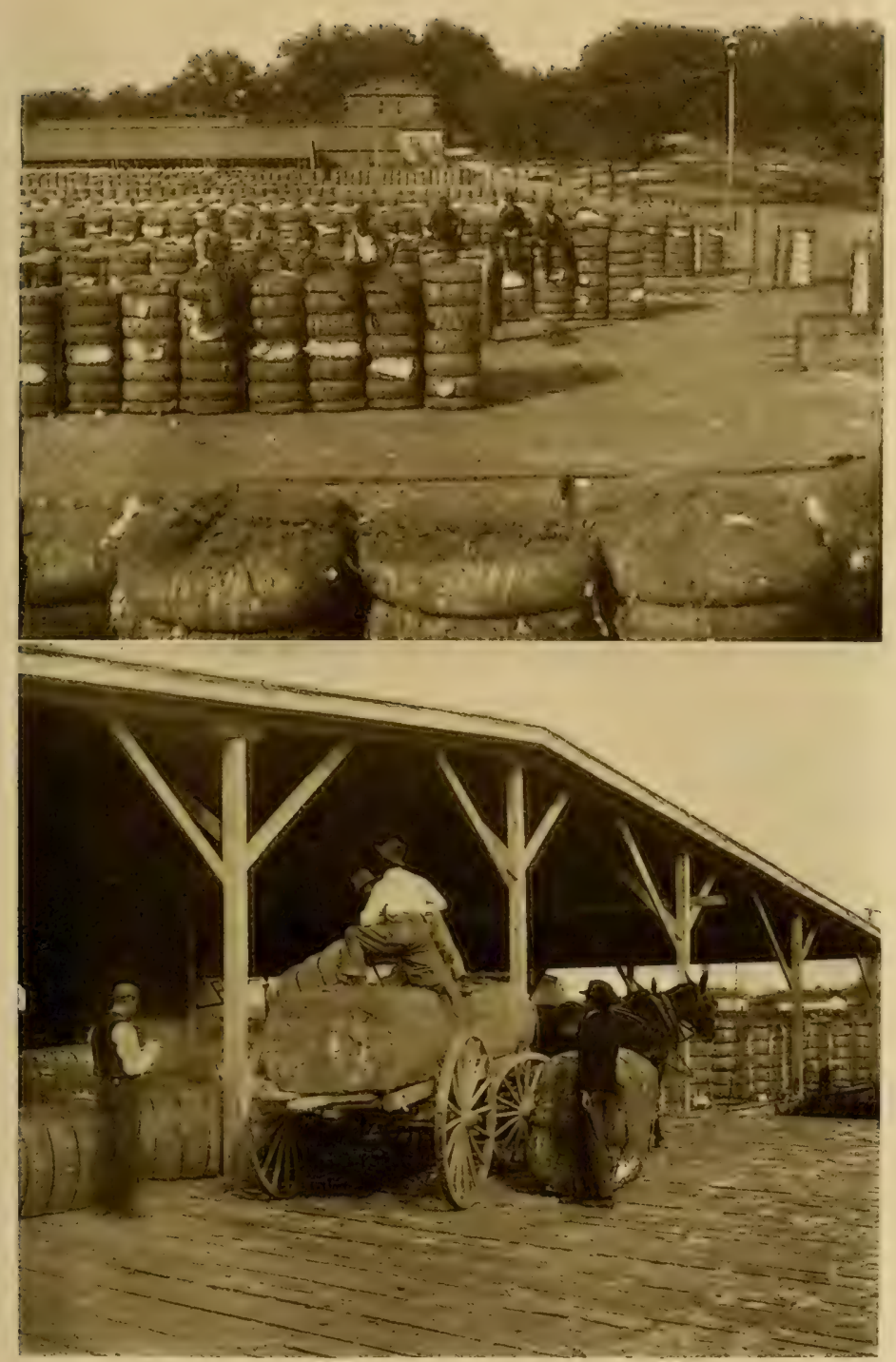

COTTON AFTER BALING.

Much cotton is left on the platform in the open-or worse, flat on the ground; in the second view a farmer's crop is being put into a warehouse. 


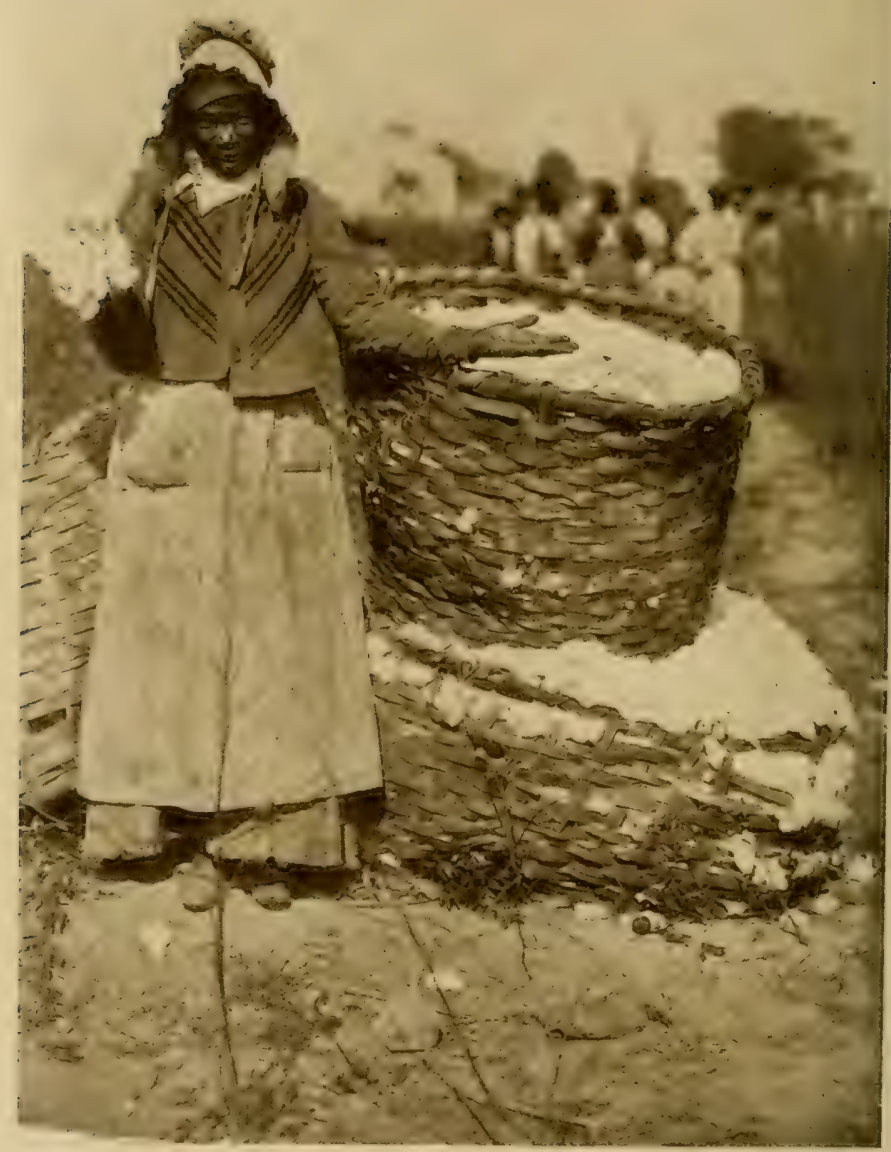

"HOW MUCH DO I GIT AT FIFTY SAINTS A HUND'ED ?"

Her task finished the picker is waiting to have her basket weighed. Then she will know how much she has earned by the day's labor-at 50 cents a hundred pounds. 
a classification for every sort of American cotton, the buyer endeavors to get the product as cheaply as possible, and the producer tries to get as much for his lint as possible. Ordinarily the judgment rests solely with the buyer. He classes fiber as he thinks it should be classed, or as he chooses to class it, and offers a market price for that grade of cotton. You can readily see that where only a single buyer is present, and especially if that one be unscrupulous to some degree, considerable loss may come to the producer and a corresponding gain to the buyer. Naturally there are tricks in buying cotton as there are tricks in other trades, and honesty and business integrity find recognition in the cotton market as they do elsewhere in life.

The most satisfactory selling is done where several buyers are on hand, and this competition as a rule means that the highest prices will be offered. Of course even in this case buyers may join hands and one do most of the buying one day, another a second day, and so on, each taking his turn and getting his cotton at the lowest price. But the daily paper now gives the farmer the prices in the leading markets of the world, and with the railways making transportation to better markets easy, he usually secures what his product is worth, or at least the market value of the grade in which it is classed.

The variety of cotton has nothing to do with the market classification. One variety may be classed "good middling," for instance, another variety "low middling," in the market scale, because of its individual superiority or inferiority as the case may be.

This classification is fixed by market conditions as follows: 
FAIR

Barely Fair

Strict Middling Fair Fully Middling Fair MIDDLING FAIR

Barely Middling Fair Strict Grood Middling Fully Good Middling GOOD MIDDLING

Barely Good Middling Strict Middling Fully Middling
MIDDLING

Barely Middling Strict Low Middling Fully Low Middling LOW MIDDLING Barely Low Middling Strict Good Ordinary Fully Good Ordinary

GOOD ORDINARY

Barely Good Ordinary Strict Ordinary

ORDINARY

Low Ordinary Inferior.

It will be seen that grades are known as full grades, half grades, and quarter grades, although the quarter grades are used very seldom in classifying the fiber. In the classification as given here the grades in capital letters are the full grades, the half grades being indicated by the prefix "strict," and quarter grades by the prefixes "barely" and "fully."

"Middling" grade is the one universally used in all cotton deals. When a price is made, it is given on the basis of middling grade. All cotton contracts or "futures" call for middling, and it becomes the standard in exchange. This does not signify, however, that contracts may not be filled with other grades, but in case a superior or inferior grade is furnished, the prices become proportionately higher or lower, as the case may be.

The buyer's judgment must be good, else his classification may be incorrect, and consequently may lead to loss. 
It is of importance to the farmer that he be acquainted with the market grades of cotton, just as the shoe dealer must be acquainted with the several grades of shoes he sells, or the merchant acquainted with the several grades of cloth that he markets over the counter.

The market end of cotton production is an important one; and to see that it should receive more attention than it has, we have only to consider that most cotton is hauled to market, submitted to the buyer, and his offer accepted without being further substantiated, either by the seller's judgment or by that of any one else. 


\section{CHAPTER XXVII.}

THE UNCEASING CONTEST BETWEEN BULLS AND BEARS

Long years ago, before the coming of the telegraph and the cable, and when the greater part of the cotton crop was produced in America and sold abroad, it was the custom of European spinners, either to send their agents to this country, or to depend upon those already here, to buy and ship cotton for their use. As trade increased in volume, and competition increased in intensity, however, better methods were required-methods that should be more certain and more constant in their results. Hence, these old ways of doing this were not in keeping with the progress and advancement of other lines of industry. The old methods no longer worked with satisfaction, and so gradually became obsolete in practice.

With the increase in the business of selling and exporting cotton by reason of the large proportions which the foreign trade attained, a class of wealthy merchants entered the field and began purchasing cotton whenever they thought prices safe, continuing their operations from the beginning of the picking season until after its close. This purchased cotton they held with the expectation of considerable reward for their labors and for the necessary risks incidental to the transaction. 
While this was a legitimate enterprise, it was nevertheless largely speculation, each merchant gaining or losing in proportion as his judgment was good or bad.

\section{LEGITIMATE AND ILLEGITIMATE SPECULATION}

This sort of speculation all of us are given to: the merchant who purchases early in the season because he anticipates higher prices later; the farmer who secures feeding stock in the belief that prices will advance, netting him a profit greater than the mere value of the finished animal at the time of purchase; the housekeeper who purchases coal in summer, believing that with the coming of winter prices to the consumer will advance; the consumer of any commodity who looks ahead and anticipates a higher price than that commodity is then commanding - each is engaging in speculation, pure and simple, but nevertheless doing a legitimate thing, dictated by wisdom and foresight.

Let this idea of speculation be distinguished from the professional speculative phase which approaches or is in every sense a "gamble." When you make a purchase of real estate you may do so because of immediate needs: or you may make the purchase in expectation of a rise in value: you have need for it now or anticipate a demand for this holding in the future. It is now worth something to you-you anticipate that it will be worth more at a future time; hence you make your purchase. If your judgment is good, if it is accurate, you profit on your risk; if otherwise, you may lose. This trade-this phase of business or commerce-is entirely consistent with morals, with commercial standing, with business principles. 
Furthermore you apply this principle in the purchase of all your supplies-all needs; you secure your luxuries as well as your necessities when you think the time and the place are best.

\section{THE MANUFACTURER'S POLICY}

The manufacturer does likewise. He goes to the market for his supplies at the time when he considers the market at its lowest point. In this the cotton spinner is not different from other men; if the market points to an advance in price, he will make his purchase now. But he runs a risk; his needs are many, his supplies costly, and prices may not advance; they may even decline. When this turn is taken, loss naturally follows and often to such an extent that all profits are absorbed in the loss. To reduce these risks to a minimum, and also to arrange so that but a margin of the value would be required for protection, contracts were early arranged which allowed a spinner to buy his cotton on the basis of future delivery. This device of trading in contracts for the future delivery of cotton was quickly adopted by the trade, especially by those concerned either with the movement or consumption of cotton. An exceedingly gratifying advantage to the spinner was this, for now he might estimate the quantity of cotton needed at a certain time, make his purchase on the basis of a future delivery, and in the meantime continue the manufacture and sale of his products. Knowing the amount of the manufacturing expenses, and now just what his cotton in the raw would cost four, six, eight or ten months in advance, he could establish his selling price, make his purchases and his sales, and all the while be relieved of worry over 
troubles incident to movement, storage, insurance, and other risks.

So far then we have found no objection. Speculation you may call it, but legitimate; since a commodity has been purchased for real actual consumption. But at this point a new actor struts upon the stage-one not concerned with the production, consumption, or movement of cotton; it is the professional speculator who sees an opportunity to take advantage of a peculiar condition of trade, and who, if he is careful and wise, is certain to profit by his anticipation of the way in which the law of supply and demand will likely operate; he will meet this condition by ascertaining in advance in every way possible, the probable direction this fundamental law will take.

\section{THE COMING OF THE COTTON EXCHANGE}

So great was this new feature in the movement of cotton from producer to consumer that it became necessary to bring form out of chaos: it must be organized, else it might break itself into pieces. And there was too much good, too much intrinsic worth in it, for this to happen.

Consequently in the early 70's Cotton Exchanges were formed in New York, New Orleans, Liverpool, operated under rules and regulations intended to protect their own members and facilitate the trade of buying and selling cotton. The central idea in these exchanges was to provide machinery that might facilitate the dealings in "options" or "futures" as they have always been called.

And what do these terms mean? We will ask a member. He says: "They are called options because the cotton contracted for is deliverable at 
the option of the seller at any time during the month for which it is sold, and they are called futures, because, as a rule, the contracts traded in are those which call for a delivery of the cotton at some future period."

\section{COTTON CONTRACTS}

The contract of the Cotton Exchange is in essentials a legal sale and purchase of cotton like other contracts, written or verbal, which call for a change in the ownership of any commodity. The cotton contract stipulates in writing that 50,000 pounds in about one hundred square bales are sold or bought, as the case may be, at a stated price, payment to be made at or before some specified future period, usually at the end of the calendar month. One of the stipulations of this kind of contract is that the cotton must be delivered within the month and the buyer must receive and pay for it. There is no option about the contract except as to the time the seller may fulfill it. The New York contract calls for the delivery at the seller's option upon three days' notice to the buyer, the delivery to be made from one warehouse. The New Orleans contract gives the buyer five days' notice of delivery and allows the seller to deliver from cotton presses and railroad depots, and from two places. These contracts are made on the basis of Middling Uplands; when the cotton is of better grade, a higher price is paid by the purchaser-and a lower price, of course, if the staple be below the market grade. Thus, on the face of the contract, any sort of cotton between Fair and Good Ordinary may be delivered. Another feature of the contract is the right of either party to call for a margin as the variation of the 
market for like deliveries may warrant, which margin must be kept good.

Such is the cotton contract. Legal it is, and almost a product in its own right. It stands for cotton, but is sold and bought because of itself, fluctuating more widely and frequently than the real product.

Since the principle of trading in cotton contracts began in its crudeness a quarter of a century ago, it has expanded to such proportions that, in the words of one of the Exchange members, "during the present season it is estimated that the total number of bales represented by the options bought and sold in the three great markets, is in excess of four hundred million, or practically forty times the entire American production. This does not mean that each bale of cotton has been sold forty times over, but it does mean that contracts for the future delivery of forty times this year's crop have been traded in."

\section{HOW THE CONTRACT WORKS}

While cotton contracts call for the delivery of cotton, it is a fact that real cotton is seldom delivered. The seller when selling the contract never expected to deliver the commodity, and the purchaser never expected to receive it. In fact, the seller did not actually have in his possession any cotton at all; and the purchaser, if cotton were delivered to him, would not know what to do with it. It would not be going too far to say that some of these sellers and buyers have never seen a bale of cotton; they might even not know what one looks like.

All of these market features have had to do with 
contracts solely. There has been no transfer of property. In fact, neither party during any part of the transaction has owned any property-except the paper on which the contract was written. This over-trading feature is unreasonable speculation of the kind which works to the disadvantage of legitimate trade, and causes prices to be advanced or depressed without a single act to justify the change in right and morals.

On the other hand, as we have previously suggested, cotton contracts for future delivery may be helpful to the producer, the manufacturer and the merchant, since they tend to distribute the movement of cotton through a period of twelve months instead of through a few months only, as might be the case now were cotton sold and moved immediately upon its being gathered. The producer would naturally suffer because of the congested condition of the market. Thespinner would profit, since this congested condition would seem to be to his advantage; but in case the spinner should under-buy, he would find it necessary to pay excessive prices-because the annual market season would be closed and the speculator would hold the key to the door. Under the present system the market is open throughout the twelve monthsa condition advantageous alike to both producer and consumer.

THE EXCHANGE AND THE SPINNER

The Cotton Exchange has therefore, a side favorable to the spinner. With him cotton is a reality: he purchases it for use in his spinning operations, and in the course of six, eight, or ten months it will be purchased by the ultimate consumer. 
During the time consumed in the operations from raw material to finished product, capital is locked up with no return until the final sale. To meet daily and monthly requirements, the spinner secures his cotton. So close is the margin of profit that any material increase in price in the raw shape may act to his disadvantage, even to such an extent as to wipe out his profits entirely. To protect these profits he can purchase contracts for future delivery which will enable him to figure actual cost in his estimates-just what price the raw product will command at some future time. It insures him on actual cost, protects him if an advance does take place. All the while, too, he has not been obliged to secure large quantities of cotton to be stored and looked after from day to day; he is saved all this trouble, risk, and expense.

Briefly then, the contract for cotton for future delivery enables the spinner to secure his raw material any time during the year, and safeguards him against a time, if such should come, when it sells for an abnormally high price. It should be remembered, however, that the market may be so manipulated as to force prices for future delivery to such heights as to threaten his profits, unless he has continued to insure and protect his takings by constant buying and selling, thus putting him on the defensive and in the tread-mill of speculation as well. These constant fluctuations day after day the year round are the evil influences at work, often to the spinner's advantage and as often to his disadvantage.

WHAT OF THE PRODUCER?

The producer may at times imagine that trading 
in cotton contracts is to his interest; indeed there are times when such trading does operate to his advantage. But the cotton farmer should remember that the machinery of the Cotton Exchange was not put in operation as a means of helping him. The organization came about solely as a provision for facilitating trading in cotton contracts, and not with any purpose of decreasing the cost of production or of increasing the selling price of the commodity. It was organized for altogether different objects, and by those altogether unconcerned with the production of cotton.

Don't be deceived, therefore, into thinking that when cotton futures advance in price, it is an effort to bring profits to the producer. On the other hand, the speculator is assuming these risks neither for the fun of it nor for charity; it is of gain for himself that he is thinking. Every unreasonable advance in price is as full of evil to the producer as an unreasonable depression in price. The "corner" profits but few farmers, because the bulk of cotton is already in the hands of the merchants and speculators; hence the farmer has an apparent reward only in the fact that the price has materially advanced beyond normal limits. While this is seemingly favorable to the producer, it acts only as a stimulus to larger acreage the following season-and by this time the corner has long exploded, leaving in its wake a depressed market to mark its track, and to receive the new supply (which is probably more than the demand calls for). Thus the price descends to still lower depths: the latest crop, in all its magnitude and with all its labor and cost is now worth much less than its more modest predecessor.

But the Cotton Exchange has two sides favorable 

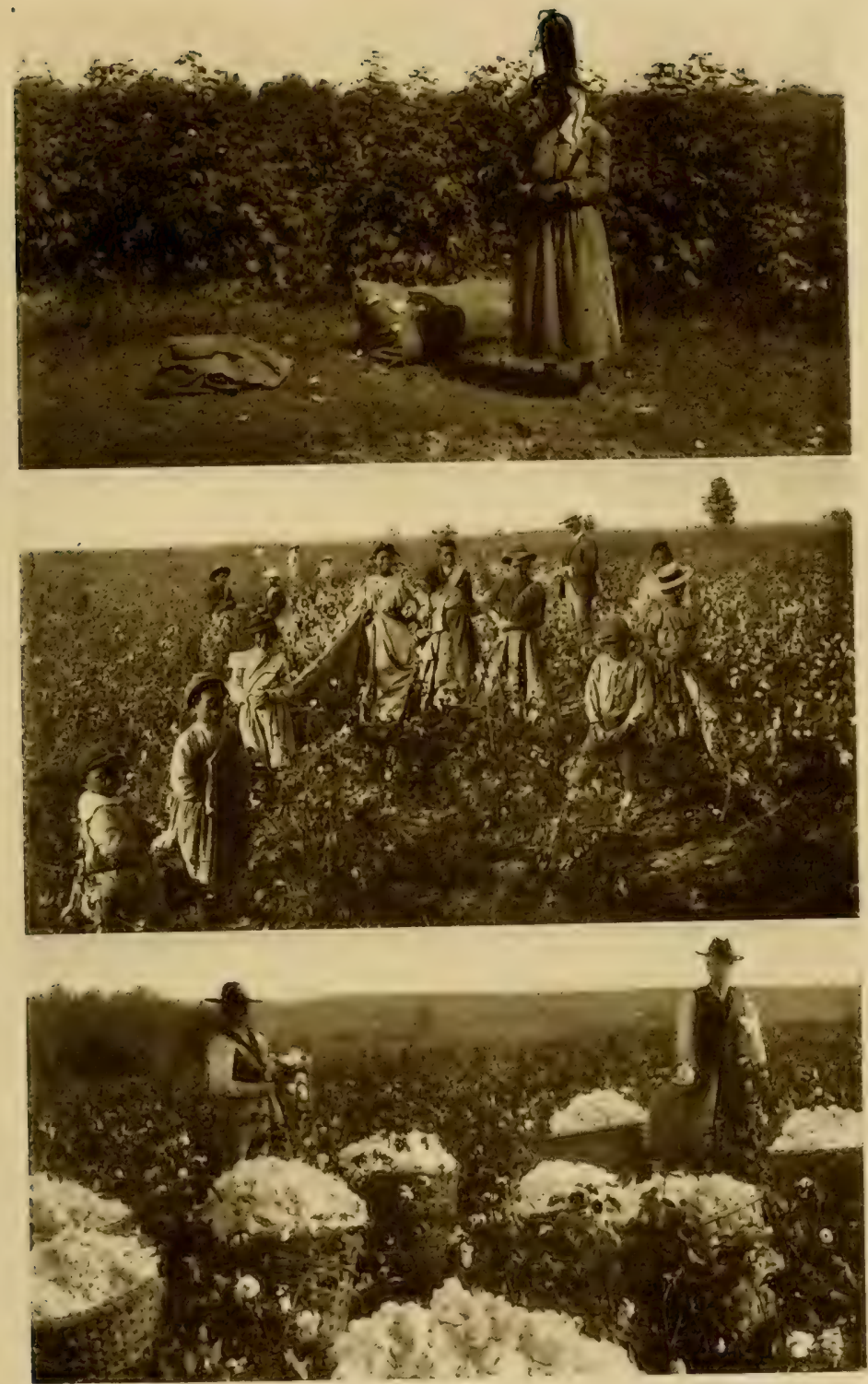

STAGES OF COTTON PICKING.

Because otherwise the fleecy locks cannot be seen for the green leaves, most pictures show picking only after frost; but it really begins long before the plants cease growing and blossuming. 


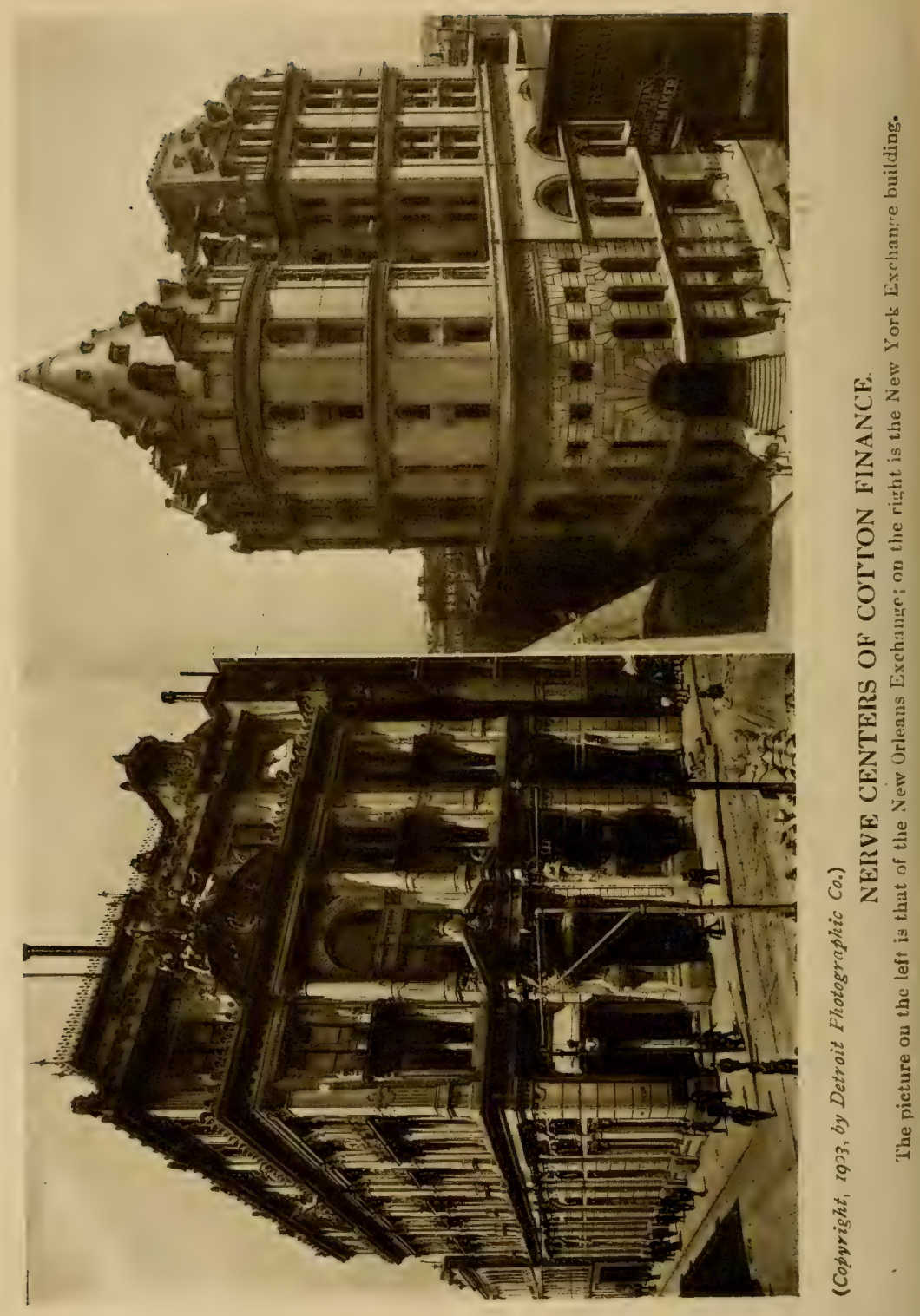


to the farmer's interests, whether or not other considerations counterbalance them.

These are: first, the extended activity of the market from a short period to an entire year; and the second, a demand for cotton created by the Cotton Exchanges in their business operations. It is safe to say that the members of the two leading Cotton Exchanges find it necessary to control annually nearly a half million bales of cotton. Here is a specific demand that exists over and above the takings of spinners. While the Cotton Exchange does not consume this quantity nor withdraw it from circulation, it does advertise the article, thereby creating a wider market for the product than would exist if spinners alone were purchasers.

But are these influences of sufficient importance to be of any material benefit to the producer? Since the Cotton Exchange was not founded with any such philanthropic design, and since in its tradings it so often operates adversely to the interests of the producer, it may readily be seen that the evils more than counterbalance the good.

So we may say that on the whole this machinery is not helpful to the farmer.

THE EVILS COME IN

The evil-in-chief is the speculative spirit in all this trading in contracts. To legitimate trade, speculation in cotton is a disadvantage-always a disadvantage. It uses all sorts of tricks and practices to distort real conditions: it endeavors to "get the other fellow on the hip" and to hold him there until he is "good and dead"; it inflates values part of the time, and part of the time it depresses 
them. True conditions, correct reports, are distorted; falsehoods and all sorts of misrepresentation are indulged in, with no other object than to make profit by subverting the legitimate play of supply and demand. Daily fluctuations in prices are due to these speculative influences designed to depress or advance. While the wise speculator endeavors to anticipate and correctly interpret the movement of the fundamental law, it is true that other ignorant ones endeavor to work in opposition to it; so these influences, playing at counter to each other, keep the ticker ever busy, recording the hourly fluctuations from season to season.

ENTER THE IGNORANT SPECULATOR

This indicates that there are two kinds of speculations: one that consistently aims to buy and sell in the face of the correct play of the law of supply and demand; the second that throws this law to the wind, knowingly or through ignorance, and accepts the situation as a "gamble," a blind chance,-as uncertain as the fling of a penny. It is the actor in this second instance who sows, knowing not what he will reap, and who introduces the most potent evil in the Cotton Exchange.

In almost every town and city of the country futures are now bought and sold. Speculative greed-getting something for nothing-draws the clerk, the journalist, the mechanic, the business man, the farmer - all trades and professions, and tempts all to try the blind chance. And this gambler finds the chance, sells without reason, buys knowing not what, nor with any understandings as to the workings and machinery of the transaction in which he engages. 


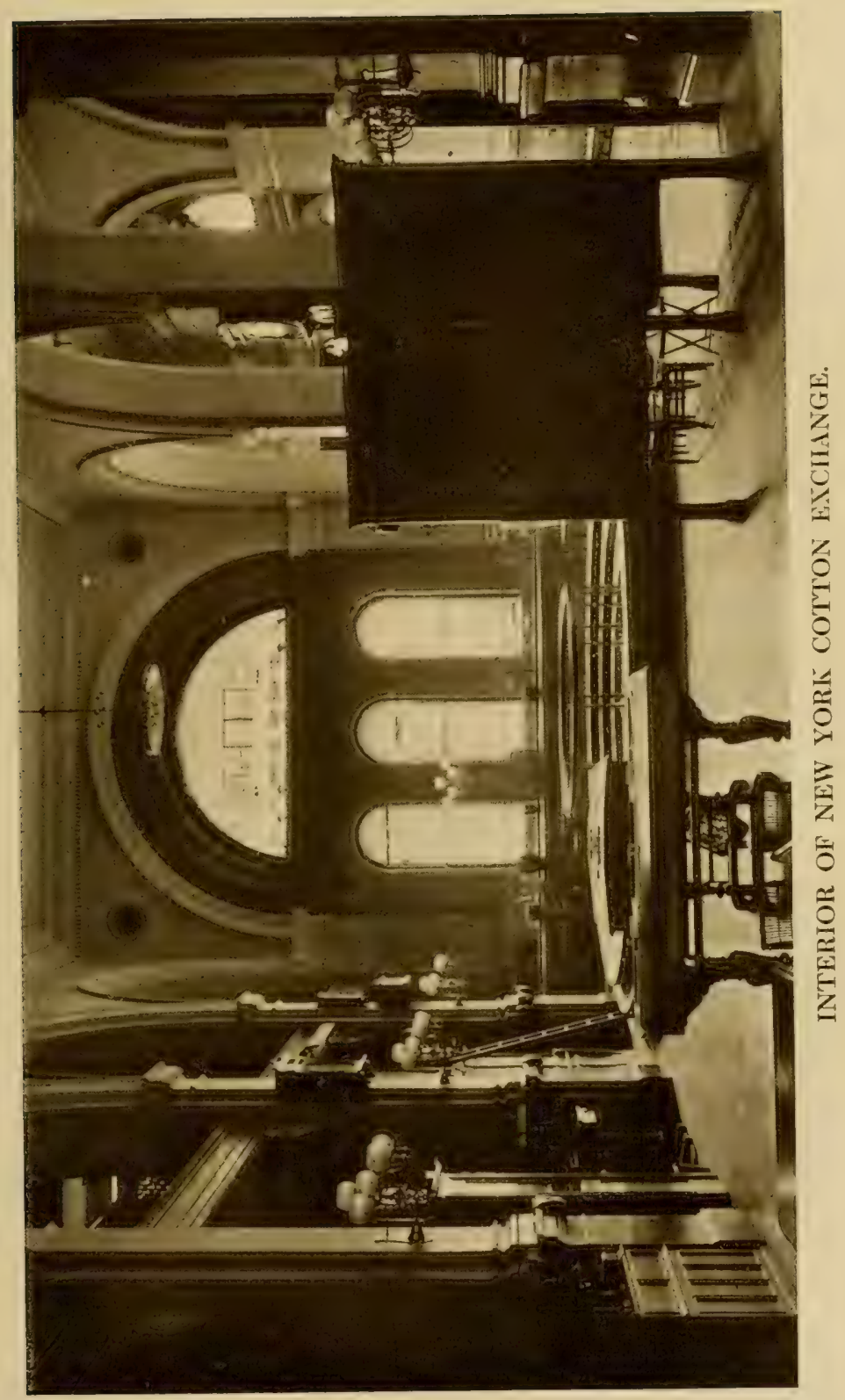




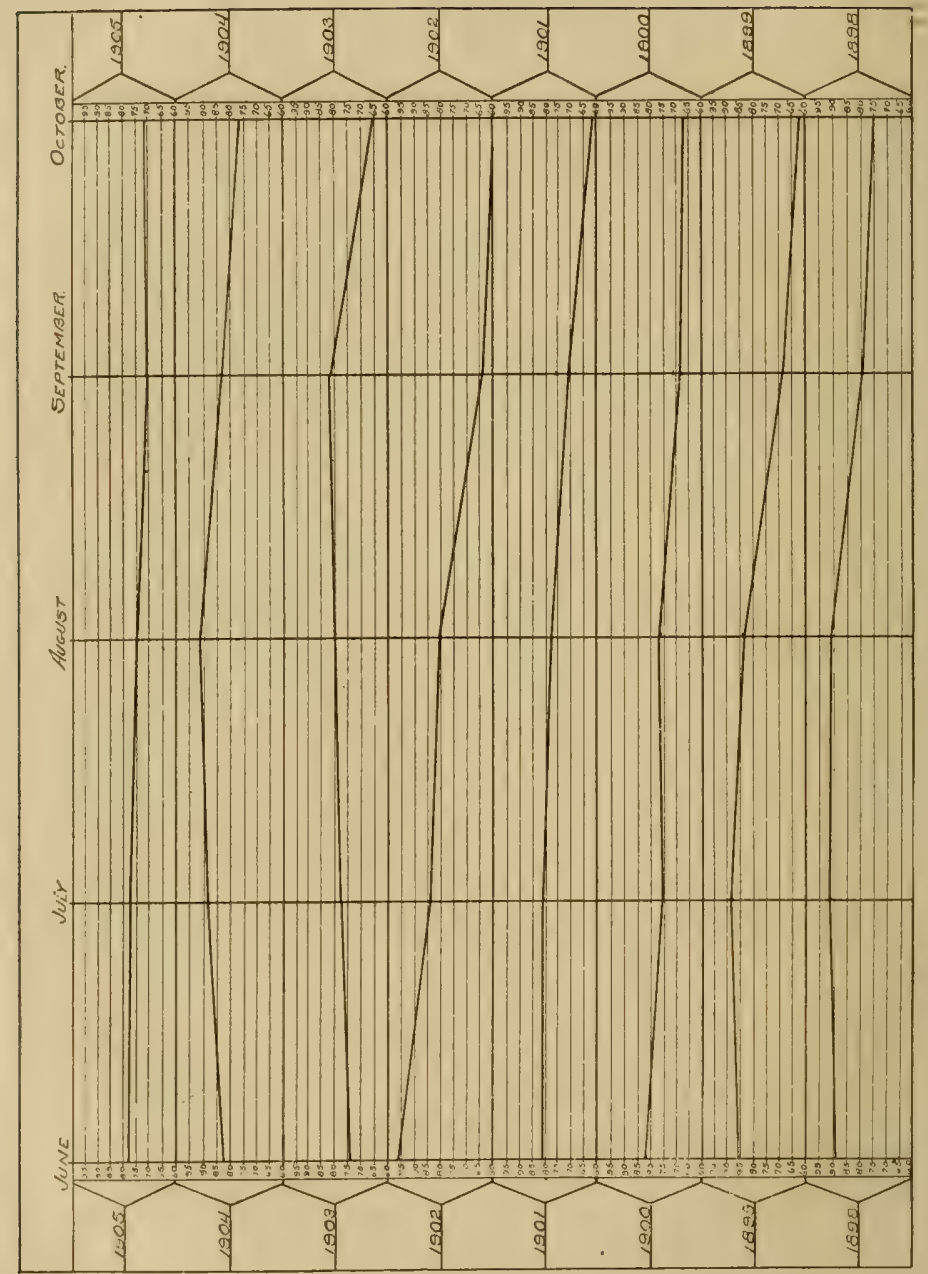

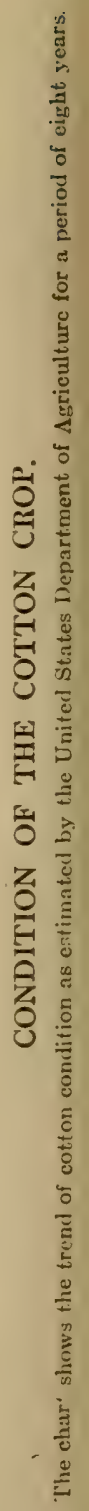


This individual may be green, an innocent rural "lamb," or a bold manipulator, securing prey on territory not even his; on the very floor of the Exchange itself he may go and operate in his unreasonable, unreasoning way. It is unnecessary to repeat the story. Chance may favor him with a step in line with the unchanging law, but once at cross-purposes with it, though ever the "corner" is scented, he topples, is sacrificed, and lost.

\section{WHERE THE REMEDY LIES}

To eliminate the foolish manipulator (small or mighty though he be) or even the principle of speculation itself, is impossible; nor can we abolish trading in contracts on the ground of illegality. They are with us, a part of our commercial methods, and with us they will stay.

What then can be done looking to regulation, that justice may be given the producer and the consumer: and protection even to those who will indulge therein? The following reforms may be helpful:

1. Complete publicity of past and probable production should be had that supply and demand may be accurately known and correctly interpreted.

2. Remedy the over-trading feature of the Cotton Exchange.

3. Abolish the system of monthly deliveries.

4. Increase the amounts required for margin.

5. Grade and sell cotton according to the practical requirements of consumption.

Publicity:-In order to save the ignorant speculator from himself, as well as protect legitimate trade, only the most complete publicity will suffice. The producer can receive no value from his prod- 
uct, unless there is a spinner to use it; hence, both are factors in this trade and both are entitled to information as complete as statistics are able to give - first to the producer, that he may know what supply and demand may do to help him with his sale: second, to the spinner that he also may know these facts and so protect himself in his purchasing Then, too, publicity will assist the otherwise ignorant players with the ticker that they may keep away from ruin, and by having reliable information thrust before their very eyes, not fly into the face of things as they are.

Over-trading:-Over-trading in the cotton market, as is the case with exaggeration of any other kind, means that the trade inevitably gets on false ground. It provides the opportunity for the "knowing ones," the strong, the mighty, not only to wrest cotton investments from the weak and immature, but it puts into the hands of the mighty, the power necessary to rob the weak of all their possessions, and to bring ruin to them and their dependents.

When this abuse is checked, the day of such extreme fluctuations as we have known heretofore will have passed and much of the evil of trading in contracts will have ended.

Monthly Deliveries:- Here is one of the unreasonable features of the Cotton Exchange machinery. Only the law of supply and demand has a right to determine real value to him who wants a commodity. Yet at three o'clock on the last day of any month as the contract now operates, cotton may sell one, two, and even three and four cents higher than a minute after that time of the same day, or at ten o'clock the day following.

This is nothing but a trick, a fictitious condition 
both unreasonable and illegal, and merits the same penalty that the usurer gets-or deserves.

Marginal Amounts:- Trading in cotton futures is stimulated and abetted because of the small margin required to enter the ring. Of course, this admits an army of ignorant, unthinking people. It is a game of chance with them-a gambling game, no higher in ethics than shooting craps or playing poker, and the chances many times more against their ever coming out unburned. What chance is there for mere strength and awkwardness in such an arena with mighty, well-trained gladiators (scientifically trained, if you please) to meet and combat? Of course, this struggle is short; and the pity is in the home where the savings of these weaker contestants are needed.

Increase the margin-make it more difficult to enter and to follow - and the evil will be clipped at the wings - less able then to do harm here; less able to cause these violent fluctuations that have adversely affected both the cotton farmer offering his holdings and the cotton spinner seeking his takings.

Grading:-Another evil is in the fact that in the Exchange sale any sort of cotton may be delivered. Suppose the farmer buys cattle and when the seller delivers them, they may be any sort or all sortssuckling calves, weaned calves, scrubs, finished beeves, etc. It is with just such a policy that cotton contracts are traded in, since the deliverable cotton may be all the way from fair to good ordinary. Right here is where (leaving the morals of the question out of consideration), the greatest grievance lies, and where it affects the pocket-book of both producer and consumer. And then these know that neither one nor the other is responsible, 
although these two factors only are concerned with commodity-all others are aliens. Cotton should be graded therefore with a view to consumption. In selling cattle, calves and scrubs are eliminated from high market grades, and surely the low grades of cotton can be eliminated also. The contract would act with more justice to all were it graded in the contract from Fair to and including Low Middling - a reasonable change, and a fair one to all concerned.

All in all, the Cotton Exchange, like business. is subject to gross misrepresentations. Much of the feeling against it is due to ignorance of its methods or to the prejudice that comes from having had one's fingers burned. That it contains much good there is no question. What its future will be only time will tell, but with proper reforms it may play a noteworthy part in the rich kingdom of cotton. 


\section{CHAPTER XXVIII.}

STATISTICS: HOW THE WORLD WATCHES WHILE THE PLANT GROWS

There is a reason why statistics of production and consumption of cotton should be made accurately, completely, and frequently. Trade has become so complex since the advent of the Cotton Exchange-because of the rapid developments of re-selling on close margins, taking advantage of fluctuations in prices and dealing in futures; and using unnatural influences to fix prices by manipulators-that every one interested has come to recognize the need of some strong disinterested agency to make reports of actual facts so that all concerned may be better guided as how to buy or sell.

The producer, the merchant, the speculator, and the consumer must ever be informed as to the movement of the law of supply and demand, that the market of neither the raw product nor the finished material, may be congested or overloaded. Let this happen, and not only that form of cotton immediately concerned, but all humanity, will suffer in consequence of the abnormal condition. The hope lies in publicity - complete and accurate. These reports must be made by disinterested parties: not by the speculator who reports a bearish condition of the market that prices may be depressed, trying to favor his own operations; nor 
by his rival with his bullish reports given in the hope that prices may advance to his profit.

It is to the Government we must look for estimates of such a character that they may be depended upon for accuracy and reliability. Besides, the Government is impartial and aims to protect both producer and consumer, since both contribute to its machinery, and for them it partially exists.

\section{WHY THE GOVERNMENT GATIIERS STATISTICS}

To the Department of Agriculture is intrusted this work; to no other Department of the Government could it be more safely and wisely left; by no other Department can the condition of the growing crop be so accurately and completely ascertained. The purpose of the Government's cotton reports is to ascertain the actual facts as to the acreage, growing condition, and the prospective yield of the crop. Its general aims may be enumerated as follows:

1. To give information to producers, consumers and dealers as to actual yields; also to report as to the actual conditions of promise.

2. To enable market centers to better balance supply against demand in defining what prices are warranted by natural conditions.

3. To insure whatever stability of prices a changing state of natural conditions allows.

4. To be so certainly authentic and comprehensive and definite for entire crop areas that interested parties cannot well credit nor warp the figures with their own estimates, and thus bring about unstable markets.

5. To enable producers to know the facts as to the promise of prices for the crop, that false re- 
ports may not mislead them into early sales at prices wrongfully made too low.

6 . To create confidence, that sales and consignments by producers may be made more freely, that dealers may more safely conduct their business with lower handling charges, and that spinners may more freely purchase stocks to hold, thus adding certainty and stability to business, that they may work on a less speculative basis, and thus bring more equitable returns from labor expenditure to all interested persons.

7. To make reports so frequently and to give facts so soon after changes in prospective conditions occur, or so soon after actual yields are gathered, that there may be the least possible element of uncertainty, of speculative conditions, to remove prices from their normal economic place.

\section{HOW COTTON STATISTICS ARE GATHERED}

The large body of people concerned with the gathering of cotton statistics may be grouped into the five following classes:

1. The State Statistical Agent and corps of aids.

2. Three Cotton Special Field Agents.

3. The County Agent for the Department.

4. The Township Agents for the Department.

5 . Individual reports of cotton farmers.

The State Statistical Agent is a paid employee of the Department who reports to the Bureau of Statistics the information which he obtains from tabulations that are sent direct to him by his corps of aids in the cotton counties of his State. These aids are selected because of their qualifications as farmers of judicial mind and individual integrity. This part of the crop-reporting service is one of 
the best means of securing reliable information. It should be further extended. The State Agent should receive a salary commensurate with the responsibilities of his position, and sufficient to enable him to maintain a well-equipped office and look after his large body of aids.

Then there are three special field agents who travel constantly through the cotton territory, each covering a group of States assigned him. These men are trained statisticians and selected because of their wide knowledge and broad information regarding the cotton crop. They travel systematically over the districts in their charge, note carefully the acreage and conditions; keep in close touch with the best informed opinion as to the cotton crop. Their knowledge and information is therefore of the highest value in correcting inaccuracies: and it is given monthly or oftener to the Statistical Bureau by mail and telegraph.

To supplement these, information is obtained from county and township correspondents who have been selected because of fitness and knowledge; from the cotton ginneries and from correspondents representing bankers, and country merchants.

\section{SCOPE OF COTTON STATISTICS}

Cotton schedules are sent to all these classes of reporters each month of the growing season. The May schedule is the first of the year and deals with the acreage and condition of cotton. Following this are the June, July, August and September schedules dealing with the condition of the crop. The August report also deals with the amount of old cotton on hand; in the November report is in- 
cluded average yield of cotton per acre, abandoned acreage, and the cost of picking.

\section{HOW COTTON REPORTS ARE HANDLED}

All reports dealing with cotton statistics are sent by telegraph (in cipher) or by mail, so as to reach Washington, where the Crop Reporting Board meets, by the first day of each month of the months in which such reports are made.

The reports of the State Field Agents and State Statistical Agents are sent to the Secretary of Agriculture in specially prepared envelopes, and delivered to him by the postal authorities in sealed mail pouches. These as they arrive are placed in a safe located in the private office of the Secretary, to which no one else has access, until the day on which the report is issued. The combination of the safe moreover, is known only to the Secretary of Agriculture and the Assistant Secretary of Agriculture.

\section{HOW THE REPORTS ARE PREPARED}

The reports previously sent in are now opened and final results made up by a Crop Reporting Board, composed of the Chief of the Bureau of Statistics as chairman and four individual members selected from the Statisticians and officers of the Department. For each month there is an incoming member, not on the sitting of the estimating committee immediately previous. On the report day, this Board with several computors meets in the office of the Statistician which is kept locked, no one being allowed to enter or to leave it. All telephones are disconnected.

When all data has been placed before each mem- 
ber of the Board, each individual computes separately his own estimate of cotton for each State. When this is done comparisons are made and discussions are engaged in before the final figures are decided upon. Each and every township, county, and State is properly "wcighted" so as to give the arithmetical value which the acreage in that area demands. On the completion of this work, the report is ready to be given out, and goes with lightning speed to almost every part of the world.

\section{HOW THE COTTON REPORT IS ISSUED}

Reports on cotton thus prepared by the Crop Reporting Board are issued on the $3 \mathrm{~d}$ of each month during the growing season. In order that the information contained in these reports may be made simultaneously throughout the entire United States, and that one part of the country may not have any advantage over another, they are handed simultaneously at a given hour (as for example, at 12 o'clock noon or 4 p. m.) on report days, to all applicants, and are given to the Western Union Telegraph Company and the Postal Telegraph Cable Company for transmission to the exchanges and to the press. These companies have reserved their lines at a designated time, and by use of a "flash" forward immediately the figures of most interest. A mimeograph statement for comparative purposes, containing such estimates of condition or actual production, together with the corresponding estimates of former years, is prepared and sent to a mailing list of exchanges, newspaper publications, and individuals. The same afternoon printed cards containing the essential facts 
concerning cotton and the most important crops of the report are mailed to 77,000 post offices throughout the United States for public display, thus placing the information within the farmer's immediate reach.

\section{MONTHLY CONDITION REPORT OF COTTON}

The cotton crop must be observed throughout its growing period if accurate conclusions are to be drawn in regard to its output. Even then only an approximate estimate can be made. Such an estimate is helpful to the producer in assisting him in disposing of his crop; it helps the spinner in making his purchases. Both depend, in some measure at least, upon facts not yet accomplished. Favorable conditions in June do not mean that an unfavorable season may not disturb growth and prospects in August or September.

A farmer once planted for twenty bales. Rain came and brought grass and troubles, threatening the crop; June had come and scarcely ten bales were hoped for. But weather during July was favorable-much sunshine during the day and little rain at night; the crop flourished, the weed became strong, and vigorous - and thirty bales were now anticipated. But more rain came, fairly covering the ground; unripe bolls began to shed, leaves turned in color, the big crop was no longer thought of - a yield of ten or twelve bales would now be all that might be expected. But better days came in August - days more favorable to the crop-growth of weed checked itself to correct proportions, the old bolls enlarged, and the farmer brightened in hope and expectation that results might be better than "things looked at one time." September 
with its picking season soon passed, and prospects for fifteen or twenty bales were now brighter: October soon passed and November ended the gathering of the crop. Twenty-six bales had been secured.

This illustration shows how fickle is the season and its crop. While in this case better returns followed than were anticipated, it is just as often true that contrary results are realized. Hence, with the cotton crop you can make no estimate by a hasty review or a glance from the window of the railroad car. You must watch the crop throughout its growing season, and all the while be prepared for any turn this capricious crop may take because of some disease or some change in weather.

The table following shows the estimates from month to month for several years as reported by the United States Department of Agriculture:

\section{MONTHLY COTTON REPORT}

United States Departaent of Agriculture

\begin{tabular}{|c|c|c|c|c|c|c|c|c|c|c|c|c|c|c|c|}
\hline & 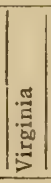 & 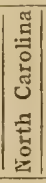 & $\left|\begin{array}{c}\tilde{n} \\
: \\
0 \\
0 \\
0 \\
0 \\
\tilde{z} \\
\tilde{z} \\
0 \\
0\end{array}\right|$ & $\mid$ & 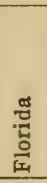 & 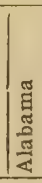 & 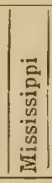 & 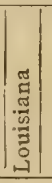 & 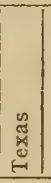 & 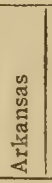 & 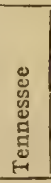 & 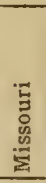 & 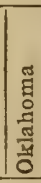 & 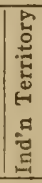 & 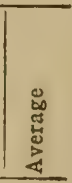 \\
\hline 1905 & & & & & & & & & & & & & & & \\
\hline June. & 87 & 83 & 78 & 84 & 88 & 87 & 73 & 73 & 69 & 73 & 87 & 84 & 88 & 81 & 77.2 \\
\hline July . & 88 & 82 & 78 & $8 \approx$ & 87 & 83 & 72 & 73 & 72 & 75 & 86 & 86 & 83 & 79 & 77 \\
\hline August & 78 & 80 & 79 & 82 & 85 & 79 & 69 & 66 & 71 & 68 & 80 & 85 & 83 & 82 & 74.9 \\
\hline September & 76 & 76 & 75 & 77 & 77 & 70 & 68 & 62 & 70 & 72 & 81 & 86 & 82 & 80 & 72. \\
\hline $\begin{array}{c}\text { October ... } \\
1904\end{array}$ & 77 & 77 & 74 & 76 & 76 & 70 & 68 & 59 & 69 & 72 & 79 & 81 & 80 & 78 & 71.2 \\
\hline June... & 82 & 84 & 81 & 78 & 88 & 80 & 85 & 86 & 84 & 84 & 85 & 82 & 93 & 90 & 83 \\
\hline July & 87 & 90 & 88 & 85 & 92 & 85 & 89 & 90 & 89 & 90 & 89 & 89 & & 87 & 88 \\
\hline August & 90 & 93 & 91 & 91 & 94 & 90 & 92 & 95 & 91 & 93 & 92 & 90 & & 91 & 91.6 \\
\hline September & 88 & 88 & 87 & 86 & 88 & 81 & 87 & 87 & 77 & 88 & 88 & 87 & & 89 & 84.1 \\
\hline October & .82 & 82 & 81 & 78 & 82 & 76 & 77 & 78 & 69 & 77 & 76 & 82 & & 83 & 75.8 \\
\hline
\end{tabular}


MONTHLY COTTON REPORT

(Continued)

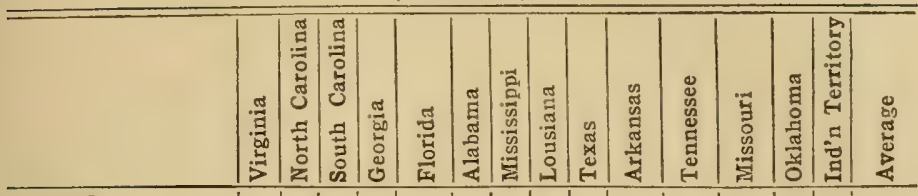

1903

June........ 72747675

July ....... 76757475

August....... 767876 77.

September .....

October...... 77 747068 1902

June..........

July...........

August........

September.....

October ....... 1901

June........ 92 878080 July......... 7877 70/72 August....... 86737578

September..... 82 72 8081

October.......7363 6773 1900

June

July...........

August....... 77807477

September.... 73646069

October ...... 71645767 1899

June........ 79878688 July.......... 868888885 August....... 88837879 September .... 87736669 October .... 76666264 1898

June ......... 86868589 July.......... 93879090 August....... 94 908991 September......91848180 October....... 84|76|79|75 $\begin{array}{llllllllllllll}81 & 73 & 78 & 76 & 70 & 76 & 83 & 83 & 72 & 76 & 74.1\end{array}$

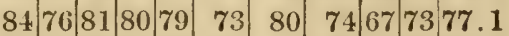
$\begin{array}{lllllllllllllll}85 & 79 & 83 & 84 & 82 & 76 & 82 & 78 & 69 & 75 & \mathbf{7 9 . 7}\end{array}$ \begin{tabular}{ll|l|l|l|l|l|l|l|l|l|l|l|l|l|}
83 & 84 & 87 & 86 & 76 & 81 & 91 & 81 & 81 & 75 & 81.2
\end{tabular} \begin{tabular}{llll|l|l|l|l|l|l|l}
70 & 68 & 69 & 71 & 54 & 69 & 71 & 74 & 71 & 72 & 65.1
\end{tabular} $100 \quad 100 \quad 100969995.1$ \begin{tabular}{lllll|l|l|l|l|l|l|l}
96 & 84 & 85 & 85 & 73 & 94 & 98 & 95 & 90 & 89 & 84.7
\end{tabular}

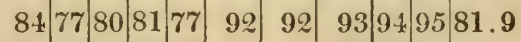
$\begin{array}{lllllllllll}75 & 54 & 68 & 70 & 53 & 75 & 82 & 73 & 76 & 68 & 64\end{array}$

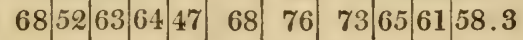
$\begin{array}{lllllllllll}88 & 76 & 82 & 80 & 81 & 81 & 78 & 83 & 88 & 85 & 81.5\end{array}$ \begin{tabular}{llllllllll|l|l|l|l}
80 & 80 & 86 & 84 & 83 & 84 & 85 & 90 & 91 & 88 & 81.1
\end{tabular} $\begin{array}{llllllllllllll}79 & 82 & 88 & 82 & 74 & 69 & 70 & 71 & 78 & 75 & 77.2\end{array}$

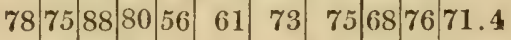
$\begin{array}{llllllllll}65 & 65 & 66 & 72 & 51 & 51 & 60 & 61 & 5761 & 61.4\end{array}$ $\begin{array}{llllllllllll}88 & 87 & 85 & 88 & 71 & 91 & 86 & 94 & 75 & 84 & 82.5\end{array}$ \begin{tabular}{ll|l|l|l|l|l|l|l|l|l}
78 & 70 & 64 & 81 & 78 & 78 & 76 & 74 & 82 & 96 & 95.8
\end{tabular} \begin{tabular}{ll|l|l|l|l|l|l|l|l|l|l|l|l|l|}
74 & 67 & 60 & 77 & 83 & 83 & 77 & 84 & 80 & 81 & 76
\end{tabular}

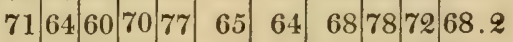

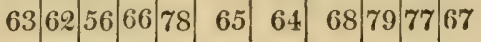

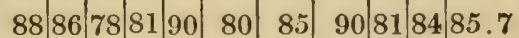
\begin{tabular}{ll|l|l|l|l|l|l|l|l|l}
90 & 88 & 83 & 85 & 93 & 82 & 88 & 88 & 78 & 91 & 87.8
\end{tabular} \begin{tabular}{ll|l|l|l|l|l|l|l|l|l|l}
93 & 84 & 86 & 86 & 86 & 86 & 84 & 86 & 80 & 93 & 84
\end{tabular} \begin{tabular}{ll|l|l|l|l|l|l|l|l|l}
77 & 76 & 78 & 74 & 61 & 62 & 76 & 85 & 60 & 53 & 68.5
\end{tabular}

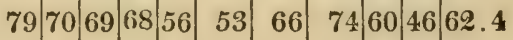
$\begin{array}{lllllllllllll}76 & 89 & 91 & 89 & 89 & 96 & 90 & 96 & 82 & 80 & 89\end{array}$ \begin{tabular}{llll|l|l|l|l|l|l|l|l|l}
83 & 91 & 94 & 90 & 92 & 93 & 92 & 87 & 92 & 89 & 91.2
\end{tabular} \begin{tabular}{ll|l|l|l|l|l|l|l|l|l}
87 & 85 & 88 & 90 & 91 & 93 & 97 & 90 & 98 & 94 & 91.2
\end{tabular} \begin{tabular}{lllll|l|l|l|l|l|l|l}
73 & 80 & 78 & 76 & 75 & 89 & 95 & 94 & 90 & 98 & 79.8
\end{tabular} \begin{tabular}{ll|l|l|l|l|l|l|l|l|l|l|}
66 & 76 & 72 & 67 & 73 & 84 & 93 & 93 & 75 & 76 & 75.4
\end{tabular} 
ANNUAL ESTIMATE OF COTTON CROP

It has been the custom of the Department of Agriculture annually on December 1st to estimate the yield in cotton for each State and the total for all the cotton-producing States. This estimate compared with the report of the Census Bureau (which is charged with the duty of publishing the exact amount produced after the crop has been entirely ginned) for the last seven years, shows that the estimates of the Department of Agriculture have been within an average of one and four-tenths per cent. of absolute accuracy, which, in view of the fact that "to err is human" is little short of miraculous.

This fact is shown in the table following:

NUMBER OF POUNDS OF LINT COTTON

\begin{tabular}{|c|c|c|c|c|}
\hline \multirow[b]{2}{*}{ Year } & \multirow{2}{*}{$\begin{array}{l}\text { Department of } \\
\text { Agriculture }\end{array}$} & \multirow{2}{*}{ Census Bureau } & \multicolumn{2}{|c|}{ Per cent. } \\
\hline & & & Over & Under \\
\hline 1899 & $4,320,193,000$ & $4,457,097,000$ & & 3.1 \\
\hline 1900 & $4,856,738,000$ & $4,846,471,000$ & .2 & \\
\hline 1901 & $4,529,954,000$ & $4,550,950,000$ & & .5 \\
\hline 1902 & $5,111,870,000$ & $5,091,641,000$ & .4 & \\
\hline 1903 & $4,889,796,000$ & $4,706,591,000$ & 3. 9 & \\
\hline 1904 & $6,157,064,000$ & $6,426,698,000$ & & 4. 2 \\
\hline 1905 & $5,083,909,000$ & $5,389,155,149$ & & 6. 0 \\
\hline
\end{tabular}

MORE FREQUENT REPORTS

The objection to the reports of the Department now may be said to lie with their infrequency. So important is correct and accurate information to the producer and consumer, and so important too is 
the cotton crop to the whole world, that it seems advisable to have the reports issued more often, instead of only once each month as is now the custom. Were this the case, the fluctuations in prices upon the appearance of the Government report would not be so marked, and the market would remain more stable, and more truly responsive to the law of supply and demand. 


\section{CHAPTER XXIX.}

PRICES: THE PUZZLING PROBLEM OF COTTON VALUES

There is an economic principle which applies to all products of the land and to all products of the shop: The final utility of the product shall determine its market value. When a commodity becomes necessary for any purpose, it will bring in the market whatever price is necessary to produce it once or to reproduce it again.

If it costs ten cents to produce a pound of cotton and ten million bales are wanted, then if there is land enough and men enough who will be satisfied to produce it at that price, ten cents a pound will be the market price. But if twelve million bales are needed and wanted, you may or you may not have a different proposition: all available cotton land may be already in use; other workers may not care to engage in the work at the price offered; and if they do not turn to it, the increased quantity cannot be grown. What follows? The economic principle answers: If cotton is in greater demand than other things, then a higher price will be offered for it in order that laborers may be attracted to it; that lands now given to other products be given to cotton; that owners of land on which ten-cent cotton would not pay, shall have the inducement of higher prices. So the additional two million bales are produced. On this basis an increase shall be 


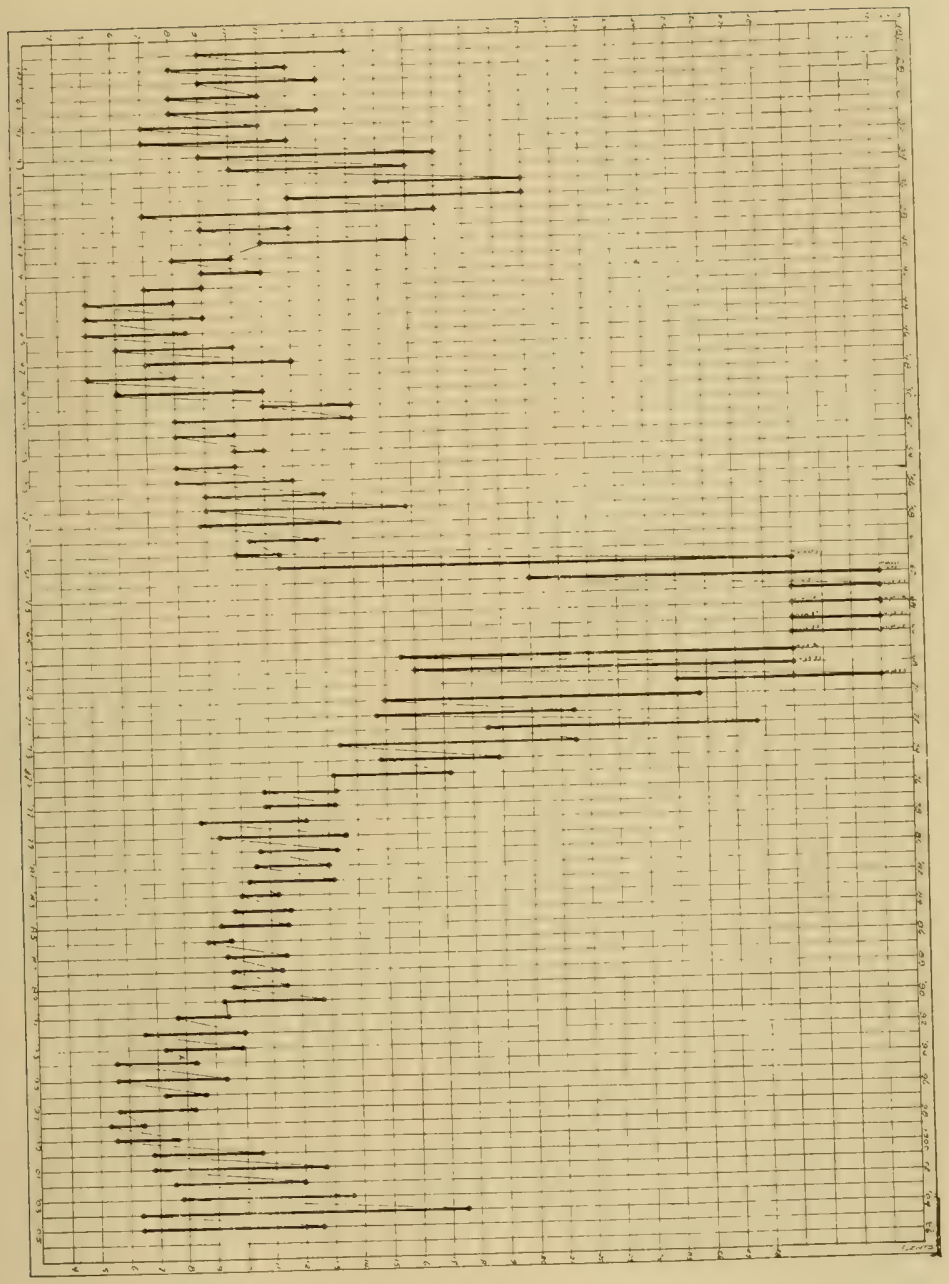

THE EBB AND FLOW OF COTTON PRICES.

The drawing shows in vivid fashion the fluctuations in prices-highest and lowest - of spot cotton for each year since 1826 . 

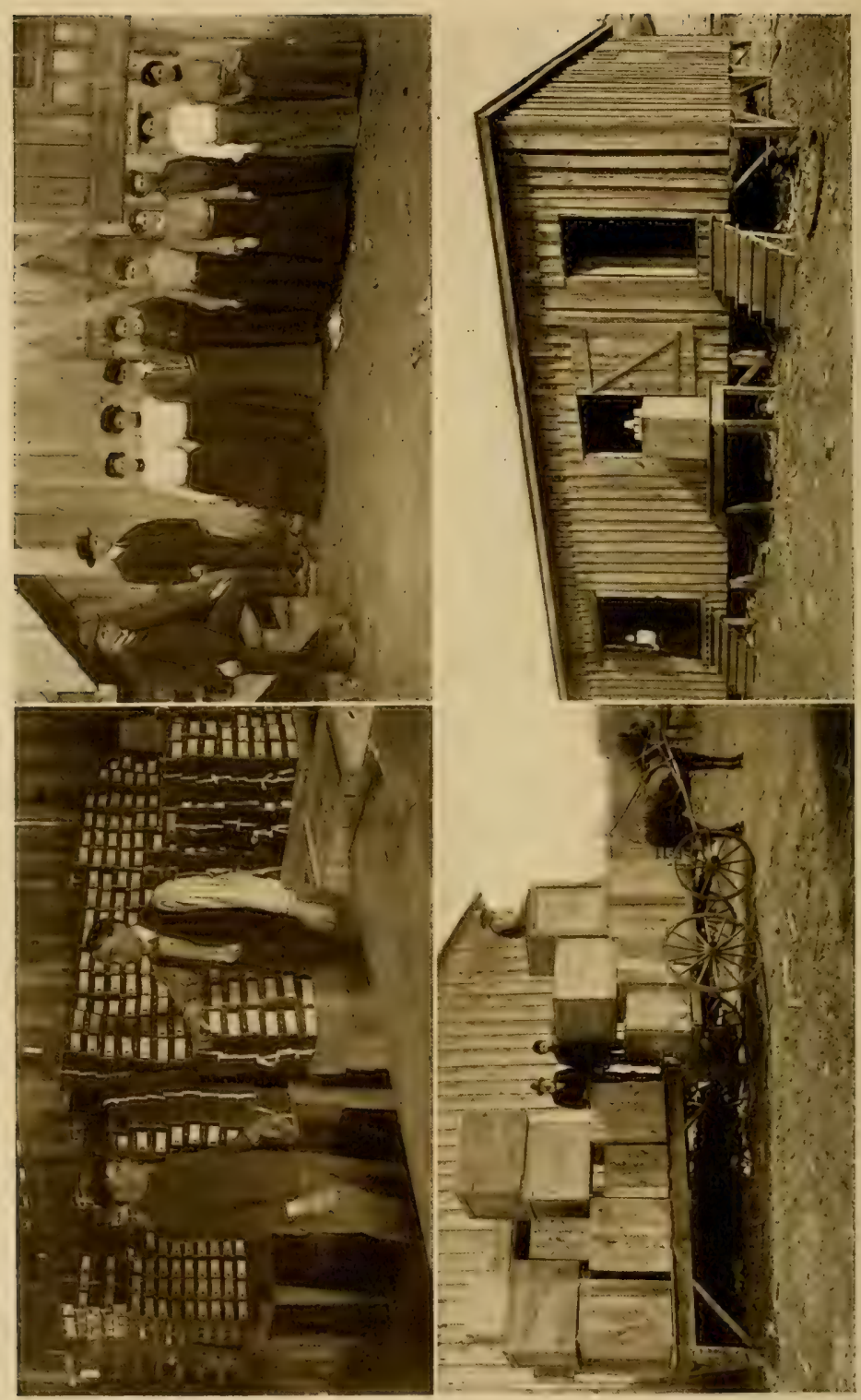

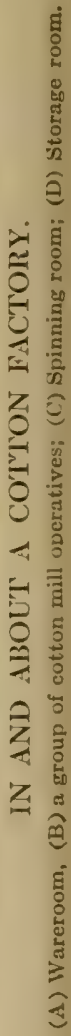


given, and the price we will say is now twelve cents. But how will this advance in price affect that received for the usual crop? It will cause it to advance also and meet the new scale in price.

It may happen that there are men enough and equipment sufficient to produce not only the normal quantity but enough to handle additional acres as well. When the call comes for more cotton it may not be met, since all lands that pay at the tencent rate are growing it already. What happens? The intensity of the demand will control. If it is insisted upon, the grower will supply it through heavier applications of fertilizers and through increased acreage. But at what price shall he sell it? He may sell it at the same price as he has heretofore been selling. But if that grown on good soil in previous years was produced and sold for ten cents per pound, which in every sense was a reasonable rate, then if he now sells this increased product at the old price, - a product that costs him more to produce since the yield is less and expense more-he will sell the increased product at less than cost, thereby losing in the enterprise.

To meet this condition brought about by opening up new lands, the grower will have to take from his normal and usual crop, returns to make good the deficiency of the new. This the wise man will not do. On the other hand, this follows in practice: Since more cotton is wanted, and since other acres are not so profitable, in order to get the same profit for the additional land as that received on other lands before the enlarged demand came, every grower will expect more per pound.

But the producing power of land does not govern price-only directs it; it is the commodity itself that fixes values, hence if twelve cents is paid for 
each pound produced on these less desirable lands, the commodity in its entirety will bring the same price, irrespective of the kind of land on which it was produced.

It follows then that not the cost of the average crop, but the cost of growing that part of the crop produced at the greater cost or greater disadvantage will govern the market price of cotton.

He who is so unfortunately situated as to grow his cotton at the greatest disadvantage gets no profit at all; while on the other hand profits go in proportion as cotton is grown with ease and economy.

\section{THE RANGE OF THE COST}

The statement is often made that cotton is grown now at a cost of from three to four cents per pound, and hence that there is a tremendous profit in the business of cotton farming-a profit of as much as two or even three hundred per cent. This being the case, we hear further, cotton sells at an unreasonable price, and nets the producer a greater reward than economic conditions justify.

That some cotton may be produced on some land and during some seasons at three or four cents per pound there is no doubt; but there is indeed a small acreage where these conditions obtain. In no way, we argue, is it justifiable to use these exceptional seasons as a basis for estimating the cost of producing cotton or for measuring profits-any more than it is justifiable to say that since some banking houses in New York City make annual profits of from 100 to 200 per cent, that is the profit realized by all banks throughout the country. The facts are 
that on the basis of present acreage and cost of production:

3 cents cost per pound represents $1 \%$ of acreage.

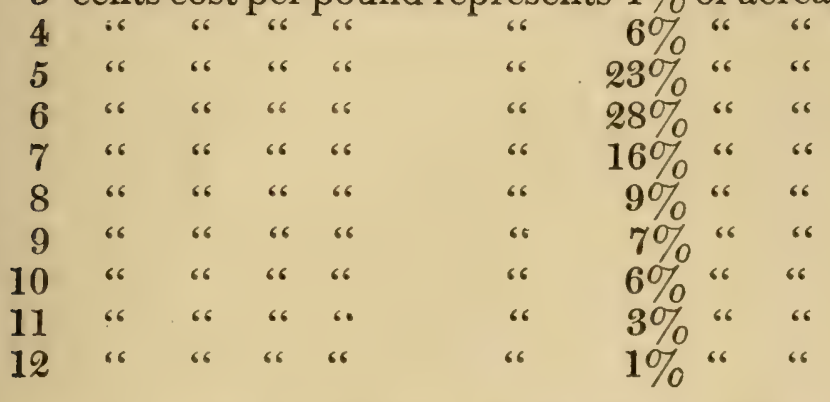

This shows that even today when cotton sells for ten cents a pound one-tenth of the acreage does no more (possibly less) than meet the cost of producing it. Sixty per cent of the crop costs between 5 and 7 cents to produce on the basis of mere cultivation. Thousands of acres of cotton are grown annually where the product pays only the rental and fertilizer bills, the tenant at the end of the season receiving no compensation at all for his labor during the period of the growth of the crop. Were it not for his poultry, his pig, his potato patch, his few peas, and the extra work he does in the winter months, he and his family would starve or be thrown on the State. These are real facts, gathered at first hand from observation and experience. Doubt them if you like; but if you observe you will be convinced of their absolute truth.

After awhile we shall abandon these unprofitable acres; we shall give them over to cowpeas and pasture, and use for cotton only those lands so adapted to the crop as to make it sure that they will net a reasonable profit. 
Eliminating the waste of ignorance which plays a part in cotton production because of the presence of the illiterate tenant, when the price falls below the cost of production because of overproduction, poor producing lands are dropped from use; those engaged in cotton farming receive smaller returns and less cotton is produced until consumption increases so as to use the product as rapidly as produced. Were one-fifth of the present acreage to be put to some other use, cotton would immediately advance in price: the four-fifths quantity would yield in value a gross revenue perhaps equal to or greater than the five-fifths at the present time and at present prices, consumption remaining the same all the while. On the other hand, were consumption to decrease one-fifth and production remain the same, the price would decline until either consumption should increase again or enough cotton lands be abandoned to balance supply and demand.

\section{PRODUCTION AND CONSUMPTION}

This adjustment between production and consumption, as we have said, is regulated by the inevitable law of supply and demand, which at times may be influenced by attachments with other commodities that may be or may not be substituted, thus adding further complications to the situation.

So cotton growing and cotton spinning long have been working partners; although they have had their quarrels, they are fairly adjusted so that supply and demand operate within rather narrow limits, conditions being in no wise open to serious 
rupture. Acreage is gradually increasing, but so also is the number of spindles; so also is the demand for the products of these acres and spindles.

While during the past twenty-five years there has been no great change in the price of the raw product, it is true that the cost of farm labor has increased with no appreciable decrease in the general cost of production; it is true also that manufactured goods have very greatly decreased in price, while here the cost of production has materially decreased because of increased skill in manufacture and the increasingly large number of labor-saving machines.

\section{PRICES OF COTTON}

That the selling price of cotton has not decreased is seen in the table below; but let it be remembered that few improved tools and implements have yet been found of service in cotton production so as to decrease the cost of growing.

HIGH AND LOW PRICES IN NEW YORK FOR MIDDLING UPLAND COTTON

\begin{tabular}{c|c|c|c|c|c}
\hline Year & $\begin{array}{c}\text { Highest } \\
\text { cents }\end{array}$ & $\begin{array}{c}\text { Lowest } \\
\text { cents }\end{array}$ & Year & $\begin{array}{c}\text { Highest } \\
\text { cents }\end{array}$ & $\begin{array}{c}\text { Lowest } \\
\text { cents }\end{array}$ \\
\cline { 2 - 3 } & 14 & 9 & 1836 & 20 & 12 \\
& 12 & 8 & 1837 & 17 & 7 \\
1828 & 13 & 9 & 1838 & 12 & 9 \\
1829 & 11 & 8 & 1839 & 16 & 11 \\
1830 & 13 & 8 & 1840 & 10 & 8 \\
1831 & 11 & 7 & 1841 & 11 & 9 \\
1832 & 12 & 7 & 1842 & 9 & 7 \\
1833 & 17 & 9 & 1843 & 8 & 5 \\
1834 & 16 & 10 & 1844 & 9 & 5 \\
1835 & 20 & 15 & 1845 & $8 \frac{3}{8}$ & 5 \\
\hline \hline
\end{tabular}


HIGH AND LOW PRICES IN NEW YORK FOR MIDDLING UPLAND COTTON

(Continued)

\begin{tabular}{|c|c|c|c|c|c|}
\hline Year & $\begin{array}{c}\text { Highest } \\
\text { cents }\end{array}$ & $\begin{array}{l}\text { Lowest } \\
\text { cents }\end{array}$ & Year & $\begin{array}{l}\text { Highest } \\
\text { cents }\end{array}$ & $\begin{array}{l}\text { Lowest } \\
\text { cents }\end{array}$ \\
\hline 1846 & 10 & 6 & 1876 & $13 \frac{3}{8}$ & $10 \frac{7}{8}$ \\
\hline 1847 & 12 & 7 & 1877 & $13 \frac{5}{16}$ & $10 \frac{13}{16}$ \\
\hline 1848 & 8 & 5 & 1878 & $12 \frac{3}{16}$ & $8 \frac{3}{16}$ \\
\hline 1849 & 11 & 6 & 1879 & $13 \frac{3}{4}$ & $9 \frac{1}{4}$ \\
\hline 1850 & 14 & 11 & 1880 & $13 \frac{4}{4}$ & $10 \frac{\frac{4}{15}}{16}$ \\
\hline 1851 & 14 & 8 & 1881 & 13 & $10 \frac{1}{2}$ \\
\hline 1852 & 10 & 8 & 1882 & $13 \frac{1}{16}$ & $10 \frac{1}{4}$ \\
\hline 1853 & 11 & 10 & 1883 & $11 \frac{1}{8}$ & $10^{*}$ \\
\hline 1854 & 10 & 8 & 1884 & $11 \frac{15}{16}$ & $9 \frac{3}{4}$ \\
\hline 1855 & 12 & 8 & 1885 & $11 \frac{1}{2}$ & $9 \frac{7}{4}$ \\
\hline 1856 & 13 & 9 & 1886 & $9 \frac{1}{2}$ & $8 \frac{7}{8}$ \\
\hline 1857 & $15 \frac{7}{8}$ & 9 & 1887 & $11 \frac{1}{2}$ & $9 \frac{1}{2}$ \\
\hline 1858 & $13 \frac{1}{2}$ & $8 \frac{7}{8}$ & 1888 & $11 \frac{3}{8}$ & $9 \frac{5}{8}$ \\
\hline 1859 & $12 \frac{3}{4}$ & $10 \frac{5}{8}$ & 1889 & $11 \frac{1}{2}$ & $9 \frac{3}{4}$ \\
\hline 1860 & $11 \frac{5}{8}$ & $10^{\circ}$ & 1890 & $12 \frac{3}{4}$ & $9 \frac{4}{4}$ \\
\hline 1861 & $38^{\circ}$ & $11 \frac{1}{2}$ & 1891 & $9 \frac{1}{2}$ & $7 \frac{3}{4}$ \\
\hline 1862 & $69 \frac{1}{2}$ & 20 & 1892 & 10 & $6 \frac{7}{8}$ \\
\hline 1863 & $93^{\circ}$ & 51 & 1893 & $9 \frac{15}{16}$ & $7 \frac{1}{4}$ \\
\hline 1864 & 190 & 72 & 1894 & $8 \frac{5}{16}$ & $5 \frac{9}{16}$ \\
\hline 1865 & 120 & 35 & 1895 & $9 \frac{3}{8}$ & $5 \frac{9}{16}$ \\
\hline 1866 & 52 & 32 & 1896 & $8 \frac{7}{8}$ & $7 \frac{1}{16}$ \\
\hline 1867 & 36 & $15 \frac{1}{2}$ & 1897 & $8 \frac{1}{4}$ & $5 \frac{7}{8}$ \\
\hline 1868 & 33 & 16 & 1898 & $6 \frac{9}{16}$ & $5 \frac{5}{16}$ \\
\hline 1869 & 35 & 25 & 1899 & $7 \frac{3}{4}$ & $5 \frac{7}{8}$ \\
\hline 1870 & $25 \frac{3}{4}$ & 15 & 1900 & $10 \frac{4}{4}$ & $5 \frac{3}{4}$ \\
\hline 1871 & $21 \frac{1}{4}$ & $14 \frac{3}{4}$ & 1901 & $12 \frac{3}{4}$ & $6 \frac{3}{4}$ \\
\hline 1872 & $27 \frac{4}{8}$ & $18 \frac{5}{8}$ & 1902 & $9 \frac{4}{4}$ & $7 \frac{4}{4}$ \\
\hline 1873 & $21 \frac{3}{8}$ & $13 \frac{5}{8}$ & 1903 & $13 \frac{5}{8}$ & $8 \frac{1}{8}$ \\
\hline 1874 & $18 \frac{7}{8}$ & $14 \frac{3}{4}$ & 1904 & $17 \frac{5}{8}$ & $6 \frac{1}{4}$ \\
\hline 1875 & $17 \frac{1}{8}$ & $13 \frac{1}{16}$ & 1905 & $12 \frac{5}{8}$ & $6 \frac{1}{4}$ \\
\hline
\end{tabular}


It is seen here that the variation from lowest to highest prices has remained quite the same since 1826, with the exception of the period of $W$ ar and Reconstruction. Of course this is a significant fact; for while all other great products of the land have decreased in selling price, cotton remains the same (within normal fluctuations) during the entire period. This fact tells more forcibly than all others of the kingship of this imperial crop and the hold it has on all the world-a kingdom that includes all land and sea in its borders, that numbers all people as subjects, and is richer than any rival crop.

\section{F́LUCTUATION IN PRICES}

Normally and theoretically, the law of supply and demand regulates the yearly, monthly, and daily price of cotton. With the advent of the Cotton Exchange this has to a certain extent been modified: its machinery has given us a more delicate movement in price fluctuations. It is the constant anticipation almost every minute- of the play of this law on the Exchange that keeps the "ticker" busy in suggesting movements and establishing prices for the staple. At times some force, with little or with much power, may work counter to this law with such intensity and strength as to force the price up or down, but only for the time being, the pendulum of prices shoving back, showing by its act its determination that the law shall not long remain disturbed. It is this feature of the cotton market that works to the disadvantage of both farmer and spinner, creating unstable situations, depressing prices for the farmer, advancing them for the manufacturer, 
and giving the profit to the intermediary alien-the cotton manipulator.

\section{THE COTTON CONTRACT IS TO BE BLAMED}

It is not our purpose here to discuss the ethical phase of the cotton contract; rather simply to observe its practical workings. The small margin required for operations on the floor of the Exchange puts into the hands of the speculator an unreasonble amount of wealth altogether out of proportion to his commitment. Said one of those in the game: "You get a better run for your money than in poker, in any game of chance, in any gamble."

To particularize, here is an example: It is possible for a man with but $\$ 100$ margin to buy or sell in the office of a broker one hundred bales of cotton for some future delivery. At the price of ten cents per pound his tradings equal $\$ 5,000$ - and his capital $\$ 100$. From its very nature this is speculation of the rankest kind. Under this system it has been shown that "a member of the New York Exchange made contracts for the purchase of 300,000 bales of cotton, worth at current prices then about $\$ 24$, 000,000 . This enormous commitment was made without the deposit of any cash guarantee or responsibility, and when default in the contracts was announced it was liquidated at a loss of approximately $\$ 3,000,000$ to the parties who sold the cotton."

Do you doubt that so long as such a system prevails, extreme and unreasonable fluctuations in the market will occur, and to the great disadvantage of both producer and consumer? Such fluctuations occur after the cotton has left the hands of the 
producer; he profits not by the increase in price, nor does the consumer who must pay it.

\section{WILL THE SELLING PRICE OF COTTON DECREASE?}

Only the law of supply and demand will establish in the long run the selling price of cotton. This law is no respecter of persons or of occupations. Get production ahead and out of reach of demand and prices will inevitably sink; get it below demand and prices will advance just so far as the commercial safety valve will permit. A supply that is greater than can be immediately consumed will depress the price, regardless of the cost of production. There is no respite; the law in the end will enforce its own decrees.

The question now arises, "If supply and demand are properly regulated and adjusted, will the normal price of cotton decrease ?"

We think not, for the reason already discussed in our consideration of those economic principles that govern the cost of the raw product. It is true that improved tools and implements will come; fertilizers will be used more judiciously, and with more economy; improved methods will be adopted; wastefulness and carelessness will be eliminated more and more; and the cotton picker will probably come to gather the cotton more cheaply-all will contribute to the lessening of the expense now prominent in cotton production. But these savings will not be deducted from the selling end-they will go to the producer. And why?

1. The laborer or tenant, negro or white, is more poorly fed, lives in a shabbier home, has fewer comforts and luxuries, receives a smaller wage, than the laborer or worker in almost any other 
form of industry in this country. Hence, as profits are increased because of savings in production, the laborer and tenant will receive better compensation.

2. The cotton planter will receive his proportion as a legitimate reward for his labor and capital. It is true that many cotton farmers are making money; they are improving their lands, their houses, their stock and their equipment; they are building better churches and educating their children. As these increase, they call for better incomes to support them; so the saving in cost will go to the planter for greater comforts for himself and his family and for reasonable luxuries as well.

\section{TEN CENT COTTON IS NOT UNREASONABLE}

Most arguments one hears about the price of cotton are in the main to the effect that cotton sells for more than it is worth.

There are many stages of profit from lint on the farm to cloth in the retail store. Nowhere, however, is profit discussed except in reference to lint on the farm. Here are the facts in the case: A one-horse farm of twenty acres produces 4,000 pounds of cotton which sells at ten cents. This gives the farmer a gross income of $\$ 400$. Looking at this from the most optimistic viewpoint, that farmer did not clear on this twenty acres more than $\$ 80$, and out of this must come interest, maintenance and accumulative gain. The manufacturer takes that cotton and from the 4,000 pounds he manufactures 16,000 yards of calico, which sells for $\$ 800$ gross. Take it that there is but a small fraction of profit on the yard, when considered in connection with the great quantities handled, his profit is no small amount. From the manufacturer 
the goods go to the jobber, and at last to the counter in the dry goods store. What are profits here? Sixteen thousand yards at 5 cents per yard cost $\$ 800$; that number of yards sold at $7 \frac{1}{2}$ cents brings gross $\$ 1200$ - a profit as great to the retail merchant as the price the farmer receives for his entire crop.

\section{THE CONTROL OF PRODUCTION}

Is it right for the producer to control the output of his commodity? Why not? So long as supply is more than demand, is it wrong in principle to waste capital, and energy and life in producing it? More than this, 5,000,000 people are directly interested in the production of cotton crops. When you flood the market with raw material, and send it forth in larger quantities than spindles can use, you disturb the stability of trade and menace the peace and happiness of these five million souls. Is there no injury here? Greater evils, moreover, sweep over the land-even in other directions-if more cotton is produced than can be used by a consuming world. It is good business, good practice, good morals, to move supply and demand along together, as they now move, and this can continue only by controlling the supply, for the present, increasing it as demand calls for more.

So long as the manufacturer, the broker, the merchant live in costly houses; so long as the spinner, the weaver, the clerks enjoy comforts in dress and live easily, so long should no one complain that the cotton farmer and his tenant likewise have similar comforts and luxuries. 

SECTION IV.

MANUFACTURES AND BY-PRODUCTS 



\section{CHAPTER XXX.}

COTTON SEED : ONCE AN OUTCAST NOW A PRINCE

When cotton is gathered it consists of both fiber and seed. These two products grow together, the fiber out of the seed, and remain together until the gin separates them. Up to this point the combined products are known as seed cotton. From the gin, lint or fiber (or cotton as it is now called), leaves in the bale to be returned to the farm, or goes direct to the market for immediate sale.

The seed, however, are still the property of the farmer, and may be carried back to the farm, where they are valuable for feed or fertilizer, or they may be sold to the oil mill. As a matter of fact, about one-third of the cotton seed supply is now sold to the oil mill, to be converted into oil, meal and hulls, and the remaining two-thirds are carried back to the farm for feed, fertilizer, and a smaller quantity for seed for the next year's crop.

At one time cotton seed were altogether wasted: manurial value was not considered; and as a feed they had never a thought. In many places in the old days cotton gins were purposely built on streams in order that the water might carry away the great accumulations of supposedly worthless seed; and in (275) 
some States laws were passed requiring ginners to clear away the seed, the rotting piles otherwise becoming offensive to the neighbors!

Now, however, the value of this part of the crop has assumed enormous proportions, and offers a revenue to the Southern farmer not inconsiderable, even when compared with the value of cotton lint itself.

Seed cotton contains about one-third lint and two-thirds seed. The crop of 1905 of $10,697,013$ bales of cotton would mean about 5,850,000 tons of seed. This valued at $\$ 16.00$ per ton, a reasonable estimate, gives us a commercial value of $\$ 88,600,000$ in the raw state, while this value of course is greatly increased in the finished product.

And to think that this product as we have just said once rotted at the gin or was washed away in creeks and rivers - forever lost to the soil and to the world!

\section{WHAT IS IN A TON OF SEED COTTON}

Only an estimate can be made, since the proportion of lint to seed varies with different varieties and different soils; but taking the general rule that "cotton thirds itself," in one ton of seed cotton there should be 665 pounds of lint and 1335 pounds of seed. This seed would yield when prepared and manufactured about 489 pounds of meal, 18 pounds of linters, 187 pounds of oil, 561 pounds of hulls, and 80 pounds of waste material such as water, dust, and sand.

With the exception of the waste, all of these are commercial commodities, and to-day find markets wherever fertilizers are used, live stock are grown, or civilized people are known. 


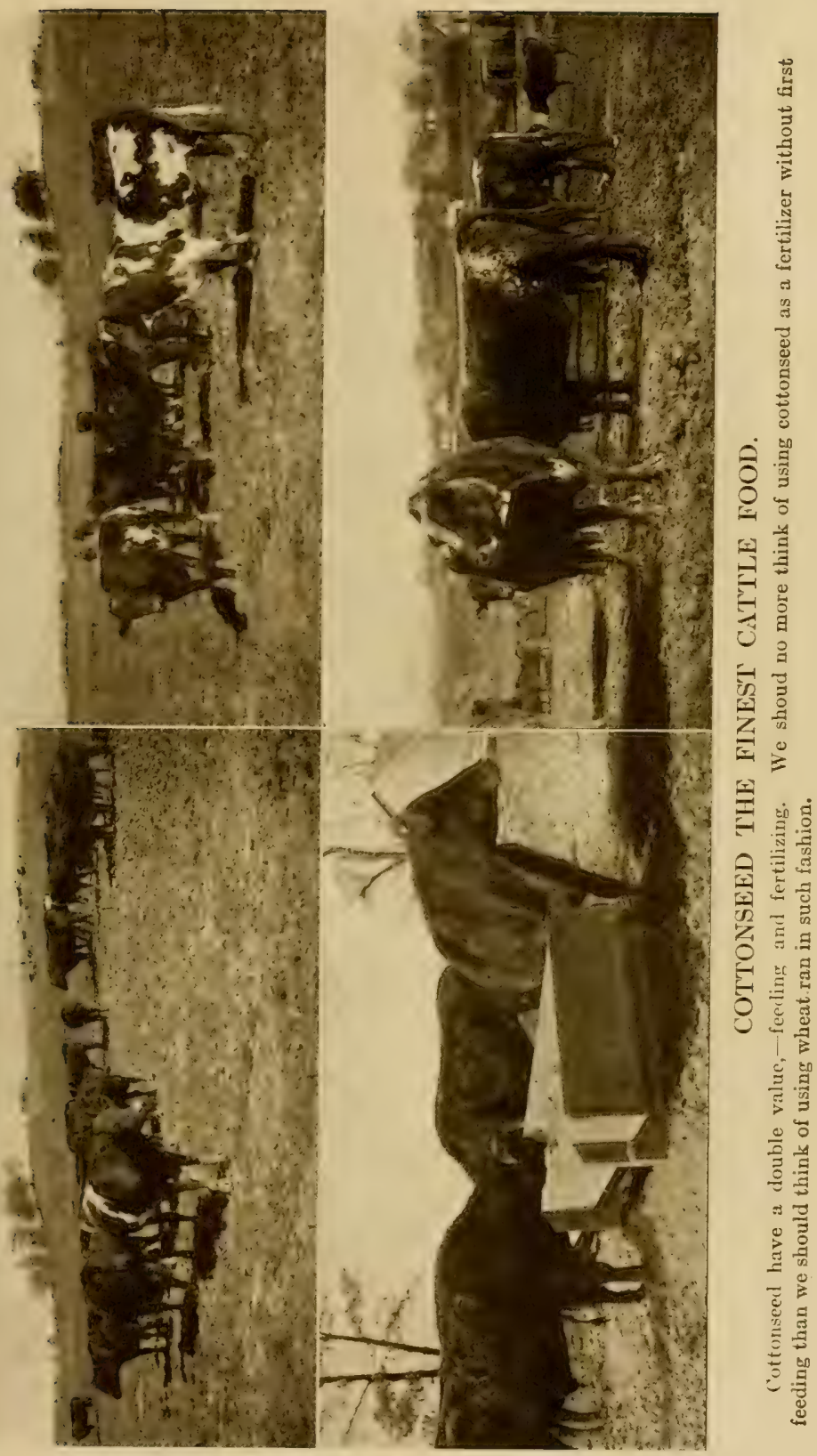




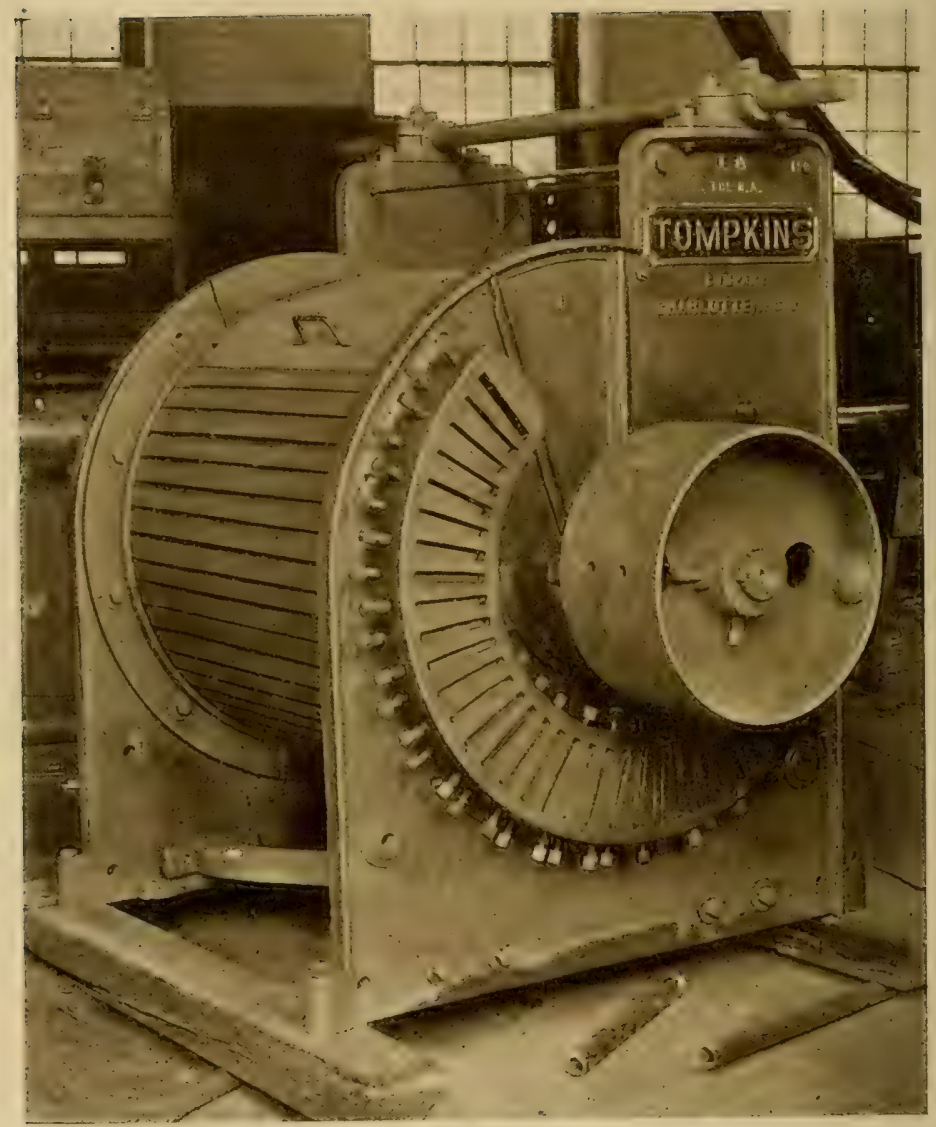

\section{COTTON SEED HULLER.}

The hulls are used for cattle food, the oil extracted from the meats, and the meal kept for feeding and fertilizing. "If cotton made no lint, the secd alone would justify its cu'ture." 
WHAT A TON OF SEED CONTAINS

Clearly to understand the value of cotton seed, we must consider the products made from them and the forms available for market use. These factors are obtained from the actual results of the oil mill. When treated for manufacture we get the following:

\section{COTTON SEED-2000 POUNDS}

(A.) Linters-27 pounds.

(B.) Hulls- -841 pounds.

(1.) Bran-Feeding Stuffs.

(2.) Fiber-High Grade Paper.

(3.) Fuel-Ashes and Fertilizer.

(C.) Meats -1012 pounds.

(1.) Cake-732 pounds.

(a.) Meal.

(1.) Feeding Stuff.

(2.) Fertilizer.

(2.) Crude oil-280 pounds. (a.) Soap Stock-soaps.

(b.) Summer Yellow.
(1.) Winter Yellow.
(2.) Salad oil.
(3.) Cotton Lard.
(4.) Cottolene.
(5.) Miners' oil.
(6.) Soap.

THE OIL MILL AND THE FARMER

It has been shown that the farmer may either sell his seed to the oil mill or use them at home. Certainly they can be profitably used on the farm. Cotton seed are not like such perishable products as fruits or vegetables,-which must be sold quickly 
leaving the farmer to take such prices as are offered without regard to the cost of production. In this case you can use your seed, if you cannot sell them on the market for what they are worth.

The fertilizing value is one measure of value and a governing principle in estimating the worth per bushel or the basis of exchange for meal.

Estimating values of cotton seed and cottonseed meal on the same basis as the cost of the ingredients in regular fertilizing materials used on the cotton farm, we get the following:

\section{One Ton Cotton Seed}

Ammonia, 75 lbs.@13.5c .............\$10.13

Phosphoric Acid, 26 lbs.@ 5 cts......... 1.30

Potash, 24 lbs.@ 5.5c ............. 1.32

Fertilizing Value..............\$12.75

This represents the actual worth of the potential plant food in one ton of seed. Allowing the same values for cost of the several ingredients in cottonseed meal we get the following:

\section{One Ton Cottonseed Meal}

Ammonia, 150 lbs.@13.5c ...........\$20.25

Phosphoric Acid, 56 lbs. @ 5c ......... 2.80

Potash, 35 lbs.@5.5c ............... 1.95

Fertilizing Value.............\$25.00

Putting this in form of a proportion we have $\$ 25.00: \$ 12.75:: \mathrm{x}: 1$. Or,

Value of meal : value seed : : $1.9: 1$.

In other words, cottonseed meal when sold for 
$\$ 25.00$ a ton contains just about twice as much fertilizing value as cotton seed. On a basis of 66 bushels of seed in a ton the value per bushel of seed is twenty cents. This price makes an even exchange, without allowing the farmer anything for hauling seed to the oil mill. When you sell seed for less than 20 cents per bushel, you actually give more than you get in return. It follows that you should always receive as much as twenty-five cents per bushel when meal sells for $\$ 25.00$ per ton.

\section{ON BASIS OF EXCHANGE}

But as a matter of fact you should never dispose of your seed except on a basis of exchange. Your soil cannot stand the continual drain upon it, if the seed are sold and nothing is put back to restore the fertility they draw from the land. All seed taken from the soil by the growing crop, should be returned to it either in form of seed, meal, or cattle manure. Since the oil in the seed has no fertilizing value, and is of no use to the farmer, he can exchange this oil for meal, the product of more especial value to him. But on what basis of exchange? As we have mentioned before, for fertilizing purposes meal is slightly less than twice as valuable as seed; but you cannot haul your seed to the oil mill and then haul the meal to your home without some compensation. This compensation should therefore be in the form of extra meal. Just what that amount shall be will depend on the distance, condition of roads, and the composition of meal. In a general way it may be said that you should receive at least 1100 pounds of meal in exchange for a ton of seed, and an additional amount to compensate you for your trouble, 
labor, and expense, incidental to making the exchange.

\section{COTTON HULLS}

From each ton of seed about 800 or 900 pounds of hulls are obtained. These hulls are used for fuel and for feed for live stock. The increased demand for the latter purpose practically calls now for the whole output, although it has been but a few years since practically all of the hulls were burned. Everywhere through the South cotton hulls are fed to cattle and mules, and in many places they form the major part of the roughage factor of the daily ration. Hulls are palatable, and in one way are nutritious, since they furnish nutrients that go to make heat and fat. Comparatively speaking, their feeding value may be ranked as being about half that of ordinary grass hay. In composition they are almost as wellbalanced as this hay, although they contain but a small quantity of digestible protein-the muscle maker. The entire oil mill output of this product readily finds a sale at from $\$ 3.00$ to $\$ 6.00$ per ton.

\section{COTTON SEED MEAL}

In every ton of seed there are about 732 pounds of meal, used exclusively for fertilizing and feeding purposes. Cottonseed meal is the most concentrated of our vegetable feeding stuffs. It is extremely rich in protein, a nutrient of especial importance for feeding all classes of farm animals.

As a feed for beef and dairy cattle, cottonseed meal is especially popular. Considering the digestible nutrients it contains, it is the cheapest 
feeding stuff on the market today. Sooner or later this fact will be appreciated and as a consequence its commercial value will advance because of the increasing demand for it as a cattle food. This will also mean a saving to the South, for if the manure is properly cared for, there is little loss of fertilizing value from the original raw material.

A PRACTICAL QUESTION IN CONCLUSION

Used as a fertilizer we get but one profit from cottonseed meal.

Used as a feed and the manure saved, we get two profits.

Which shall we choose? 


\section{CHAPTER XXXI.}

COTTON OIL : THE KING FEEDS AS WELL AS CLOTHES HIS SUBJECTS

The cotton oil mill does not take simply the seed and grind them, putting them in better form for fertilizing and feeding purposes, but it removes from the seed the property that for these purposes is more objectionable than serviceable. For oil in the seed, for feeding to live stock, is unfavorable to digestion, especially where any considerable quantity is used; in no sense is it of use to the soil, nor does it serve as a source of food or show itself of any use to the plant. Consequently it is of advantage to the farmer to have the oil extracted from his seed-the other ingredients being returned to him - simply as a means of preparing his product for use and leaving out of consideration the thought that he is reimbursed for his time and labor.

THE RISE OF THE OIL MILL

The oil mill at first came slowly into favor. A good many decades ago attempts were made to establish mills; for vegetable oils have long been in demand; and then, too, there was promise of profits in the business. While at first a few mills were established by individuals or independent corporations, the cotton oil business was developed into large proportions by a single large company. Naturally, however, the success of this company 
brought rival companies into the field, and to-day wherever cotton is grown there are mills of various sizes converting raw seed into crude oil, meal and hulls.

THE PROCESS OF MANUFACTURING

Seed are gathered wherever obtainable and then delivered at the oil mill. Arriving here they are shoveled into a basket elevator which empties into a conveyor in the top of the building, and from thence they are distributed wherever storage room is available. Seed are now screened so as to get rid of bolls and other impurities, sand, dust, etc.

This process of cleaning is the first step in the production of oil. Now seed go to the linters, where the short fibres are removed; and from here they go to the huller-a contrivance fitted with sets of knives that cut the seed into many small pieces. The heavier part of the seed, the meat, drops out and goes in one direction, while the hulls are carried in another. This operation is further perfected by having all of the droppings pass through sieves or screens which allow the meats to go through, but retain the greater part of the hulls. The hulls are next sent to places where they may be stored away, or carried to the press for baling. The meat now passes through a series of rollers intended to crush the particles and cells. From here it goes to heaters and kettles, and is cooked, the time of this cooking varying from 15 to 40 minutes according to the judgment of the cook, and the condition of the seed.

When this operation has been completed the meats are placed in a hydraulic press where the oil 
is pressed out, and the other ingredients moulded into cakes.

The operation now required to complete the work consists of preparing the crude oil for the refinery and the cake for commerce. For consumption in our country nearly the whole of the cake is ground, putting it into a better form both for feeding and fertilizing purposes.

\section{THE SIZE OF MILL}

The cost of transportation and seed storage is one disadvantage in the process of manufacturing oil and meal. But this difficulty is now overcome by the multiplication of small oil mills,-local enterprises springing up all over the Cotton Belt and each doing the work of its own community. And (what is true of few other lines of manufacturing) the small oil mill does the work about as efficiently and economically as the large one.

The small mill in fact has a peculiar advantage in that it has the interested support of the farmers of the neighborhood. It should be as much a part of the community, and should be operated in the service of the farmers just as much as is the cooperative creamery or the local flour mill in our Western States. The community mill will get its seed almost entirely from the neighborhood, and meal and hulls will, or should be, entirely used by the farmers of the community; consequently there is no freight to pay on seed or on their products.

The item of storage is of considerable consequence, since a chain of delivery can be arranged that will keep the mill at work, and not require large quantities of seed to be kept on hand at any time. 
The small mill consumes all the way from two to five thousand tons of seed each season and may use as much as 25 to 50 tons each day. At the prominent railroad centers are mills of larger capacityusing from 150 to 200 tons of seed daily, or from twenty to fifty thousand tons each season. These make large profits since seed can be shipped from any distance and the product delivered without great expense to the mill.

As a commercial enterprise, this is all very well, but the seed is the product of the farm, and should be consumed on the farm; there is no other system that is not actual land-robbing. Consequently, from its nature the oil mill is still a local factor, a community factor, and a farm factor, and is just as important in the disposition of this part of the cotton crop as is the shredding machine or the threshing machine for the diposition of the corn or wheat crop, the only difference being that the mill is stationary and we carry the seed to it, while shredding and threshing machines go through the community and work on each individual farm.

With this idea accepted, it clearly follows that the cotton oil mill is indispensably connected with the community, and sooner or later the local cooperative enterprise must become the rule wherever cotton is grown.

\section{CRUDE OIL}

The operations of the oil mill have to do with the production of cake and hulls on one hand, and with the production of oil on the other. We may say that the mill itself came as a means of securing oil from the seed, and that meal and hulls are a by- 
product of this manufacture rather than primary objects. But so valuable have these two commodities become that their importance is now even greater than that of the oil itself.

Oil as it leaves the press is known as crude oil, and has not a great many uses until it passes through the refinery for the completion of the manufacturing process. While we can have a number of oil mills and while these may be small in size, the refining mill is so complicated as to be very expensive, difficult of operation, with running expenses further heightened because costly labor must be used. But we do not need so many refineries. The great bulk of the raw seed necessitates a large number of oil mills, not only because of money saved in freight, but because of the fact that with many local mills the farmers can readily dispose of their seed or secure meal in exchange for them.

Oil, on the other hand, is a very concentrated product. From a ton of seed something like forty gallons of oil are obtained. It readily follows that the oil contained in a great number of tons of cotton seed can be transported in the same bulk space as is required for one ton of raw seed.

So from all directions in the State crude oil may go to some one or more central points to be refined, and from these points distributed for manufacture into commercial products.

In the process of getting oil in its crude form two products result: crude oil proper, and the settlings or "foots" as they are called. The first named product is drawn off and goes to the refining tank, from whence it is barreled for shipment. The settlings usually go back to heater tanks and are either pressed again or barreled and shipped as soap stock. 


\section{OIL IN THE REFINING TANK}

Crude oil when taken from the settling tanks may be either shipped direct to refineries, or if, as is often the case, a refinery is located in connection with the oil mill, it may be refined at once.

In the refining process oil is heated gently, stirred constantly, and treated freely with air which enters through a perforated pipe at bottom. Impurities are still present in the crude oil, and these are partially gotten rid of through the free use of caustic soda or potash; this coagulates them, causing them to collect and fall to the bottom of the tank. The next step is to draw off the oil and make the final preparation for its shipment. Before it can go, however, it must be washed with water in order that the potash may be dissolved and removed. Since oil is lighter than water, separation gradually takes place in the mixture and the oil slowly rises to the top where it is carefully drawn off, at last to be filtered and put into barrels.

\section{WHAT IS MADE FROM THE OIL}

Refined oil is known as "summer yellow" and of course, is of a higher commercial value than the crude oil. Prime summer yellow is known as butter oil, and is largely used in the manufacture of oleomargarine, butterine and even as an adulterant for butter itself.

The highest grade of summer yellow is often subjected to cold pressure, which gives a product known as salad oil for cooking, dressing, and other household products. Then, too, large quantities of summer yellow have for a long time found their way into Italy where it is treated, to be sent later to 
all the world as olive oil. The greater part of our so-called olive oil now used in this country bears absolutely no relation to the olive tree, but is simply high grade summer yellow especially treated, and labeled as genuine olive oil.

Summer yellow is also treated with bleaching powder, which removes the yellow color, and it is then used in the manufacture of compound lard and like materials. So popular has it become in this form, that it is now manufactured under its own name or as cottolene.

Winter white oil is the same product but cold pressed. It is used in many ways from the manufacture of medicinal compounds to oil for the miner's lamp.

In numerous other ways does this refined cotton oil product supply the wants of man; and it seems likely that we have only just begun to appreciate its value and that in future we shall have use for greater quantities, much of the product to be used in directions not yet even dreamed of.

\section{ITS USE IN ADULTERATING INEXCUSABLE}

Cottonseed oil has its own work to do, its own place to fill. Its value is too great, too important, too manifest, for us to wish to see it fraudulently used. There is no line of argument to justify the sending of cotton oil or any of its manufactured products into the world under false names save to ask praise and reward intended for something else-losing withal the renown and the reward that its own merits justify.

This adulterating practice has been carried entirely too far. Cottonseed oil may make as good salad dressing as olive oil, but it should be sold 
under its own name and not as olive oil; it may be made into good "butter" but since the cow has a copyright on that name, no other product has either a commercial or moral right to use it; it may be as good as hog lard, but it has no right to the name of either hog or lard.

So this masquerading under names of old established products has brought cotton oil into more disrepute than all its deficiencies have ever done; or to put it more vividly, cotton oil, with its good qualities masquerading under false names, its less useful forms appearing under its own name, has thereby surrendered to other products much of the praise its merits deserve and has kept for itself all the blame of its shortcomings.

Cotton oil has merits enough of its own to stand on its own bottom and to fight its own battles. As soon as those responsible for its evil ways realize this, the better it will be for the commodity.

THE SIZE OF THE INDUSTRY

Estimating the 1905 cotton crop at 10,697,013 bales of lint the production of seed would be nearly or quite five million three hundred and fifty thousand tons. On the supposition (and this is the evidence of the past) that two-thirds of these will go back to the farm, the other third used at the oil mill, we have nearly one million seven hundred and eighty-five thousand tons for the mills. On the basis of forty gallons of oil in each ton we will have the enormous production of more than seventy-one million gallons of oil from our 1905 cotton crop. This, when sold in crude form at twenty cents per gallon brings to the mills of the South fourteen million two hundred and eighty thousand dollars for oil alone. 


\section{CHAPTER XXXII.}

MEAL AND HULLS: KING COTTON ALSO FEEDS OUR FLOCKS AND HERDS

The correct solution of the cotton seed question is the use of the cotton oil mill, whether privately installed or by co-operative endeavor, for every community. To this mill all seed should be brought except what is saved for the next year's crop, that the oil -otherwise useless and wastedmay be extracted and put on the market as a commercial product; the by-products-meal and seed-should then be returned to the farms from which they were taken. On each farm then there will be the equivalent of the seed, but now in the form of meal and hulls, to take the place of the fertility withdrawn from the soil by the cotton crop.

The meal and hulls should not be returned to the soil in their organized and original condition, however, but first fed to live stock, so as to secure the finished product-making begun with the factory, further extended to the oil mill, and now completed on the factory-farm. For the farm is a factory: and factory-farming should be your plan of operating.

HOW THE PLANT WORKS

The cotton plant, you know, feeds from soil and 
air. It lives on disorganized materials. While it enjoys a ration in which cottonseed meal forms a part, yet it does not use this material before nature has rotted or decomposed its component parts. The same amount of effort that nature uses in doing this work, live stock may give, and to their profit. In other words, what is food for the plant is not food for the animal; what is food for the animal is not food for the plant. In other words, just as the oil mill takes the oil from the seed, and yet turns back to the farmer all the elements of the seed that he can utilize, so the animal takes from the seed certain properties useful to it, and yet returns to the soil practically all the matter the soil could utilize for its enrichment. Meal is food for the animal but not food for the plant, until nature does to it precisely what the animal does to it. This is to decompose it. The animal is benefited because it grows and becomes fat in breaking up the organized forms of meal and fat. When the animal gets through with its work, it returns the fertilizing elements to the soil in the form of liquid and solid excrement.

\section{THE FACTORY FARM}

The cattle industry should be a part of cotton farming; not simply to raise feeding stuffs on the farm, but to change these from the raw state into finished forms. That is what any factory does: the cotton factory, for example, takes raw cotton and makes it into finished products. On the factoryfarm the cotton farmer will take his meal, hulls, grasses, corn stover and hays, and manufacture them into such finished products as milk, butter, cheese and beef. For we lose one of the import- 
ant values of our meal when it is used simply as a fertilizing stuff: we lose the tissue form that plants in their growing made.

Now, we use our meal largely as a fertilizing material. We estimate that value at $\$ 25.00$ per ton. But the dairy farmer and the beef farmer find cottonseed meal an invaluable food at that price. Hence it must have both a feeding and a fertilizing value.

Let us see: does butter or milk or cheese or beef use the fertilizing material of the meal? Surely not, for in a whole ton of butter, but 48 cents of fertility is found. In a ton of milk but $\$ 2.80$ of fertility is found. Does it go in the dairy stock? Of course not, else these dairy animals today would be as large as houses or barns. The material they used found its way back again to the soil. First it went into the feed lot, and the barn-yard, or wherever excrement dropped. But if not wasted it is in the land. Experiments show that after allowing for various quantities used by the animal products, such as butter, milk, beef and the like, and legitimate wastes that naturally follow the management of cattle, fully three-fourths of the original fertility may be saved and returned to the soil.

THE DOUBLE VALUE OF MEAL AND HULLS

We therefore have two values: one for feeding, and one for fertilizing. This may be expressed as follows:

Value as a feeding stuff........ \$25.00

Value as a fertilizer........... 18.75

Total value .............\$43.75 
When cottonseed meal is used simply as a fertilizer, therefore, there is a loss of $\$ 18.75$ on every ton thus utilized- $\$ 18.75$ a ton actually thrown away by the cotton farmer who is not thrifty enough to raise stock and to get all the profits from his seed. There is no proposition less open to argument than that on every farm on which meal is used as a fertilizer, we should first feed that meal to cattle so as to secure the double value.

And then also bear in mind that our cotton lands need animal manures, more than fertilizers, for whenever and wherever used, stable manures show a greater efficiency than their actual nitrogen, phosphorus, and potassium content would indicate. This is because they supply humus so much needed by all our lands, sick as they are from the onecrop system.

Much of the meal now produced in the South finds its way to the dairy farms of Germany, England and the northern and western parts of our own country.

Rich in protein, which is the basis of milk production, meal is naturally winning much favor as a dairy ration. A dairy cow with a capacity of three gallons of milk daily, requires two and onehalf pounds of digestible protein. She can get this only from the protein of the food she consumes. Oil or starch or fiber will not make protein. You cannot convert lead into gold by any process, nor can you take foods like timothy hay, orchard grass, corn stover, corn and like products, and make them furnish protein for the milk ration. Cottonseed meal stands foremost of all vegetable feeding stuffs in the quantity of digestible protein it contains. It follows then, that the cotton farmer, since he produces meal and since he produces the 
most valuable dairy food, should combine dairy farming with cotton farming. In this way double profits may be made and cotton lands may be improved.

EFFECT OF COTTONSEED MEAL ON BUTTER

When meal is fed as a part or as the whole of the concentrate of a dairy ration, it raises the melting point of butter. As a matter of fact, cottonseed meal makes a harder butter than any other feed. A number of tests have been made, and the value of cottonseed meal as a superior butter-producing food is proved beyond all doubt. When fed in combination with hulls with no other feeding stuffs, a relatively inferior butter is produced, but when combined with such materials as corn ensilage, corn stover, and cowpea hay, no better butter can be made by any feeding ration in the world.

\section{THE VALUE OF MEAL AS A DAIRY FOOD}

It is not stating the case too strongly to say that as a food for dairy cows cottonseed meal is superior to all others. When compared with wheat bran, the importance and value of which is known wherever butter is made, cottonseed meal increases the quantity of milk one-fifth. When compared with corn meal, the milk production is greatly increased. This is evidence enough to show that the value of cottonseed meal as a dairy food is not yet generally appreciated, and that for years to come, constantly increasing quantities will be used by wide-awake dairymen.

MEAL AND HULLS FOR BEEF PRODUCTION Already the beef industry is assuming consid- 
erable proportions in the Cotton States, but when its present condition is compared with its real possibilities, what we have already done is quite inconsiderable indeed. Meal and hulls make up the bulk of the required fattening ration. To combine these two feeding stuffs, put them about in proportion of one pound of meal to four of hulls. As soon as the taste is acquired, both feeds are eaten with eagerness and with relish.

But best results are not obtained by this sort of feeding. Cattle, like ourselves, enjoy and profit by variety in food. Meal and hulls should be combined with other feeding materials such as ensilage, corn stover, cowpeas, hay, etc.

We cannot go far in this study of the feeding value of cotton by-products without accepting the indisputable proposition that the South will never make the money from its great staple that it ought to make until we find on every farm feeding steers and other cattle to utilize the meal and hulls that we bring from the oil mill in exchange for our seed.

EFFECT OF COTTONSEED MEAL ON STEER FAT

Tests have been made in which cottonseed meal has been compared with corn and which show that meal produces a fat having a higher melting point than that of corn-fed steers. The evidence of butchers and packers is in favor of cottonseedmeal-fed cattle.

The best quality of beef and beef fat, however, is produced when the animals get the meal in connection with other concentrates and roughage materials. 
EASE OF FATTENING BEEVES WITH COTTONSEED

MEAL

Beef that meets the ideal for the plate must contain lean meat as well as fat. To give the highest satisfaction it must be marbled-have both lean and fat. Lean meat comes from the protein of the food, fat from the fat and carbohydrates of the food. This being the case, cottonseed meal and hulls possess the three materials for making beef possessing these two qualities. It is impossible to make better beef than when the cattle are given meal and hulls combined with corn ensilage or corn stover.

HOW CORN AND MEAL COMPARE AS FATTENING FOODS

In the popular mind corn represents the highest ideal as a grain and fattening food. On many farms meal is exchanged for Western corn, the owner thinking the latter a superior food, in fact regarding it as indispensable for live stock of any kind; and so he disposes of his home grown products rich in digestible nutrients and high in fertilizing materials, buys corn in exchange (with freight charges and dealer's profits added) corn being indeed a food of high quality for fattening purposes, but very low indeed in fertilizing value.

What are the facts on this point as revealed by feeding tests?

In Station tests, one pound of cottonseed has been found to equal in feeding value-beef producing value-1.13 pounds of corn meal; in other words, for feeding beef cattle preparatory to the market, cottonseed is superior to corn meal. 
When cottonseed meal was compared with corn meal, pound for pound, it was proved conclusively that 1.73 pounds of corn meal were required to produce the same weight of beef as one pound of cottonseed meal produced.

This shows that in beef production one ton of cottonseed meal is equal to 1.73 tons of corn meal. Hence for feeding purposes, when corn is worth fifty cents per bushel or $\$ 18.00$ per ton, cottonseed meal is worth $\$ 30.80$ in beef production.

Can the cotton farmer longer neglect the cattle industry, when he has in his own hand the feed which is most efficient and at the same time the least expensive and which possesses the richest manurial effects?

Cattle raising should go hand in hand with cotton culture. When so combined, they afford an ideal system of agriculture and more completely blend in promoting both profits and the maintenance of fertility than any other sort of land and animal management. We cannot too often emphasize the fact that the opportunity of the South lies in this direction.

Will you take it up or permit it to pass by, as you have been doing heretofore?

Let the idea prevail all the time that fertilizers can be purchased best in the form of cattle foods; take a dollar and buy concentrates like meal and hulls, and first feed these, using the voidings and waste for the manurial effect on the land. You must not get away from this fundamental fact that the meal and hulls contain two values-one for feeding and one for fertilizing - and that in using them as a fertilizer alone, you are deliberately throwing away one profit- $\$ 18.75$ for every ton of the meal. 
MEAL AND HULLS FOR HORSES AND MULES

Horses and mules may be fed moderate quantities of meal and hulls with great advantage. No danger attaches to the use of hulls, but meal has always been fed rather sparingly. In recent years many experiments have been conducted which show that meal can form a part of the grain ration both profitably and satisfactorily. From two to four pounds may be used daily, although it is best not to make it a constant and regular diet.

\section{COTTONSEED MEAL FOR CALVES AND PIGS}

For reasons unknown meal seems not to be a desirable feeding stufi for calves and pigs. For a few weeks meal may be fed with impunity, but there soon comes a time when bad results follow-sometimes death.

\section{WE NEED MORE LIVE STOCK}

While there is profit today in the razor-back hog, the long-legged, thin back, scrub steer, and the light carcassed wether, we need more animals and better animals.

The by-products of our oil mills are not fully consumed: we need more cattle and sheep to utilize these materials. Of course, meal and hulls are no longer wasted; if the Cotton Belt is unable to utilize the product, the rest of the world is eager to secure it. But why should the South permit this? Its lands suffer, since a ton of its meal when shipped away, means just so much valuable plant food, so much actual Cotton Belt soil-richness, sent elsewhere to build up lands in some other State. So 
long as butter and cheese and beef come to the South by express and freight, there is a demand, an opportunity, for the production of these commodities in Southern territory.

Until every cotton farm possesses foundation stock for cattle and sheep and swine breeding, there are too few animals; until enough are raised to supply local markets, and to consume locally raised feeds, the live stock supply is short-and the cotton farmer fails to realize his opportunity for wealth and prosperity.

\section{WE NEED BETTER GRADES OF STOCK}

It is sadly true that the live stock of the Cotton Belt is extremely inferior. The average cow produces but 2,000 pounds of milk annually; the average steer matures in four or five years, and then only with a weight of 800 or 900 pounds.

Is growing this kind of stock economy?

Do you cultivate your corn with a hoe or with a cultivator? Do you harvest your wheat with a sickle or with a harvester? Do you separate seed by hand or use the gin? Do you even travel long distances now on horse-back, or do you go on the steam car?

Surely not. You use the most up-to-date tools and implements, and follow modern methods in everything but your live-stock machines : for the old scrub cow and scrub steer are simply out-of-date machines.

More live stock then, and better, that the South may feed its own meal, to make its own butter, its own cheese, its own milk, its own meat: to get not only the profit of growing cotton and other feeding stuffs, but a profit in feeding it by means of the 
manufactured products it makes. So true is this it requires no one to champion. the reasonableness of the proposition; rather it should be the effort of every farmer, whether he possesses a few acres or many, to try to grow not only cotton, not only roughage material like peas and corn and meal and hulls, but live stock as well, that the by-products of his many crops may combine with others to produce milk and meat and butter and cheese; and at the same time produce a large quantity of home-made manures to rejuvenate and to build-up cotton lands.

This is the great thought in the true philosohpy of farming; it is the magic key that unlocks the door to successful effort; it is the introduction to the throne of agricultural prosperity, and the beginning of a better and fuller life on the farm. 


\section{CHAPTER XXXIII.}

\section{THE RISE OF COTTON MANUFACTURING}

From time immemorial cotton has been used in the manufacture of textile fabrics for man, furnishing clothing for his body and sundry home comforts. It was not until a century or two ago, however, that its use for this purpose began to assume large proportions. Many important discoveries had first to be made; many great inventions perfected, before cotton could be manufactured so as to supply human wants at a cost in labor commensurate with the value of the fabric made.

But so important a fiber, with such tremendous opportunities for large production, was not long to go undeveloped and unused, when man, reaching that stage in civilization where he should have need for it, adopted it as a rich find; pressed it into service at once; put his ever-ready genius to master the problems of its production, its culture, its manufacture, until the day should come when to it, more than to all other fibers combined, attention and skill and labor should be given.

\section{THE BEGINNINGS OF COTTON MANUFACTURE}

The first factory was the cottage home. Long before the coming of the cotton factory, cotton was 
known to a limited extent to England and to other countries of average civilization. Cotton possessed value as a textile fabric. And that these advantages were early appreciated there can be no doubt, since it was readily used whenever it could be obtained. Naturally, however, there could be no large growth solong as the supply varied constantly.

We must understand, however, that for a century or more cotton had been used in a limited way for the weft or transverse threads of the web; the warp, or longitudinal threads, being of linen yarn, produced mainly in Germany and Ireland. Cotton factories were of course unknown in those days, weaving being largely done in the homes of the weavers. This cotton-linen fabric was, during these times, made in these cottage homes, and later carried to the market, to which points the city merchants came and made their purchases.

Sometime about the middle of the eighteenth century we find the beginning of a new era, when merchants began to send agents into the country to develop this embryonic but isolated factory system. The plan as introduced and carried out, secured linen for warp, and cotton for weft as had been used before; but now the merchants (through their agents) provided the raw materials, and hired the weavers to do the work. Before this time the weavers made all their purchases and sold their products themselves. Now the materials were furnished and they received wages for their labor. A radical change, you will see, had been inaugurated which doubtless worked to the common advantage of both parties.

Up to this time cotton had been spun by means of the common spinning wheel in the weaver's own house-the same spinning wheel whose monot- 
onous roar, gloomy and melancholy as the north wind itself, may yet be heard on wintry days in many a humble home of the rural South: if one cares to study the question further, let him read Thomas Buchanan Read's famous poem, "The Closing Scene." Of course the work of this hand spinning wheel was-and is-slow and laborious, and it followed naturally that the product should be relatively expensive, and the wage of the laborer small indeed.

\section{THE COMING OF IMPROVED INVENTIONS}

The inauguration of the new scheme in manufacturing was bound to work to its advantage, and hasten its development. It was no longer an individual concern. It now became a community interest, so governed, controlled and directed.

Singular indeed is it that just at this critical period a number of improved inventions should be made, following one another just as men most needed them, and covering too, such widely different fields of human activity. Even the schoolboy has heard of the epoch making spinning-jenny of Hargreaves; spinning-frame of Arkwright; power loom of Cartwright; Watt's steam engine and Whitney's cotton gin.

First the spinning-jenny came in $176 \%$, enabling from 16 to 30 threads to be spun with the same facility as one had been spun previously to that time, and it was subsequently brought to such perfection that a little girl was enabled to work from 80 to 100 spindles.

While this invention itself marked a great advance, it did not go far enough, since the jenny then in use was applicable only to the spinning of 
cotton for weft or transverse threads, being unable to give that firmness and hardness which is required for the longitudinal threads or warp.

But the spinning-frame came a few years later. A really wonderful machine this was, spinning a large number of threads of any degree of fineness and hardness, calling on the operator simply to feed cotton to it, and to tie threads that broke accidentally. Up to this time the hand loom was required for all of the work of weaving. That meant, of course, long, weary days for many, many people. Now something better was in store. The power loom was to supersede the work of the hand. And next, just as power is needed, behold it also comes! For Watt has succeeded with his steam engine, ready to supply the manuf acturer with a new power applicable to every purpose, easy to control, and readily placed where most convenient, and right in the midst of an industrious people.

But what are these inventions without cotton? Can cotton farming and manufacturing become extensive while the seed must be separated from lint by hand?

It has been said that " necessity is the mother of all inventions." Surely if cotton goods were to be manufactured, it was necessary that cotton be produced cheaply and that it be easily prepared for manufacturing.

And so finally this brilliant series of practical inventions is completed with Whitney's cotton gin.

Other inventions leading to the improvement of those here mentioned or blending with them in such a manner as to make their work more efficient, called for increased quantities of raw cotton which could now be supplied economically and in quantities sufficient to meet the world's needs. 
Cotton manufacturing increased in England as did cotton production in America, and both so worked together that the cotton industry from seed to loom assumed large proportions, and has since continued to grow with every passing decade.

\section{PERFECTING THE INVENTIONS}

But these inventions still left gaps between cotton in its raw and its finished state, and these difficulties had to be met and gradually overcome.

Of the inventions having direct relation to the spinning-jenny and the spinning-frame, the most important was that of the mule. Neither one of these other machines was complete in itself. It was left for Crompton to invent the machine which should retain the drawing out and winding features of the jenny, and that should have at the same time the rollers of the old spinning-frame.

It will be seen that this new invention retained features of both the spinning-jenny and the spinning-frame. It was in this sense a hybrid; and later, by reason of this fact, it was given the name of mule, which it has ever since retained.

A marvelous machine it is, called by whatever name, and it is in every sense one of the most wonderful and most easily operated machines that has ever been constructed. At the present time spinning mules are made as much as one hundred and twenty feet long, some having 1300 spindles which spin and wind 64 inches of thread in 15 seconds; and only a couple of persons are needed to attend to the whole machine. The extremely fine yarns that are now made are the product of mule spinning, as well as much of the best soft thread used in manufacturing hosiery and underwear. 
In looms, improvements have also been made that have contributed to greater ease in weaving. The old loom necessitated stopping whenever the yarn in the shuttle was exhausted and until a freshly filled shuttle could be inserted. Now such improvements have come that the shuttle may be filled without being removed and without replacing the shuttle itself, in either case without stopping the loom at all. This is a matter of considerable consequence since as much as one-half of the labor cost of converting a pound of cotton into woven cloth is in weaving.

\section{WHAT BECOMES OF YARN?}

Yarns are used in many ways. In our country spinning and weaving are usually done by one and the same establishment. But in Great Britain and on the continent of Europe, the spinning and weaving operations are almost invariably separate, and as a rule bear no relation to each other.

Throughout the cotton manufacturing world a great part of the yarn goes at once into plain cotton cloth. It is also used for warp in woolen and worsted goods, and also for knitting into underwear. Considerable quantities of yarn are used for this purpose.

For sewing thread and the finest grade of cotton thread for weaving, Sea Island cotton is principally used on account of its length,evenness and strength. After it has been spun into yarn it is next converted into thread by doubling and twisting until it is of the desired thickness and strength.

COTTON MANUFACTURING IN AMERICA

As early as 1787 records show that Great Britain consumed nearly $23,000,000$ pounds of cotton. 
A century later more than $1,650,000,000$ pounds were consumed in making cotton goods, these having a commercial value of nearly $\$ 400,000,000$. For 1904-05 her consumption is estimated as 1,794,000,000 pounds.

But while England early became noted for cotton manufacturing and has always led in cotton consumption and in number of spindles operated, America has had no small part in this wonderfu? development. At first progress was made slowly. Although the Southern States shared largely in starting cotton manufacturing, the first factory being in South Carolina, the Cotton States soon addressed themselves more exclusively to cotton farming, yielding to New England the supremacy in manufacturing the goods. One of the earliest manufacturing plants was established at Slaterville, $R$. I., and as early as 1816 consumed 100,000 bales of cotton, turned out 181,000,000 yards of cloth, employed thousands of operatives, and had a working capital of many millions of dollars.

The greatest center of cotton manufacture has been in the city of Fall River, Mass. As late as 1900 the two adjoining counties of Bristol in Massachusetts (in which Fall River is located) and Providence in Rhode Island contained about thirty per cent. of the spindles in the United States.

The power loom was first put in use in mills at Waltham, Mass., from which place, after the experiment had been found successful, it went in every direction where cotton manufacturing had gone.

SIZE OF THE WORLD'S INDUSTRY IN SPINDLES

The unit of production in the cotton industry is the spindle. A large number of spindles is nec- 
essary in any mill, as the quantity of thread produced per spindle is small. For instance, a mill with 10,000 spindles manufacturing No. 20 yarn, will produce in a day from a third to four-tenths of a pound of thread per spindle or from 3000 to 4000 pounds total output. Yarn cannot be woren, cloth cannot be manufactured, until spindles first spin the lint into thread. The steady increase in number of spindles throughout the world is set forth in the following table:

\begin{tabular}{|c|c|c|c|c|}
\hline Countries & 1561 & 1575 & 1990 & 1900 \\
\hline $\begin{array}{l}\text { Great Britain } \\
\text { Continent of Eu- } \\
\text { rope. . . } \\
\text { India. } \\
\text { United States. }\end{array}$ & $\begin{array}{r}30,300,000 \\
10.000,0000 \\
338,000 \\
5,000,000\end{array}$ & $\begin{array}{r}39,000,000 \\
19,400,000 \\
1,100,000 \\
9,500,000\end{array}$ & $\begin{array}{r}43,750,000 \\
24,575,000 \\
3,270,000 \\
14,190,000\end{array}$ & $\begin{array}{r}46,000,000 \\
33,000,000 \\
4,400,000 \\
19,4 \div 5,000\end{array}$ \\
\hline
\end{tabular}

\section{TORLD'S CONSUMPTION OF COTTON}

The average consumption of cotton throughout the world may be estimated at fifteen million bales annually. The leading centers of cotton manufacture are not at the source of supply, but are thousands of miles awar, where population is dense and labor abundant, trained and efficient.

The consumption of cotton for sereral periods of manufacturing development is shown in the table following:

\begin{tabular}{|c|c|c|c|}
\hline Country & 1875 & 1890 & 1900 \\
\hline $\begin{array}{l}\text { Great Britain . . . . } \\
\text { Continent of Europe. } \\
\text { India } \\
\text { United States....... }\end{array}$ & $\begin{array}{r}1,500,000 \\
250,000 \\
290,000 \\
300,000\end{array}$ & $\begin{array}{r}3,354,000 \\
3,630,000 \\
920,000 \\
2,350,000\end{array}$ & $\begin{array}{l}3,269,000 \\
4,576,000 \\
1,000,000 \\
3,640,000\end{array}$ \\
\hline
\end{tabular}


For last year (1904-05) Messrs. Latham, Alexander \& Co., the well known New York cotton authorities estimate the consumption of the sereral countries as follows:

\section{ESTIMATED CONSUMPTION 1904-05}

Great Britain (500-pound bales) 3,588,000 bales Continent ( 500 pound bales) $5,148,000$ bales United States ( 500 pound bales) 4,310,255 bales Of light weight bales (areraging less than 500 pounds), the consumption of other countries last year was as follows:

East India............. 1,350,000 bales Japan ............... 875,000 bales Canada.............. 130,000 bales Mexico .............. 70,000 bales Various............... 35,000 bales

Total.............15,506,255 bales

\section{EXTENT OF COTTON INDESTRY IN AMERICA}

Cotton manufacturing did not derelop rapidly in the United States until the latter part of the nineteenth century, when it not only made great growth in New England, but assumed enormous proportions in the Southern States, the seat of cotton production.

In the early days of the industry cotton was carded and spun by machinery but wearing was done entirely by the hand loom. This was true as late as $1815^{\circ}$ when the first power loom was installed, and it was a long time after that 
before the hand loom became an inconsiderable factor in cotton goods making. Especrally in rural districts, it had its place, along with the spinning wheel, in nearly every well regulated home.

Cotton manufacturing in the United States has been extended gradually in all directions, increasing in annual output, capital and labor employed, until it has become one of the great industries of the land.

This development is seen in the table below:

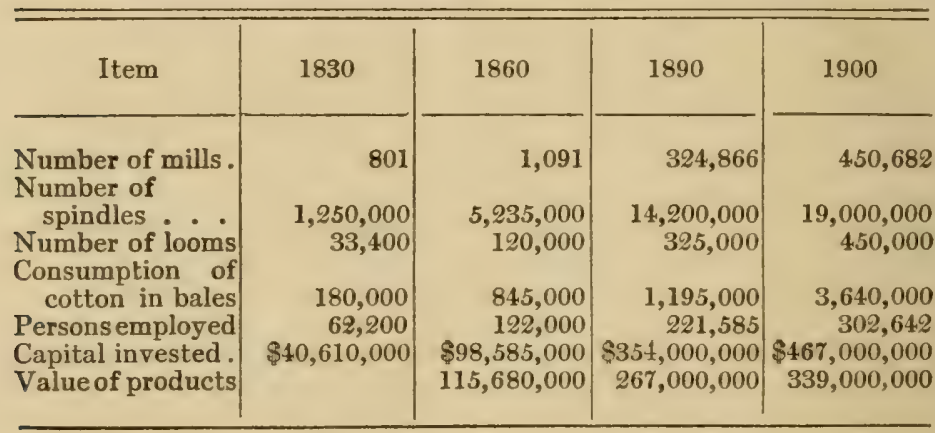




\section{CHAPTER XXXIV.}

THE COTTON FACTORY IN THE SOUTHERN STATES

"The four Southernmost States make a great deal of cotton. Their poor are almost entirely clothed in it in winter and summer."

So wrote Thomas Jefferson in 1786. Without doubt his observation was first-hand and authentic. But where was this cotton manufactured? In a cotton mill somewhere? No, that cannot be, for no cotton mill had yet been built on American soil. The cotton was home manufactured from lint, the seed having first been hand-picked. This manufacturing was done in the home, for the home use of the inhabitants and the household. With the coming of the cotton gin, not only did the production of cotton increase, but its manufacture and use increased as well.

Before the Civil War slave women, directed by their mistresses, largely clothed the plantation force with "homespun," as it was called. And it may be noted that even now, in spite of the cheapness of the manufactured product, many an oldfashioned country woman still cards her cotton into rolls, spins the product into thread on the spinning wheel, and with laborious shuttle weaves the thread into vari-colored counterpanes for her beds, into "breeches cloth" for her good man, or into underclothing for herself. 


\section{OUR FIRST COTTON MILL}

In the year 1787, Mrs. Ramage, widow of a South Carolina planter, realizing its greater economy and so anticipating its financial success, erected a small cotton mill on James Island, near Charleston. Small in size and operated by horsepower, this was the first cotton factory erected on American soil, although a little later in the same year, another cotton factory, somewhat larger in capacity, was started at Beverly, Massachusetts. Then, years later, a second factory was built at Statesburg. Georgia was the second State to begin cotton manufacturing, but it was not until 1809 that a small factory was erected at Louisville, this being also operated by horse-power. Two years later a much larger factory was built in Wilkes County, this one known as the "Bolton Factory." This building "was 60 feet by 40 feet, two stories, attic and basement, and was constructed of brown sandstone." It was the first factory of any consequence in Georgia.

In North Carolina no factory was built until 1818 when one was erected in Edgecombe County, which "began operating with 288 spindles, employed about 20 hands, and consumed 18,000 pounds of cotton, or according to the weights of those days, about 64 bales."

\section{LITTLE INTEREST IN COTTON MANUFACTURING}

While a great many cotton factories sprang up in the Southern States from 1800 to 1860, the South as a whole, cannot be said to have given manufacturing very substantial encouragement. Rather it was discouraged-sometimes rather emphatically. 

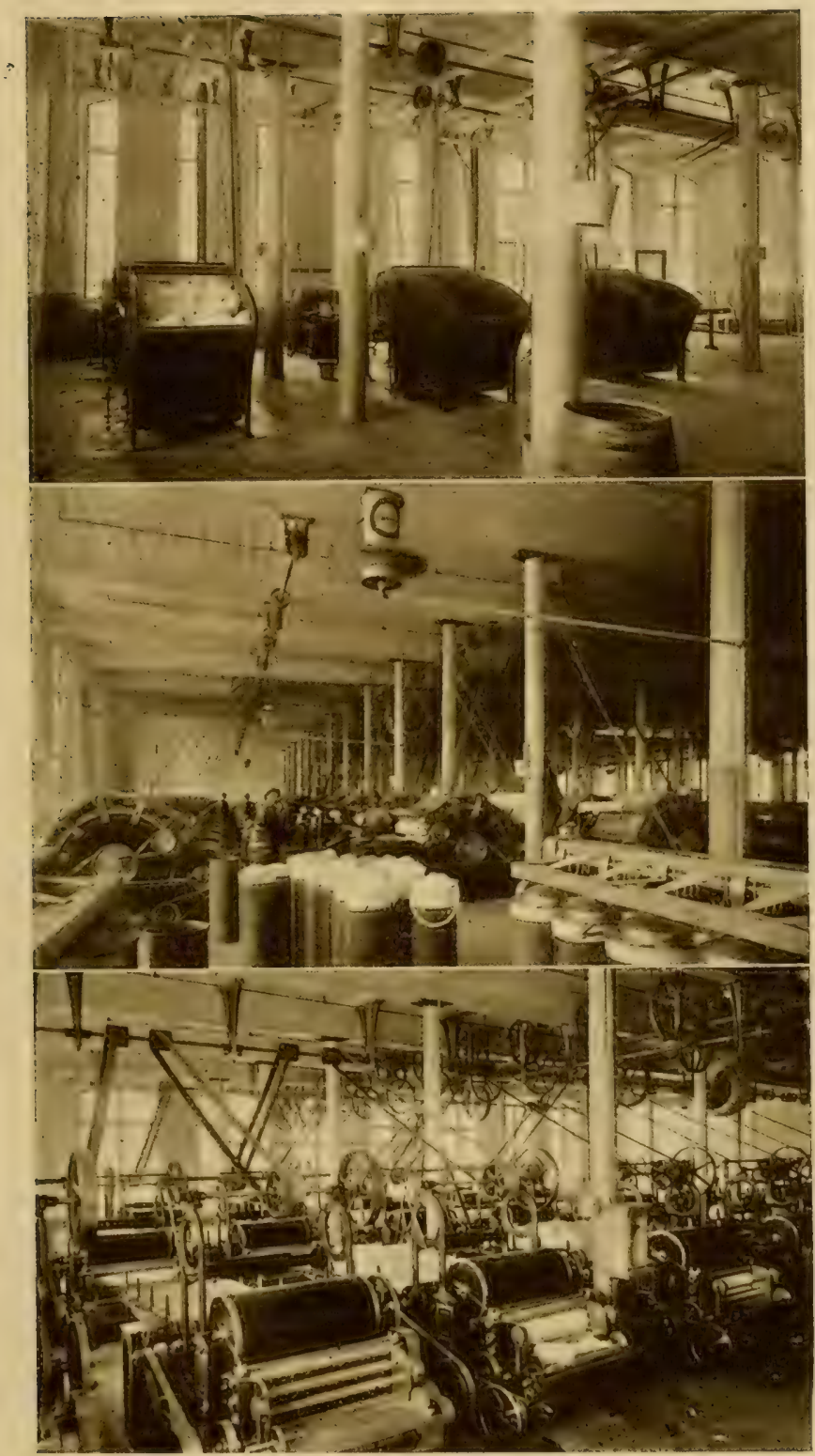

INTERIOR VIEW OF CO'IVION MILL.

(A) Opening room showing openers; (B carding room showing cards and drawing frames; (C) lap room showing lap machines. 

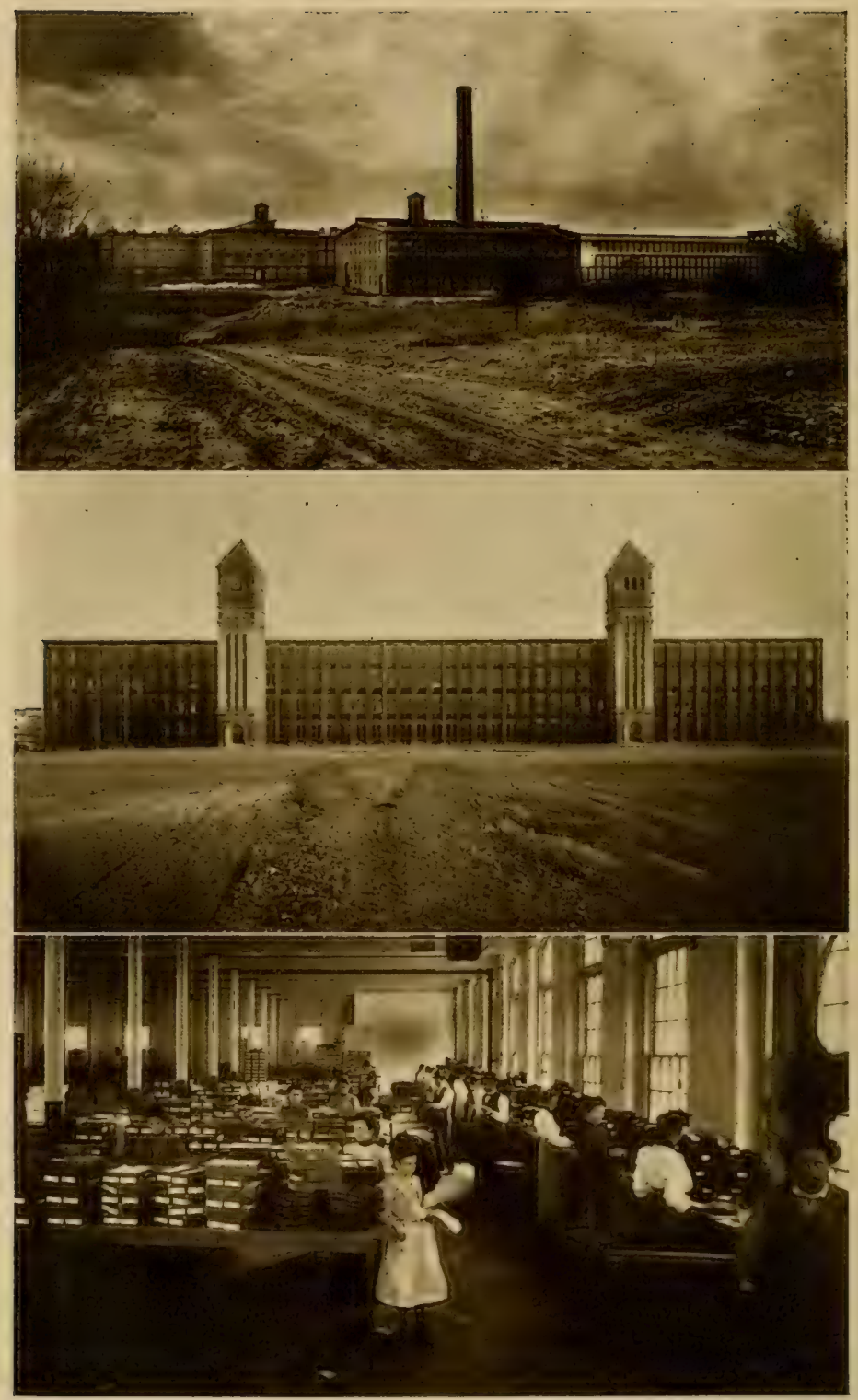

COTTON MANUFACTURING IN THE SOUTH.

(A) White Oak Mills, Greensboro, N. C., the largest American factory for the manufacture of blue denims; (B) Olympia Mills, Columbia, S. C., one of the largest in the South; (C) preparing goods for shipping. 
There were objections to the class of people it would attract; to the unwholesome influence of cotton factory life. It was argued that the South could better and more profitably develop the side of production, and leave the manufacturing to other places and to other people. It would mean more wholesome living, freer, purer life combined with individual independence and National safety. No doubt there was some ground for these arguments. The laborer was needed in the fields and could be ill-spared for the factory and its incidental duties. Production was to be developed; it was the basis on which the factory must be built; why cripple it, to engage in another industry, neither so desirable nor so profitable?

As a consequence of this unfavorable sentiment, comparatively few mills were erected, although some of those in the South were of considerable size and importance. In South Carolina, for instance, a factory was erected as early as 1846 which "contained 8400 spindles and 300 looms" -not a large one for our day, but one of no little note at the time it was built. And in North Carolina in 1844 "it was estimated that 25 mills represented a capital of $\$ 1,050,000$, operated 50,000 spindles, employed from 1200 to 1500 hands, and consumed 15,000 bales of cotton." But for the development of slavery, Southern cotton manufacturing would doubtless have overcome all objections of its growth and have reached its present important position a great many years ago.

\section{RISE OF SOUTHERN COTTON. FACTORIES}

As it is, War and Reconstruction demoralized everything, and the great development in Southern 
cotton manufacturing has occurred during the past twenty years. Here the Carolinas, Georgia, Alabama make the best showing chiefly by reason of better climatic conditions and more abundant water power. The slow development during the middle of the last century, and the rapid progress made within the last score of years, is seen in the following table giving the number of mills and spindles:

\begin{tabular}{|c|c|c|c|c|c|c|}
\hline \multirow[b]{2}{*}{ Year } & \multicolumn{2}{|c|}{ SOUTH CAROLINA } & \multicolumn{2}{|c|}{ NORTH CAROLINA } & \multicolumn{2}{|c|}{ GEORGIA } \\
\hline & Mills & Spindles & Mills & Spindles & Mills & Spindles \\
\hline 1850 & 18 & 36,500 & 28 & 40,000 & 35 & 51,150 \\
\hline 1860 & 17 & 30,890 & 39 & 41,884 & 33 & 85,186 \\
\hline 1870 & 12 & 34,940 & 33 & 39,897 & 34 & 85,062 \\
\hline 1880 & 14 & 82,424 & 49 & 100,209 & 40 & 198,656 \\
\hline 1890 & 44 & 415,158 & 105 & 418,900 & 62 & 465,811 \\
\hline 1900 & 115 & $1,908,692$ & 218 & $1,428,066$ & 107 & $1,016,258$ \\
\hline 1905 & 61 & $3,171,099$ & 263 & $2,207,102$ & 129 & $1,452,668$ \\
\hline
\end{tabular}

\begin{tabular}{|c|c|c|c|c|}
\hline & \multicolumn{2}{|c|}{ ALABAMA } & \multicolumn{2}{|c|}{ Other Southern States } \\
\hline Year & Mills & Spindles & Mills & Spindles \\
\hline$\overline{1850}$ & 12 & 16,960 & 77 & 119,961 \\
\hline 1860 & 14 & 35,740 & 69 & 130,352 \\
\hline 1870 & 13 & 28,046 & 62 & 156,101 \\
\hline 1880 & 16 & 49,432 & 44 & 137,737 \\
\hline 1890 & 17 & 89,158 & 55 & 356,142 \\
\hline 1900 & 49 & 550,966 & 87 & 709,605 \\
\hline 1905 & 66 & 824,687 & 88 & 819,141 \\
\hline
\end{tabular}

\section{RELATION OF CONSUMPTION TO PRODUCTION}

An interesting relationship is seen when the quantity of cotton consumed is compared with the quantity raised in each of these four leading cotton manufacturing States. 
SOUTH CAROLINA

\begin{tabular}{c|r|r|r}
\hline \hline Year & Bales consumed & Bales produced & $\begin{array}{c}\text { Per cent. } \\
\text { of Crop used }\end{array}$ \\
\cline { 1 - 1 } 1850 & 9,929 & 300,901 & 3.3 \\
1860 & 8,648 & 353,412 & 2.4 \\
1870 & 10,811 & 224,500 & 4.8 \\
1880 & 33,624 & 522,548 & 6.4 \\
1890 & 164,814 & 859,000 & 19.2 \\
1900 & 501,290 & 743,294 & 67.4 \\
1905 & 625,190 & $1,100,837$ & 56.7 \\
\hline
\end{tabular}

It is seen here that in the thirty years from 1850 to 1880 South Carolina doubled consumption in proportion to her production; in the next ten years this increased six times; while in 1900 it had increased 25 times.

NORTH CAROLINA

\begin{tabular}{c|r|r|r}
\hline Year & Bales consumed & Bales produced & $\begin{array}{r}\text { Per cent. } \\
\text { of Crop used }\end{array}$ \\
\cline { 1 - 1 } 1850 & 13,617 & 73,845 & 18.4 \\
1860 & 13,045 & 145,514 & 8.3 \\
1870 & 9,632 & 144,935 & 6.6 \\
1880 & 27,642 & 389,598 & 7.1 \\
1890 & 140,817 & 588,000 & 23.9 \\
1900 & 408,338 & 554,032 & 73.7 \\
1905 & 602,150 & 664,934 & 90.5 \\
\hline
\end{tabular}

In 1850 North Carolina consumed slightly over one-fifth of her total production of cotton. Ten years later but one-tenth was consumed. This change was due not to decreased consumption but to the fact that the acreage has doubled. It was not until about 1890 that consumption increased on production, when it reached nearly 
one-fourth; ten years later consumption called for three-fourths of total quantity produced; five years later, in 1905, almost the entire quantity produced was consumed-or its equivalent-within the borders of the State.

ALABAMA

\begin{tabular}{c|r|r|r}
\hline \hline Year & Bales consumed & Bales produced & $\begin{array}{c}\text { Per cent. } \\
\text { of Crop used }\end{array}$ \\
\cline { 1 - 1 } 1850 & 5,208 & 564,429 & .9 \\
1860 & 11,406 & 989,955 & 1.2 \\
1870 & 7,385 & 429,482 & 1.7 \\
1880 & 14,702 & 699,654 & 2.1 \\
1890 & 30,364 & $1,011,000$ & 3.0 \\
1900 & 157,832 & $1,021,845$ & 15.4 \\
1905 & 223,872 & $1,249,685$ & 17.9 \\
\hline
\end{tabular}

GEORGIA

\begin{tabular}{c|r|r|r}
\hline \hline Year & Bales consumed & Bales produced & $\begin{array}{c}\text { Per cent. } \\
\text { of Crop used }\end{array}$ \\
1850 & 20,230 & 499,491 & 4.3 \\
1860 & 30,235 & 701,840 & 4.1 \\
1870 & 24,821 & 437,934 & 5.7 \\
1880 & 71,389 & 814,441 & 8.8 \\
1890 & 164,981 & $1,310,000$ & 12.6 \\
1900 & 365,878 & $1,271,573$ & 28.1 \\
1905 & 483,335 & $1,759,000$ & 27.5 \\
\hline
\end{tabular}


CONSUMPTION AND PRODUCTION IN SOUTHERN STATES

\begin{tabular}{r|r|r|r}
\hline Year & Bales consumed & Bales produced & $\begin{array}{c}\text { Per cent. } \\
\text { of Crop } \\
\text { used }\end{array}$ \\
\cline { 1 - 1 } 1850 & 80,300 & $2,469,093$ & 17.2 \\
1860 & 101,688 & $5,387,052$ & 3.3 \\
1870 & 83,068 & $3,011,994$ & 1.9 \\
1880 & 188,398 & $5,755,359$ & 2.8 \\
1890 & 526,856 & $7,472,511$ & 3.3 \\
1900 & $1,570,812$ & $9,142,938$ & 7.1 \\
1905 & $\mathbf{2 , 1 7 2 , 9 9 2}$ & $10,697,013$ & 20.3 \\
\hline
\end{tabular}

This table shows that from 1850 to 1890 there was little gain in the percentage of Southern cotton manufactured at home. While the quantity consumed increased all the while, the quantity produced likewise increased, much of the time in greater ratio than the increase in consumption. In 1890, however, as indicated in the table, the percentage manufactured in the Southern States was more than twice what it was in 1880, although the production had itself increased as much as 25 per cent. During the past ten years the consumption has grown very rapidly.

\section{SOUTHERN MANUFACTURING FAVORS THE PRODUCER}

Not only has the Southern factory-owner certain manifest advantages over his brother in New England, but the cotton farmer is also a gainer in having the factory at his door. Since New York and Liverpool are the important market places of the world, they naturally establish prices, and consequently the Southern consumer pays prices 
similarly offered at New York. Hence the producer practically saves this item of expense of freight in transportation.

It has been calculated by the Industrial Commission that the difference in cost in marketing cotton is as follows:

To local mill from farm, $50 \mathrm{c}$ per bale.

To Northern or Western mill from farm, $\$ 3.00$ per bale.

To foreign mill from farm, $\$ 5.00$ to $\$ 7.00$ per bale.

Hence, it is apparent that Southern manufacturing helps the producer as well as the consumer. 


\section{CHAPTER XXXV.}

\section{THE MAKING OF COTTON GOODS}

In considering which is our most important manufacturing industry, you will not be long in coming face to face with the fact that next to food, clothing is a first necessity of mankind. Many other things which we have come to regard as necessities might be dispensed with; but according to the old Bible story, the need of clothing was the first thing to occur to our first parents after they had eaten of the tree of knowledge; and from the primitive fig-tree costume of Adam and Eve in the Garden, the art of clothing has had a steady and wonderful evolution, century after century, generation after generation, year after year. The savage man has his passion for food, but the desire for clothing is the first step toward civilization, and the step which has been reached in attention to dress will indicate perhaps as closely as anything else the progress a people has made away from barbarism.

So it is that in clothing the earth's teeming millions, cotton stands forth today King indeed, wool and hemp having but a small place in comparison-Cotton triumphant as the result of a test running through the ages! And every operation 
from growing the seed to manufacturing the finished cloth is full of interest to those who watch intelligently.

The first step in cotton manufacturing, when cotton arrives at the mill in the form of a bale, is the opening process which consists of simply removing the ties and bagging (a fabric made of rope) that enclose the bale. The mixing operation is next. Were all cotton just alike, and of the same uniformity, mixing would not be necessary, but fiber comes from lowlands and highlands, in long or short staple, of one variety or many varieties; so, unless thoroughly mixed, goods of widely varying quality will be produced.

Many bales are therefore mixed together, by hand or by machine, the purpose all the time being to get a considerable quantity of cotton as uniform in quality as possible.

From here cotton goes into a large machine that makes the lap, or gauzy film of cotton-first sheets of fleece three or four feet wide, but so very thin that sand, broken leaves and other impurities drop from it of their own weight. And this is one of the reasons why the lap is made-to rid the cotton of these impurities, else yarn would be of poor quality. Three or four times this lapping process is repeated, the second and third machines using the product of the preceding ones. As a rule, four laps or films of the first machine pass through the second machine at once. All the while it is being further cleaned and prepared for the carding machines.

$\mathrm{Up}$ to this point there has been no change in the form of cotton. It has been opened and the heavy impurities have fallen out, but it remains still the white, fluffy, fleecy material-now in rib- 

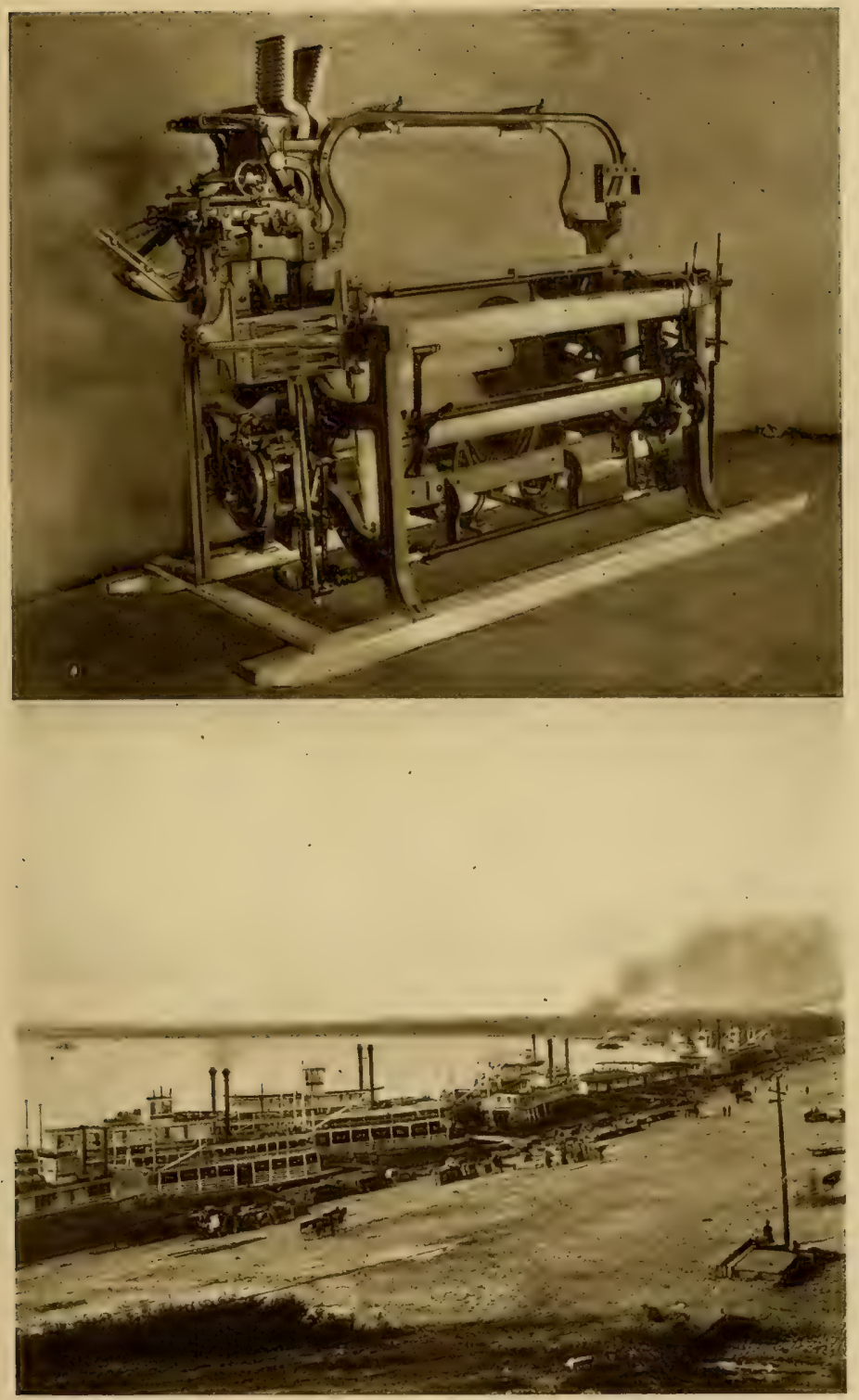

MANUFACTURING.

(A) the Fancy Dobby Loom: (B) cotton commerce calls for a great many steamcrs to get the raw cotton abroad. 


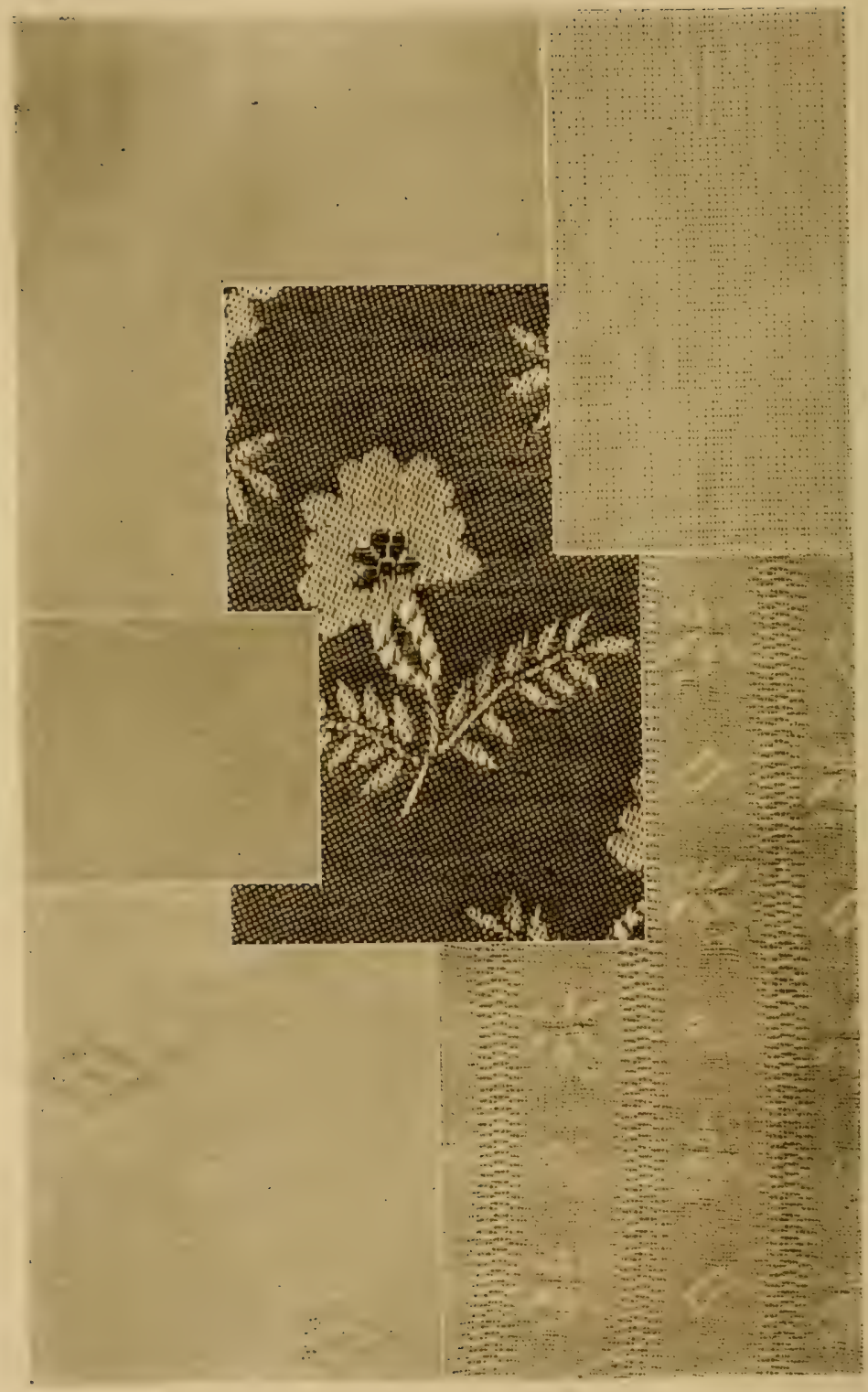

COTTON FABRICS.

(A) Sheeting; (B) print cloth; (C) sateen; (D) Fancy Dobby Cloth; (E) Jac quard Cloth; (F) also Jacquard Cloth. 
bon form ready to go into a large roll or sheet, known as the completed "lap."

\section{CARDING}

The carding machine receives the lap. Its series of cylinders covered with wire brush take it around their course and deliver it at the front of the machine, now in the shape of a cord of untwisted cotton known as the sliver.

And here you see a beautiful sight indeed! The fleecy white lap rushes eagerly into the combs, and as quickly disappears, soon again coming into view, white and spotless as ever, but now changed in form, for it has become a long round cord that is by and by to be the thread used in weaving our cotton fabrics.

Next the sliver goes to the drawing-frame. Here a sort of doubling-up work is to be done. Something like six slivers or untwisted cords are fed into the machine, out of which comes but one, but that one is better than the other six, for the fibers, attenuated and drawn out, are now more nearly parallel, more even and uniform.

While the sliver that leaves the drawing-frame is but a sixth of the size of all that entered it, it is still too large and altogether too easily broken; the cord must be lessened in size and twisted a number of times that it may be strong and even. This work can be done only gradually, else mishaps will occur and make good thread an impossibility.

From the drawing frame the sliver goes to the slubber, which gives it its first twist, reduces it in thickness, renames it roving, and then passes the roving on to the intermediate and roving frames, 
which concludes the work preparatory to having roving spun into thread.

\section{SPINNING}

The roving is now transferred to a spinning machine for the final process of making the yarn or thread. The purpose sought here is fineness of the requisite degree and the twisting and winding of the thread to make it ready for the weaver. One of two machines may do the work: the mule or the ring frame, either of which makes a thread which is used largely without further treatment whatever.

The mule is used for the finest threads that are made, and also for soft twisted yarns for knitting purposes.

The thread is now spun, and only a few things remain to be done before it may be sent to factory and used in the loom.

Spooling comes first, a simple process of winding yarn from spinners' bobbins on spools by means of the spooler. This done, it is now passed on to the warper. Threads are laid in the slasherbeam that sizing may be done in order to facilitate weaving. Sizing is made of starch, tallow, and some preservative to prevent mildew. Finally the threads are drawn through the harness-for weaving and manufacturing of cloth is begun-an operation not difficult in plain goods. But as yarns are made finer and more fancy cloth produced, the art of weaving becomes quite complicated and painstaking.

\section{WEAVING}

In the weaving room the loom is the all-import- 
ant machine. And here you doubtless recall old traditions that have come down through your family of the time when cotton was not only spun in the home but woven there as well. Now, though the hand loom and the spinning wheel have almost disappeared, they have had their share in history making.

As has been suggested before, the loom uses two sets of threads, known as warp and filling. The set running throughout the length is the warp, and those threads extending from side to side, make the filling, weft, or woof.

The loom works on the principle of three movements: the first separates the threads of the warp longitudinally into two sets, leaving a space through which to pass the weft; the second passes the filling through that space, and the third presses the thread of filling up against the one preceding it. All weaving is built upon this principle, though different processes have been employed in making the different fabrics.

Looms may be divided into three classes: plain looms, (operated either by hand or power), fancy looms, and Jacquard looms.

An important part of the power loom is the harness. This is simply a skeleton frame of rods placed parallel to one another on which are a series of heddles, with eyes at the center through which the warp threads pass. These heddles for plain goods are generally knit from cotton with an eye through the center and varnished so as to work freely through the threads. As the number of harnesses is increased, weaving becomes more complicated, and produces finer cloth and more costly fabrics.

Plain looms, as a rule, have but two harness 
shafts, though there may be as many as six when twills and sateen are made, while fancy looms and Jacquard looms possess a great many moresometimes as many as twenty-five or thirty.

The harness in connection with the hand loom is controlled by the action of the weaver's foot on the treddles. The shuttle is propelled by hand, and the stroke of the handle or batten, usually hung from an elevated stand, is also made by hand.

\section{OPERATION IN WEAVING}

In plain weaving all threads are drawn through the harness shafts. In the middle of each harness is a small eye, through which each individual thread is drawn, the thread passing through the harness shafts alternately. On the front harness shaft you will find one of these and another on the back. This enables one-half of the threads to be raised in one pick of filling. This pick simply lays in the filling thread, which is accomplished by the shuttle passing between; the first harness is lowered while the second harness is raised, and another pick of filling is inserted. This operation goes on, one thread at a time, until the desired length of cloth is woven.

By raising the warp threads in the fabric diagonally, we have still a higher step in weaving. This is known as drill or twill weaving. In drill weaving three harnesses are used usually, and in twill four or more.

The making of sateen is another step in advance; here five or six, or even eight, harnesses are generally used, sometimes as many as twelve or fourteen. You are familiar with the lustrous appear- 
ance of this style of goods. This is obtained by covering the intersections of warp and filling. While sateen weaves are derived from twill weaves, the threads are not raised as in twills.

Standard gingham cloth is made from two colors of warp and two colors of filling, checked with one another. They are made in various colors: black and white, brown and white, green and white, and in other combinations of colors. These ginghams are also used as the basis for plaids or over-checks, so that in this kind of weaving many fancy effects in colors are produced, requiring more skill for operation, and enhancing the value of the woven product. Fancy effects may be made in stripes, checks, or figures.

Mercerized cloth is also made of cotton, and both plain and fancy effects may be made. The silky appearance of the product is obtained by immersing cotton threads in a solution of caustic soda, and while thus immersed they are held very tight. These threads are two ply, that is, two twisted together. Before being immersed in the caustic soda solution they are passed through a gas frame (this being done very quickly, so as not to injure the thread) to take off the roughness so that the smooth texture may be obtained. In weaving fancy goods threads may be drawn through the harness shaft in any order, depending on the pattern to be produced.

There are many grades of fancy cloth produced, depending upon the design, the quality of the thread, number of harnesses the machine possesses, and the skill of the operator. Weavers call the machine that makes fancy goods a "Dobby."

A still further advance in the production of fancy cloth has come with the invention of the 
Jacquard loom, a machine named after a Frenchman who was its inventor. The fabrics produced on the Jacquard vary considerably in extent. Any kind of animal, vegetable, or floral effect may be produced upon the cloth. This kind of product usually sells at a higher price than any other fancy cloth. Fancy fabrics, such as shirt waists, dress goods, table covers, and the like, are woven by this machine.

\section{CLASSES OF COTTON GOODS}

In a general way we may say that five different kinds of cotton goods are made through the use of these several kinds of machines.

1. Plain Goods:-We find here print cloth, sheeting, mull, lawn, Madras, nainsook, tea cloth, etc. The only difference in these kinds of cloth lies in the number of threads, picks per inch, the fineness of the yarn, and the finish given after weaving. American cotton may be used for all of these weaves excepting Madras, for which purpose Sea Island or Egyptian cotton is required.

2. Twills:-These fabrics, having lines running diagonally across, include different kinds of linings such as those used for men's coats, women's coats, dress linings, and the like. This weave is also extensively used for denim, out of which overalls and other coarse goods are made.

3. Sateen:-This style of fabric is used quite extensively for shirt waists, dress linings, and dress goods.

4. Fancy Cloth:- The greater part of the cloth used for children's dresses, women's shirt waists and dresses, various kinds of trimmings, scrim for draperies and heavy towels, are included in this class. 
5. Jacquard Fabrics:-Included in this class are the most complicated forms of fancy fabrics. They are also used for cloths suitable for making shirt waists, dress goods, bed spreads, table covers, and novelties.

While cotton is used for many other purposes as thread and underwear, the greater part of it goes into such commercial goods as have been mentioned here.

\section{RELATIVE VALUES IN COTTON MANUFACTURING}

Of course plain weaving, since it requires less skill and involves less complication than other forms, possesses the least commercial value. Sheeting may be taken as an example. It sells for five cents a yard, although only one pound of cotton is required to make three or four or even five yards of cloth-depending upon the weight. In this respect then, a pound of cotton bought at ten cents a pound is sold, when manufactured, at eighteen or twenty cents a pound.

On the contrary, embroidery, one of the highest forms of cotton goods manufactured, sells at twenty dollars a pound. The skill required in its manufacture, the complications of the various processes, have made from a single pound of cotton (of the best quality, of course) a pound now worth twenty dollars. All other cotton goods on the market have a commercial value ranging in price from that of the lowest grade of sheeting to that of the highest forms of embroidery.

\section{WHAT A POUND OF COTTON WILL MAKE}

Cotton weaving yarns are made and sold by the pound. The finer the threads, the greater the 
number of yards in a pound. Hence, any fabric varies in cost, and in the number of yards made from a pound of raw cotton in proportion to the fineness of the yarn from which it is woven.

Taking averages only, one pound of cotton worth ten cents may be manufactured into:

$1 \frac{1}{2}$ yards of Denim worth 18 cents.

4 yards of Sheeting worth 20 cents.

4 yards of Bleached Muslin worth 32 cents.

7 yards of Calico worth 35 cents.

6 yards of Gingham worth 45 cents.

10 yards of Shirtwaists worth $\$ 1.50$.

10 yards of Lawn worth $\$ 2.50$.

25 Handkerchiefs worth \$2.50.

56 spools of No. 40 Sewing Thread worth $\$ 2.80$.

In giving these figures only an estimate of the number of yards can be made. This will vary according to the fineness of the yarns, the number of threads, and "picks" per inch in the cloth.

The threads that are used in weaving are known as "numbers" or "counts." The thinner the thread the greater the number it will have. This matter may be stated thus: A pound of cotton is passed through all the preparatory machines in the mill-lapping, carding, drawing, slubbing, and spinning; if this one pound of raw cotton is made into one thread measuring 840 yards the "number" or "counts" of the thread will be 1 . If a pound of cotton is drawn out to 1680 yards the "counts" will be doubled. So a pound of cotton may be drawn out to almost any desired length, making the fabric (with which the threads are woven) vary in weight according to the thickness of the threads. It is a common occurrence to spin a pound of cotton into 84,000 yards of thread or even to a length exceeding one hundred miles. 
In this chapter, of course, only a mere outline of fundamental facts has been attempted, and any adequate treatment of the subject would require an entire volume. But we hope it has enabled the reader to get a better idea of the cotton fiber in its final phase preparatory to entering on its destiny in clothing mankind. 


\section{CHAPTER XXXVI.}

CONCLUSION:-THE EPIC OF THE COTTON THAT IS YET TO BE WRITTEN

We have now followed the progress of the cotton plant-followed it in history from the time the ancient disciples of Brahma in the Orient first began its use; followed it in growing from the time the seed is put into the cool, fresh earth in spring until its snowy harvest is gathered in December; followed it in marketing and manufacturing from the time it passes through Whitney's gin until the once-rejected seed are turned to a thousand growing uses of mankind and the lint is set to its task of making prince's palace more gorgeous or beggar's body more comfortable; followed it in commerce from the sunny fields of Texas or Mississippi to the frozen regions of the Arctic or the sleeping Empire of the Celestials, or to our newcaught, sullen peoples in far-away Asia or Africa.

And yet we have not written, as we should like to write, the real Epic of the Cotton. In fact, it cannot be written yet, for we have not yet come to a realization of the full significance of the South's great industry.

It is indeed a rich heritage that we have-a monopoly of the American export crop which not only surpasses any other in value, but is worth more than all others combined; a monopoly of the one 
great crop of the world for which Nature has provided no substitute; the basis of a commerce whose influence is measured only by the rising tide of enlightenment and whose condition is the thermometer of civilization; the crop which, when properly handled, is of all our crops the one least exhaustive of the land's fertility, and which yields a seed that would in itself make cotton worth cultivating if it had no Fleece of Gold to keep its tens of thousands of modern Argonauts upon our every sea; yielding the richest of cattle feeds, it will yet dot the hills and valleys of the South with a million flocks and herds, and so restore our famished "old fields" to virgin richness and beauty; our manufacture of cotton, now only begun, will also grow in the Piedmont South until the hum of our spindles shall be heard as far as those of England herself; and the Panama Canal will soon for the first time open full the doors of the Orient to our commerce, and Southern industry will throb afresh, as if new blood had been poured into its veins. Then, indeed, shall we have a section sunny in climate, in people, in prospects; we shall add to the chivalry and courage of the Old South the progress and prosperity of the New-and in the coming literary awakening, some more gifted author will at last write the real Epic of the Cotton, and in American letters the South's own snowy fields will become as famous as New England's gifted sons and daughters have made the ice fields of the colder North. 


JUL ia 1005

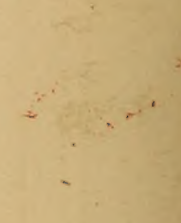

APR 91947 



\section{LIBRARY OF CONGRESS

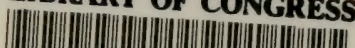

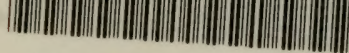 \\ 0000927060?}

